\title{
Invitation au terrain
}

Mémoire personnel de la construction du projet socio-anthropologique

Albert Doja

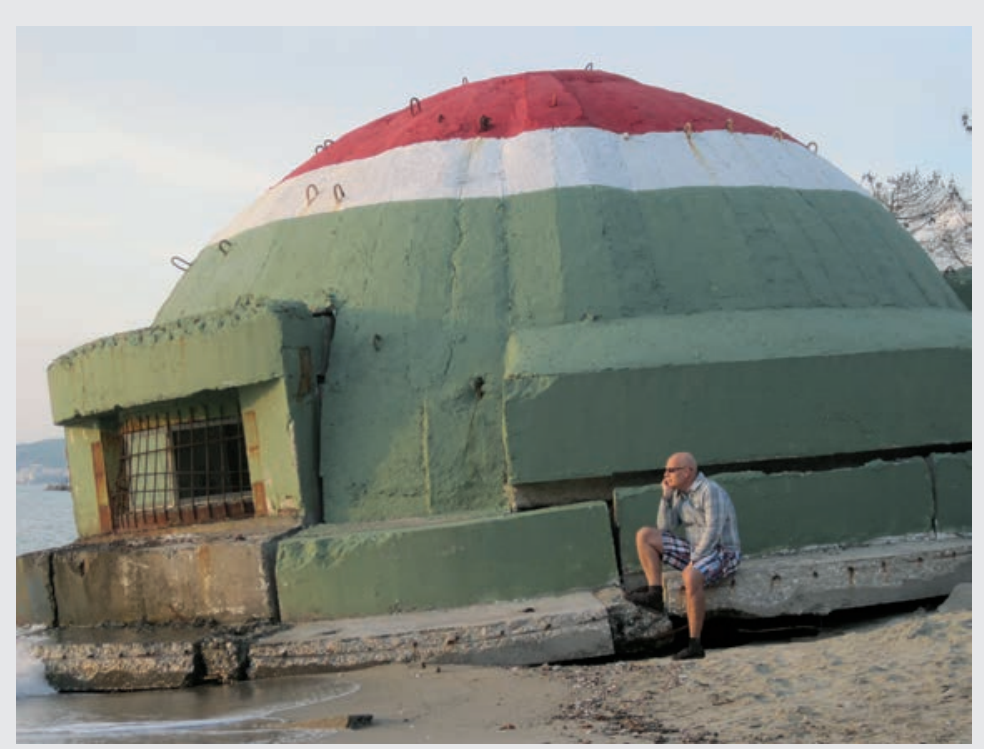

\section{FORUM EUROPE DES CUITURES $\mathbf{Q}$}


De l'organisation sociale aux discours et pratiques qui construisent la notion de personne chez les Albanais, en passant par les relations interethniques et les dynamiques interculturelles des valeurs morales dans l'ensemble des Balkans, l'auteur trace le parcours de ses recherches sur les processus symboliques qui structurent les identités sociales, les relations de parenté et de genre, ainsi que les idéologies nationales des cultures, des religions et des langages. Méthodologiquement, s'il a dû s'abstraire de sa propre société, comme socio-anthropologue, il a dû faire un effort supplémentaire : après s'en être détaché, il a fallu la pénétrer à nouveau afin de la reconnaître et l'expliquer socio-anthropologiquement. À ce niveau, l'expérience transculturelle souligne une conversion des complications et des incertitudes du travail de terrain vers la stabilité relative de la connaissance socio-anthropologique. L'objectivité expérientielle d'une telle démarche permet de comprendre de façon plus intime la réalité qualitative exprimée dans les frontières symboliques des identités locales, dans une aire culturelle définie comme un champ composite et instructif. En définitive, si la construction identitaire et la dynamique interculturelle sont importantes, une appréhension plus précise et plus rigoureuse de la totalité sociale est obtenue via une nouvelle méthodologie permettant de construire un meilleur modèle d'explication théorique.

Vous avez une connaissance approfondie... une présentation pénétrante... Une fois de plus cette lecture m'a permis de mesurer l'étendue de vos connaissances et la rigueur, la pertinence de votre dialectique... (Claude Lévi-Strauss)

On ne peut qu'être profondément frappé par la grande envergure des observations d'Albert Doja... Souvent il révèle une sensibilité ethnographique presque éclatante... (Michael Herzfeld, Harvard University)

\section{囚}

Membre de l'Académie des Sciences d'Albanie et Professeur de Sociologie-Anthropologie à I'Université des Sciences \& Technologies de Lille, Albert Doja a obtenu le Doctorat à l'EHESS (1993) et l'Habilitation à l'Université Paris Descartes (2004). Professeur des universités en France, il a enseigné en Angleterre, Irlande et Albanie. II a fait des recherches de terrain dans plusieurs autres pays et s'intéresse à la politique du savoir et à la dimension idéologique et stratégique de la culture et de l'identité.

\section{P.I.E. Peter Lang}

Bruxelles 




\section{Invitation au terrain}

\section{Mémoire personnel de la construction du projet socio-anthropologique}

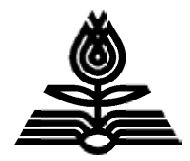

\section{P.I.E. Peter Lang}



Albert Doja

\section{Invitation au terrain}

\section{Mémoire personnel de la construction du projet socio-anthropologique}


Toute représentation ou reproduction intégrale ou partielle faite par quelque procédé que ce soit, sans le consentement de l'éditeur ou de ses ayants droit, est illicite. Tous droits réservés.

(C) P.I.E. PETER LANG S.A.

Éditions scientifiques internationales

Bruxelles, 2013

1 avenue Maurice, B-1050 Bruxelles, Belgique

www.peterlang.com ; info@peterlang.com

ISSN 2031-3519

ISBN 978-2-87574-023-6 (paperback)

ISBN 978-3-0352-6299-5 (eBook)

$\mathrm{D} / 2013 / 5678 / 06$

Ouvrage imprimé en Allemagne

Information bibliographique publiée par « Die Deutsche Nationalbibliothek » « Die Deutsche Nationalbibliothek » répertorie cette publication dans la « Deutsche Nationalbibliografie "; les données bibliographiques détaillées sont disponibles sur le site http://dnb.n-db.de. 
À Maurice Aymard 



\section{Table des matières}

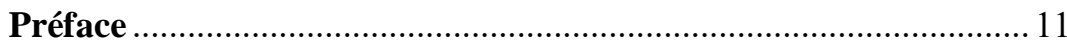

Introduction. Le savoir anthropologique ....................................... 13

INTERMÈDE

Comment on devient anthropologue ............................................... 25

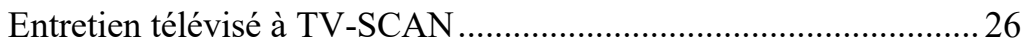

Entretien à l'initiative d'Excellence Albanaise ...................................40

ChAPITRE 1

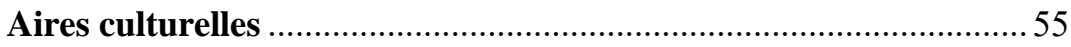

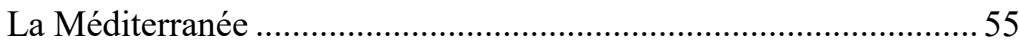

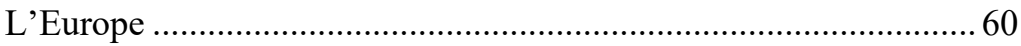

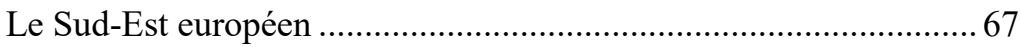

CHAPITRE 2

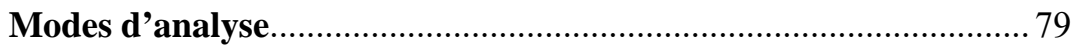

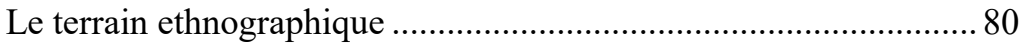

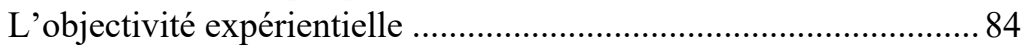

Profondeur historique et approche comparative.............................. 91

\section{Chapitre 3}

Champs thématiques .................................................................. 101

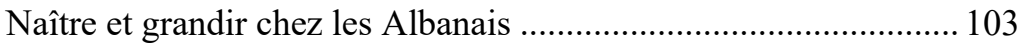

Techniques du corps et pratiques d'éducation.................................. 107

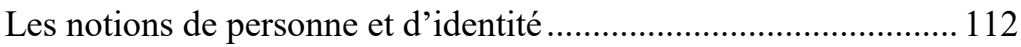

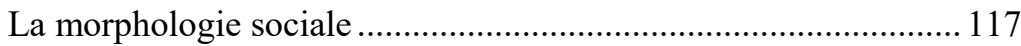

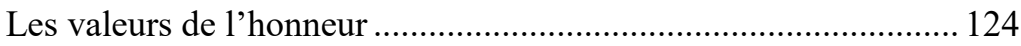

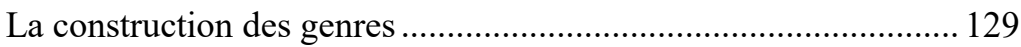

Transformations sociales et politiques ........................................ 140

\section{Chapitre 4}

Prolongements.

\section{Annexes}

Deux lettres de Claude Lévi-Strauss .............................................. 161

Résumé du rapport de soutenance HDR......................................... 164

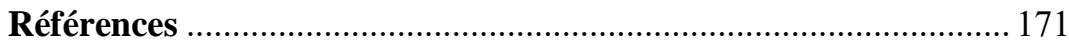





\section{Préface}

Ce texte s'est inspiré de la première partie, reprise, revue, remaniée, fusionnée, mise à jour et sensiblement augmentée du Mémoire d'Habilitation à Diriger des Recherches en sociologie et anthropologie, soutenu à l'Université Paris Descartes, Faculté des Sciences Humaines et Sociales, en Sorbonne, le 18 juin 2004.

Dans l'intermède deux entretiens sont également repris dont l'un télévisé, accordé à TV-SCAN, une chaine de télévision nationale en Albanie, en mai 2011, et l'autre accordé à l'Initiative d'Excellence Albanaise en contribution à un ouvrage commémoratif à l'occasion du Centenaire de la Proclamation de l'Indépendance de l'Albanie, célébré le 28 novembre 2012.

Je remercie à cette occasion tous mes maitres et enseignants, mes collègues, mes collaborateurs de terrain et mes étudiants qui, lors de mon parcours de formation, mes activités de recherche, mon travail de terrain ou mon enseignement, m’ont aidé à préciser ma pensée. 



\section{INTRODUCTION \\ Le savoir anthropologique}

Toutes les formes d'activités humaines, mentales et matérielles, visent toujours à produire un monde d'œuvres et de créations qui sont des intermédiaires symboliques entre l'homme et l'univers. L'homme n'est pas directement dans le monde, il construit pour vivre, entre le monde et lui, un univers de médiateurs qui sont des systèmes de signes et de langages. Les techniques, les sciences, les institutions sociales, les religions, les langues, les arts, tout ce qui constitue les faits de civilisation, sont des constructions, des espèces de médiations entre l'homme et le monde, l'homme et les autres, l'homme et lui-même. Chez l'homme, en quelque sorte, il y a toujours ce que Cassirer appellerait la pensée symbolique.

L'anthropologie est cette branche de la science sociale qui cherche à définir le concept heuristique de la culture en termes opérationnels et analytiques. L'anthropologie est passée du concept de la culture utilisé comme synonyme de «civilisation» englobant une large variété d'activités humaines à la théorisation de la culture comme objet d'analyse scientifique. L'approche anthropologique considère la culture comme une partie intégrante de l'existence humaine et souligne l'importance croissante de la culture dans tous les aspects de la vie moderne. Ce domaine comprend les nouvelles technologies et leur influence sur la vie quotidienne et la culture populaire, comment la culture construit les identités et démarque les différences entre les groupes. Des problématiques qui analysent la révolution globale dans la production et la circulation des «biens culturels", aussi bien que le développement des industries multimédias qui dominent les réseaux de circulation et de communication, considèrent ce que la culture fait à nous, ce que nous faisons avec et si les processus de globalisation et de changement culturel peuvent être contrôlés.

Le monde du XXI ${ }^{\mathrm{e}}$ siècle est davantage défini par les opportunités et les défis posés à la culture et au bien-être social par les technologies avancées et les nouveaux moyens d'information et de communication. En combinant la recherche empirique à la construction théorique et à la résolution de problèmes dans des engagements réels, on pourra fournir un modèle pour affronter ces défis et opportunités et arriver à une vision unifiée de l'intégration de la connaissance. Le but est d'aborder les 
questions de façon à inciter des efforts de collaboration pour pouvoir affronter les problèmes et les opportunités technologiques d'aujourd'hui avec un souci d'amélioration de l'efficacité des institutions, de la qualité de vie chez soi et au travail (en salle de classe aussi), aussi bien que de la perspicacité des décideurs publics et privés. Une compréhension critique des effets réciproques de la technologie et de la culture contribueront à la construction de la société technologique du demain.

Cependant, la notion de culture est utilisée aussi bien pour se référer aux représentations et aux expressions symboliques de l'expérience humaine, que pour distinguer les stratégies d'adaptation humaines de celles en grande partie instinctives des animaux. Beaucoup de travaux qui ont gagné une large acceptation parmi les anthropologues ont montré que la culture indique les manières dont les êtres humains interprètent leur biologie et leur environnement. Selon ce point de vue, la plupart des changements culturels peuvent être attribué à l'adaptation humaine aux événements historiques. D'ailleurs, étant donné que la culture est vue comme le premier mécanisme d'adaptation des humains et qui a lieu beaucoup plus rapidement que leur évolution biologique, la plupart des changements culturels peut être regardé comme une culture s'adaptant à elle-même. En concevant la culture de cette façon, les anthropologues essayent de trouver des moyens de distinguer le comportement culturel du comportement sociologique et psychologique.

Un des objectifs essentiels de l'anthropologie est d'expliquer la complexité de la diversité culturelle en réduisant cette diversité aux modèles universels du comportement social et de l'architecture mentale sans rien perdre de l'information disponible. Dans cette perspective, la culture est conçu à la fois sur trois niveaux : comme système socioculturel dont le caractère normatif sert à restructurer les identités ; comme système idéationnel fondé sur l'apprentissage culturel des symboles qui servent à se forger une image identitaire; et comme modèle distributif et partagé des idées, des significations et des connaissances, non pas à travers des routines culturelles préprogrammées mais par un processus social d'apprentissage, de transmission et de transformation des savoirs et de la connaissance de soi, d'autrui et du monde. En tant que telle la culture se situe et se transmet à l'intérieur des groupes sociaux, mais elle se réfère premièrement à quelque chose qui est universellement partagée.

Or l'anthropologie sociale est surtout intéressée par le fait capital qu'il n'y a pas un homme en général, qu'il n'y a pas de civilisations qui demeurent toujours les mêmes. Ce qu'il faut voir, c'est en fonction de ce que la totalité des faits culturels est à une époque donnée et à un lieu précis, ainsi que l'homme qui leur correspond d'une manière ou d'une autre. L'homme étant ce qu'il fait, l'homme n'existant que par ses 
œuvres, c'est à travers ces œuvres, c'est-à-dire l'ensemble des faits de civilisation, qu'on doit étudier comment l'homme s'est constitué luimême historiquement. C'est pourquoi l'anthropologie prend les grands cadres, l'espace et le temps, la personne et l'image, les comportements, les normes et les valeurs pour essayer de voir comment dans les différentes cultures se différencient les unes par rapport aux autres dans la façon dont tout cela s'est organisé, c'est-à-dire, quelle est la configuration culturellement spécifique de l'ensemble des faits où l'on peut trouver à l'œuvre les grandes fonctions sociales.

L'intention anthropologique est d'essayer de montrer les écarts et les distances par rapport à ce que les autres sont. Parmi les disciplines variées qui tentent de décrire et d'expliquer la pensée et l'action humaine, l'anthropologie sociale a toujours tiré sa distinction dans son intérêt pour l'Autre. En partant du tableau des pratiques et des attitudes mentales de l'homme que nous sommes, la vocation de l'anthropologue est de regarder comment ce tableau se dessine autrement dans d'autres contextes, dont l'acquisition est donnée par l'expérience ethnographique, incessante mise à l'épreuve de soi par l'autre et de l'autre par soi. Il s'agit de construire un système de référence général où puissent trouver place le point de vue de l'indigène, le point de vue de l'ethnographe, et les erreurs de l'un sur l'autre. Car l'anthropologie sociale, comme l'a exprimé Merleau-Ponty (1960), paraphrasant LéviStrauss et devenant son porte-parole, n'est pas une spécialité définie par un objet particulier, les sociétés primitives ou les nations réifiées. Elle est une manière de penser, celle qui s'impose quand l'objet est autre, et exige que nous nous transformions nous-mêmes. Aussi devenons-nous les anthropologues de notre société, si nous prenons suffisamment de distance envers elle, comme j'ai eu l'occasion de le faire, en l'occurrence, en étudiant la construction culturelle de la personne à travers les pratiques de naissance et de succession d'âges chez les Albanais (Doja 2000a).

L'objet classique de la recherche pour l'anthropologue a été la tribu exotique dans une partie du monde lointain et retiré. Au tournant du $\mathrm{XX}^{\mathrm{e}}$ siècle il y a eu une révolution méthodologique passant de l'anthropologie de cabinet au travail de terrain. Les chercheurs se sont immergés dans la vie sociale de la tribu et ont appris le langage local de manière à appréhender, dans les termes de Malinowski, le "point de vue natif». Toutefois, les raisons de base de la recherche n'ont pas changé. L'intérêt principal de l'anthropologie a toujours concerné les " autres cultures », le concept d'ethnie devenant le « fantôme de référence » de l'ethnologie. Le chercheur sur le terrain observe avec attention et répertorie les coutumes curieuses et souvent bizarres, afin d'ajouter une autre facette intéressante dans la panoplie des actions et des pensées humaines à 
l'avantage de ceux qui demeurent de l'autre côté de la barrière. Cela semble avoir confirmé pour longtemps l'idée que les objets classiques de l'investigation anthropologique seraient finalement les cultures condamnées.

Dans le même état d'esprit, l'approche classique considérait les différentes formes symboliques et pratiques culturelles populaires ou prémodernes comme un îlot de survivances préservées des contacts de la culture savante et moderne. Elles étaient pensées en termes d'appartenance à une culture et à une religion dites «populaires » ou «authentiques», parce que primitives et voire même préhistoriques, comme dans le cas de la pratique présumée de la couvade ou l'existence des vierges jurées de tenir lieu d'hommes chez les Albanais, qui sont considérées comme des vestiges d'un matriarcat hypothétique ou bien comme «un reflet du passage du matriarcat au patriarcat» (Gjergji 1964). On prétendait en rendre compte en leur assignant une place précise dans le devenir historique, selon une vision qui, avec sa profession évolutionniste, voudrait au moins simuler les procédés d'une méthode de classification. Ainsi, une fois rangées dans les tiroirs du temps les formes culturelles n'avaient plus d'autre secret à livrer, une « survivance » n'avait plus de fonction.

La connotation d'archaïsme attachée aux notions d'ethnie et de tribu ou de folklore conduit de plus en plus d'anthropologues à réfuter leur pertinence pour décrire les sociétés dites « exotiques》 ou «traditionnelles ». L'analyse de la situation coloniale comme un phénomène complexe et dynamique, impulsée dans les années 1960 dans le domaine africain par les recherches de Georges Balandier (1955) en France aussi bien que par celles de Max Gluckman (1956) et ses collègues de l'école de Manchester (Mitchell 1956; Cohen 1969), a conduit à mettre fortement en cause les visions primitivistes des sociétés traditionnelles (Kuper 1988). Le critiques vigoureuses portées par Edmund Leach (1989) à la notion même de "société traditionnelle» ou de «culture traditionnelle » imposent l'idée que celles-ci - sans aller jusqu'à les considérer comme autre chose que les produits de l'imagination de l'anthropologue - sont pour autant définies en terme d'approche, c'està-dire construites de manière «conventionnelle» en tant qu'outils conceptuels et opératoires d'investigation anthropologique.

Ainsi, il faudra insister que la distinction de la société, de la culture ou des attitudes mentales, par le terme « traditionnel » définit avant tout le genre de l'approche. Ce terme insiste sur la position ethnographique de la démarche, s'appuyant, autant que possible, sur des matériaux régionalement situés et datés, contextualisés d'un point de vue historique et ethnographique, social et idéologique, politique et religieux, comme j'ai procédé par exemple à propos des données qui représentent 
l'ensemble des traditions orales et rituelles et des représentations collectives de la naissance et de la socialisation chez les Albanais (Doja 1990b). Ce souci de rigueur n'exclut pas des retours en arrière vers le passé plus lointain ou des considérations au présent. Toutefois, le cœur de la démonstration concerne essentiellement ce type de société ou de culture, rurale dans la plupart des cas, qui est communément appelée traditionnelle, par une commodité de langage, généralement acquis dans le cadre des études européennes. Il faudra insister cependant sur la qualification « conventionnelle », non seulement parce qu'il s'agit d'une construction conceptuelle qui est par définition conventionnelle, mais aussi parce que l'outil conceptuel même, ainsi construit pour les besoins de l'investigation anthropologique, se veut renvoyer avant tout à un certain mode «conventionnel» de transmission de la tradition, des savoirs et des pratiques : par la voie orale ou gestuelle et, principalement, par l'intermédiaire de la famille et du voisinage. Cette manière de voir les choses a d'autant plus d'avantage qu'elle permet de prévenir contre toute définition du concept de société par une vision substantialiste, comme une entité discrète dotée d'une culture propre, ou que la culture de ce type de société soit restée immuable à travers les siècles. Bien au contraire, en se transmettant, les connaissances se sont modifiées et ont intégré avec le temps des expériences diverses.

Il serait erroné d'ailleurs de croire que la culture est transmise depuis les origines de toutes pièces et de façon inchangée, sans influences extérieures. Bien au contraire, elle intègre à chaque génération des apports nouveaux, venant de la presse, de l'école, de la littérature de colportage ou de la presse tabloïde, au statut ambigu mais beaucoup plus proche sans doute du traditionnel que du savant. L'insertion fonctionnelle des formes culturelles prémodernes dans la modernité qui les maintient devient possible et même nécessaire du fait que les conventions sont rendues fonctionnelles après toutes sortes de résémantisations réflexives qui témoignent aussi bien du présent qu'elles servent que du passé qu'elles réadaptent. Les occasions n'ont pas manqué pour montrer notamment comment les conventions culturelles ont évolué et se sont adaptées, ainsi que la place qu'elles ont occupée dans l'évolution historique, sociale, culturelle et idéologique de la société moderne et contemporaine (Doja 1998b).

L'originalité de la culture vient probablement de ce qu'elle remodèle, restructure les apports divers dans un ensemble qui acquiert ainsi des caractéristiques spécifiques, surtout en matière d'éducation et de socialisation. De là, l'existence encore très forte de certaines conventions culturelles dans l'ensemble des sociétés européennes. On pouvait les croire perdues sous le fracas des connaissances savantes et de la culture de masse. Cependant, quand on les connaît, on en retrouve 
facilement la trace au cœur de chacun. Elles s'appuient sur le concret corporel et parlent en termes de symbolisations et d'associations. Elles sont enracinées en chacun depuis la plus tendre enfance. Leur grande force est sans doute d'être implicites, s'appuyant sur un ordre du monde intuitif et qui semble aller de soi, bien que largement construit et résultant de la distribution dissimulée des relations de pouvoir et des projets politiques. Alors que la morale venue de l'éducation institutionnalisée se présente au contraire comme une série explicite de recommandations qui entraînent en retour soit une adhésion soit une remise en question.

$\mathrm{Au}$ moment où, à côté de la société prémoderne et de la société moderne en Europe, on considère aussi les sociétés non-européennes, objet constitutif de l'anthropologie, le regard n'est plus simplement une confrontation temporelle entre le présent et le passé à l'intérieur d'une même culture, mais il se porte sur une confrontation entre des types différents de cultures. Par l'intermédiaire des sociétés non-européennes, le jeu devient multiple. Est-ce que les sociétés européennes prémodernes sont des sociétés archaïques au même titre que les sociétés noneuropéennes, objet essentiel de l'anthropologie " classique »? Est-ce que les sociétés non-européennes doivent désormais être comprises à travers ce que nous savons de certains aspects de la société prémoderne ? Quel est le rapport entre les «primitifs » et les «modernes»? Est-ce que les sociétés européennes prémodernes viennent se placer en quelque sorte à mi-chemin entre les sociétés «primitives » et les sociétés « modernes »?

$\mathrm{Au}$ centre de la réflexion anthropologique, il n'y a pas seulement la confrontation entre sociétés d'aujourd'hui et sociétés d'hier, mais il y a un effort de comparatisme généralisé. Cela veut dire que l'anthropologue s'efforce dans chaque cas d'introduire la comparaison avec des cultures différentes, d'instaurer une façon d'utiliser des allées et venues pour établir une compréhension d'un univers qui est différent de celui qui paraît plus courant ou plus moderne. De cette façon, l'anthropologie a fait de l'altérité une dimension constitutive de l'identité. L'évocation de la société prémoderne, dont les derniers liens avec la société contemporaine se défont et se refont, permet notamment de s'interroger en anthropologue social. Cette interrogation sur la société prémoderne signifie finalement une interrogation sur la société moderne, et notamment dans sa dimension idéologique et dans la place qui est faite aux valeurs sociales et culturelles.

$\mathrm{Au}$ cours du $\mathrm{XX}^{\mathrm{e}}$ siècle, les anthropologues ont surtout essayé de trouver l'origine, le fondement ou l'essence de l'humain, qu'ils situaient au niveau des pratiques et des formes de relations de parenté, de mariage, de genre ou de sexualité, et qu'ils avaient tendance à décrire comme des substances atemporelles. Les premiers anthropologues 
étaient profondément influencés par le paradigme grandissant de la culture et de l'identité, mais ils faisaient plutôt dépendre l'essence humaine à partir de la procréation et de la reproduction, de sorte à inclure la sexualité dans l'institution du mariage. En un demi-siècle, leur intérêt s'est progressivement déplacé vers les relations de parenté. Deux écoles paradigmatiques se sont ainsi développées, la théorie de la filiation et de l'alliance, dont les défenseurs les plus énergiques furent Radcliffe-Brown (1952) et Lévi-Strauss (1949/1967), ou ce que l'on est venu à connaître, respectivement, sous le nom d'école britannique et d'école française d'anthropologie.

La théorie des relations de parenté fut abondamment critiquée, notamment pour sa non-universalité, son formalisme extrême ou son manque de cohérence en tant que domaine, de sorte qu'au début des années 1970, de nombreux anthropologues ont préféré se diriger vers la question des genres, fréquemment associée, et parfois subsumée, à l'analyse du prestige, du statut ou du pouvoir. Au cours de ces dernières décennies, beaucoup d'anthropologues, surtout ceux qui travaillaient sur la sexualité et la question des genres, ont remis en cause la vérité universelle de la sexualité, des relations de parenté, du mariage et des genres. En particulier, depuis qu'ils ont admis l'idée essentielle que la subjectivité humaine est le produit aussi bien des relations de pouvoir et de savoir (Foucault 1976/1994, 1980) que des «technologies » de la construction de la personne (Foucault 1988), les ethnographes ont délaissé l'étude des normes paradigmatiques au profit de celle des pratiques normalisantes et des différentes formes de subjectivité et d'assujettissement qui en résultent.

En particulier, certains fondements de la réification et de la naturalisation primordiale des cultures et des traditions ont été ébranlées et déconstruites, se laissant observer comme étant constamment contestées, changeantes et poreuses. Les relations de pouvoir au sein des collectivités sont désormais perçues comme affectant les projets politiques euxmêmes, tandis que la reconnaissance d'une réalité socialement construite fait apparaître le genre comme ce qui façonne non seulement les relations de pouvoir, mais aussi ce que nous étudions et comment nous l'étudions. Bien que nous soyons immédiatement immergé dans un enchevêtrement compliqué et controversé d'opinions et d'expériences diverses, les réflexions critiques au sujet des questions d'identité, de la construction des genres ou des relations de pouvoir, présentent l'avantage d'embrasser cette confusion pour en faire une source de connaissance émancipatrice, susceptible de nous aider à découvrir de nouvelles directions au sein de la théorie sociale.

Avec l'extinction des empires coloniaux et les énormes transformations sociales actuelles, résumées par les termes de "globalisation» et 
de "modernisation", le sujet de l'investigation anthropologique a rencontré des critiques essentielles et s'affronte à de nouveaux défis. Globalisation ne signifie pas nécessairement occidentalisation, comme elle n'implique pas nécessairement la modernisation selon les lignes suivies par les premières nations industrialisées. En outre, l'échange macro-régional des biens et des personnes, de pair avec les formes nouvelles de communication basée sur la connectivité virtuelle aux dépens de la proximité physique, génèrent diverses cultures et souscultures. L'objet classique de l'anthropologie, les cultures «nonoccidentales » ou « prémodernes » n'ont pas disparu de la carte, comme il a été craint par les romantiques et espéré par les optimistes du développement. Au lieu de cela, ces cultures ont seulement bougé pour s'approcher davantage de nous et plusieurs d'entre elles se font entendre plus clairement qu'auparavant. Les mouvements politiques, en invoquant la distinction réelle ou putative de ces cultures, "s'ethnicisent" en conséquence, ce qui fait en retour que le modèle dominant du conflit dans le monde apparaisse largement comme un conflit ethnique.

Contrairement aux suppositions anciennes, les groupes ethniques et les cultures n'ont jamais été des entités d'une durée temporelle constante ni d'une autodéfinition dérivée indépendamment des contacts extérieurs. Ils se sont formés et articulés au contact les uns avec les autres, parfois en conflit, parfois pacifiquement à travers les divisions de travail. Les cultures tribales, décrites comme apparemment insulaires par les anciens anthropologues, étaient rarement aussi isolées et elles le sont considérablement moins aujourd'hui. Les vieux concepts de «tribu» et d' « ethnie » sont largement remplacés par le terme " groupe ethnique », utilisé souvent comme synonyme de «culture ». Le changement décisif n'est donc pas la disparition des groupes ethniques mais le degré plus élevé de l'interaction entre eux-mêmes. Un résultat remarquable, qui semble échapper aux théories classiques sur la modernisation, est le renforcement des solidarités locales et particularistes. Les nationalistes et les apologistes des cultures locales donnent toujours la proéminence à l'inaltérable essence des origines des entités ethniques dont ils font la propagande. En revanche, l'anthropologie actuelle s'appuie sur les groupes ethniques et les cultures en tant que "constructions », souvent d'origine coloniale, perspective qui a trouvé des adeptes en France aussi (Amselle 1990, 2000). L'essentiel de cette façon de voir les constructions de groupes et de cultures est qu'elles sont sujettes à de multiples pressions adaptatives, elles se transforment en conséquence et peuvent devenir susceptibles à des manipulations délibérées.

Si on veut essayer de comprendre l'interaction entre groupes sociaux d'une échelle relativement large, appelés groupes ethniques ou nations, il faut commencer par l'identification des agrégats de gens qui les 
composent. Ce n'est pas du tout une tâche facile parce que, particulièrement dans les conflits violents, les mêmes définitions et les mêmes compositions de groupes sont manipulées et contestées. Les formes pacifiques d'interaction peuvent poser les problèmes similaires. On risque ainsi, inévitablement, de ne pas trouver un terrain ferme sur lequel pouvoir placer le point de vue d'observateur, qui n'est ainsi localisé que dans une constellation où tous les éléments changent constamment non seulement leurs positions relatives mais aussi leur substance et leur quantité. Voilà pourquoi, contrairement à la plupart des opinions "profanes » et aux représentations avancées souvent par les membres des groupes, particulièrement par les leaders de certains macro-groupes, les anthropologues soulignent le caractère construit des groupes concernés, la fluidité et le caractère processuel de leurs contacts.

L'anthropologie sociale « classique » a enrichi nos connaissances sur l'humanité à plusieurs niveaux. Dans cette lignée, l'étude de l'interaction entre groupes ethniques, insistant sur les relations interethniques et la dynamique interculturelle, tout en soumettant les concepts de base de l'identité, de l'ethnicité et de la culture à l'investigation théorique, peut devenir scientifiquement innovant. Tenant compte de tout ce qui est valable et qui a de l'importance dans la tradition anthropologique, incluant l'accent sur l'ethnographie de terrain, les thèmes de recherche sont centrés sur les domaines où les problèmes de construction identitaire, de relations sociales et d'intégration deviennent saillants dans le monde actuel et couvrent un spectre assez large. Le but est d'appréhender et de donner un sens à tout un éventail de variantes ou de facettes d'identités et de citoyennetés, d'ethnicités et de nationalismes aussi bien que de communismes ou de transitions travaillant à l'arrièreplan politique, sous-jacentes à la collision des valeurs morales et idéologiques distinctes et à l'émergence des nouvelles valeurs sociales en conséquence de la dynamique interculturelle.

Dans ce parcours, il ne s'agit pas seulement de démontrer la maîtrise de la région ou du «terrain » de recherche, du point de vue historique, linguistique et culturelle, mais avant tout d'intégrer productivement ces connaissances, de façon cohérente et circonstanciée, dans les discussions théoriques contemporaines les plus importantes en anthropologie sociale. Certes le champ est construit de manière historique, ethnographique et comparative. Or, même si cette comparaison s'arrête essentiellement aux frontières d'une région ou d'une aire culturelle, il faudra par ailleurs discriminer entre généralisation et comparaison pour pouvoir proposer des considérations théoriques plus générales. Car on pourra apporter beaucoup plus à la connaissance et à la compréhension de la société albanaise dans le contexte sud-est européen, si l'approche est à 
même de rendre plus intelligible à l'anthropologie générale le système représentationnel et l'organisation sociale de cette société. C'est ce qui permet de penser plus clairement les phénomènes concrets et de fournir une construction épistémologique qui puisse donner corps à un projet où les données de l'évidence empirique sont introduites dans une synthèse conceptuelle de compréhension dans le cadre d'une approche dédiée aux institutions centrales, aux symboles et aux valeurs dominantes.

En présentant un compte-rendu analytique et approfondi des concepts émiques et des aspects sociaux, psychologiques et symboliques qui témoignent des réalités de la spécificité culturelle albanaise et des modes de vie albanais, l'évidence empirique est nécessairement située dans les arguments sociologiques et anthropologiques des discussions théoriques courantes par rapport aux identités sociales, aux valeurs culturelles, aux relations de pouvoir, ainsi qu'au poids de la coutume et de la tradition. Il est important avant tout que les processus socioculturels soient envisagés dans leur développement en fonction d'enjeux sociaux et politiques circonstanciés parce que définis par des rapports de force internes à la société et par les relations avec d'autres sociétés. Du moment que ces rapports et relations sont générateurs de domination, de discriminations et de résistances, il y a sûrement des incidences sur la compréhension de la dynamique culturelle des valeurs sociales.

L'accent de ma démarche insiste sur la construction théorique de l'objet anthropologique, élaboré dans la triple perspective de l'anthropologie des systèmes sociaux, la sociologie des systèmes symboliques et l'histoire des valeurs culturelles. C'est ce qui a donné lieu à des structures transversales, distinctes et complémentaires, qui ont jalonné les champs thématiques et les sujets explorés et qui pourrait se résumer sous trois rubriques transversales et complémentaires :

- L'objet de ma recherche a concerné les comportements culturels, aussi bien que les intérêts, les valeurs et les normes des groupes sociaux, dans le domaine des constructions et des recompositions identitaires, du point de vue individuel et collectif, symbolique et réel, ethnique et national, ou social et politique.

- La méthode centrale a été le travail ethnographique sur le terrain et l'analyse anthropologique des données, qui ont pu prendre plusieurs formes, incluant l'utilisation d'une série de techniques.

- La recherche est conduite en Europe du Sud-est, plus particulièrement chez les Albanais, en comparaison avec d'autres parties du monde, incluant l'Europe.

Au premier abord il semble y avoir une certaine tension entre ces trois aspects. D'une part, les sujets essentiels de cette problématique 
portent sur le système des formes d'expression orale et de représentation collective des processus de construction identitaire et de socialisation, débouchant sur les processus éducatifs symboliques et non-institutionnalisés, aussi bien que sur la notion de personne, les relations de genre et de parenté, la famille et l'organisation sociale, ou encore sur le territoire, la mémoire et l'héritage historique, la religion, le langage et les autres déterminants de l'identité collective. Il faudra dans ce contexte envisager les problématiques complémentaires concernant l'ethnicité, les relations interethniques et la dynamique interculturelle des valeurs sociales par rapport à l'évolution des traditions et aux transformations politiques et sociales.

D'autre part, le travail ethnographique sur le terrain concerne typiquement un seul groupe ethnique et de ce fait il apparaît inapplicable à l'étude de l'interaction culturelle entre différents groupes ethniques, d'autant plus que la méthode classique a toujours été monographique par sa portée et non pas comparative dans sa conception. Or, dans l'analyse anthropologique des données cette méthode nécessite d'être étendue dans l'espace comme dans le temps. Pour rendre compte de la convergence de ces aspects, après un intermède d'entretiens, il est nécessaire dans le chapitre suivant de préciser davantage les contours de définition de l'aire culturelle et les outils conceptuels et méthodologiques, incluant des méthodes ethnographiques, historiques et comparatives, avant de tracer l'itinéraire des activités et de cerner les centres d'intérêts. 



\section{INTERMÈDE}

\section{Comment on devient anthropologue}

Lors d'un entretien télévisé sur le métier d'anthropologue, accordé à TV-SCAN, une chaine de télévision nationale en Albanie, en mai 2011, je me suis concentré sur ma trajectoire de parcours personnel afin de tracer en quelque sorte le développement de l'anthropologie dans un pays d'Europe du Sud-Est à l'intersection des traditions d'Europe occidentale et d'Europe orientale. Entre autre, j'ai aussi essayé d'identifier les différentes façons de pratiquer les études folkloriquesethnographiques qui contrastent avec la pratique contemporaine de l'anthropologie sociale, avec la nécessité résultante d'embrasser la méthodologie anthropologique dans les études albanaises d'aujourd'hui. À l'occasion du Centenaire de la Proclamation de l'Indépendance de l'Albanie, célébré le 28 novembre 2012, une Initiative d'Excellence Albanaise m'a demandé une contribution à un ouvrage commémoratif réunissant les entretiens avec 100 intellectuels considérés comme représentant l'excellence albanaise d'aujourd'hui. Dans ce nouvel entretien je prolonge et j'approfondis les questions liées à l'état des études albanaises sur l'héritage culturel et l'histoire nationale ou encore le débat entre structuralisme et poststructuralisme, mais aussi d'autres sujets qui se rapportent davantage à la situation de l'institution universitaire albanaise en général dans un cadre comparatif, notamment avec la France, qui met en évidence les cultures académiques contrastées dont j'ai eu l'occasion de faire l'expérience. ${ }^{1}$

Le débat que j'ai soulevé sur l'évolution historique et politique des différentes traditions disciplinaires est probablement intéressant pour autant qu'il fait entendre la voix d'un universitaire nouvellement installé en France et qui exprime des vues différentes venant d'ailleurs. Or, même s'il est situé sous d'autres cieux, le débat n'est que faussement

\footnotetext{
Une version retranscrite de l'entretien télévisé à TV-SCAN est antérieurement publié dans MAPO Gazette, le 4 Juin 2011, alors que l'entretien à l'Initiative d'Excellence Albanaise est publié dans 100 Histori Suksesi në 100 Vjetorin e Pavarësisë [100 Success Stories in the Centenary of Independence], Tirana: Albanian Excellence, 2012, pp. 155-160. Dans la version traduite et publiée ici j'ai apporté quelques modifications pour éviter les redites et j'ai profité pour clarifier quelques ambiguïtés, pour corriger quelques erreurs qui avaient échappé ou pour ajouter certains passages qui ont été supprimés par erreur dans l'édition précédente des deux entretiens ici assemblés.
} 
trop particulier, car il n'est pas trop éloigné du développement des idées de la discipline dans le paysage intellectuel européen en général et français en particulier. Car le descriptivisme de beaucoup de travaux ethnologiques en France ou ailleurs en Europe de l'Ouest n'est effectivement pas trop éloigné des études folkloriques en Albanie et en Europe de l'Est, ce qui se révèle dans la difficulté et la nécessité, encore aujourd'hui, de définir et d'établir pleinement les orientations méthodologiques, théoriques et institutionnelles d'une socio-anthropologie proprement dite en France. Plus particulièrement, une analyse plus circonstanciée des différentes traditions ethnographiques et ethnologiques dans le paysage universitaire français semble aussi nécessaire, en contrepoint de la sociologie d'une part et de l'anthropologie générale dominante d'autre part.

\section{Entretien télévisé à TV-SCAN}

Professeur Albert Doja, vous êtes un anthropologue bien connu dans le monde entier comme l'un des chercheurs les plus éminents dans ce domaine des études albanaises. Même si l'anthropologie sociale demeure toujours pas suffisamment pratiquée, voire même presque inconnue en Albanie, pouvez-vous nous dire d'abord comment vous-même vous êtes devenu un anthropologue?

Tout s'est passé sur un coup de chance, complètement par hasard. Je suis venu à connaître l'anthropologie sociale ou culturelle, car c'est de cela que nous parlons ici, à un moment où je ne savais pas que j'étais sur le point de la connaître. Ma formation première fut d'abord essentiellement en linguistique. Quand j'étais étudiant, j'ai été très attiré par les nouveaux courants de la linguistique générale, l'analyse structurale en linguistique en particulier était très à la mode à cette époque. J'ai été très passionné par le sujet; je prenais les auteurs et je n'arrêtais pas de les lire tous. J'avais une sorte d'« obsession », si l'on peut dire, quand je commençais la lecture d'un auteur, je ne pouvais pas m'empêcher d'aller jusqu'au bout de toutes ses œuvres. Un de ces auteurs qui m'a beaucoup enthousiasmé au cours de mes études linguistiques était Roman Jakobson. Je suis sûr que n'importe lequel de mes collègues linguistes en Albanie connait très bien qui est Jakobson et quelle est son importance pour le développement de la linguistique générale, ainsi que le grand élan que son travail a donné au développement des sciences sociales de son temps. On pourrait dire, la linguistique moderne, on peut dire qu'elle est née sous l'influence des travaux de Jakobson. Comme j'ai dit, après que je suis venu à bout de tous les travaux de Jakobson, à un certain moment, j'ai été impressionné par l'un de ses articles, un court article en effet et probablement pas très important, mais une 
analyse très, très détaillée d'un poème de Charles Baudelaire, un des plus célèbres poètes français du $\mathrm{XIX}^{\mathrm{e}}$ siècle. Il s'agissait de l'un des plus connus sonnets de Baudelaire, "Les Chats », magistralement analysé avec la meilleure rigueur des techniques structurales (Jakobson \& LéviStrauss 1962). J'ai noté que dans cet article Jakobson n'était pas seul, mais co-auteur. À l'époque, de l'autre auteur, je n'ai jamais entendu parler : un certain Claude Lévi-Strauss ! J'allais apprendre plus tard que c'était l'anthropologue le plus célèbre de tous les temps, mais à ce moment, en raison de la grande impression que j'ai eu de l'article sur «Les Chats » de Baudelaire, par simple curiosité intellectuelle, je me suis dit qui est celui-ci, pourquoi Jakobson a écrit un article avec lui, et j'ai essayé de connaître son travail. C'était une chose très difficile en Albanie sous le régime communiste de l'époque, mais avec la complicité de Jean-Paul Champseix, mon professeur de français qui est maintenant Professeur de littérature comparée à l'Université de Saint-Etienne en France, j'ai réussi à faire commander les œuvres complètes de LéviStrauss par la Bibliothèque du Département d'études françaises de l'Université de Tirana. Par la suite, je ne pouvais rien que les lire tous. C'est ainsi que j'ai découvert l'anthropologie sociale qui allait par la suite dominer tous mes intérêts d'études à venir.

Certes, cela est très important pour vous parce que, en soi, la relation entre Roman Jakobson et Claude Lévi-Strauss est très importante pour l'histoire même de l'anthropologie. Plus tard, vous irez à Paris, au Laboratoire d'anthropologie sociale fondé et dirigé pendant une longue période par Lévi-Strauss lui-même, pour terminer vos études de doctorat en anthropologie sociale. Ayant travaillé pendant de nombreuses années comme anthropologue, vous avez connu manifestement de nombreuses situations et des réalisations différentes. C'est pourquoi je tiens à ce qu'on s'arrête à un moment ou à une période de votre parcours comme chercheur, qui vous rend encore heureux quand vous vous en souvenez.

Un des moments culminants de ma vie d'enseignant-chercheur est mon élection en tant que membre à part entière de l'Académie des Sciences d'Albanie. Sans aucun doute il s'agit d'un événement très important pour moi, parce que c'est la preuve de l'estime et de l'appréciation de ce que j'ai fait jusqu'au moment de mon élection, mais c'est aussi un moment très important pour la discipline de l'anthropologie sociale en Albanie. Bien sûr, dans pareils cas on a tendance à dire que c'était la première fois qu'un anthropologue est élu à l'Académie, que j'étais le premier à être élu dans ce domaine, et ainsi de suite. Mais je ne veux pas dire de ces choses. Plutôt, je veux considérer le moment de mon élection à l'Académie comme un moment symbo- 
lique, un moment significatif pour la discipline de l'anthropologie, qui remonte dans le temps, je tiens à relier ce moment à des anniversaires qui sont si l'on peut dire aussi importants et significatifs du point de vue symbolique. J'ai été élu en 2008 membre à part entière de l'Académie. Et cette date, en ce moment, me rappelle trois anniversaires célèbres auxquels je voudrais relier mon élection. Ainsi, au lieu de considérer mon élection à l'Académie comme la première chose importante et significative qui s'est passé dans le domaine de l'anthropologie en Albanie, je voudrais associer mon élection à l'Académie à une tradition centenaire.

En fait, cent ans avant mon élection, en 1908, pour la première fois dans le monde la première chaire d'anthropologie sociale a été créée. À l'Université de Liverpool en 1908 Sir James Frazer a été le premier au monde à être élu titulaire d'une chaire d'anthropologie sociale. Ce centenaire est très important pour n'importe quel anthropologue, mais il est particulièrement significatif à l'anthropologie sociale en Albanie, parce que la tradition venant de Frazer, même si aujourd'hui elle est plutôt obsolète et même si le nom que Frazer avait choisi pour sa discipline n'a rien à voir avec la discipline que nous avons aujourd'hui, cette tradition centenaire a offert pendant très longtemps, peut-être trop longtemps même, je dirais, étonnamment de façon paradoxale et certainement malheureuse en effet, elle a offert les paramètres et les critères qui définissent encore aujourd'hui la tradition des études folkloriques et ethnographiques sur la culture populaire en Albanie, que d'une manière ou d'une autre on prétend qu'elles pourraient être considéré comme l'équivalent de l'anthropologie sociale, dans la mesure où c'est cette tradition qui se poursuit et continue à être pratiqué, malheureusement, par les chercheurs d'aujourd'hui dans ce domaine en Albanie.

Le deuxième anniversaire est aussi un centenaire, le centenaire de la naissance d'Eqrem Çabej, le plus éminent des chercheurs albanais. Eqrem Çabej est né en 1908 et, cent ans plus tard, je suis élu à l'Académie. Ceci est important pour moi parce que Eqrem Çabej reste encore le savant le plus éminent, non seulement en raison de son travail dans la linguistique historique, mais surtout parce qu'il a si fortement influencé les études albanaises dans pratiquement n'importe quel domaine, de telle sorte que les études albanaises ne sauraient être conçues sans son impact. Moi-même, quand j'étais jeune, j'étais aussi très influencé par les œuvres d'Eqrem Çabej. Et ce qui m'a le plus marqué c'est surtout sa méthode et sa rigueur du travail scientifique. Même si je pourrais dire que, peut-être comme la tradition de Frazer qui est encore et toujours suivie dans les études sur la culture populaire, en fait la tradition de Çabej qui est suivie plus généralement dans les études albanaises aurait dû également déjà être dépassée. Malheureusement, il 
ne semble pas encore être le cas, mais je voudrais, personnellement, je voudrais que les études albanaises aient pu être entièrement dégagé à la fois de Frazer en anthropologie et d'Eqrem Çabej en linguistique historiques ou en général dans les études albanaises que beaucoup en Albanie aiment encore à appeler « albanologiques ».

Le troisième anniversaire est encore un centenaire, c'est en effet le centenaire de la naissance du plus grand anthropologue que j'ai connu, celui que j’ai mentionné dès le début. Claude Lévi-Strauss est né en 1908 et moi, élu à l'Académie des Sciences en 2008, ne peut pas résister à relier mon élection en tant qu'anthropologue en Albanie à ce grand anniversaire. Comme je le disais, Claude Lévi-Strauss est et il sera probablement longtemps encore le plus grand anthropologue, et il aura la plus grande influence, non seulement pour mon travail en tant qu'anthropologue, mais aussi pour les générations d'anthropologues, d'aujourd'hui et à venir dans le futur.

De toute évidence, Lévi-Strauss est très important non seulement pour la discipline de l'anthropologie et les anthropologues comme vous, mais aussi pour toutes les sciences sociales et leurs évolutions dans ces dernières décennies à travers le monde. En effet, si je me souviens bien, dans une de vos conférences publiques à l'Université Européenne de Tirana vous avez dit que "si le XVIII siècle fut le siècle de Kant et le $X I X^{e}$ siècle fut le siècle de Marx, le XX $X^{e}$ siècle restera sans doute le siècle de Lévi-Strauss ». Toutefois, après nous avoir montré qu'un des meilleurs moments pour vous, c'était tout simplement votre élection à l'Académie des Sciences et que vous considérez cela non pas comme un événement isolé qui pourrait être important uniquement pour vous mais comme une continuation, associée à une série de traditions intellectuelles d'une signification particulière pour l'ensemble de la discipline de l'anthropologie en tant que telle, je suis sûre que vous devez également avoir un autre côté de la médaille, au cours de votre travail, vous devez avoir rencontré quelques difficultés ici et là, et il serait intéressant de partager un petit moment de difficulté, que vous pourriez regretter ou qui pourrait vous rendre mal à l'aise quand vous vous en souvenez.

C'est une question très difficile. Le moment le plus difficile est probablement lorsque l'on vient devant la caméra de télévision pour répondre à ce type de questions. Dans le travail comme dans la vie on est toujours confronté à des difficultés, parfois très dures et parfois moins dures, au point que maintenant je ne sais pas exactement quoi dire. Mais pendant que j'y pense, peut-être la chose la plus difficile pour moi en tant qu'anthropologue, quelque chose qui me rend mal à l'aise en tant qu'anthropologue, c'est exactement ce qui fait que l'anthropologie 
sociale en tant que discipline est presque inconnue en Albanie. Je vais essayer de vous en dire plus ou moins, vous donner mon point de vue de ce que pourquoi il en est ainsi en Albanie. Je tiens à relier cela à nouveau à ce que je viens de dire. Comme je l'ai dit je suis venu à connaître l'anthropologie à travers le travail de Roman Jakobson. Mais il est intéressant de rappeler que Claude Lévi-Strauss a également reconnu que Roman Jakobson a eu une influence majeure dans sa carrière intellectuelle et je pourrais même dire que, dans une certaine mesure, l'histoire de la discipline, comme vous venez de remarquer, l'anthropologie a grandement bénéficié de la connaissance, de l'amitié étroite et de la coopération étroite entre Roman Jakobson et Claude Lévi-Strauss. Ils se sont rencontrés à New York, dans les années de la Seconde Guerre mondiale, comme ils étaient tous les deux persécutés par le nazisme allemand. Roman Jakobson était russe et Claude LéviStrauss était français, mais tous les deux étaient d'origine juive et ils ont trouvé refuge aux États-Unis. Là, lorsqu'ils enseignaient à l'École libre de New York, ils assistaient dans les conférences qu'ils donnaient l'un et l'autre, ils se sont sentis à proximité intellectuelle et ils se sont liés d'amitié. C'est exactement de cette connaissance, de cette amitié intellectuelle, qui a servi, si l'on peut dire, comme une étincelle intellectuelle qui a permis au structuralisme linguistique de devenir un fait majeur de la nouvelle anthropologie structurale. Sans doute, le structuralisme est déjà relégué dans l'histoire de la linguistique, pour autant que ses cadres conceptuels, ses méthodes et ses objectifs sont radicalement redéfinis sous l'influence de Noam Chomsky et des réactions à la linguistique chomskyenne. Le structuralisme appartient aussi au passé des sciences sociales, non pas parce qu'il est remplacé par quelque approche alternative convaincante, mais parce que la mode structuraliste des années 1960 a suscité tellement de mécompréhensions qu'elle a compromis ses promesses et ses réalisations. N'empêche qu'on peut dire que l'héritage de l'anthropologie structurale, qu'on doit à Claude Lévi-Strauss, a dû fournir à l'anthropologie moderne son vrai caractère scientifique et sa méthode sans précédent.

La difficulté est de comprendre pourquoi la tradition moderne de l'anthropologie sociale n'est pas encore connue en Albanie. Il est peutêtre choquant, mais j'ai eu quelque chose comme un soupçon lorsqu'en 2008 j'ai assisté à la Conférence nationale pour la commémoration du centenaire de la naissance de Eqrem Çabej, là où le respect de toutes les sciences albanaises et tout le monde intellectuel albanais a été montré, beaucoup mieux que je peux le faire ici, au plus illustre représentant des études albanaises. Entre autres, c'était un professeur de l'Université de Vienne où Eqrem Çabej a fait son doctorat, et qui nous a montré une série de souvenirs et une série de documents de sa vie en tant qu'étudiant. Tout cela était fort intéressant et nous suivions tous avec 
beaucoup d'intérêt en effet. Entre autres choses, nous avons vu un diaporama de plusieurs de ses professeurs. À un certain moment, j'ai remarqué avec surprise que l'un des nombreux professeurs de Eqrem Çabej était également Nikolaï Sergueïevitch Troubetzkoy. En fait, il a été professeur de philologie slave à l'Université de Vienne de 1922 jusqu'à sa mort en 1938, qui coïncide en effet avec le temps des études doctorales de Çabej. Peut-être pour beaucoup, c'est un nom inconnu, mais je suis convaincu que pour mes collègues linguistes c'est l'un des plus grands noms de la linguistique. Qui plus est, Troubetzkoy était dans une certaine mesure l'âme intellectuelle de Roman Jakobson. Troubetzkoy et Jakobson se sont rencontrés lors du premier congrès international de linguistique en 1928 pour rejoindre ce qui est connu comme le Cercle linguistique de Prague, où les méthodes d'analyse littéraire structurelle ont été mises au point au cours des années 1930. Il est parfois difficile de distinguer les vues de Troubetzkoy de celles de Roman Jakobson, qui est crédité de la diffusion des points de vue de l'École de Prague après la mort de Troubetzkoy. Tout cela a dû avoir une grande influence dans la mesure qu'elle a fourni un élan sans précédent au développement de la linguistique moderne et de la sémiotique, qui sont justement nées dans ce cercle d'érudits. Troubetzkoy et Jakobson sont peut-être, si l'on peut dire, à considérer comme une seule et même chose, parce qu'ils appartenaient à la même tradition scientifique.

Maintenant, quand on connait la mesure par laquelle Claude LéviStrauss a été affecté, avec une telle importance pour la nouvelle science de l'anthropologie, par sa rencontre avec Roman Jakobson, qui est à nouveau reproduite en quelque sorte à mon humble niveau, puisque $\mathrm{j}$ ' ai eu également, comme je le disais, presque la même illumination à partir de la lecture des œuvres de Jakobson qui m'a permis de prendre conscience de Claude Lévi-Strauss et de l'anthropologie moderne. Par conséquent, à ce moment-là, quand j'ai vu que parmi les professeurs de Eqrem Çabej était également Troubetzkoy, je suis resté bouche bée de stupéfaction et je me suis dit, pourquoi bon sang Çabej n'est pas affecté, pourquoi mon Dieu il ne mentionne jamais Troubetzkoy dans son travail, quand nous savons tous combien ses idées ont été importantes pour le développement de la linguistique moderne. Et je me suis tourné vers Xhelal Ylli qui était proche de moi à la Conférence commémorative, un vieil ami des années d'études qui est maintenant un linguiste rattaché à l'Université de Hambourg en Allemagne, pour lui dire exactement ce que j'ai pensé. Je lui ai dit comment cela a pu être possible. La raison est très simple, me répondit-il. Dans les conditions du régime communiste Çabej ne pouvait pas s'occuper de telles choses, de sorte qu'il n'a fait que traiter avec les études étymologiques ou l'histoire ancienne de la langue albanaise. Pas nécessairement, je lui ai dit, il aurait pu en faire autrement. Et j'ai rappelé à mon ami un autre linguiste 
qui est aussi célèbre que Troubetzkoy et Jakobson, je veux dire Emile Benveniste qui a travaillé exactement dans le même domaine que Çabej. Ainsi, même dans ce domaine, dans le domaine même où Çabej a travaillé, la linguistique albanaise aurait pu s'organiser et se développer dans le nouvel esprit des approches analytiques, puisque Benveniste a également travaillé dans le domaine de la linguistique et de l'étymologie indo-européenne qui sont exactement les champs dans lesquels Çabej a travaillé en Albanie. En fait, il n'est pas surprenant que Benveniste n'était pas seulement un linguiste remarquable, mais aussi un très proche collaborateur de Claude Lévi-Strauss, puisqu'ils ont fondé ensemble L'Homme, la revue anthropologique le plus reconnu aujourd'hui en France. Malheureusement, et mes collègues linguistes devront savoir mieux que moi combien loin de la tradition pratiquée par Benveniste le genre d'études étymologiques qui préoccupent encore les études albanaises d'aujourd'hui sont exactement situées. Inutile de dire combien cela m'a fait une impression pénible. Comment se fait-il que le grand Çabej n'a pas pu se laisser influencer par les développements modernes de la linguistique, mais il est allé en arrière vers les grammairiens anciens? Comment est-il possible qu'il n'a pas suivi l'école linguistique de Prague et Troubetzkoy qui avait été son propre professeur, sans parler de Benveniste qu'il n'a probablement pas connu, même s'ils ont tous les deux vécu et travaillé dans le même temps et même si les deux ont cité à peu près les mêmes auteurs. Il est encore plus frappant que Benveniste ait pu donner quelques étymologies correctes de certaines gloses albanaises problématiques, comme par exemple l'origine sémantique du terme par lequel la notion de lignage et de parenté est exprimée en albanais, que j'ai également utilisé dans mon travail sur les structures d'organisation sociale chez les Albanais (Doja 1999a) et dont Çabej aurait davantage bénéficié s'il avait connu les travaux de Benveniste. En bref, ce que je veux dire, c'est qu'à mon avis, c'est un moment très douloureux que je ne sais pas comment expliquer. Je ne sais pas, je ne peux pas savoir comment expliquer pourquoi Eqrem Çabej n'a pas été ouvert aux développements modernes dans sa science, afin de venir nous donner une nouvelle influence, ce qui aurait pu ouvrir une nouvelle voie pour le développement de la science albanaise. Je le dis avec tristesse que c'est peut-être justement cette non-ouverture, dont je ne vois que le résultat malheureux, c'est peut-être ce blocage ou sa non-ouverture qui a bloqué et continue de retenir les études albanaises coincées dans le XIX ${ }^{\mathrm{e}}$ siècle.

Peut-être pour cette raison je tiens à vous demander votre opinion plus spécifiquement sur le problème de l'anthropologie sociale dans la situation actuelle en Albanie? 
En voilà une autre question encore plus difficile, parce que je ne sais pas quoi dire. Je ne sais pas quoi dire, non pas parce que je ne sais pas ce qui se passe, mais je ne sais pas quoi dire parce que je ne peux pas trouver quelque chose, un genre d'études qui puissent être équivalentes à l'anthropologie sociale et culturelle, de quoi nous parlons ici. En fait, l'anthropologie est malheureusement très chic, et ce n'est pas le cas uniquement en Albanie, mais dans presque tous les autres pays d'Europe de l'Est, en particulier lorsque des personnes de diverses formations et professions, qui deviennent des personnalités publiques dans les médias, aiment à se présenter comme ayant leur mot à dire au sujet de «l'anthropologie», ce qui pourrait être vu comme la capacité à manipuler des théories générales sur la nature humaine, la culture et la société. En effet, depuis que le nom de «l'anthropologie» a commencé à être entendu en Albanie, et je fais ici référence à l'anthropologie sociale et culturelle, même sans connaître sa signification, mais comme un nom à la mode, nombreux sont ceux qui ont cru que l'anthropologie était quelque chose qu'ils avaient toujours fait, tout simplement comme Monsieur Jourdain de Molière, qui tout à coup s'est rendu compte qu'il «parlait en prose » sans le savoir. D'autres se sont réveillés un beau matin, en fait, environ trois ou quatre ans auparavant, aux alentours de 2008 lorsque l'Institut de la Culture Populaire a également changé son nom et qui coïncide, ce qui n'est pas surprenant, avec mon élection à l'Académie des Sciences au premier fauteuil de l'anthropologie. En bref, ils ont décidé qu'ils sont devenus des anthropologues, sans se soucier qu'ils n'ont jamais eu aucune formation professionnelle ou académique du tout. Simplement, ils pensent que s'ils mettent l'étiquette anthropologique à eux-mêmes ou à leurs travaux ethnographiques et folkloriques ils pourront se considérer comme des anthropologues ou leur travail sera considéré comme une anthropologie et leurs collections archaïques comme une méthode d'ethnographie dans le sens de l'anthropologie.

La vérité est que, en Albanie, il n'y a rien eu d'équivalent à l'anthropologie sociale, ni avant ni pendant la période socialiste, et c'est toujours le cas encore aujourd'hui. Ce qui est normalement présentée comme l'équivalent à l'anthropologie sociale est connu en Albanie comme des études de la «culture du peuple» (kultura popullore), même si les protagonistes font de fausses distinctions entre le folklore et l'ethnographie, car dans tous les cas il s'agit ou bien d'ethnographie folklorique ou bien de folklore ethnographique. L'histoire institutionnelle des étiquettes est tortueuse et elle devient encore plus difficile surtout lorsque la formation professionnelle fait défaut, mais en Albanie comme dans les autres pays d'Europe de l'Est ces études ont porté sur les investigations de la culture matérielle, les objets d'art populaire, les traditions orales, les mythes, les croyances, les coutumes, et ainsi de 
suite. En général, ce type d'études fait partie des études plus vastes qu'en Albanie on aime appeler «albanologiques». La différence entre plusieurs désignations, tels que "folklore » qui s'occupe de traditions orales, « ethnographie » qui porte sur les objets et les coutumes populaires, ou encore «anthropologie physique» qui s'occupe des caractéristiques raciales, doit se considérer essentiellement comme une question de répartition des tâches au sein d'un projet commun d'histoire nationale. La même chose pourra se dire non seulement à propos de l'historiographie qui s'occupe des temps anciens, mais aussi de l'archéologie qui s'occupe des vestiges de la culture matérielle et de la philologie qui s'occupe avant tout des reliques de la langue. Quelle que soit l'étiquette, dans tous les cas, en vertu de leur histoire, leurs origines et leur nature, ces études sont une sorte d'études qui se concentrent sur leur propre culture nationale, sur la culture de la nation à laquelle appartient le chercheur, et qui célèbrent un modèle national qui est censé être profondément enracinée dans le passé. En tant que telles, les études de la culture du peuple restent tournés vers le passé, appliquées comme elles sont à mettre en œuvre le projet de découvrir l'origine la plus ancienne et l'état immaculé de la culture du peuple et de l'esprit du peuple, ce qui a inévitablement orientés ces études vers les intérêts nationalistes.

En effet, il n'est pas surprenant de voir les intellectuels, les écrivains et les critiques littéraires lancer et conduire des débats sur la «psychologie » et "l'âme nationale » albanaise, en mélangeant dans leurs arguments le passé glorieux, le patrimoine culturel, la culture du peuple, le territoire ethnique, le principe du «sang» ou les caractéristiques raciales. Les questions de langue, de philologie, de traditions orales et de coutumes du peuple ont fourni les arguments de base pour le grand débat sur la modernité en Albanie. Comme ailleurs en Europe centrale et orientale, le discours sur le folklore, sur la culture et sur les « manières de vivre » du peuple ont contribué à l'essentialisation du caractère national, ce qui a donné des arguments au nationalisme. Quand on médite sur les «défauts » du caractère national ou de la psyché nationale, cette autoréflexivité peut se présenter aussi sur le mode «critique ». Plus fréquemment, cependant, c'est plutôt un éloge panégyrique. Dans sa forme extrême, l'étude de la culture de son propre peuple devient une célébration de sa propre exclusivité. Dans ce processus, la culture du peuple devient une réalité imaginaire qui se réfère à un peuple imaginé, offrant essentiellement des formes émotionnelles et irrationnelles d'identifications et d'unifications, ainsi qu'une base à toutes les formes d'exclusion et d'intolérance. C'est ce qui donne à la culture du peuple imaginaire son sens réel, offrant une unification collective oppressive, telle qu'elle apparaît habituellement lorsque l'invention systématique de la tradition devient dangereuse à plusieurs égards, plus particulièrement en autorisant concrètement la manipulation politique, 
qui a finalement servi à légitimer les solutions politiques impatientes et intolérantes.

Les études de la culture du peuple, orientées comme elles sont vers sa propre culture et ses détails culturels, vers la recherche d'authenticité et d'antiquité des coutumes et des valeurs culturelles d'une société donnée, qui est la société propre du chercheur, en tant que telles, ces approches pourraient se considérer comme une sorte de folklorisme. Certes, il serait difficile de voir dans le folklorisme un cadre méthodologique ou une approche disciplinaire. Il s'agit plutôt d'un terme qui se réfère à l'invention ou l'adaptation du folklore, comprenant la mise en scène de tout élément d'une tradition en dehors du contexte culturel dans lequel il est créé, ce qui implique souvent des changements de formes, de significations et d'objectifs de la part des acteurs. Or, comme l'a montré la pratique culturelle spécifique du folklorisme à l'apogée de la Volkskunde allemande, une telle pratique, délibérément ou involontairement, en fait, plutôt intentionnellement que non, devient une proie tout en nourrissant les idéologies politiques des revendications nationalistes ou des régimes totalitaires. Tel fut le cas en Allemagne, où les études de la culture du peuple allemand, la soi-disant Volkskunde, ont cédé à l'idéologie et propagande nazie pour légitimer les politiques racistes, nationalistes et fascistes. Tel fut également le cas avec la mythologie serbe de la bataille de Kosovo à l'appui du chauvinisme serbe depuis le $\mathrm{XIX}^{\mathrm{e}}$ siècle jusqu'à la dernière guerre sur le Kosovo dans les années 1990. Très exactement de la même façon, sous le régime communiste en Albanie et dans tous les autres régimes communistes en Europe de l'Est, ce genre d'études se sont offertes d'elles-mêmes, plus que toute autre discipline des sciences sociales, au service de l'idéologie communistenationaliste comme les auxiliaires zélés de cette répression terroriste que la société albanaise a connue comme dans les autres pays communistes.

Je vois que vous êtes très critique des études folkloriques de la culture du peuple en Albanie et des études albanaises en général, mais pensezvous qu'il existe un signe ou l'espoir d'un changement?

Absolument! Ce que je viens de dire ne signifie pas que, après l'effondrement du socialisme et la chute du régime totalitaire en Albanie, il n'y a pas une nouvelle génération de chercheurs désireux d'utiliser ou de s'appuyer sur les théories et méthodologies de sciences sociales contemporaines, y compris la méthodologie anthropologique. Il y a effectivement un nombre croissant de travaux qui ont commencé à laisser leurs marques dans l'opinion académique albanaise et même internationale. Je connais très bien les jeunes anthropologues en Albanie et je travaille en étroite collaboration avec la plupart d'entre eux. En effet, beaucoup d'entre eux, comme Smoki Musaraj, Olsi Lelaj, Sofia 
Kalo, par exemple, ont été mes assistants, à un moment ou à un autre, dans les dernières années quand j'ai travaillé en Albanie. Certains d'entre eux ont fait des comptes rendus, d'autres ont même traduit certains de mes travaux en albanais. Avec d'autres encore, nous participons régulièrement ensemble à des conférences et des débats académiques, comme c'est le cas avec Nita Luçi, Albert Nikolla, Gerda Dalipaj, Enkelejda Sula et beaucoup d'autres, avec de jeunes chercheurs de talent dans d'autres disciplines avec une affinité élective pour l'anthropologie, comme Abazi Enika en sciences politiques et relations internationales, Gentiana Kera et Enriketa Papa en histoire, ou même avec des gens comme Nebi Bardhoshi et Amanda Kodra, de l'Institut actuellement soi-disant d'Anthropologie Culturelle, malgré leur position ambivalente, aspirant à embrasser l'anthropologie moderne mais sans formation adéquate et travaillant dans la méthode folklorique des vieux cadres institutionnels. Sans doute, le problème n'est pas avec la nouvelle génération prometteuse. Je veux simplement dire ici que les études de la culture du peuple, la tradition académique de ces études comme une discipline, en termes des objectifs de recherche qu'elles se sont fixés, ces études se situent complètement à l'opposé de l'anthropologie sociale. Dans leur cas, ces études ont encore besoin de se retrouver et se remettre, et je ne pourrais simplement que les exhorter instamment de le faire, surtout aujourd'hui dans les nouvelles conditions quand la société albanaise s'est ouverte à la mondialisation et à la démocratisation. Entre autres choses, il leur faudrait adopter une sorte de cosmopolitisme et de méthodologie comparative, en d'autres termes, il leur faudra utiliser l'analyse comparative qui pourrait les rapprocher de l'anthropologie. Si les études albanaises de la culture du peuple seront en mesure de réaliser cette transformation dépendra de nombreux facteurs institutionnels et personnels, y compris la volonté des jeunes chercheurs pour en finir de flirter avec les anciennes méthodes, ainsi que la possibilité pour eux d'obtenir une formation professionnelle adéquate.

En Mars 2011 j'ai été invité par Chris Hann à 1'Institut Max Planck d'anthropologie sociale à Halle, en Allemagne, pour contribuer à un atelier de recherche, où un certain nombre d'anthropologues de différents pays européens, principalement de l'Europe de l'Est et du Sud-est, nous nous sommes réunis pour discuter et essayer de réévaluer la contribution tant soit peu modeste, même si elle est problématique, de ce qui est parfois considéré comme l'équivalent de l'anthropologie sociale dans les pays de l'Est, je veux dire la tradition folklorique des études de la culture du peuple. J'étais avec des collègues d'autres pays, mais aussi avec certains de mes jeunes collègues venant d'Albanie, pour chercher ce qu'on pourrait faire de cette tradition, disons, afin qu'elle soit renouvelée, renforcée, révisée, de sorte que ce genre d'études aussi puisse atteindre en quelque sorte les normes requises de l'anthropologie mo- 
derne. Et en ce moment, à la suite de cette réunion que nous avions eu à l'Institut Max Planck en Allemagne, je suis en train de travailler pour donner un aperçu de l'évolution historique de cette tradition de recherche en Albanie, en pensant donner une évaluation critique, certes aussi équilibrée que possible, pensant que cette réévaluation, ce tour d'horizon historico-critique, pour l'appeler ainsi, sera de quelque utilité pour les jeunes chercheurs qui seront à l'avenir dédiés à l'anthropologie, comme moi je me suis engagé jusqu'à ce jour. Une telle évaluation critique de la tradition folklorique des études de la culture du peuple en Albanie, je crois, est encore nécessaire et importante, surtout pour ce groupe de jeunes chercheurs qui ont déjà commencé à œuvrer pour la réforme et la modernisation de ce champ d'études, et dont je me considère faire partie moi-même aussi, en dépit de l'âge, comme je l'ai montré jusqu'à maintenant avec mes contributions pour initier une tradition albanaise de l'anthropologie sociale. En effet, je crois fermement que la maturité ne pourra pas nous empêcher d'embrasser et d'encourager l'innovation, tout comme il est également vrai que la jeunesse n'est pas une garantie contre le conservatisme folklorique. En tout cas, si tous, ensemble, on prend audacieusement une attitude critique envers les études folkloriques de la culture du peuple en termes d'approches et de méthodes, ce sera sûrement pour mieux servir d'éclaireurs pour l'ensemble des interprétations que la jeune génération de chercheurs devra adopter dans les futures analyses anthropologiques. Car nous devrons absolument situer l'analyse anthropologique le plus loin possible de la prospective limitée des anciens chercheurs et des études historiques et folkloriques traditionnelles de la culture du peuple, qui restent marquée par l'isolement intellectuel et sont stigmatisées par l'association avec des idéologies moralisatrices ou nationalistes, exceptionnellement dures et revanchardes en particulier dans leur variante communiste.

Outre le fait que vous êtes un anthropologue dévoué, et membre de l'Académie des Sciences de l'Albanie, vous devez également faire partie de nombreuses autres organisations scientifiques internationales. Je voudrais savoir comment l'on travaille dans ce cadre, par exemple, si vous pouvez nous dire quelque chose au sujet des échanges d'expérience.

Comme je l'ai dit, j'ai passé la majeure partie de ma carrière universitaire à travailler à l'étranger dans les universités et autres établissements de recherche dans un certain nombre de pays européens, comme en France, en Angleterre, en Irlande, en Belgique, mais aussi en Albanie. Cela m'a permis que d'une manière ou d'une autre d'être une partie intégrante de cette communauté scientifique internationale, avec laquelle 
je vois ici en Albanie, non pas tant les liens, mais les relations semblent manquer. Faire partie de la communauté universitaire internationale, c'est être capable, non pas seulement d'avoir des contacts avec des chercheurs étrangers, les rencontrer dans des conférences internationales, se lier à eux en leur faisant des faveurs et s'attendre à être flatté de leur part. Faire partie de la communauté universitaire internationale c'est pour ainsi dire être en mesure d'entrer en dialogue avec cette communauté, ce qui veut dire avoir dépassé l'isolement intellectuel qui a caractérisé et que malheureusement continue de caractériser les études albanaises. En ce sens, je peux dire que la recherche, aussi avancée qu'elle soit, il me semble qu'aujourd'hui elle ne saurait être une recherche académique dans le plus simple sens du terme si elle reste toujours isolée, si elle ne fait pas partie de cette communauté académique internationale, où tout chercheur est considéré comme égal à tous les autres et peut entrer en dialogue et discuter avec les autres chercheurs de cette communauté, sur de petits sujets même, d'intérêt étroit, qui intéressent uniquement les membres d'une société particulière, disons, qui nous intéressent pour l'étude de notre propre culture nationale. Mais comme dans le cas des études albanaises, par exemple, les chercheurs doivent nécessairement se libérer des préjugés, élargir au plus possible la base comparative et soumettre les données albanaises à une analyse interprétative qui puisse devenir valable pour être utilisée ailleurs par d'autres chercheurs pour étudier des problèmes similaires dans d'autres sociétés et d'autres cultures. C'est la seule façon pour un anthropologue de faire face aux sujets importants et de plus en plus généralisables qui intéressent et préoccupent la discipline de l'anthropologie dans son ensemble.

En ce qui me concerne, j'ai eu la chance, je peux dire, l'opportunité et la possibilité, mais aussi une grande chance, que, en plus des nombreuses publications sur diverses questions de la culture et de la société albanaise, j'ai aussi participé à une série de débats au sein de la communauté universitaire internationale qui ont concerné le développement de la discipline de l'anthropologie, l'histoire de l'anthropologie, et si je peux dire, l'épistémologie de l'anthropologie, la faculté de l'analyse anthropologique pour expliquer les faits sociaux. À titre d'exemple, je peux dire que j'ai publié une série de travaux dans des revues internationalement reconnues, non seulement au sein de l'anthropologie, mais aussi interdisciplinaires, où $\mathrm{j}$ 'ai pris position dans le débat anthropologique entre structuralisme et poststructuralisme, un débat déjà ancien qui a opposé quelques-uns des plus grands savants et qui est surtout liée au débat que Jacques Derrida a élevé contre Claude Lévi-Strauss. C'est un débat qui pourrait se considérer comme l'événement constitutif du nouveau tournant poststructuraliste que les études en cours ont connus dans les sciences sociales internationales les plus avancées. J'ai rouvert le débat, je l'ai repris pour faire valoir une nouvelle position et une 
réévaluation critique (Doja 2006b). Peut-être il n'y a pas lieu ici pour discuter longuement ma contribution et voir spécifiquement comment j'ai réussi à réfuter l'attaque de Derrida, non seulement comme infondée, mais aussi comme une instance de désinformation arrogante et délibérément trompeuse. En tout cas, je peux dire que mes publications sur cette question ont laissé leur marque dans la communauté académique internationale et je pourrais même dire qu'ils ont laissé une marque que je considère comme inoubliable pour moi, car Claude LéviStrauss lui-même, en 2006, quelques années avant sa disparition, il m'a écrit à ce sujet.

J'ai quelque trois ou quatre lettres de lui, mais il m'a écrit spécialement pour me féliciter et pour me faire part de sa propre opinion par rapport à ma position dans ce débat. C'est évidemment quelque chose qui ne pourrait pas s'effacer de ma mémoire et dont je ne pourrais pas manquer d'être fier. Mais cet événement, cette lettre, a une autre importance encore plus spéciale. Sachant que Lévi-Strauss ne s'est presque jamais déclaré publiquement sur ce débat, du moins il n'a jamais pris la peine d'élaborer suffisamment une opinion, la position qu'il m'a fait savoir dans sa lettre, une position inconnue auparavant, prend de ce fait une importance particulière. Voyant cela, reconnaissant l'importance de la position de Lévi-Strauss, j'ai pris contact avec une revue anthropologique, l'une des revues les plus lues à l'international, à savoir Anthropology Today, et j'ai demandé au directeur de la revue de publier ce que Lévi-Strauss m'avait écrit sur ce débat. Ainsi, la lettre manuscrite que Lévi-Strauss m'a adressée le $1^{\text {er }}$ Juillet 2006 est publiée en 2010, au vol. 26, $\mathrm{n}^{\circ}$ 5, d'Anthropology Today, avec ma contribution commémorative qui célébrait son œuvre et son impact sur la pensée scientifique et intellectuelle contemporaine (Doja 2010a). Je ne peux m'empêcher d'admettre que cela a été un grand honneur pour moi. Inutile de dire que cela a été l'un des meilleurs moments les plus significatifs de ma vie académique.

Arrivé à la fin de notre conversation, je voudrais savoir sur quoi vous travaillez maintenant, si vous pouviez nous dire peut-être quelque chose sur votre prochain projet de recherche ou autre projet professionnel.

En Septembre 2011, je m'installe à nouveau en France. Après avoir passé avec succès les procédures du concours national de sélection, j'ai été nommé et titularisé par décret présidentiel dans un poste de professeur des universités titulaire de sociologie et d'anthropologie à l'Université de Lille. Sûrement, je m'attends à d'autres défis, mais aussi, je l'espère, à de nouvelles réalisations dans mon futur parcours universitaire. 


\section{Entretien à l'initiative d'Excellence Albanaise}

Prof Doja, votre curriculum vitae est si riche et si remarquable que l'on peut avoir le vertige. En plus d'être élu à l'Académie des Sciences d'Albanie, vous êtes aussi Professeur des universités en France. Pouvez-vous nous parler de votre position?

Il ne me semble pas très clair qu'est-ce qui est le plus important dans votre question, ma position comme membre de l'Académie des Sciences au fauteuil d'anthropologie sociale et comme Professeur titulaire à l'Institut de sociologie et d'anthropologie de l'Université de Lille en France ou le « vertige » qui semble vous venir de mon curriculum vitae. La position de professeur titulaire des universités que j'occupe actuellement en France est du ressort du Président de la République française, dans le sens que la nomination et la titularisation est faite par décret présidentiel. ${ }^{2}$ En soi, cela peut dire quelque chose sur le niveau du statut de professeur des universités en France, mais aussi sur le chemin difficile des nombreuses étapes et procédures de concours et de sélection. En tout cas, c'est peut-être la « richesse remarquable » du curriculum vitae que vous mentionnez, qui parle peut-être plus que tout autre chose de la difficulté du travail et de la réussite dans le monde universitaire. Je suis sûr que n'importe qui d'autre comme moi doit savoir que pour réussir dans le milieu universitaire ne suffit pas «travailler autour de soi », comme on peut dire souvent en Albanie, mais on doit traverser la mer à pied, comme dit le proverbe, de part et d'autre sans savoir si oui ou non il existe vraiment un rivage à atteindre.

Vous êtes allé faire vos études en France dans les années qui ont suivi l'effondrement du communisme. Vous avez d'abord fait votre doctorat à l'École des Hautes Études en Sciences Sociales à Paris d'où vous avez. commencé un brillant parcours universitaire, non seulement en France, mais aussi en Angleterre et en Irlande. Les débuts ont dû être difficiles pour vous et je suis curieux de savoir ce que vous retenez de l'Albanie que vous avez laissée derrière vous?

Pendant le peu de temps quand je suis retourné travailler en Albanie, j'ai eu la chance de répondre à des questions similaires. D'une manière ou d'une autre, ces questions m'ont exprimé l'admiration pour mes réalisations, dont la raison est le plus souvent supposée être le «bon sort » que j'ai dû avoir pour faire mes études de doctorat en anthropolo-

2 Décret du 29 septembre 2011 portant nomination, titularisation et affectation (enseignements supérieurs), Journal officiel de la République française $n^{\circ} 0228$ du 1 octobre 2011 , texte $\mathrm{n}^{\circ} 97$. 
gie à la prestigieuse École des Hautes Études en Sciences Sociales (EHESS), où l'on peut encore sentir la présence de tous les grands noms de l'anthropologie, les sciences sociales et la théorie française. Même quelqu'un que je ne connaissais pas m'a écrit spontanément par e-mail il y a plusieurs années, me disant combien j'aurais dû être fier de faire mes études à une école tellement associé aux grands noms de Claude LéviStrauss, Michel Foucault, Pierre Bourdieu, Jacques Derrida et beaucoup d'autres gens illustres. Avec cela, en quelque sorte, mes anciens collègues manifestent leur regret de ne pas avoir le même sort, tandis que les plus jeunes montrent leur espoir de pouvoir un jour faire ce que j'ai fait. J'ai essayé de rassurer les uns et les autres que ce n'est pas le doctorat à l'EHESS qui a fait de moi un bon universitaire, mais c'est moi qui ai fait un doctorat à l'EHESS. Si j'ai pu le faire, c'est parce que j'avais déjà obtenu en Albanie la culture du travail académique soutenu et systématique. J'ai également bénéficié des relations avec mes anciens collègues avec qui je travaillais avant mon départ pour étudier en France, surtout de l'énergique Professeur Alfred Uçi, qui a été une source d'inspiration et d'encouragement par son exemple. C'est mon travail qui m'a conduit plus tard à la nécessité d'acquérir de plus solides bases théoriques et méthodologiques qui feront de moi un universitaire et qui rendront possible ma carrière à l'avenir.

Comment vous avez-vous vécu votre premier contact avec la France? Qu'est-ce qui vous a le plus impressionné?

Travailler au Laboratoire d'anthropologie sociale fondé par Claude Lévi-Strauss et terminer son doctorat à l'EHESS, c'est à la fois un grand honneur et un grand stress. En fait, il fut un temps dans ma formation anthropologique lorsque, quand formé au début des années 1990 dans un endroit comme la France, je trouvais Lévi-Strauss simultanément inspirant et terrifiant, ce qui m'a finalement convaincu de la supériorité de ce que j'avais appris. Dans la phase suivante, quand depuis septembre 2000 je me suis installé en Grande-Bretagne où j'ai accepté un poste d'enseignant à l'Université de Hull, tout mon savoir anthropologique appris à l'école française fut tellement défié par les nouvelles approches anglo-américaines, au point qu'il m'a semblé que j'avais tout à réapprendre dès le début. Cependant, avec maturité, je suis venu à réaliser que, avec Lévi-Strauss, il y a peut-être davantage de vérité dans la phase suivante que dans la phase précédente de ma formation. En fait, Claude Lévi-Strauss a prévu et anticipé l'avènement de ce que je crois être l'avenir d'une anthropologie théorique. Héroïque comme il est salué, par Susan Sontag dans les années 1960, sa vision et son ambition était d'assurer à la discipline une clarté méthodologique, une rigueur scientifique et une conscience globale. 
Vous avez eu la possibilité d'échanger vos idées avec Lévi-Strauss luimême, n'est-ce pas?

Je ne peux pas oublier quand j'ai eu l'occasion de rencontrer Claude Lévi-Strauss pour la première fois. Je venais tout juste d'arriver à Paris pour commencer ma thèse de doctorat et le Laboratoire d'anthropologie sociale organisait un pot dans la bibliothèque imposante. Je me suis approché de lui et j'ai essayé de lui montrer certaines données ethnographiques albanaises d'une manière très typique, c'est-à-dire en pensant tout naturellement que $\mathrm{j}$ 'avais quelque chose à dire qui pourrait l'intéresser. Je me souviens que c'était quelque chose sur les motifs des ballades médiévales albanaises, des chants guerriers, des lois coutumières, de l'organisation sociale albanaise, et ainsi de suite. Sûrement, il a accordé une attention particulière à ce que je lui disais, vraisemblablement juste par courtoisie, mais je lui reste reconnaissant pour son encouragement à l'égard de mon attitude de théorisation plutôt atypique dès cette époque mais que j'aurai à développer plus tard. Je lui ai parlé de la possibilité de rapporter ce que je lui disais à la théorie de la prohibition d'inceste et à l'analyse structurale des mythes dans le but de révéler une dimension idéologique cachée et le caractère instrumental des valeurs sociales comme la morale de l'honneur, dont le seul but ne serait pour moi que de faire taire la faculté humaine d'agir, agency comme on dit en anglais, celle des femmes en particulier, sous l'apparence de cohérence structurelle. Était-il toujours à mon écoute simplement par politesse, surtout à mes idées critiques encore insuffisamment développées sur la relation interactive entre structure et agence sous l'influence de l'idéologie et de la culture comme instruments de l'hégémonie politique et du pouvoir? Incroyable mais vrai, lors d'une autre rencontre, même dix ans plus tard, non seulement il n'avait rien oublié de ce que je lui avais dit dix ans plus tôt, mais il s'est même infailliblement souvenu de ma position théorique et il me l'a rappelé avec presque les mêmes termes.

Vous avez contribué à l'étude anthropologique de la société albanaise : quelle est l'importance et à quoi servent ces études?

L'anthropologie sociale est une discipline qui s'intéresse aux gens organisés en différents groupes sociaux, comment ils pensent, agissent, se comportent et produisent ce qu'on appelle «culture », et où l'on inclue les institutions, les normes et les règles de comportement, ainsi que les manières de penser et d'interagir avec l'un l'autre. À première vue, il semble que l'objet de l'anthropologie est l'étude des différentes coutumes dans d'autres cultures. En effet, à l'époque quand je travaillais à l'Institut de culture populaire, je devrais étudier les caractéristiques de la culture albanaise comme une culture particulière d'une société parti- 
culière. Mais non, quand on est familiarisé avec la connaissance anthropologique, très vite on se rend compte que ce qui est important à l'anthropologie ne sont pas l'identification et la description des coutumes, des traditions orales, des objets matériels ou des différents traits culturels et raciaux d'un peuple ou d'une nation, encore moins s'il s'agit de la propre société ou nation de l'anthropologue. Je dirais même que ce genre de retrait sur soi-même serait incompatible avec la position dans laquelle se trouve la société albanaise aujourd'hui, dans une période où l'on dit être ouvert au cosmopolitisme, à l'intégration à l'Europe, à la démocratie, aux droits de l'homme partout dans le monde. Ce qui est important à l'anthropologie est la compréhension des processus socioculturels à travers l'étude des mécanismes internes invisibles en quelque sorte qui se trouvent en dessous de la surface visible des faits, de sorte à ce qu'on puisse expliquer, par exemple, les problèmes sociaux d'aujourd'hui. C'est précisément l'essence de l'anthropologie, d'expliquer le processus dans lequel nous nous trouvons et à travers lequel nous avons été créés tels que nous sommes.

Vous avez sans doute beaucoup contribué à l'étude anthropologique de la culture et de la société albanaise, et vous êtes aussi sans doute le meilleur expert albanais de l'œuvre de Claude Lévi-Strauss, l'un des esprits les plus brillants du siècle dernier. Pouvez-vous nous parler brièvement de vos projets ou les orientations de vos derniers travaux?

Certes, l'étude anthropologique de la culture et la société albanaise prend une place importante dans mon travail, en particulier les dimensions idéologiques des pratiques culturelles et des discours sur l'identité, la religion, la nationalité, l'histoire ou les relations de genre et d'autres interactions sociales. En plus de ces questions, entre autres choses, je suis également engagé dans un travail de long terme sur le rôle politique et idéologique de la production et de l'utilisation des connaissances. Ce projet n'est pas seulement liée à l'utilisation politique des études pour justifier un pouvoir totalitaire, comme je l'ai montré dans mes travaux déjà anciens sur la «folklorisation » de la culture populaire communiste en Albanie (Doja 1998b), mais aussi à la dimension idéologique des connaissances produites par les savants occidentaux. Dans la plupart des cas, ils reprennent à leur propre compte la façon dichotomique de penser qui est censée provenir des structures sociales albanaises plus traditionnelles mais renforcée durant le socialisme, selon laquelle il n'est pas rare que les chercheurs sont classés dans les catégories d'" albanais » et d' « étranger » ou d' « amis » et d' « ennemis ». De cette façon, même si à l'occasion ils ont pu faire leurs preuves avec compétence dans les universités occidentales, les chercheurs albanais sont souvent ignorés ou mal interprétés, comme s'ils ne pouvaient tout au plus qu'ajouter des 
exégèses et des renvois aux théorisations « étrangères ». Et en ce moment, je suis en train de travailler pour un aperçu de l'évolution historique des études sur la culture populaire et l'histoire nationale, par les chercheurs albanais comme par les chercheurs étrangers, pour essayer de fournir une évaluation critique, certes aussi équilibrée que possible. Je pense que si on veut faire des pas importants en avant dans les études albanaises il faudra avant tout une réévaluation historico-critique des résultats et des échecs de jusqu'à maintenant.

Plus concrètement, entre autres choses, je vais essayer de montrer comment et pourquoi l'intérêt de « recherche » en Albanie, en particulier l'exploitation de l'Albanie du Nord, au début et à la fin $\mathrm{du} \mathrm{XX}^{\mathrm{e}}$ siècle s'est avéré promouvoir consciemment ou inconsciemment un genre de littérature sur la culture et la société albanaise, qui n'est autre chose qu'un pur acte construit d'ethnocentrisme et mélangé d'exotisme, de «balkanisme » et autres « orientalismes » en «marges de l'Europe ». À titre d'exemple, une monographie récente par un professeur d'histoire à l'Université de Vienne sur Skanderbeg (Schmitt 2009) n'est pas tant à blâmer en raison d'une répudiation et démystification du caractère national du héros albanais du $\mathrm{XV}^{\mathrm{e}}$ siècle, comme la plupart des Albanais le croient. Assurément, en dépit qu'il prétend attirer plus d'attention à une dimension balkanique plus large qui ne devrait pas incorporer des schémas ethno-nationaux modernes, dans sa monographie il a fait de son mieux pour montrer exactement l'ampleur du stock non-albanais de Skanderbeg. D'ailleurs ce n'est pas par hasard que, pour lui et ses associés, l'origine ethnique des chercheurs est également considérée encore comme importante. En tout cas, je crois que tout Albanais devrait être fier d'une telle présentation de leur héros national, comme le « Nouveau Grand Alexandre des Balkans», même si cela n'est pas forcément un compliment pour un travail universitaire. Plus important, cependant, semble être le cadre explicatif de l'auteur et sa lecture erronée de certains faux documents, quand il prend le rapport de diplomates italiens comme si c'était ce que l'envoyé de Skanderbeg a réellement dit au Pape Nicolas V en janvier 1454. Alors que, dans un style typique des rapports diplomatiques, ils ont plutôt mélangé les faits avec leur propre interprétation des faits. Une telle lecture si erronée est sûrement soit volontaire soit autrement inconcevable pour un historien $\mathrm{du} \mathrm{XXI}^{\mathrm{e}}$ siècle. Il a néanmoins réussi à projeter les stéréotypes contemporains d'orientalisme et de balkanisme sur les prétendues lois tribales albanaises, vendettas sanguinaires, et autres du même genre dans sa caractérisation d'un personnage du $\mathrm{XV}^{\mathrm{e}}$ siècle, on dirait presque de la même façon que l'ancienne génération d'écrivains autrichiens et allemands qui étaient généralement intéressés à des découvertes sensationnelles afin d'acquérir un prestige artificiel. S'il en est ainsi, il aurait mieux fait de caractériser Skanderbeg comme un homosexuel aussi, car cela aurait été 
être plus en vogue de nos jours. De la même manière cependant, les chercheurs albanais de la culture du peuple et de l'histoire nationale, dans leurs efforts pour saisir les traditions «authentiques » et «populaires » de la culture n'ont servi que le but ultime d'une construction de la soi-disant spécificité nationale et d'une vue particulièrement archaïque de la culture et de l'histoire nationale. En dernière analyse, l'ensemble de ces études reproduisent les vieux modèles de particularisme et de déterminisme culturel, alors qu'elles sous-estiment indûment un potentiel plus important pour générer une compréhension plus éclairée des spécificités de la logique culturelle albanaise.

D'autre part, je me suis engagé dans un projet similaire depuis que je suis installé en Irlande comme membre chercheur au Collège des Sciences Humaines de l'Université de Limerick. Il s'agit d'un projet de réflexion à long terme sur l'évaluation et l'élaboration d'une nouvelle vision pour le développement futur de l'anthropologie et de la théorie sociale. Dans cette réflexion je m'appuie principalement sur l'héritage théorique et méthodologique de l'anthropologie structurale et de l'œuvre de Lévi-Strauss, reconsidérée à la lumière des réalisations et des préoccupations de l'anthropologie contemporaine. Les principaux résultats de ce projet sont déjà publiés pour la plupart, même s'ils sont dispersés à travers un certain nombre de revues internationales (Doja 2005e, 2006a, 2006b, 2006c, 2007, 2008a, 2008b, 2010a). J'ai juste besoin d'un peu plus d'effort et de beaucoup plus de temps pour les réunir dans un livre bien articulé. En tout cas, mon objectif, à travers une critique de la rhétorique postmoderne du poststructuralisme, c'est d'initier un mouvement qu'on pourrait qualifier de néo-structuralisme morphodynamique et constructiviste et qui pourrait intégrer ce que je crois être le meilleur des traditions françaises et anglo-américaines.

Vous avez un curriculum très riche dans la recherche scientifique comme dans l'enseignement universitaire : quelles sont les différences pour vous et qu'est-ce que vous préférez le plus?

Je ne sais pas quoi dire! Dans la recherche il y a des attentes inégalées. Après de longues recherches, vous devez nécessairement avoir " trouvé " quelque chose de nouveau qui est évalué dans la mesure d'une publication. Lorsqu'on y est parvenu on se dit : « Je l'ai fait », il est impossible de ne pas être rempli par une excitation sans précédent, même si on a l'habitude de garder cela pour soi et personne ne saura rien à ce sujet. Or presque la même chose peut vous arriver aussi avec l'enseignement. Je me souviens quand j'ai été devant la classe pour la première fois. Je venais de terminer l'école secondaire et pour la première fois j'ai eu à enseigner dans une école primaire dans un village reculé d'Opar sur les hauts plateaux de Korça dans le sud-ouest de 
l'Albanie. Quand je suis entré en classe, j'ai été terrifié par trente ou quarante paires de petits yeux qui me regardaient fixement comme s'ils s'attendaient à je ne sais pas quoi dire. Honnêtement, je n'ai pas pu tenir et je me suis instinctivement tourné vers le tableau comme s'il pouvait me protéger. Bien sûr, avec l'expérience $\mathrm{j}$ 'ai appris à me maitriser, mais toujours quand je suis devant l'auditoire j'ai une sorte d'émotion, quelque chose comme le trac. Et comme je suppose que cela arrive à un artiste sur scène, c'est en surmontant ce genre d'émotion qu'il m'arrive souvent, et je suis moi-même le premier à être surpris, de dire des choses que je n'aurais jamais pensé avant. En tout cas, la préférence essentielle d'un chercheur universitaire est que tout ce qu'on fait doit avoir absolument une valeur aussi longtemps qu'on essaye d'atteindre à quelque chose de nouveau. En ce sens, la recherche et l'enseignement sont différentes mais complémentaires et dans tous les cas mes préférences vont toujours vers la possibilité d'apporter quelque chose de nouveau. En effet, je ne peux pas attendre d'en finir avec ce que j'ai en main, avec ce à quoi je suis en train de réfléchir et de travailler, car je veux toujours faire autre chose, quelque chose qui est nécessairement nouveau et que je ne sais pas encore ce qu'il peut être ou ce qu'il peut apporter. Parce que ce qui est nouveau est quelque chose qu'on ne sait pas ce que c'est, car si on le savait, ce ne serait plus nouveau, n'est-ce pas?

Vous avez fait vos études doctorales en France et vous contribuez par votre recherche et enseignement dans plusieurs universités reconnues en Europe. Maintenant que vous avez obtenu le plus haut statut dans la hiérarchie universitaire, comme membre de l'Académie des Sciences d'Albanie et comme Professeur de sociologie et d'anthropologie à l'Université de Lille, j'aimerais savoir par rapport au monde universitaire où est la différence entre la France et l'Albanie? Est-ce que ce sont les élèves ou les collègues qui sont différents, ou les différences sont-elles dans les orientations théoriques, les intérêts de recherche ou les standards académiques?

$\mathrm{Au}$ fait, c'est un truisme d'affirmer que le monde universitaire est un petit monde dans le grand monde de la société. Dans chaque société, en France comme en Albanie, le monde académique avec ses problèmes ne saurait que refléter nécessairement les problèmes sociaux du monde dans son ensemble. Or, tant la société albanaise que la société française sont dans un carrefour important, quoique différent, mais qui nécessite pareillement des choix audacieux. La société albanaise subit des transformations radicales dans presque tous les domaines, tous les aspects et tous les détails. Cependant, tout semble témoigner de la dynamique et de la vitalité avec laquelle les transformations sont effectuées plutôt que 
des résultats escomptés. En effet, dans le même temps la société albanaise subit également des destructions radicales dans presque tous les domaines, en particulier dans les valeurs sociales. Apparemment, tout cela est lié à des traditions non encore consolidées en raison de cette transition sans fin et problématique que la société albanaise a commencée il y a cent ans à la recherche de soi-même et qui s'est accéléré ces vingt dernières années. Tout ce dynamisme de transformation et de destruction est clairement reflétée partout, y compris dans le monde universitaire. Les étudiants et les chercheurs sont avides de connaissances et de réussites, plus que jamais, en particulier de connaissances modernes les plus avancées et de réussites professionnelles les plus élevées. Même si en général, tout le monde s'efforce de parvenir à tout et n'importe quoi, à n'importe quel prix et par n'importe quel moyen. En conséquence, même si on peut obtenir tout ce qu'on veut, toute réussite, toute performance et toute réalisation est très vite dévalorisée. Le processus est sans aucun doute facilité par les politiques publiques d'études supérieures de masse à tout prix et sans discernement, ainsi que par l'augmentation de l'éducation pas chère prise en charge avec beaucoup de diligence par les universités lucratives. Le pire, c'est que le résultat de ces politiques est d'autant plus multiplié qu'on remonte dans les niveaux universitaires, culminant avec la vulgarisation et la dévalorisation des études doctorales et des titres universitaires.

Alors que la société française est une société avec une longue tradition consolidée et des valeurs sociales durables dans tous les domaines, et je dirais même dans le monde universitaire plus que partout ailleurs. Dans ces conditions, les transformations de toute nature sont lentes, difficiles à réaliser, et ce qui est pire, elles sont considérées comme inutiles. Or la France aussi se trouve actuellement devant des défis de taille. Ils sont liés autant à l'accélération des processus de transformation à travers le monde et en Europe qui mettent de plus en plus en question la position de la France comme un leader dans la production des idées et des valeurs, comme aux problèmes sociaux et économiques internes qui minent de plus en plus la cohésion sociale et culturelle. Dans ces conditions, devant tels défis, la difficulté ou l'impossibilité de transformation semble aboutir à une paralysie interne qui n'est pas loin de se convertir en une destruction réelle de valeurs. Dans le milieu universitaire, par exemple, ces dix dernières années il y a beaucoup d'efforts en matière de réformes dans l'enseignement supérieur. Dernières en date, ce sont les assises nationales de l'enseignement supérieur et de la recherche organisées par le nouveau gouvernement. Cependant, très peu de choses ont changé, apparemment en raison d'une résistance générale au changement. Peut-être cela est dû aux origines mêmes des valeurs constantes sur lesquelles la France est elle-même construite. Peut-être le poids des réalisations théoriques françaises précédentes, 
même si les grands noms sont déjà partis, rendent tant soit peu difficile les initiatives originales de la pensée universitaire et de la pratique de recherche, pour ne laisser souvent de place qu'aux commentaires exégétiques ou aux applications occasionnelles.

$\mathrm{Si}$ on faisait une comparaison avec les anciens pays socialistes tels que l'Albanie, dans les pays occidentaux comme la France leur échec est souvent considéré comme un résultat de la privation de la liberté d'expression et de créativité. Mais ceux qui ont vécu dans les conditions $\mathrm{du}$ socialisme savent très bien combien naïves sont de telles opinions. Car nous avons très bien vécu comment le système a échoué non seulement par la privation de la liberté d'expression et de création qui était le résultat direct d'une auto-fermeture autarcique, mais aussi et surtout par le nivellement par le bas des valeurs sous la pression d'un égalitarisme autant utopique que désastreux. Bien entendu, en France des efforts considérables sont déployés pour internationaliser l'enseignement supérieur et la recherche, ainsi que pour encourager les initiatives créatives en introduisant une gamme de mesures incitatives qui prennent en compte la hiérarchie des valeurs académiques. Or curieusement, dans la plupart des cas, ces réformes sont mal comprises dans un contexte politisé qui empêche de réaliser que l'enseignement supérieur et la recherche font partie avant tout des richesses stratégiques nationales en dehors des querelles politiciennes. Très souvent, ces réformes font face à une opposition farouche et malheureusement très populaire pour garder les traditions précédentes inchangées, en particulier afin de maintenir un statut égal pour tous. Aveuglé par une évolution des carrières dans un cadre administratif considéré comme acquis une fois pour toutes, on oublie trop souvent que les mérites et les performances académiques demanderaient plutôt à être sans cesse évaluées et réévaluées dans un contexte mondial des évolutions dans l'enseignement supérieur et la recherche.

Si la manière dans laquelle les réformes sont menées pourrait toujours se discuter dans la forme et le contenu, récemment on a vu des associations savantes et professionnelles d'universitaires français qui ont demandé l'abrogation du principe même de l'évaluation individuelle. Dans d'autres cas, c'est l'ensemble des membres d'un labo ou d'un autre qui se sont fermement opposés en bloc par un refus collectif de candidature à la "prime d'excellence scientifique », dont la campagne venait de s'ouvrir pour le CNRS, par exemple. Décriée comme « injuste et nuisible à la qualité du travail collectif», la prime d'excellence scientifique est considéré comme un nouveau système ou processus d'individualisation concurrentielle des rémunérations qui « dénature et entrave l'objectif de revalorisation des traitements et des carrières de l'ensemble des chercheurs », surtout quand on pense « tout particuliè- 
rement à tous les travailleurs précaires de la recherche et de l'enseignement, pour lesquels le montant de cette prime peut à bon droit être reçu comme une insulte ». Le principe même de prime d'excellence scientifique est contesté dans la mesure où l'on considère que «ces primes contribuent artificiellement à individualiser les mérites»d'un travail qui ne saurait être que collectif.

Apparemment, l'égalité, l'une des valeurs plus constantes du républicanisme français, semble se laisser manipuler, de même qu'en Albanie communiste, pour devenir une revendication d'égaliser tout le monde sous le même dénominateur commun d'évaluation, sans se soucier que plus le dénominateur est commun à tout le monde plus on fait le nivellement par le bas. Dans ces conditions, non seulement on assiste à une fuite continue des cerveaux là où les mérites plus que tout autre chose se font mieux apprécier, mais il devient d'autant plus difficile de faire de nouvelles choses, surtout quand on a vu et on a vécu comment les choses se font ailleurs. Mais cela ne veut pas dire que c'est impossible. Et c'est là apparemment, peut-être plus que toute autre chose, que le système français diffère du système albanais. Car le bienfondé du système universitaire français, et de la société française en général, c'est que quand les choses sont faites, elles ne sont pas faites pour être détruites le lendemain, mais pour demeurer.

\section{Et l'Albanie, quelle est l'image que vos collègues s'en font?}

Si vous ne parlez que de mes collègues, je peux dire sans hésitation que, comme tout chercheur universitaire, ils ne peuvent pas avoir des idées reçues sur l'Albanie ou sur toute autre chose qui provient des médias, des opinions fixes ou des études antérieures. Non, un vrai chercheur est avant tout curieux. Un chercheur n'a pas de talent particulier, la seule chose qui caractérise un chercheur digne de ce nom est d'être toujours passionnément curieux pour comprendre tout ce qu'il ne connait pas encore.

Après de nombreuses années en France et en Europe, en 2006 vous êtes revenu en Albanie pour quelques années. Comment voyez-vous aujourd'hui l'Albanie? Revenez-vous souvent? Au-delà des collaborations avec des institutions de recherche albanaises, envisagez-vous toujours un autre retour au pays?

Je dois vous rappeler que j'ai quitté l'Albanie comme un étudiant et je suis retourné comme anthropologue affirmé. Quand en 2006 je suis revenu travailler quelques années, sur l'invitation du Programme des Nations Unies pour le Développement pour fonder la nouvelle Université de Durrës, ce qui m'a permis de faire les premiers pas pour mettre en 
place l'enseignement de l'anthropologie en Albanie, je n'ai pas trouvé le pays que j'ai quitté, mais un pays inconnu et étranger que je devais connaître et comprendre. Une chose pareille peut se produire à tout émigrant qui revient au pays après une longue période à l'étranger. Mais si la méthodologie ethnographique est une expérience de la confrontation incessante de soi par l'autre et de l'autre par soi-même, si la contemplation anthropologique, ou le «regard éloigné » comme LéviStrauss l'a appelé, permet ce genre de distance qui devient la clé pour comprendre l'humanité et pour découvrir ce que l'on partage avec les autres, alors pour un anthropologue, il sera nécessaire de faire un effort supplémentaire par rapport à sa propre société. Tout d'abord, pour étudier sa propre société, l'ethnographe doit s'en détacher complètement. Mais après être totalement sorti de sa propre société, pour l'étudier, l'anthropologue doit absolument y entrer à nouveau. Pour cette raison, nous pouvons donc devenir l'anthropologue de notre propre société, comme j'ai eu l'occasion de le faire, par exemple, en étudiant les pratiques et les rituels du cycle de vie et leur impact sur la construction culturelle de la notion de personne chez les Albanais (Doja 2000a), à condition de l'approcher pour la connaître à nouveau, la re-connaître, la comprendre et l'expliquer, après avoir pris d'abord suffisamment de distance envers elle.

En ce sens, le retour au pays est toujours très important, parce que le temps de retour en Albanie m'a permis, comme toujours, d'acquérir cette expérience personnelle supplémentaire et nécessaire du travail de terrain. Je crois qu'une telle expérience doit être le seul moyen d'obtenir une compréhension plus que superficielle de ce qui motive le comportement des gens dans leurs communautés sociales dans l'Albanie d'aujourd'hui, de même que pour saisir la connaissance de la réalité intime qui est exprimée dans les frontières symboliques des identités locales, surtout quand un ensemble complexe de groupes existent, qu'il s'agisse de groupes différenciés ou non au niveau religieux, culturel ou social. De cette façon, l'Albanie contemporaine devient pour moi ce terrain où l'idée de l'anthropologie prend sens, non pas comme l'étude exclusive des « autres » cultures et sociétés, mais comme l'interprétation mutuelle des cultures et, finalement, de la conscience de soi réflexive et critique, qui rend l'ethnographie radicale possible et fait comprendre les choses telles qu'elles sont.

Après tant d'années, à quel point vous sentez-vous français? Quels sont les éléments de la culture française que vous aimeriez «importer » en Albanie et quels sont ces éléments de tradition albanaise que vous voudriez « exporter »à Paris? 
Mes compatriotes, malheureusement trop influencés par les études albanaises d'aujourd'hui, continuent à penser avec des concepts très anciens selon lesquelles le caractère national ou ethnique de l'identité est donné une fois pour toutes et reste inchangé dans le cours des siècles, parce que l'identité est déterminée par des traits éternels tels que le sang, la langue, la culture, la religion, le territoire, l'histoire et ainsi de suite. Dans mon cas, après de nombreuses années en France, la première fois que je me suis « senti » français fut seulement après avoir quitté la France pour m'installer en Angleterre. Chaque fois que je connaissais quelqu'un, j'entendais dire que j'étais «Français »! J'insistais que je suis Albanais et pas Français, mais pour quelqu'un qui ne savait pas qui sont et comment sont les Albanais j'avais toutes les caractéristiques typiques de celui qu'ils pensaient devoir être un Français. Bien sûr, tout le monde avait raison, moi qui insistais que je suis Albanais et mes amis britanniques qui ne voyaient en moi que leur Français et rien de plus. Or, tout cela montre bien que le caractère ethnique ou national de l'identité se définit par un processus continu d'interaction sociale au cours duquel les différences et les similarités culturelles deviennent ou ne deviennent pas importantes comme catégories sociales. Lorsque la même chose m'arrivait plus tard en Irlande, non seulement mes amis irlandais ne " pouvaient » pas connaître comment voir en moi mes traits albanais, mais ils ne «voulaient» pas voir en moi ces quelques traits anglais que j'aurais dû acquérir lors de mon séjour en Angleterre, même si ces caractéristiques sont très similaires aux leurs et qu'ils connaissaient fort bien. Ainsi, en Irlande aussi, je ne pouvais que demeurer encore une fois un Français! Or cela, en effet, ne montre rien, encore une fois, sur la nature ethnique ou nationale des traits culturels. En effet et avant tout, la culture et les autres caractéristiques que l'on suppose qu'elles déterminent l'identité ne sont pas des données tangibles. La culture comme la langue qui fait partie de la culture sont faites de règles inconscientes qui nous permettent de parler et de communiquer dans le cas spécifique de la langue ou de penser et de se comporter dans le cas plus général de la culture. Or si la langue n'est pas ce que nous disons, la culture n'est pas non plus ce que nous faisons ni les caractéristiques visibles de notre comportement et de notre action. La culture est plutôt un processus qui permet la vie en société, alors que les caractéristiques culturelles, même si elles peuvent paraître semblables ou différents selon le cas, elles n'ont de sens que dans ce processus. En outre, si les caractéristiques culturelles peuvent être importés ou exportés, elles n'ont que l'aspect comme auparavant, car dans d'autres contextes sociaux, participant à d'autres processus, elles prennent également d'autres significations, qui dans la plupart des cas, n'ont rien en commun avec les significations précédentes. 


\section{Pouvez-vous décrire quelques souvenirs de Korça, votre ville natale?}

Je me souviens d'abord de mon professeur de dessin à l'école primaire, une jeune femme très belle, peut-être un peu âgée pour être une jeune femme, mais très remarquable. Elle était la fille du célèbre peintre Vangjush Mio. Pour moi, à cet âge, elle était une icône, comme un vrai tableau, le symbole vivant de l'excellence et de la noblesse qui se dégagent des paysages urbains de ma ville natale peints par son père. Je me souviens à quel point j'ai toujours essayé de dessiner aussi bien que je pouvais, sans doute pour être agréable à mon professeur plus que toute autre chose, car je ne me souviens d'avoir jamais fait un bon dessin du tout. En tout cas, après avoir fini l'école primaire, pour des raisons familiales, je n'ai pas pu poursuivre mes études dans l'une des écoles secondaires de la ville natale, mais dans une école professionnelle à Tirana la capitale. Même si beaucoup plus prisée que l'école secondaire classique, c'était après tout une école de seconde classe. Je ne peux pas faire sortir de mon esprit la réaction vigoureuse de mon professeur de dessin qui fut apparemment la seule à essayer de m'empêcher de m'inscrire à cette école. Elle pensait qu'il fallait absolument que je poursuive mes études à l'école classique parce que j'étais un élève très intelligent et que je ne devais pas perdre ma chance pour devenir un bon ingénieur ou un autre excellent professionnel de ce genre. Encore aujourd'hui je me demande comment elle a pu se rendre compte que je devais être un si bon élève pour devenir un excellent professionnel ou ingénieur. Je n'étais même pas capable de faire un dessin décent qu'elle aurait pu garder dans son esprit !

Un autre souvenir est encore une fois liée à l'école élémentaire, puisqu'après j'ai dû quitter ma ville natale pour m'installer à Tirana la capitale. Cette fois, je me souviens de mon professeur de musique, qui fut l'un des membres du groupe connu sous le nom de Groupe Caractéristique de Korça. Même à ce jour j'écoute avec plaisir et nostalgie la musique et les chansons genre fin-de-siècle français de ce groupe. Ils sont inoubliables pour moi, les visages de ces vieux hommes charmants qui chantaient et jouaient avec tant de passion. Peut-être parce que la musique a toujours été et reste encore une de mes plus fortes passions, même si je n'ai jamais pu la pratiquer. En tout cas, je ne peux pas oublier comment, pendant la classe de musique, le professeur me disait toujours de ne pas chanter parce que la forte voix de mon chant lui semblait perturber le rythme du chœur de la classe ! J'ai toujours été tourmenté de savoir pourquoi mon professeur n'a jamais vu avec quelle passion je voulais chanter et faire de la musique comme lui. Peut-être ma passion pour la musique est-elle née précisément parce que je ne pouvais jamais être en mesure de faire de la musique? 
Le dernier souvenir que je veux mentionner est lié à ma classe de sport à nouveau à l'école primaire. De la classe sportive j'ai les plus beaux souvenirs. Non pas à cause du sport, parce que je n'ai jamais été doué et je n'ai jamais aimé le sport. Mais grâce à la classe sportive, nous pourrions, garçons et filles, avoir plus de chances pour rester ensemble. Même si certains de mes amis, en particulier quelques-unes des filles sont devenues des sportives bien connu dans l'équipe de basket de Korça, et même dans l'équipe nationale de basket, à l'époque le plus grand plaisir pour nous était d'être ensemble. C'est du moins ce qu'il me semblait, comme si la classe sportive était le seul moyen de nous donner un espace qui semblait impossible aux autres, un espace de liberté et d'inspiration que nous seuls pouvions comprendre et avec quoi il nous semblait défier le monde entier qui à l'époque nous entourait.

\section{Que pensez-vous de l'initiative d'excellence albanaise?}

Je n'ai jamais pensé que je pourrais faire partie de ce qu'on pouvait appeler l'excellence. Pour moi, cette qualification est uniquement réservée à ce que l'on n'a pas encore atteint, à ce que l'on vise toujours sans probablement jamais pouvoir atteindre. Si vous me faites penser que j'ai pu l'atteindre, c'est effrayant ! Que puis-je faire après ? 



\section{CHAPITRE 1}

\section{Aires culturelles}

Mes investigations sur la construction des identités sociales chez les Albanais ou les autres sociétés sud-est européennes, comme l'étude des relations interethniques et de la dynamique culturelle des valeurs sociales à l'intérieur de cette région ont tiré profit, dans la perspective anthropologique, des approches de recherche qui se réfèrent simultanément aux phénomènes comparables dans d'autres parties du monde, incluant plus particulièrement les apports des études méditerranéennes et de l'anthropologie européenne. Plus particulièrement, je me suis concerné par ces aspects de la vie sociale explorés en quelque détail dans la littérature anthropologique et qui ont attiré plus spécialement l'attention ethnographique réflexive, à savoir la construction sociale du rapport social des sexes et de la sexualité, le mariage et la famille, les croyances et les pratiques religieuses, l'ethnicité et le nationalisme, la modernisation et la transition. L'exploration est pourtant effectuée sous l'arrièreplan de la construction de l'aire culturelle en terme d'approche, c'est-àdire comme un outil conceptuel d'investigation anthropologique, et non pas par une vision substantialiste, comme une entité discrète dotée d'une culture propre.

\section{La Méditerranée}

L'intérêt anthropologique pour la Méditerranée et le monde méditerranéen est apparue à partir des années 1960 à l'occasion de deux colloques fondateurs, en 1959 à Burg Wartenstein en Autriche et en 1961 à Athènes à l'initiative de Julian Pitt-Rivers (1963) et John Peristiany (1966). Les antécédents d'une anthropologie des sociétés méditerranéennes sont plus lointains selon les pays et selon les relations de l'anthropologie à d'autres disciplines dans les divers contextes nationaux. La recherche de terrain en anthropologie moderne a commencé dans les années 1950 et parmi les premiers travaux il y a eu aussi des monographies de l'aire méditerranéenne. Ce n'est que plus tard au tournant des années 1960 que l'on s'efforça de formaliser le projet comparatif collectif pour mettre sur pied une anthropologie de la Méditerranée. Dès lors, vont se multiplier les conférences thématiques (Peristiany 1966, 1968, 1976a, 1976b ; Peristiany \& Handman 1989 ; Peristiany \& Pitt-Rivers 1992 ; Gilmore 1982, 1987), les enquêtes sur le 
terrain et les travaux monographiques (Peters 1990; Pitt-Rivers 1954/1971, 1977 ; Friedl 1963 ; Campbell 1964 ; Stirling 1965 ; Gellner 1969 ; Lison-Tolosana 1966/1983 ; Schneider \& Schneider 1976, 1996 ; DuBoulay 1974 ; Gilmore 1980).

En même temps se développe une réflexion anthropologique sur le monde méditerranéen conçu sur le modèle d'une aire culturelle sous l'impulsion des efforts effectués par Conrad Arensberg (1963) pour délimiter des aires culturelles en Europe et qui définit la Méditerranée comme une aire avec ses caractéristiques propres. En France, la géographie humaine et l'école historique des Annales ont posé une Méditerranée des «infrastructures » par la quête de permanences dans des registres aussi divers que la division sexuelle des rôles, les structures matrimoniales, les techniques, les rites et les croyances.

La Méditerranée a offert un terrain privilégié pour étudier de manière comparative et sur le long terme les relations entre facteurs écologiques, techniques, économiques, historiques et culturels. En effet, un certain nombre de comparaisons demeurent éclairantes. Les travaux de Fernand Braudel (1949/1979) ont montré comment le monde méditerranéen a été façonné par une longue histoire reliant ses différents peuples les uns aux autres. Cette approche est renforcée par des travaux plus anciens sur les échanges culturels entre Christianité et Islam particulièrement au niveau populaire (Hasluck, F. 1929/2000), aussi bien que par des études historiques de la culture des frontières, qui ont exploré le caractère des zones unies autant que divisées par les frontières qui les définissent, suggérant que les gens des frontières, Musulmans ou Chrétiens, avaient plus en commun les uns avec les autres qu'avec la culture des capitales (Inalcik 1973).

Pendant une trentaine d'années il s'est constitué une véritable anthropologie du monde méditerranéen autour d'un certain nombre de thèmes fondateurs, les gatekeeping concepts telles que l'honneur et la famille, ou le clientélisme et la sociabilité, consacrés par une tradition établie surtout dans les pays anglophones (Peristiany 1976b ; Pitt-Rivers 1977 ; Gellner \& Waterbury 1977). Elle s'emploie à donner un contenu à la notion de société méditerranéenne en mettant en évidence, au-delà de la diversité réelle des sociétés et des cultures, l'existence de formes d'organisation sociale apparentées et de valeurs partagées. Ainsi l'ensemble de ces travaux et recherches anthropologiques sur les cultures méditerranéennes a contribué à dessiner une tradition intellectuelle « méditerranéiste », à la recherche de similarités dans la longue durée et s'efforçant de démontrer le primat relatif de l'unité sur la diversité (Boissevain 1979).

Les six millénaires de conquêtes militaires, d'échanges économiques, de colonisations réciproques et de conversions religieuses ont proba- 
blement abouti à l'invention simultanée de formes sociales et culturelles similaires ou identiques (Davis 1977 ; Berque 1989). Face à l'énorme diversité linguistique, ethnique et religieuse du bassin de la Méditerranée, les anthropologues ont plaidé pour une uniformité interne à la région sur la base des traits culturels tels que le complexe de l'honneur et de la honte qu'on présentait, surtout depuis les années 1960, comme des notions méditerranéennes reliant valeurs sociales, identités sexuelles et structures familiales. D'autres traits culturels furent aussi souvent privilégiés comme l'agriculture de charrue et l'élevage de bovins et d'ovins, la dot et l'orientation urbaine des stratégies matrimoniales, les relations de patronage et de clientélisme, ou encore l'inégalité sociale accompagnée ou masquée d'idéologies égalitaires (Giordano 2012).

Certes, si les similarités sont acquises, le temps est venu de souligner à nouveau les différences aussi. Ainsi, le fossé économique et politique s'est creusé entre les deux rives de la Méditerranée, ce qui a entraîné aussi des adaptations et des reconversions académiques. Si l'anthropologie de la rive Nord a rejoint "l'européanisme », confortée dans ce mouvement de retour par la rhétorique politique ambiante (Goddard 1994), celle des rives méridionale et orientale a été happée par les études sur le monde arabo-musulman et le Proche Orient. Ainsi, après l'euphorie des débuts et une période faste d'une vingtaine d'années, le temps est-il cependant venu pour les remises en cause, parfois virulentes, de la pertinence du monde méditerranéen comme cadre d'investigation anthropologique.

$\mathrm{Au}$ cours des trois dernières décennies ou presque, on a de plus en plus critiqué, sur un mode post-moderne et anti-orientaliste, la notion d'anthropologie méditerranéenne. En passant en revue les travaux vaguement inspirés de cette catégorie d'anthropologie de la Méditerranée, l'évaluation critique des thèmes fondamentaux dans la théorie et méthode anthropologique-concernant par exemple les concepts et pratiques de travail de terrain ethnographique ou l'observation participante ainsi que l'attention exclusive à l'approche communautaire s'appuie sur ce qui est jugé être des approches anhistoriques, une absence de justification du concept même de Méditerranée, une exoticisation et ruralisation de la culture méditerranéenne, une vue anachronique de la région et de ses populations, qui finalement cédé à des généralisations injustifiées soutenues par une approche sociologique basée sur des clichés et des stéréotypes.

Plusieurs anthropologues ont critiqué de façon radicale la considération de la Méditerranée comme regional category en fustigeant le caractère artificiel de l'objet, qui serait uniquement créé pour objectiver la distance nécessaire à un exercice légitime de la discipline et qui s'abriterait derrière quelques thèmes fédérateurs fortement stéréotypés 
(Herzfeld 1980, 1984 ; Wikan 1984 ; Pina-Cabral 1989; Sant-Cassia 1991). À ces critiques virulentes, pour la plupart venues d'outreAtlantique, se sont jointes celles d'anthropologues originaires des régions méditerranéennes. Pour nombre d'entre eux aussi, le qualificatif réducteur de «méditerranéen » doterait l'hétérogène d'une homogénéité factice et serait le produit des représentations fantasmatiques de chercheurs venus du nord. Cette défiance est particulièrement ancrée sur les rives méridionales et orientales où, dans les références quotidiennes, littéraires ou savantes, la Méditerranée est fantomatique ou suspecte. À ces préventions sur la légitimité de la notion s'ajoute, ici et là, le sentiment qu'un paradigme monologique, celui de l'anthropologie sociale britannique, a tenté d'imposer ses théories et ses méthodes à travers les études méditerranéennes, en ignorant les traditions scientifiques locales et leurs acquis (Bourguet \& Lepetit 1997).

Dans ce contexte, la réflexion sur la «Méditerranée » a amené plusieurs auteurs à contester la validité même de sa conception unifiante et l'utilité de son cadre comparatif, ce qui soulève le problème de trouver des définitions alternatives pour des catégories de comparaison régionale. S'agit-il d'ériger le bassin méditerranéen en une " aire culturelle » dont on scruterait les régularités à travers l'espace et le temps? La Méditerranée devrait-elle se comprendre comme une arène d'interactions, sa cohérence, sinon son unité, étant définie en termes de siècles de contact, de conflit et de coexistence ? Peu soutiennent un point de vue aussi radicalement essentialiste que les critiques ont grossi jusqu'à la caricature. Il est contesté que la seule compréhension braudelienne des échanges historiques puisse nécessairement conduire à une aire culturelle, car «le contact mutuel intense par lui-même ne justifie pas l'étiquette d'unité » (Gilmore 1982).

Cependant, dans cet exercice, il n'est pas facile de se débarrasser du concept d'aire culturelle. En effet, les critiques de la catégorie de Méditerranée supposent souvent que les unités de comparaison régionale doivent être homogènes et que la comparaison n'est utile qu'en présence de similarités. Or, la comparaison est particulièrement productive quand elle procède aussi par des contrastes et des inversions, dans des unités qui, comme la Méditerranée, présentent aussi bien des similarités que des différences. Mais si le terme «méditerranéen » ne sert pas à qualifier des traits communs sociaux et culturels, désigne-t-il alors les oppositions en miroir (mirrored) entre le christianisme de l'Europe du Sud et l'islam de l'Afrique du Nord (Gellner 1985; Wolf 1984)? S'agit-il alors de prendre acte des vicissitudes unificatrices et diviseuses de l'histoire et de considérer la Méditerranée comme un lieu privilégié de l'exercice du comparatisme à bonne distance, dans un monde «méditerranéen » qui est à envisager comme un espace de dialogue et 
d'affrontements où les identités des uns et des autres se définissent dans un jeu de miroirs de traditions, de comportements, de convictions religieuses?

Bien qu'il existe des points de vue opposés, selon lesquels les sociétés de la Méditerranée sont différenciées ou non à l'origine (Goody 2000), c'est plutôt la combinaison des convergences historiques avec des parallèles synchroniques dans la culture qui fournit l'uniformité interne et les particularités à l'aire méditerranéenne. Les sociétés méditerranéennes présentent sans doute " un air de famille » légué par une histoire complexe. Mais à l'opposé de cette conception unifiante, ce qui donne sa cohérence au projet d'un comparatisme méditerranéen, ce ne sont pas tant les ressemblances repérables que les différences complémentaires qui forment système.

Ainsi, plutôt que de s'attarder sur la notion de la Méditerranée envisagée comme une aire culturelle qui englobe une réalité culturelle figée, amène à reproduire des modèles colonialistes et nationalistes et n'apporte aucun bénéfice conceptuel, les nouvelles interrogations sur son statut épistémologique visent à scruter les processus de variations au sein de cette région. Les nouveaux travaux illustrent, par leur diversité et la variété des positions des uns et des autres, comment la Méditerranée est posée tantôt comme un objet tantôt comme un simple cadre de la recherche ou adoptant un point de vue intermédiaire. Cette polyphonie des discours sur le monde méditerranéen témoigne des différences entre écoles nationales, voire régionales, entre postures méthodologiques mais aussi entre manières de concevoir le présent et l'avenir d'une terre de conflits aussi vifs et interminables (Albera, Blok \& Bromberger 2001).

Ces études présentent certains changements de perspective importants dans l'anthropologie du bassin méditerranéen. Sans être ni radicalement iconoclastes ni obstinément conservateurs, et représentant plusieurs styles intellectuels, histoires d'engagement dans l'anthropologie de la région et traditions nationales de recherche, ces travaux offrent une bonne base pour une certaine évaluation sérieuse. Chacun s'ajoute au fonds d'idées déjà en jeu et fait avancer la discussion en soulignant des facettes jusqu'ici négligées. Même si ces travaux n'offrent peut-être pas une critique complètement radicale des thèmes fondateurs, ils offrent une réitération utile des points existants et historiques importants, ainsi qu'un déplacement des modèles plus anciens. Plus généralement, ils temporalisent et spatialisent notre compréhension des sociétés et des cultures de la région. Cette critique intermédiaire est souvent prise entre un grand malaise avec l'état des catégories dominantes et une hésitation pour les rejeter d'emblée. On saisit, en particulier, l'évolution historique de l'honneur afin de montrer sa mutabilité incessante et analytiquement déstabilisante, bien que les auteurs, conscients de la spécificité histo- 
rique de tels développements, optent discrètement pour la critique au lieu de complaisance, et pour la différentiation au lieu de conformité.

Car la nouvelle vague examine également dans quelle mesure les acteurs sociaux et politiques locaux invoquent l'idée d'une culture méditerranéenne, tout en s'interrogeant sur l'usage qu'on fait de cette idée. En effet, c'est l'application problématique de la notion de créolisation qui soulève les véritables enjeux conceptuels. Elle amène à s'écarter des soubassements idéologiques des conceptions de l'identité locale et de l'épistémologie anthropologique où s'inscrit la notion d'aire culturelle méditerranéenne, tout en soulignant l'inévitable complexité des origines sociales et culturelles de toutes les entités qui se présentent aujourd'hui comme unies et revendiquent un passé qui aurait un seul foyer d'origine (Herzfeld 2001).

\section{L'Europe}

La préoccupation intensive avec les sociétés non-européennes a mis au crédit de l'anthropologie sociale des résultats qui fournissent de meilleures compréhensions de leurs cultures, ce qui renvoie non simplement à la connaissance européenne des autres traditions, mais aussi à une perspective de l'Autre réfléchie sur soi-même. En renversant la perspective, l'approche anthropologique offre de nouvelles considérations à l'intérieur même des sociétés européennes. En effet, il est actuellement considéré comme important que des projets anthropologiques sont réalisés sur le terrain de l'Europe. Cela permet d'ouvrir des perspectives nouvelles et non-conventionnelles pour appréhender les conditions européennes, en l'occurrence dans les études sur la construction des identités sociales ou sur les relations interethniques et la dynamique culturelle des valeurs sociales. Un lien entre les études effectuées à l'intérieur de l'Europe et les études basées à l'extérieur de l'Europe est donc systématiquement recherché, puisqu'une anthropologie de l'Europe est hautement souhaitable dans la mesure qu'elle n'est qu'une démarche dans la poursuite d'une anthropologie globale, dont la finalité ultime et légitime est de rendre compte de l'unité et de la diversité humaine dans son ensemble, sans limites spatiales ou temporelles.

Cependant, dans l'histoire de l'anthropologie sociale et culturelle, l'Europe est encore une idée neuve, ou presque, dans la discipline. Il a été longtemps estimé que l'entreprise anthropologique, avec son soubassement ethnographique, était pour l'essentiel inadaptée à la connaissance des sociétés et des cultures du continent européen, à l'exception de survivances locales d'institutions anciennes ou de particularismes ethniques menacés par l'emprise des États-nations et des modèles de civilisation qu'ils diffusent. 
Ainsi, les travaux consacrés aux sociétés européennes se présentent pourtant comme une collection hétéroclite d'enquêtes d'inspirations diverses, folklorique, linguistique, géographique, historique, sociologique, etc. Venue tard dans le cadre institutionnel de la recherche, l'anthropologie européenne se trouve de surcroît marquée par une extrême diversité des traditions scientifiques, épistémologiques et académiques. Particulièrement en ce qui concerne le champ conceptuel, certains des termes clés de la discipline organisent des configurations sémantiques différentes d'un pays à l'autre, comme en témoigne le complexe formé par les notions de peuple, de nation et d'ethnie. La portée même conférée aux recherches sur l'Europe varie dans de larges proportions. Enfin l'opposition entre « civilisés » et « primitifs », constitutive de la naissance de l'anthropologie sociale, trouve son équivalent en anthropologie de l'Europe avec l'opposition entre «savant» et "populaire », qui est encore au cœur des travaux développés par nombre d'écoles nationales de folklore et d'ethnologie.

$\mathrm{Au}$ retard historique et à l'éclatement scientifique s'ajoutent d'autres raisons qui tiennent à l'histoire même de l'Europe, au pluralisme culturel, aux conceptions différentes du fait ethnique et des raisons de s'y intéresser. L'émergence précoce d'États nationaux, affrontés à l'existence de groupes ethniques et de cultures tantôt hégémoniques tantôt minoritaires, a conduit très tôt à assigner à l'anthropologie de l'Europe une fonction politique de légitimation ou de contestation de l'ordre établi. Au poids des diverses idéologies s'est ajouté celui de la sollicitation politique, notamment dans le cadre des régimes autocratiques et totalitaires. Nombre de recherches ont été menées dans le seul but de fonder ou d'infirmer des revendications ethniques, ou bien d'ériger une classe sociale en agent exclusif de la création culturelle. Exemples de projets pseudo-culturalistes et d'instrumentalismes politiques de la recherche sont illustrées, entre autres, par la Volkskunde allemande au soutien de la campagne de propagande nazie des années 1930 et 1940 (Gerndt 1987), la politique folkloriste du cycle épique du Kosovo au soutien du nationalisme serbe depuis le XIX ${ }^{\mathrm{e}}$ siècle jusqu'à nos jours (Gossiaux 1995 ; Kaser \& Halphen 1998) ou encore, durant l'époque communiste dans les pays d'Europe centrale et orientale, la folklorisation des traditions culturelles et historiques comme un instrument pour justifier et exalter les fondations dites « authentiques » des régimes politiques et idéologiques, comme j'ai eu l'occasion de voir pour le cas albanais (Doja 1998b). De manière plus générale encore, l'influence exercée par certains courants de pensée a longtemps poussé les anthropologues de l'Europe à interpréter les différences culturelles en termes de hiérarchie (Bausinger 1993). 
Les premières recherches sur l'Europe se réclamant explicitement des méthodes de pensée et d'enquête de l'anthropologie sociale et culturelle se multiplient notamment grâce à l'intérêt des anthropologues anglo-saxons pour les sociétés riveraines de la Méditerranée, de la péninsule ibérique à l'Ouest jusqu'aux Balkans à l'Est, qui restent toujours les plus étudiées, bien qu'on relève aussi des recherches menées dans les Îles britanniques, en France, en Norvège, en Suisse ainsi que dans plusieurs sociétés de l'Europe centrale (Theodoratus 1969; Nixdorff \& Hauschild 1982; Goddard, Llobera \& Shore 1994). Ces travaux témoignent d'une rupture d'avec la tradition intellectuelle héritée des ethnologies nationales et des enquêtes folkloristes (Stocking 1996). Ils se présentent pourtant, pour la plupart, sous forme de monographies des communautés locales, traversées par les tonalités structural-fonctionnalistes, dont l'approche visait plutôt les périphéries de l'Europe dans les petits villages lointains traités comme s'ils étaient des sociétés auto-suffisantes. C'était toujours une part d'anthropologie en Europe, plutôt qu'une anthropologie de l'Europe, qui demeurait encore un territoire inexploré et indéfini.

Peu de chercheurs ont tenté de conduire des recherches comparatives de quelque ampleur, ou d'élaborer des synthèses régionales, à l'instar de John Davis (1977) sur la Méditerranée ou de Robert Anderson (1971) sur l'Europe. Lorsque Conrad Arensberg a souligné la nécessité de revoir le vieux concept d' « aire culturelle » se référant à une combinaison mixte des «traits culturels » qui sont à considérer comme « hiérarchiquement » ordonnés à différents niveaux d'abstraction, il a proposé provisoirement une formulation des «aires culturelles » européennes comprenant la frange atlantique, les plaines d'Europe centrale, les pays méditerranéens et les régions circum-alpines (Arensberg 1963). Si une telle taxonomie des régions européennes a manifestement négligé de prendre en considération l'histoire, le souci de se référer d'emblée aux problématiques de l'anthropologie générale, la dimension réduite des unités d'observation, le respect des frontières nationales, le problème des langues et des publications locales, qui font que cette littérature ne soit pas directement accessible à une plus large audience, sont autant de facteurs qui ont considérablement freiné le développement de la démarche comparative au sein de l'anthropologie européenne (Freeman 1973). Si légitimes et prometteuses soient-elles (Cuisenier 1979) et malgré les initiatives transnationales d'intégration (Beitl, Bromberger \& Chiva 1997 ; Chiva \& Jeggle 1987 ; Giordano \& Rolshoven 1999)), les recherches à l'échelle de l'Europe entière ou de l'une de ses régions ou ses aires linguistiques, susceptibles de fonder une anthropologie européaniste, restent encore rares. 
Néanmoins, si les tentatives à aborder des aspects institutionnels et culturels de la société de type moderne au niveau de l'Europe, saisis à une plus vaste échelle, sont encore rares, l'élaboration des discussions récentes en vue d'une régionalisation et découpage heuristique de l'Europe reposent précisément sur l'histoire. Dans une tentative de mettre l'accent sur l'évolution des dynamiques sociales et des flux économiques qui conduisent à la caractérisation de l'Europe comme un système de "régions historiques » (Giordano 2012), plutôt qu'une entité homogène fermée ou limitée à n'importe quel trait substantiel, un concept plus rigoureux que celui d' " aire culturelle » est élaboré et mis en œuvre pour l'analyse des processus socioculturels. L'Europe ou la Méditerranée sont ainsi conçues et expliquées comme un contexte pertinent ou une arène d'investigation scientifique, un système ou soussystème, qui repose sur une théorie des systèmes régionaux rappelant l'analyse des systèmes mondiaux (Wallerstein 2004).

En outre, l'analyse des tendances les plus récentes dans la discipline relève que le développement de "l'anthropologie de l'Europe" est passé par l'intérêt sur la région méditerranéenne comme une aire culturelle aux travaux sur les transformations sociales après la chute du socialisme et avec l'expansion de l'Union européenne. Quand, dans les années 1980, une forte fragmentation a rongé l'anthropologie socioculturelle dans ses fondements théoriques et méthodologiques et beaucoup d'autres aspects - domaines de recherche, sujets d'intérêt, approches générales, modes d'écriture et discours intellectuels - le champ de l'anthropologie européenne s'est progressivement élargi pour devenir plus sophistiqué, en même temps que l'anthropologie rentrait définitivement chez soi, dans les pays d'origine des anthropologues professionnels (Boissevain 1994). Alors que l'Europe se développe en l'Union européenne et devient progressivement une forte présence politique et institutionnelle, ces évolutions conduisent à la redécouverte de l'Europe comme un objet d'étude socialement pertinent et scientifiquement légitime pour l'anthropologie sociale et culturelle, ce qui représente une reconnaissance explicite que l'Europe fait partie du répertoire de base de l'anthropologie dans l'étude de toute l'humanité (Goddard, Llobera \& Shore 1994 ; Kockel, Craith \& Frykman 2012). Non seulement l'Europe en tant qu'une entité historique, ou un concept philosophique ou littéraire, mais les anthropologues explorent désormais de façon convaincante les processus nationaux et supranationaux, les nouvelles réalités et processus qui se produisent sur la scène européenne et mondiale, et surtout l'émergente entité sui generis de l'Union européenne, qui embrasse un large domaine d'institutions et de développements politiques (Bellier \& Wilson 2000; Shore 2000 ; Niedermüller \& Stoklund 2001). 
En d'autres termes, l'anthropologie de l'Europe aborde toutes les questions socialement pertinentes dans le contexte de l'Europe contemporaine, en reconnaissant la pluralité et la diversité de cette entité sui generis et de ses éléments constitutifs et en analysant les faits de son interdépendance mondiale. Cela signale de façon implicite ou explicite une discipline renouvelé dans sa théorie, ses méthodes, ses thèmes et son discours intellectuel. En effet, l'anthropologie n'est pas seulement amenée à appliquer sa gamme classique des méthodes et des outils de recherche à l'étude d'un certain nombre de cultures spécifiques en Europe, mais elle a la vocation d'être une anthropologie théoriquement stimulante et méthodologiquement innovante dont l'ambition est de contribuer à la compréhension et l'explication des questions socialement pertinentes. D'autant plus que ce point de vue a rendu suffisamment clair que justement ce travail sur les sociétés européennes est devenu central pour les développements actuels de base dans la théorie anthropologique générale. Notamment, le développement de l'anthropologie réflexive actuelle est rendu possible grâce aux mouvements qui ont fait passer l'étude de l'Autre primitif ou archaïque, prémoderne ou populaire, en situation néocoloniale ou dans sa communauté locale, vers l'étude des processus dynamiques et transactionnels de transformations sociales, de modernisation et de globalisation.

Dans ce contexte, l'Europe peut être à la fois un mythe, juste un nom ou une métaphore comme dans le mythe grec, un concept, une idée, un état d'esprit, une réalité métaphysique, ou elle est plutôt le résultat de processus historiques et politiques passant de l'Empire romain au Saint Empire à l'Union européenne. Au-delà d'un accord commercialéconomique ou projet politique d'union institutionnelle, elle est aussi une réalité culturelle, un espace d'échanges et d'interaction intellectuelle, ou encore une projection vers l'avenir, un rêve ou fantasme de réalisation incertaine, pour autant qu'elle s'apparente à un contrepoint nécessaire aux forces d'hégémonie mondiale, une identité-refuge contre les incertitudes du processus apparemment inexorable de la mondialisation. Dans le processus de construction de la nouvelle Europe, il peut également s'agir de plusieurs projets à la fois, un club d'États-nations, un État supranational, une fédération ou confédération, ou encore une entité sui generis, un système politique ouvert à des procédures constitutionnelles non-restrictives. Pourtant, dans la construction d'une anthropologie de l'Europe, il s'agit de s'engager aux défis de la mondialisation et de l'interdépendance mondiale, aux défis des mouvements de population, ainsi qu'au défi de la grande diversité interne à l'Europe même, au niveau social, économique et culturel. Une anthropologie de l'Europe révèle la nécessité de changer nos manières de penser façonnées sur la base de présomptions vieillies et se débarrasser des notions et clichés anachroniques, si nous voulons donner un sens à l'idée d'une Europe 
comme entité unifiée, en particulier en termes culturels. Une anthropologie de l'Europe devient d'autant plus importante quand nous prenons en compte les processus de dynamique interculturelle et de construction identitaire en contexte européen, surtout par rapport aux aspects déterminants pour la réalisation d'une identité européenne et pour la promotion, l'évaluation et l'organisation d'une attitude européenne plus interculturelle.

Ainsi l'anthropologie de l'Europe devient l'étude de questions substantielles et théoriques dans une collaboration ouverte à la sociologie et d'autres disciplines, dont l'objectif est l'exploration des liens existant entre l'héritage historique et culturel, ou encore la religion et le nationalisme, mais aussi l'intégration des approches symboliques avec une dimension historique des identités politiquement contestées et des transformations postmodernes où l'agence sociale est notablement bien établie et de valeur prouvée. Un rattachement aux débats contemporains sur les remaniements identitaires et les relations interculturelles en Europe, à la suite des nouveaux phénomènes de régionalisation et de globalisation, n'en est qu'une suite logique qui privilégie notamment l'explosion des nationalismes et des conflits politico-religieux aussi bien que les migrations et les efforts d'intégration européenne.

Les réflexions portant sur les constructions idéologiques et identitaires, aussi bien que la nature des mouvements et des engagements politiques régionaux ou nationaux, peuvent probablement constituer une base solide pour orienter le développement de la réflexion anthropologique sur la dynamique des relations interculturelles, incluant à la fois les conflits et les dynamiques sociales et politiques, idéologiques et religieuses, régionales et nationales. Les perspectives pour une approche anthropologique de la dynamique des valeurs sociales et des relations interculturelles, aussi bien que des migrations transfrontalières, se dessinent alors dans le cadre des transformations sociales et politiques de l'ensemble de l'Europe.

Effectivement, les mouvements migratoires en provenance de l'Est ou d'ailleurs soulèvent la question des remaniements identitaires en Europe, de même que les réflexions et les pratiques concernant l'impact de l'idéologie démocratique occidentale à l'épreuve de la démocratisation en Europe centrale et orientale, reflète nécessairement les rapports tendus entre le discours universaliste des processus transitoires, dérivant des idéaux libéraux du marché, de la démocratisation et la globalisation, et les idéologies et pratiques particularistes évidentes dans les communautés locales. D'autant plus que les interactions et les processus sociaux croisant la division politique et savante de l'Europe posent la question de savoir comment cette opposition a été remaniée par la guerre froide et maintenant reformulé à nouveau dans le contexte de la 
transition postcommuniste et de l'intégration de l'Union européenne. À ce propos, je m'intéresse plus particulièrement à considérer comment un simple phénomène, par exemple la religion, la langue, l'ethnicité ou le nationalisme, est compris de façons divergentes selon l'emplacement symbolique qui est assumé par l'investigateur.

Notamment, le travail sur l'Europe de l'Est acquiert ainsi un intérêt particulier à travers l'évidence pratique des transformations politiques, économiques, sociales et culturelles des deux dernières décennies et des perspectives de recherche qu'elles représentent. Dans ce contexte, il faudra avoir constamment en vue que la théorie du lien social fondé sur une universalité des valeurs sociales et culturelles communes comme principe de fonctionnement de ces sociétés s'est effondré dans la région face à la montée récente des aspirations à la modernisation et à la démocratisation, aussi bien qu'au nationalisme et au renouveau de la religion. L'obligation de mettre en chantier les compréhensions des perspectives comparatives face à l'évolution des pays sud-est européens et de toute l'Europe orientale, dans le cadre du développement des régionalismes actuels, fait mieux comprendre comment les anciennes valeurs normatives sont susceptibles d'être mobilisées à des fins productives sans rupture des liens sociaux. Car les chocs révolutionnaires actuels ont déjà produit des effets qui ne vont pas tous dans le sens d'une acceptation uniforme des cultures et des idéologies instrumentales et rationnelles.

Les bouleversements géopolitiques de l'Est ne peuvent pas soudainement effacer le fait que ces pays aient vécu pour la plupart sous régime communiste, dont on peut lire les traces à chaque coin de rue, dans chaque mentalité, dans chaque élément de la vie sociale. Quoi qu'on en pense, la réalité autocratique a marqué l'espace public et privé des pays est-européens et balkaniques. L'idéologie, la pratique et l'influence du communisme n'expliquent pas tout, loin de là, et rien n'est plus flagrant que l'histoire irrégulière de la modernité sociopolitique affleurant sous l'ère communiste à l'Est. Dans ce contexte, toute analyse simpliste devient proprement inapplicable.

Les deux transitions que les pays de l'Est européen ont connues ou connaissent, la transition forcée au socialisme et la transition devenue, semble-t-il, nécessaire au capitalisme, font de leur histoire un laboratoire extrêmement riche pour l'étude comparative des processus complexes. La disparition du collectivisme, par exemple, favorise l'éclosion d'un champ d'expérimentation originale. Le développement économique et social escompté doit prendre en considération à la fois la libéralisation intervenue et les échecs subis en Occident par des pratiques inadaptées, tant en milieu rural qu'en zone urbaine. Dans ces conditions, il y a certainement des liens étroits avec les spécialistes de la région, plus 
particulièrement dans les pays ex-socialistes où il est nécessaire de s'engager en dialogues avec les spécialistes de la «transitologie».

Cependant, force est de constater que dans les travaux de la première vague la Russie et les pays d'ex-Union soviétique ont mobilisé la plus grande part de l'attention des chercheurs. Aussi la plupart des travaux s'intéressant aux processus de transition en Europe orientale ont-ils porté uniquement sur les transformations économiques et juridiques selon le modèle occidental (Doja 1995a). La famille, par exemple, semble être au cœur des remaniements et des bouleversements que connaissent désormais ces pays, mais cet aspect reste encore très peu étudié. On s'attache généralement au passage à l'économie de marché et à la montée des États de droit. Quoique ces dimensions soient naturellement majeures dans la nouvelle donne à l'Est, au-delà de ce double intérêt exclusif, régional et thématique, il est nécessaire de porter un nouveau regard sur le domaine de construction des identités sociales et de transformations familiales et sociales, aussi bien que de s'ouvrir de nouvelles perspectives sur les aspects comparatifs des relations interethniques et la dynamique culturelle des valeurs sociales.

Les transformations et les mutations sociales auxquelles est confrontée la société actuelle mettent en avant des problèmes de perception et de compréhension des réalités changeantes et imposent une révision des modes d'organisation sociale. Les activités traditionnelles sont condamnées à se transformer ou à disparaître. Au-delà de l'exploration de la vie quotidienne sous le socialisme d'État, comment et pourquoi le communisme a été d'abord soutenu et démoli par la suite, l'objet d'analyse concerne en première instance l'appréhension des transformations sociales dramatiques actuelles, comment la démocratie et la société civile sont imaginées, quelles significations sont attachées aux différents types de nationalismes et de citoyennetés, aussi bien que les questions se rapportant à la culture des moyens de première nécessité et du sousdéveloppement, à la corruption et aux criminalités comparatives, aux migrations transnationales et au tourisme, à la situation des minorités ethniques et linguistiques et au rôle des élites dans la vie politique. Pour que les mutations rapides deviennent des transformations positives et durables, il est nécessaire qu'elles passent par une meilleure connaissance des réalités humaines et sociales aussi bien que par la formation et la socialisation des acteurs. La compréhension des mentalités et des mécanismes de la vie sociale se pose ainsi tout naturellement au cœur des processus de mutation.

\section{Le Sud-Est européen}

Dans le contexte européen, les sociétés du Sud-Est, à l'intersection du monde méditerranéen et du reste de l'Europe, apparaissent comme un 
miroir grossissant dans lequel l'Europe nouvelle se confronte à ses propres contradictions et sombres souvenirs, reflétant la civilisation " moderne» dans son ensemble. La région reflète la façon dont "l'Europe » elle-même a été historiquement construite en opposition à l'Orientalisme. Se trouvant à l'intersection de divers axes, la zone considérée comme « Balkans » représente un espace limitrophe, chevauchant physiquement et historiquement un champ ambigu, paradoxalement lié à l'Antiquité classique et à l'anachronisme contemporain. Contrairement à l'étrangeté absolue incarnée par la notion de l'Orient, ce qui est connu comme Europe du Sud-Est en fait semble avoir constitué un domaine transitoire porté en équilibre entre lumières et ténèbres, entre civilisation et barbarie. Dans un sens, en reflétant la manière dont la civilisation européenne «moderne » a été construite, la région invite peut-être à une révision possible de nos modèles conceptuels pour comprendre la modernité et le modernisme. Dans ce sens, ces sociétés nous invitent à une révision de la manière dont l'ensemble de la civilisation européenne se conçoit.

L'aire sud-est européenne n'est pas seulement l'Europe balkanique post-byzantine ou ex-ottomane, pas plus que l'Europe de l'Est des politologues contemporains ou l'Ouest des Balkans des artisans de l'Union européenne, ou encore le lieu d'expansion de certains modèles occidentaux ou d'enracinement d'identités locales, mais bien tout cela à la fois. Dans une perspective comparative, le domaine géopolitique de l'Europe du Sud-est peut faire l'objet d'investigations approfondies, dont l'explication ne reposera que sur la définition de l'interdépendance de divers facteurs aboutissant parfois à des contradictions historiques. $\mathrm{Au}$ long de l'évolution historique, les facteurs politiques, culturels et idéologiques (tradition gréco-romaine et byzantine, influences orientales, tendances d'occidentalisation, etc.) ont toujours joué un rôle plus important que les conditions sociales et économiques, contrairement à ce qu'il en fut en Europe occidentale.

Il y a ici un sujet intéressant de variations orientales sur le thème des «Balkans » en tant que géographie symbolique et frontière symbolique dans la politique culturelle de l'ancienne Yougoslavie (Bakic-Hayden \& Hayden 1992) ou d'autres pays sud-est européens. Les anthropologues peuvent offrir une large gamme de ressources sur l'imaginaire des Balkans et faire place aux diverses manières d'après lesquelles les peuples de l'Europe du sud-est ont compris, élaboré ou rejeté la notion de Balkans et de Balkanisme. Le problème de savoir qui au juste est Balkanique et qui est Européen demeure vigoureusement contesté en Europe du sud-est. Cependant, ce qui peut être désigné sous le nom d'un genre particulier de "Balkanisme» a évolué indépendamment de l'«Orientalisme » et dans certains aspects à l'encontre de celui-ci, étant 
donné que les identités balkaniques propres ont été résolument construites en opposition aux « Orientaux », c.-à-d. aux souverains ottomans et leurs héritages (cf. Todorova 1997). Contrairement à l'Orientalisme, qui installe une dichotomie nette entre l'est et l'ouest, « le Balkanisme est un discours au sujet d'une ambiguïté imputée ». De la même manière que l'Europe de l'Est plus globalement, les Balkans sont ainsi arrivés à être explicitement définis comme carrefour de civilisations, avec les peuples balkaniques semblant demeurer «dans une zone crépusculaire qui n'est illuminée ni par la radiation de l'Ouest ni par la lueur exotique de l'Est $»$.

L'histoire culturelle, sociale et géopolitique des sociétés sud-est européennes et de la société albanaise en particulier constitue l'un des développements de ce qu'on a appelé la «question d'Orient». À moins qu'on ne la situe dans une perspective plus longue, on définit couramment celle-ci comme l'ensemble des problèmes géopolitiques posés, depuis le milieu du XVIII ${ }^{\mathrm{e}}$ siècle, par la décomposition de l'Empire ottoman. Comme l'a remarqué Michel Roux (1992 : 162), la forme même de l'expression "question d'Orient» indique bien son origine. Formulée par des hommes d'États, diplomates et intellectuels occidentaux, elle dénote un impérialisme ethnocentrique dans lequel les grandes puissances, tour à tour alliées et rivales, poursuivent à la fois le maintien d'un équilibre européen et la réalisation de leurs objectifs propres. Dans cette optique, la question d'Orient se réduisait à une série de problèmes politiques à régler. Il s'agit pourtant d'une "région intermédiaire », située entre l'Occident et l'Orient, et centrée sur la Méditerranée. Prendre conscience de son unité dynamique, c'est effacer la coupure entre l'Est et l'Ouest, le Sud et le Nord et reconnaître le caractère synthétique de la civilisation européenne, assimilant les traditions historiques et politiques, dans leurs dimensions culturelles multiples, romaine et hellénique, byzantine et ottomane, slave et germanique, chrétienne et islamique, démocratique et autocratique.

Depuis des époques lointaines, des mouvements de populations brutaux ou pacifiques ont perduré, dont l'histoire a dressé une liste impressionnante. Ces vagues successives se sont mêlées en une alchimie d'intégrations et de rejets qui ont fait naître les peuples sud-est européens actuels. Le modèle républicain à la française a voulu les enfermer dans des États-nations mais ils débordent tous de leurs frontières trop rigides. Porteurs d'une culture plurimillénaire, ils forment dans la péninsule le tissu humain de base sur lequel sont venus se greffer les nouveaux apports des conquérants ou des colons de l'époque historique.

L'un des principaux substrats du peuplement sud-est européen est constitué par des groupements illyro-thraces d'origine indo-européenne. Alors que les Grecs ont fait mouvement vers le sud au milieu du $2^{\mathrm{e}}$ 
millénaire avant J.C., en se mélangeant aux autochtones policés par la Crète pour donner naissance à la civilisation mycénienne et par la suite à celle de l'Athènes classique, les Illyriens se sont perpétués durant deux millénaires non sans de nombreux apports successifs, en particulier celui des Latins et plus tard celui des Slaves, pour donner naissance au peuple albanais. La colonisation romaine s'est développée à partir de la Grèce et si la civilisation gréco-romaine préservait la langue et la culture d'époque hellénistique, les autres populations intégrées à l'Empire, à l'exception des Albanais, ont été romanisées. La pénétration des Slaves a entraîné une slavisation progressive de toutes les populations sud-est européennes, à laquelle ont échappé à nouveau les Grecs et les Albanais, mais aussi les Roumains, qui ont assimilé les nouveaux venus. Byzance succède à Rome comme État impérial et domine la région jusqu'au $\mathrm{XV}^{\mathrm{e}}$ siècle. Durant toute une période de dissidences, surtout après le schisme de 1054, les Églises orthodoxes d'Orient partagent la région avec l'Église catholique de Rome. Avec la chute de l'Empire byzantin, c'est le tour de l'Empire ottoman auquel se rattache une tradition islamique. Le christianisme a subsisté, mais contrôlé et persécuté par les Ottomans, disputés parfois par l'Empire russe, qui renouait avec la tradition chrétienne orthodoxe, ou par l'Empire habsbourgeois, qui renouait avec la tradition catholique.

L'empire ottoman a représenté un type de frontière d'État, intermédiaire entre les empires anciens et le système moderne européen d'État. Incarnant les préceptes de l'Islam, il n'a pas reconnu jusqu'à la fin du $\mathrm{XVIII}^{\mathrm{e}}$ siècle le concept de frontières d'État dans le sens européen, mais plutôt une division du monde en deux sphères culturelles : le monde de l'Islam et le monde de la guerre. Mais même cette division rigide n'a pas pu être strictement maintenue. Par exemple, un espace contesté occupé par des nomades a émergé tout le long des frontières IslamicoByzantines pendant la stabilité relative du $\mathrm{X}^{\mathrm{e}}$ siècle. Autour du XIII siècle, une culture de guerriers saints (Ghazi) a surgi avec un type correspondant du côté Byzantin (Akritai). C'est cette zone intermédiaire, où guerre et commerce s'alternaient souvent, qui a facilité la pénétration et la conquête de l'empire Byzantin par les Ottomans. Plus tard, aux confins occidentaux de la puissance ottomane, une frontière militaire bien plus complexe a émergé. Dans ce «triplex confinium » (Roksandic 1998), trois empires, Ottoman, Habsbourgeois et Vénitien, se confrontaient et coexistaient pendant trois siècles. Entre-temps les petites guerres, les transferts de population, les catastrophes naturelles et les incertitudes profondément enracinées ont formé une société de frontière qui a inventé une variété de stratégies de survie, qui pouvaient aller du commerce frontalier et de la fraternité de sang jusqu'aux conversions religieuses et politiques (Inalcik 1973). Dans ces conditions, c'est avant tout une culture de guerre qui a émergé sous la forme des guerriers de 
frontière chrétiens appelés Uskoks ou Krajisnik, auxquels sont liés ces ballades de frontière bien connues dans les territoires frontaliers SlavoAlbanais, comparables aux ballades de frontière du côté EcossaisAnglais.

Mais ce qu'il faudra souligner avant tout c'est que la politique ottomane n'a pas reculé devant des transferts de populations et des entreprises de colonisation, tandis que l'activité économique dans les frontières d'un empire étendu à trois continents se traduisait par d'amples mouvements de populations. De ce formidable brassage de populations, une très grande diversité culturelle, ethnique, linguistique, religieuse et politique subsiste dans l'aire culturelle sud-est européenne. Les sociétés sud-est européennes comprennent plusieurs groupes ethniques, parlant différentes langues ou dialectes et adhérant à trois religions principales, malgré le fait que la littérature ethnographique indique souvent une similarité remarquable des structures sociales et des adaptations écologiques, aussi bien que de leurs expressions idéologiques. C'est le lieu de partage par excellence entre les Empires romains d'Orient et d'Occident, entre l'islam et le christianisme, entre l'orthodoxie et le catholicisme, entre les blocs politiques et idéologiques de la guerre froide. Au cœur même de ce foyer se trouve, sûrement plus que tout autre composante, le « faible chaînon » entre le monde latin, grec et slave, comme Fernand Braudel a qualifié le cas albanais. Car le seul exemple albanais renferme en soi probablement l'essentiel d'une série de problématiques comparatives culturelles, historiques et géopolitiques. L'approche d'une population partagée de part et d'autre d'une frontière politique (les Albanais et les Kosovars), recoupant structures sociales et politiques, nationalismes et religions, relations interethniques et migrations, est certainement très riche d'enseignements, au moins tout autant sinon plus que le cas irlandais ou basque, pour n'en citer que ces deux-là.

Si des régions devaient être définies selon un seul type de savoir, les Balkans seraient caractérisés de façon étroite par la religion, ou suivant certains facteurs linguistiques ou ethniques communs, alors que les facteurs de diversité sont souvent ignorés. En outre, les frontières générées par un ensemble de critères disciplinaires n'ont pas coïncidé avec d'autres définitions, conduisant à des débats de frontière parmi les spécialistes de la région. Il se révèle ainsi quasiment impossible d'articuler ensemble les données localisées dans le Sud-est européen, malgré les tentatives de mise en ordre de la diversité sud-est européenne, par les travaux des ethnologues et en dehors du champ de la discipline, car effectuées selon des critères hétérogènes entre eux. Les quelques découpages empiriques de l'Europe du Sud-est, proposés par les anthropologues à l'échelle européenne (Arensberg 1963), ne se superposent que grossièrement aux cartes susceptibles d'être dressées en fonction de 
critères géographiques, de la répartition des éléments de culture matérielle, des familles linguistiques, des aires religieuses ou encore des ensembles historiques, aux frontières floues et changeantes, tels qu'ils portent les marques accumulées des événements majeurs du passé sudest européen.

Ces découpages ne coïncident pas davantage, même s'ils y font souvent référence, avec la carte des substrats ethniques, qui renvoie davantage aux illusions de la "chasse aux ancêtres " qu'à une réalité pertinente. La diversité balkanique est effectivement renforcée par le fait que les populations données pour homogènes par la tradition des études historiques, voire ethnologiques, ont pour cadres d'identité collective des sous-ensembles définis par des frontières sociales et territoriales. Il serait trop simple d'imaginer, à la manière des historiens nationalistes $\mathrm{du} \mathrm{XIX}^{\mathrm{e}}$ siècle, une stabilité de blocs ethniques justifiant des frontières modernes intangibles. D'ailleurs, le lien ethnique n'est pas nécessairement déterminant pour rendre compte de la particularité des genres de vie. Ainsi on pourrait multiplier les exemples qui mettent en évidence le poids de l'histoire, surtout après la conquête ottomane, dans les formations des entités culturelles d'aujourd'hui.

Une manière de voir serait peut-être de concevoir " l'aire culturelle » et les frontières historiques des Balkans ou de l'Europe du Sud-est comme un dispositif heuristique, défini dans des buts analytiques ou pédagogiques spécifiques, considérant ses frontières comme des constructions intellectuelles, temporaires, discutables et enchevêtrées. Ceci a l'avantage de s'interroger sur des définitions, des traits et des frontières, plutôt que de les passer sous silence. La civilisation sud-est européenne devrait être comprise dans son ensemble, chacune de ses composantes ayant fait partie, à une époque historique donnée, d'une construction culturelle, religieuse ou politique plus vaste. Elle se situe à une aire de confrontation sur laquelle des Empires et des États aspirant à la puissance ont constamment débordé, où orthodoxie, catholicisme et islam se touchent et s'entremêlent, par-dessus des découpages et des espaces de coexistence ethnoculturels et ethnolinguistiques différents. Autant de particularismes et de clivages discrets, souvent ignorés ou dénaturés par le modernisme actuellement dominant dans les cultures nationales, tout comme autrefois par la volonté de nivellement des grands corps impériaux.

Dans ce contexte, l'idée de frontières linéaires rigides le long des lignes nationales et la puissance de les imposer sont venues d'Europe occidentale. Le modèle français stipulant que les frontières d'un État doivent correspondre à celles naturelles et nationales suivant une seule langue et une culture, s'est internationalisé et largement diffusé avec des résultats divers. Vers la fin du $\mathrm{XIX}^{\mathrm{e}}$ et le début du $\mathrm{XX}^{\mathrm{e}}$ siècle il a égale- 
ment émergé dans les petits États successeurs en Europe du sud-est, qui tous débordent au-delà de leurs frontières trop rigides. L'existence prolongée de sociétés multiculturelles formées par des intérêts dynastiques a repoussé au $\mathrm{XX}^{\mathrm{e}}$ siècle le passage des frontières historiques à celles ethniques avec de lourdes conséquences. Pendant cette période, l'histoire a enregistré une liste impressionnante de mouvements brutaux ou paisibles de populations, de migration interne, de colonisation, d'installations forcées et d'expulsions. Cette alchimie d'intégrations et de rejets avait créé un kaléidoscope de peuples qui ne pouvaient pas être compartimentés d'une manière ordonnée suivant le dessin de frontières linéaires. Redessiner la carte de l'Europe du sud-est alors que la puissance ottomane a graduellement reculé était un cauchemar pour les cartographes, le résultat d'une série de compromis malheureux entre les intérêts contradictoires des grandes puissances et les aspirations des peuples subjugués luttant non seulement pour l'indépendance mais également pour des frontières basées sur des revendications historiques.

Une Grande Serbie, Grande Croatie, Grande Roumanie, Grande Hongrie, Grande Bulgarie, Grande Grèce, Grande Albanie, toutes encore plus grandes, étaient des réclamations mutuellement irréconciliables. Mais tous les États sud-est européens ont implanté des politiques nationalistes planifiées, relayées par les corps de connaissances intellectuelles (théories de l'ethnos ou de la culture populaire). D'ailleurs, depuis le $\mathrm{XVIII}^{\mathrm{e}}$ siècle, l'élément décisif de la constitution des écoles nationales folkloriques et ethnologiques dans le Sud-est européen fut précisément la recherche ethnique, mise en avant pour soutenir les prétentions à l'indépendance. Les revendications se sont alors exprimées dans la littérature, dans les recherches et les publications folkloriques ou l'organisation des musées ethnographiques. Ces traditions ont encore beaucoup en commun avec les assertions erronées des primordialistes, mais les investigations empiriques dans ces sociétés requièrent certainement l'engagement avec les chercheurs locaux et leurs traditions intellectuelles distinguées sur plusieurs aspects.

Plus tard, dans une tentative qui a prétendu mettre fin aux conflits des revendications nationalistes entre les États du bloc socialiste, ce fut la puissance soviétique qui imposa le principe de l'intangibilité et de l'inviolabilité des frontières héritées de la Seconde Guerre mondiale. Considérant que « la stabilité des frontières est une condition fondamentale et préalable à une paix durable en Europe », les autorités communistes ont revendiqué avoir mis fin aux conflits nationaux incessants, qui opposaient les États de l'Europe centrale et orientale avant l'établissement des régimes communistes. L'intangibilité des frontières n'a pas été réduite à leur stabilité ; cela signifiait que les frontières entre 
les États prévalaient sur les frontières ethniques ou linguistiques, et qu'elles ont la valeur de frontières nationales.

Aujourd'hui l'anthropologie, la sociologie historique et l'histoire sociale des structures familiales, des stratégies matrimoniales et patrimoniales, des relations de propriété ou des formes nombreuses de solidarité sociale et culturelle, aussi bien que les recherches sur les traditions orales, les représentations collectives et les formes symboliques, tentent d'une manière ou d'une autre de redécouvrir et de réévaluer les différences et les ressemblances. J'ai eu l'occasion de discuter l'héritage historique (Doja 2000d) et la diversité locale (Doja 1998a) des conventions culturelles albanaises, mais l'histoire des cultures sud-est européennes nécessite une nouvelle reformulation, que j'ai eu l'occasion de présenter lors d'une communication préliminaire à Vienne. ${ }^{1}$

Les études sud-est européennes sont extrêmement vastes et complexes. Sujette aux influences extérieures rivales autant qu'aux pressions internes, l'aire sud-est européenne est au vrai sens du terme un champ d'expérience pour des systèmes alternatifs. Il faudrait, paradoxalement peut-être, rechercher une insaisissable unité, et donc la pertinence de l'idée d'une culture, d'une civilisation et d'une histoire sud-est européenne, dans cette diversité même, en quelque sorte dans une coexistence des dissemblances, préservées plus fortement qu'ailleurs. La démarche, ainsi définie, pourrait conférer à cette partie de l'Europe un visage distinct tout en déterminant une problématique qui lui soit proprement applicable.

Notamment, l'adoption d'une anthropologie de la construction des identités sociales dans les cultures sud-est européennes m'a semblé présenter beaucoup d'intérêt en raison des matériaux qu'elle a pu mettre en œuvre et de sa portée théorique. Cette problématique, de la même façon que les sujets afférents des relations interethniques et de la dynamique culturelle des valeurs sociales, ont fait couler beaucoup d'encre parmi les adeptes des écoles ethnocentriques locales. Les religions et les mythologies sud-est européennes, les problèmes de la vengeance et de l'honneur sont tantôt occultés tantôt idéalisées, alors que les problématiques de la personne et de l'identité sociale, de la parenté, de la famille et de l'organisation sociale, des morales sociales et des relations de propriété, des migrations et des transformations sociales, ont souvent été négligées, ou tout au moins rarement traitées dans leur ensemble.

«Writing culture in history : the view of anthropologist for understanding religious and cultural instruments of ethno-politics in historical perspective », Internationale Tagung: Zwischen verdrängter Erinnerung und künftiger Identität, die Zukunft Mittel-Ost- und Südosteuropas, Wien : Österreichisches Ost- und Südosteuropa-Institut, 13.-15. Dezember 2001. 
À ce propos, l'originalité des informations, des matériaux et des réflexions, présentées par des descriptions ethnographiques sélectives et minutieusement multi-situées, ainsi que la maîtrise des concepts utilisés, m'ont fait déboucher, au premier abord de manière inattendue dans ce contexte, sur un questionnement concernant l'unité et la spécificité de la région culturelle albanaise dans le contexte sud-est européen, tout en se rattachant à des débats socio-anthropologiques contemporains. En conséquence d'une longue coexistence en proximité territoriale, des relations économiques et sociales serrées, de l'influence réciproque et des destinées historiques communes, les régions de l'aire de peuplement albanais se sont forgé des consciences sociales communes, exprimées dans des traditions culturelles spécifiques. Dans la plupart de mes travaux, je me suis spécialement efforcé de montrer que les différences locales des traditions culturelles albanaises existent parallèlement à leurs caractères communs, comme le sentiment d'appartenance au même groupe ethnique existe à travers les variantes locales et régionales des traits culturels et de la variété idéologique et religieuse (Doja 1998a). J'ai souhaité ainsi apporter aux européanistes des références comparatives précieuses et aux spécialistes des rites de passage et des formes de socialisation matière à réflexion et à intérêt.

Le travail sur cette région acquiert ainsi un intérêt particulier à travers l'évidence pratique des transformations politiques, économiques, sociales et culturelles des deux dernières décennies et des perspectives de recherche qu'elles représentent. Dans ce contexte, il faudra avoir constamment en vue que la théorie du lien social fondé sur une universalité des valeurs sociales et culturelles communes comme principe de fonctionnement de ces sociétés s'est effondré dans la région face à la montée récente des aspirations à la modernisation et à la démocratisation, aussi bien qu'au nationalisme et au renouveau de la religion. L'obligation de mettre en chantier les compréhensions des perspectives comparatives face à l'évolution des pays sud-est européens et de toute l'Europe orientale, dans le cadre du développement des régionalismes actuels, fait mieux comprendre comment les anciennes valeurs normatives sont susceptibles d'être mobilisées à des fins productives sans rupture des liens sociaux. Car les chocs révolutionnaires actuels ont déjà produit des effets qui ne vont pas tous dans le sens d'une acceptation uniforme des cultures et des idéologies instrumentales et rationnelles.

Les bouleversements géopolitiques de l'Est ne peuvent pas soudainement effacer le fait que ces pays aient vécu pour la plupart sous régime communiste, dont on peut lire les traces à chaque coin de rue, dans chaque mentalité, dans chaque élément de la vie sociale. Quoi qu'on en pense, la réalité autocratique a marqué l'espace public et privé des pays est-européens et balkaniques. L'idéologie, la pratique et 
l'influence du communisme n'expliquent pas tout, loin de là, et rien n'est plus flagrant que l'histoire irrégulière de la modernité sociopolitique affleurant sous l'ère communiste à l'Est. Dans ce contexte, toute analyse simpliste devient proprement inapplicable.

Les deux transitions que les pays de l'Est européen ont connues ou connaissent, la transition forcée au socialisme et la transition devenue, semble-t-il, nécessaire au capitalisme, font de leur histoire un laboratoire extrêmement riche pour l'étude comparative des processus complexes. La disparition du collectivisme, par exemple, favorise l'éclosion d'un champ d'expérimentation originale. Le développement économique et social escompté doit prendre en considération à la fois la libéralisation intervenue et les échecs subis en Occident par des pratiques inadaptées, tant en milieu rural qu'en zone urbaine. Dans ces conditions, il y a certainement des liens étroits avec les spécialistes de la région, plus particulièrement dans les pays ex-socialistes où il est nécessaire de s'engager en dialogues avec les spécialistes de la « transitologie ».

Cependant, force est de constater que dans les travaux de la première vague la Russie et les pays d'ex-Union soviétique ont mobilisé la plus grande part de l'attention des chercheurs. Aussi la plupart des travaux s'intéressant aux processus de transition en Europe orientale ont-ils porté uniquement sur les transformations économiques et juridiques selon le modèle occidental (Doja 1995a). La famille, par exemple, semble être au cœur des remaniements et des bouleversements que connaissent désormais ces pays, mais cet aspect reste encore très peu étudié. On s'attache généralement au passage à l'économie de marché et à la montée des États de droit. Quoique ces dimensions soient naturellement majeures dans la nouvelle donne à l'Est, au-delà de ce double intérêt exclusif, régional et thématique, il est nécessaire de porter un nouveau regard sur le domaine de construction des identités sociales et de transformations familiales et sociales, aussi bien que de s'ouvrir de nouvelles perspectives sur les aspects comparatifs des relations interethniques et la dynamique culturelle des valeurs sociales.

Bien que les images de la balkanisation et les luttes intestines aient disparu légèrement de l'horizon intellectuel pendant la guerre froide, remplacées par des images de sociétés collectives et autoritaires, depuis 1991 elles ont été rétablies sous leurs aspects les plus négatifs, dont le tribalisme et les vendettas, la cruauté et les atrocités barbares. Dans le discours populaire au moins, les événements en ex-Yougoslavie semblent avoir donné crédit à l'image de la balkanisation comme caractéristique culturelle de définition de l'Europe du sud-est, la séparant jusqu'à un certain degré du reste de l'Europe Centrale et Orientale. Cependant, le cas yougoslave mis à part, semblant anormal ou comme une exagération des tendances trouvées ailleurs, le paradigme postsocialiste sug- 
gère-t-il une certaine spécificité de l'Europe du sud-est? La question est de savoir si dans les analyses académiques comme dans l'opinion publique, le nationalisme et les appartenances ethniques exclusives violemment revendiquées, sont en train de remplacer le socialisme d'État en tant que marqueur de délimitation principale de l'Europe orientale et sud-orientale. Étant donné les difficultés auxquelles les générations précédentes d'anthropologues ont fait face en identifiant des traits culturels, est-ce que les phénomènes comme le nationalisme sont lus au moins implicitement comme expressions culturelles de l'unité régionale ? Le nationalisme est-il devenu le nouveau concept unifiant l'Europe de l'Est, en particulier l'Europe du sud-est, et qui semblerait définir non seulement ces aires mais aussi indiquer le point central de la recherche à travers les genres de questions posées et le type de recherche financée? 



\section{CHAPITRE 2}

\section{Modes d'analyse}

Pour connaître la société «réelle», on ne peut plus se contenter d'une recherche sur les groupements tant soit peu « exotiques », limitée à l'étude des communautés rurales ou à l'étude des aspects "survivants » ou «déviants » des ensembles sociaux et des comportements culturels. Cette approche peut livrer des aperçus précieux sur le détail des inventions culturelles particulières et même corriger les théories scientifiques avancées par les savants locaux. Mais pour se garder d'adopter des notions qui seraient peut-être des reconstructions de structures et de valeurs arbitraires, ethnocentriques et intemporelles (Herzfeld 1987), l'anthropologie actuelle préfère une démarche dans la perspective historique et ethnographique, respectant les différences et rejetant toute approche en termes de survivances et de folklorisme ou de définitions externes et ethnocentriques.

Du point de vue méthodologique, j'ai essayé de me situer loin de la prospective limitée des chercheurs antérieurs et des études historiques, folkloriques et ethnographiques traditionnelles, marquées par l'isolation intellectuelle et stigmatisées par l'association avec des idéologies moralistes ou nationalistes, qui furent exceptionnellement dures et revanchistes surtout dans leur variante communiste. Avec un intérêt explicite de fournir des descriptions nuancées des faits sociaux, j'ai appuyé mes analyses non seulement sur la méfiance du nationalisme, mais aussi sur des enquêtes empiriques informées par une connaissance profonde et circonstanciée des méthodes et des théories les plus importantes en anthropologie sociale.

Mon intention n'est pas de fournir une image tant soit peu approfondie et exhaustive de la culture albanaise dans le contexte sud-est européen, ni savoir ce que les formes et configurations culturelles ou régionales spécifiques sont chacune pour son propre compte, mais découvrir la façon dont elles se ressemblent et diffèrent les unes des autres. Au lieu d'un savoir positif sur l'homme ou la société, ce sont ces "écarts différentiels » qui, selon Lévi-Strauss (1958 : 358), constituent le véritable objet de l'anthropologie. Ainsi, la contribution majeure de mon activité de recherche demeure dans l'investigation empirique des phénomènes ethnographiques et leur construction imaginée comme un objet d'investigation analytique. En même temps, une large variété de mé- 
thodes supplémentaires sont utilisées pour soutenir l'usage des méthodes ethnographiques normalisées et multi-situées du travail de terrain, pierre angulaire de l'anthropologie comme science sociale empirique.

\section{Le terrain ethnographique}

Notamment, les analyses anthropologiques que j'ai développées dans mes travaux de recherche se sont appuyées sur un spectre large de données de terrain et de sources primaires originales. Essentiellement, l'ensemble de ces données proviennent de différentes régions d'Albanie, à commencer par les importantes recherches de travail résidentiel, une année de septembre 1976 en juin 1977 en Haute Opar et une période de près de cinq ans de 1981 à 1985 en Basse Mokra, zones rurales reculées en Albanie du sud, ce qui a débouché sur des travaux ethnographiques portant sur l'étude du patrimoine culturel de la population locale (Doja 1985, 1986a, 1986b). Le travail extensif sur ce terrain était très important parce qu'il m'a permis l'observation des rythmes saisonniers et la gamme complète des événements du cycle de vie dans les groupes domestiques, d'autant plus que pour ce type de recherches la profondeur du temps nécessite d'être poussé au-delà de la période usuelle de deuxtrois ans.

Ce travail s'est poursuivi de 1985 à 1990 dans le cadre de l'Institut de Culture Populaire de l'Académie des Sciences d'Albanie par des missions systématiques de recherches ethnographiques sur le terrain, individuelles ou en équipe, d'une durée moyenne de trois à quatre mois par an dans plusieurs régions rurales en Albanie, dont celle de Devoll au Sud-est, celle de Has au Nord-est ou celle de Lura au Nord. Ces missions ont constamment vérifié les hypothèses de travail et affiné les méthodes de recherche. La sélection des répondants, par exemple, s'est effectuée selon les disponibilités parmi les membres de petits groupes bien définis, présentant des caractéristiques plus ou moins particulières du point de vue de leurs connaissances et expériences «culturelles ». Plusieurs stratégies d'enquête ont été successivement utilisées, ajustant pendant l'entretien la formulation des questions à la situation de chaque répondant, au fur et à mesure que les progrès de l'observation et de la recherche faisaient apparaître ou non l'intérêt de l'évocation de certains thèmes. Les données ont été ensuite recoupées de différentes manières, incluant des visites rapides à d'autres sites, pour s'assurer de leur fiabilité.

D'autres missions ponctuelles sur le terrain furent plus ciblées du point de vue thématique, par exemple, pour appuyer une recherche portant sur les traditions orales et rituelles des stratégies matrimoniales, qui a débouché sur la publication d'une série d'études de cas (Doja 
1987, 1988a). D'autres missions m'ont permis de collaborer à la publication d'un ouvrage de documents de tradition narrative (Doja 1988b), dans la collection « Patrimoine culturel des Albanais » sous les auspices de l'Académie des Sciences d'Albanie. Une autre série de missions, organisées en équipe de 1987 à 1990 dans plusieurs régions d'Albanie, ont abouti à la publication, sous ma direction dans la même collection, d'un ouvrage de documents de tradition orale, centré essentiellement sur la naissance et la socialisation (Doja 1990b). Les résultats de ces travaux de terrain ont aussi débouché sur des réflexions théoriques et des analyses empiriques, respectivement sur les fables et légendes de tradition orale (Doja 1989) et sur les représentations collectives des traditions relatives à la naissance et la socialisation (Doja 1990a).

L'étude des transformations sociales et des cycles de développement des familles et des groupes requiert des investigations renouvelées périodiquement, souvent en s'appuyant sur le travail des chercheurs précédents. Il faudra noter alors les investigations systématiques lors de mes retours réguliers depuis 1990 dans les régions que j'ai d'abord connues par mon travail de terrain, ce qui m'a fait obtenir une perspective longitudinale de l'impact des transformations sociales sur les communautés locales. Dans ce processus de socialisation, la connaissance et les hypothèses ont été révisées continuellement, les généralisations prématurées ont été rejetées, les questions inutiles voire trompeuses ont été abandonnées. Une investigation plus systématique est devenue possible seulement dans les phases plus avancées de la recherche, quand la terminologie et les informations de base indispensables aux lignes directives pour les entretiens ont été acquises.

À partir des années 1990 j'ai pu également effectuer de la recherche ethnographique extensive parmi les migrants albanais en Europe de l'Ouest, plus spécifiquement en France, en Belgique, en Italie, en Grèce, en Angleterre, ou en Suisse. En France, notamment, mon travail de terrain auprès des populations immigrées s'est situé dans le cadre de collaborations et d'engagements personnels dans le milieu associatif des centres d'insertion sociale et professionnelle en Région parisienne ou bien dans le cadre des missions d'expertise judiciaire et d'interprétariat auprès des tribunaux de Paris. C'est surtout la connaissance de deux communautés albanaises relativement compactes, établies au moins depuis les années 1950 à Sucy-en-Brie en Région parisienne et à Bruxelles respectivement, et reliées entre elles en quelque sorte par des relations d'intermariage, qui s'est avérée être d'un intérêt particulier, puisqu'il se trouve qu'elles ont conservé plus qu'en Albanie certains modèles des formes culturelles et des comportements sociaux. Il est important aussi de souligner à cette occasion que, lors de mon installation en Grande Bretagne, dans le cadre de ma Maîtrise de Conférences à 
l'Université de Hull, j'ai codirigé un projet de recherche doctorale qui m'a permis de participer et de contribuer directement sur le terrain aux efforts d'intégration des réfugiés bosniaques et kosovars dans la région du Yorkshire.

Pour compléter le tableau, depuis 1997, à travers des activités de consultant chez Research International France et d'autres cabinets de conseil, j'ai eu l'occasion de réaliser aussi des études de stratégie marketing et de communication, au moyen d'enquêtes qualitatives par entretiens directifs et semi-directifs, d'analyses et de rapports professionnels. À ce propos, il faudra noter aussi mes enquêtes auprès des personnels des professions médicales en Italie, à l' occasion d'un cycle de conférences invitées (en italien) à l'École de Médecine Intercommunale de Toscane «Albero della Salute » à Prato (près de Florence) en 2003, qui m'ont permis d'explorer les opinions médicales des praticiens dans les services de gynécologie et de pédiatrie, de maladie infectieuse et d'hygiène, de santé mentale et autres services médico-sociaux par rapport aux individus et aux groupes en situation d'émigration.

Dans tous les cas, d'un point de vue purement ethnographique, l'ethnographie existe seulement si les coordonnées géographiques, historiques et socioculturelles sont définies avec précision. Cependant, une approche ethnographique basée autant que possible sur un matériau régional identifié par rapport à sa location dans l'espace et le temps signifie que je devais décider s'il valait mieux de me concentrer sur un seul emplacement, avec le risque de succomber à la fascination des singularités inhérente à tout travail monographique, ou de travailler sur une série d'emplacements, avec le risque de perdre en compréhension et en substance ce que je gagnerais dans l'extension et la généralisation. Aussi attrayant et efficace que l'approche monographique puisse être, l'aire culturelle albanaise et ses prolongements sont trop variés dans leur réalité ethnographique, trop diversifiés et pour trop longtemps dans des régions historiquement distinctes (voir Doja 1998a), pour que je puisse saisir les causes d'un système culturel relativement uniforme et logique dans ses représentations collectives et ses formes symboliques sans essayer de relier cet ensemble à différents types d'organisation sociale.

C'est, donc, l'expérience ethnographique qui m'a incité à rejeter l'option monographique en faveur d'une ethnographie multi-située et des comparaisons contrôlées dans le temps et l'espace, utilisant autant des données en provenance d'une même région mais recueillies à des périodes différentes que des données en provenance de régions voisines ou graduellement plus éloignées. Une telle approche seule rend possible de dépasser l'incommensurabilité, au moyen d'une sélection de cas commensurables comme points de départ et un élargissement graduel de la perspective de recherche (Eggan 1954; Marcus 1995). L'inter- 
prétation et la comparaison des textes figurent manifestement dans ce domaine, car il est important de comprendre comment, non seulement les groupes ethniques (Anderson, B. 1983/2006), mais surtout les communautés locales et toutes autres formes d'appartenance sont imaginés.

Cela implique d'apporter la même attention particulière que jusqu'à maintenant - comme j'ai fait par exemple dans la plupart des résultats de mes travaux de terrain, surtout ceux que j'ai effectués entre 1985 et 1990 dans plusieurs régions rurales d'Albanie - aux importantes sources historiques traditionnelles, comme les collections de documents d'archives, les corpus de normes juridiques de droit coutumier, les anthologies de littérature orale et les monographies ethnographiques, ou encore des documents dépouillés dans la littérature de voyage et les autres publications périodiques à caractère d'information, qui fournissent des données culturelles signalées dans différentes régions albanaises ou habitées par les Albanais depuis le début du XIX ${ }^{\mathrm{e}}$ siècle. Ce qui n'empêche pas de s'élargir aussi aux œuvres de littérature écrite, aux textes produits par les intellectuels, aux pamphlets et aux déclarations de la part des mouvements politiques, culturels ou religieux et la façon dont tout cela devient accessible pour les membres des groupes.

Je me suis aussi servi de tous les indices d'analyse et d'interprétation, de classification et de synthétisation des faits ethnographiques en tenant compte des travaux anciens et récents des représentants albanais ou plus largement est-européens que j'ai pu avoir à ma disposition en dépouillant la littérature ethnographique et folklorique. Plus particulièrement les documents de tradition orale relatifs à la naissance et à la socialisation m'ont donné l'occasion de publier une des collections représentatives de l'héritage culturel albanais (Doja 1990b). Cette publication était l'occasion pour moi de réunir non seulement un patrimoine culturel riche et représentatif mais aussi, dépassant un caractère d'exposition, de présentation et de description des faits, d'inaugurer un perfectionnement des critères de collecte, de classification et d'interprétation des documents. Une attention particulière est portée, dans la mesure des possibilités, aux indications détaillées concernant les contextualisations historiques et ethnographiques, géographiques et régionales, sociales et économiques, politiques et idéologiques, culturelles et religieuses. Des informations supplémentaires se trouvent aussi sur les conditions exactes de l'origine des données, concernant le temps et l'espace, les communautés locales, les modalités rituelles et cérémonielles de pratique et de réalisation, les agents de transmission et les informateurs par rapport à leur âge, genre et statut familial, ainsi que les conditions d'écriture ethnographique et d'enregistrement technique.

Ce n'est pas un hasard alors que les résultats de mes premiers travaux de terrain n'ont pas cessé d'alimenter par des données ethnogra- 
phiques de première main mes réflexions ultérieures de recherche, portant sur la naissance et la socialisation (Doja 2000a), ainsi que sur la construction des identités sociales, les relations interethniques et la dynamique culturelle des valeurs sociales (Doja 2004a). C'est ce qui fut le cas aussi avec mon travail de terrain à Kosova pendant 2001 et 2002, grâce au soutien de l'Open Society Institute de la Fondation Soros basée à Budapest, qui a débouché sur une analyse des facteurs humains, culturels et sociaux des processus de démocratie et de démocratisation dans la région (Doja 2001b).

De cette façon, ce que j'ai pu perdre par rapport à une connaissance plus approfondie de la population d'un seul village, je l'ai gagné par l'obtention d'une image que je pourrais voir en rétrospective comme représentative du changement social et des modes de vie albanais. Dans l'ensemble, cette approche m'a permis aussi d'incorporer des comparaisons avec d'autres cultures européennes et au-delà, en raison de plus larges généralisations théoriques. Les formes de comparaison dans ce domaine peuvent se développer sans être nécessairement dirigées vers les questions d'universalité. Elles peuvent se limiter à un nombre de cas caractéristiques, afin d'atteindre sur cette base des généralisations plus prudentes. Pareilles stratégies ont à la fois des avantages et des désavantages et la clé d'une recherche réussie reste dans le fait de trouver le niveau approprié de la comparaison et de la spécification des variables. $\mathrm{Au}$ niveau optimal, les uns gagnent en appréhensions détaillées et réalistes dans le cadre de relations fonctionnelles concrètes qui seront occultées par de plus larges catégories nécessaires au degré élevé de la généralisation. D'autres gagnent en qualité représentationnelle parce que plus « qualitative » et on n'avance les données issues de cas historiques et culturellement spécifiques que pour soutenir des comparaisons limitées. Il n'y a ici sûrement pas de compromis. On peut très bien abandonner l'exigence de validité universelle ou d'un degré élevé de vérification des hypothèses, à quoi peut se substituer le traitement d'un large nombre de cas.

\section{L'objectivité expérientielle}

Sans doute, les commentaires généraux sur la méthode ethnographique sont également applicables à l'ensemble de mes propres expériences et activités de recherche sur le terrain. Quand, au tournant du dernier siècle, Boas et Malinowski insistaient sur l'importance moderne du travail de terrain, ils croyaient fermement qu'ils inauguraient une nouvelle époque, plus scientifique, du développement de la discipline. En revanche, au tournant de ce siècle plusieurs anthropologues ont souligné les éléments de subjectivité qu'entraîne le travail de terrain. Une plus grande conscience des questions de réflexivité et l'attention 
accordée aux procédés d'écriture sont ainsi devenues utiles pour renouveler le paradigme ethnographique en anthropologie (Clifford \& Marcus 1986). Néanmoins, la critique postmoderniste n'a pas offert d'alternative cohérente au but de la description objective. Comme une science sociale, la vocation de l'anthropologie est d'expliquer et de comprendre la diversité humaine à travers les comparaisons et les investigations systématiques qui, sans être équivalentes à la précision des sciences exactes, arrivent à pouvoir fournir des conclusions généralisables. La logique du processus de recherche est la même que dans les sciences naturelles, mais différents types de complications sophistiquées nécessitent d'être pris en compte. Il n'est pas des moindres le fait que les gens étudiés aient leurs propres théories sur eux-mêmes et sur les intentions $\mathrm{du}$ chercheur, au point que des réseaux complexes d'influences mutuelles nécessitent d'être démêlés, comme par exemple, les exigences élevées du travail de terrain, les préjugés de genre, la tendance à compter exclusivement sur les informateurs «représentatifs», ou encore davantage dans mon cas, l'étude non moins problématique de la propre société de l'anthropologue.

Le travail de terrain est normalement effectué dans un cadre relativement restreint, sur la base du face-à-face et des contacts soutenus. Au moyen du travail de terrain, les anthropologues acquièrent une seconde socialisation qui leur fournit la compétence culturelle, c'est-à-dire l'acceptation de la part de la culture qu'ils approchent et qui les accueille. Sans doute, les premiers mois d'un projet de terrain ont souvent un caractère exploratoire. Mais plus la compétence linguistique est importante et plus on a appris les modes de conduite appropriée, plus on est graduellement accepté sur le terrain, qui souvent, quoique non nécessairement, consiste dans des groupes fortement soudés qui ne sauraient être pénétrés par d'autres méthodes.

Or, l'exigence de cette approche est très élevée, dépassant la nécessité d'un haut degré de compétence linguistique. Car si la fiabilité des données ethnographiques ne peut provenir que du fait de travailler dans la langue locale, elle devra être maitrisée à un degré permettant la participation à des conversations de groupe et la compréhension des énonciations non spécifiquement dirigées à l'enquêteur. Dans les situations d'entretien formel plus ou moins structuré, il est très facile pour les préconceptions du chercheur de dominer les échanges, mais cela est presque impossible dans la culture albanaise où la discrétion est importante et où la plupart de la communication s'effectue dans ce qui est caractérisé comme un code très restreint.

Par contre, la participation à des groupes plus larges, dans une interaction quotidienne, et le fait de surprendre ou d'entendre par hasard les conversations des autres, tout cela peut générer des intuitions originales 
dans des structures significatives aux gens locaux eux-mêmes, à leurs modèles à la fois «représentationnels » et " opérationnels » (Holy \& Stuchlik 1983). C'est ainsi, m'appuyant sur ma propre expérience ethnographique de recherches sur le terrain, j'ai réalisé que l'occurrence d'une telle expérience a été pour moi la seule façon de me former une opinion et de comprendre au-delà du superficiel ce qui motivait le comportement des autres. C'est ainsi que j'ai acquis l'appréhension intime de la réalité qualitative exprimée dans les frontières symboliques des identités locales, surtout quand il existait un mélange compliqué de groupes, différenciés ou non du point de vue social, culturel ou religieux.

Toutefois, il ne m'a été bien entendu ni possible ni nécessaire que je puisse connaître d'expérience tous les aspects et détails de la société dont je parle. En effet, si en tant que sociologue ou anthropologue on s'assigne la tâche de produire de la théorie fondée sur les données ethnographiques et historiques de terrain, comme Glaser et Strauss (1967) y ont insisté, on fait un travail qui ne peut être effectué que par le sociologue ou l'anthropologue. Les chercheurs locaux et les spécialistes d'une région particulière, dans leur vaillant effort pour obtenir et décrire des faits, tendent à oublier que l'offre distinctive de la sociologie et de l'anthropologie est la théorie et non pas une description aussi bien détaillée ou appuyée sur une recherche de collecte la plus exhaustive possible. En fait, les compilations d'atlas folkloriques ou d'archives ethnographiques et historiques sont supérieures à n'importe quel sociologue ou anthropologue pour ce qui est des descriptions de données, mais elles montrent en même temps leur manque de pertinence sociologique et anthropologique qui corrigerait l'idéologie conventionnelle derrière l'" amas poussiéreux» de ces accumulations de données. Comme le dira Merleau-Ponty (1960) à l'occasion de la présentation de son illustre protégé, il suffit qu'on ait quelquefois et assez longuement appris à se laisser enseigner par une autre culture, car on dispose désormais d'un outil de connaissance nouveau, on a repris possession de la région sauvage de soi-même qui échappe ainsi à l'emprise de sa propre culture et par où on communique avec les autres. Ensuite, même à sa table, et même de loin, on peut recouper par une véritable perception les corrélations de l'analyse la plus objective.

À ce propos, il me semble nécessaire d'être prudent envers une approche excessivement programmatique du travail de terrain, comme il est enseigné aux universités et codifiée dans les manuels d'ethnographie. Durkheim a pensé que le sociologue serait à même de fonder l'objectivité de sa démarche à condition d'étudier "les faits sociaux comme des choses » (Durkheim 1895/1988). Il est possible que le sociologue et le démographe, voire le psychologue social, atteignent 
un certain niveau d'objectivité en réduisant leur objet à l'état de chose, statistiques, sondages, questionnaires. Mais le propre de la méthode ethnographique, c'est qu'elle ne se contente pas de cette simplification, même si le travail de terrain peut générer des données aussi bien qualitatives que quantitatives ou que l'analyse de tout type de données requiert aussi de la quantification numérique.

Plusieurs anthropologues utilisent effectivement des questionnaires et recueillent des données qui permettent des évaluations quantitatives dans la forme de recensement des données locales, par exemple par rapport à la modélisation des stratégies de mariage. Les développements récents des techniques qualitatives en informatique sont également utiles à détecter les modèles récurrents décrits dans les notes de terrain. De même, les nouvelles technologies audiovisuelles sont utilisées à la fois pour la collection des données sur le terrain et pour l'analyse ultérieure, à tel point que parfois les nouvelles technologies permettent de commencer l'analyse sur le terrain même. Cependant, toutes les données objectives collectées sur le terrain et qui peuvent entrer dans l'inventaire de la description ethnographique, territoire, population, habitat, techniques, institutions, croyances ou autres, ne sont absolument rien, sinon dans la mesure où elles se réintègrent dans une expérience vécue.

Les conditions de vie et de travail de l'ethnographe sont telles qu'il est d'abord retranché physiquement de son groupe pendant de longues périodes. Par la brutalité des changements auxquels il s'expose, exil, faim, maladie, parfois danger, avec la contradiction constante de ses propres croyances et coutumes, l'ethnographe est victime d'une sorte de déracinement chronique. Lévi-Strauss dira que "plus jamais il ne se sentira chez soi nulle part », mais restera à jamais psychologiquement mutilé (1955: 59). Sous cet aspect, le travail sur le terrain ne relève pas simplement de l'expérimentation, mais surtout du côté expérientiel de l'anthropologie. Il s'agit de quelque chose qui ne peut pas être éprouvé indirectement, mais d'une expérience personnelle directe que tous les membres de la profession vivent nécessairement.

Néanmoins, plus qu'une qualification technique, plus qu'une voie obligatoire vers l'apprentissage professionnel, le travail sur le terrain ouvre une dimension de perspicacité intellectuelle impossible à réaliser dans le cadre abstrait et formel de l'enseignement académique. La plus subjective des expériences, la passion de l'ethnographe, comme LéviStrauss l'appelle, peut être une source de connaissance objective, se référant non seulement au fait banal de la collecte de données, à l'observation simple et l'enregistrement d'une réalité exotique. Le travail de terrain représente un moment crucial, avant lequel l'anthropologue pourra posséder des connaissances discontinues, mais qui ne formeront jamais un tout avant qu'il s'engage dans le travail de 
terrain afin qu'elles « se prennent » en un ensemble organique et acquièrent soudain un sens, qui leur manquaient antérieurement (Lévi-Strauss 1958 : 409). Ainsi, il y a une raison très profonde, qui tient à la nature même de la discipline et au caractère distinctif de son objet, que l'anthropologue a besoin de cette expérience originale du terrain. Audelà de sa fonction prosaïque d'observation et de description, le travail de terrain est une transformation intellectuelle ultime, un genre de reconfiguration mentale du sujet observant-en-participant.

De toutes les sciences, l'anthropologie est seule, sans doute, à faire de la subjectivité la plus intime un moyen de démonstration objective. Car c'est bien un fait objectif que le même esprit, qui s'est abandonné à l'expérience et s'est laissé modeler par elle, devienne le théâtre d'opérations mentales qui n'abolissent pas les précédentes et transforment cependant l'expérience en modèle, rendant possibles d'autres opérations mentales. En fin de compte, la cohérence logique de ces dernières se fonde sur la sincérité et l'honnêteté de celui qui peut dire, comme l'oiseau de la fable : "J'étais là, telle chose m'advint, vous y croirez être vous-même », et qui réussit, en effet, à communiquer cette conviction. (Lévi-Strauss 1960/1973 : 25)

La passion de l'ethnographe est passive dans la mesure où l'ethnographe s'abandonne à l'expérience ethnographique qui permet à son esprit d'être, littéralement, modelé par cette expérience. L'expérience subjective devient un modèle objectif. Il est significatif ici comment Lévi-Strauss décrit que, tandis que l'esprit devient le « théâtre » d'une expérience ethnographique, il ne perd pas entièrement sa configuration originelle. Dans l'espace du «même esprit ", il y a une coexistence « d'opérations mentales ", de soi-même et de l'autre, et une combinaison dialectique des deux dans le modèle qui en résulte. S'abandonner aux transmissions inconscientes de l'expérience du travail de terrain, permettre à son esprit d'être ainsi «remodelé», pour employer la métaphore de Lévi-Strauss, revient à s'ouvrir à un mode intuitif et associatif de pensée que les «empiricistes hyperactifs », qui s'adonnent à l'accumulation infinie des données, ne peuvent jamais réaliser. On pourrait dire alors que l'expérience sur le terrain est dialectique, parce qu'il y a une cohérence logique par laquelle l'expérience elle-même est niée, conservée et assimilée dans la transformation de l'observation empirique « crue » au savoir théorique « cuit».

Toutefois, l'anthropologue se propose d'étudier un grand nombre de sociétés, dont l'une présente un caractère particulier d'être la sienne. Pour rendre son objet homogène il suffira peut-être de s'abstraire de cette société particulière, de la considérer du dehors au même titre que les autres. Or, l'antinomie ethnographique ne relève pas de la morale mais de la connaissance. On ne la définirait qu'à moitié en disant qu'elle consiste, pour les anthropologues, dans l'obligation contradictoire où ils 
se trouvent d'étudier les sociétés différentes «comme s'ils en étaient» et leur propre société «comme s'ils n'en étaient pas». La situation réelle est plus complexe. Car si, à l'extrême rigueur, on peut se contenter de la formule qui précède pour définir la relation de l'ethnographe aux sociétés différentes, elle cesse d'être applicable dans l'autre cas. Étudiant sa propre société, l'ethnographe doit d'abord s'en détacher aussi complètement que de telle ou telle société africaine ou mélanésienne, aussi lointaines qu'elles n'apparaissent que comme simples noms dans la nomenclature ou points sur la carte. Mais s'il est vrai que l'anthropologue ne pourra prétendre avoir réussi sans s'être incorporé la conception de la société et du monde de l'autre, que ce soit de l'Africain ou du Mélanésien, alors il lui faudra accomplir un effort supplémentaire vis-à-vis de sa propre société. Après en être sorti, il lui faudra y entrer à nouveau, afin de la re-connaître et l'expliquer anthropologiquement.

Dans ces conditions, il y a nécessairement une signification profonde dans le fait que je suis né et j'ai grandi dans la tradition culturelle albanaise, que je suis formé dans la tradition socio-anthropologique française, que j'ai travaillé dans la tradition anthropologique anglo-saxonne, que j'ai un engagement, maintenu pendant plusieurs années, dans des relations personnelles étroites entre l'Europe du Sud-est et l'Europe de l'Ouest, vivant et travaillant depuis de longues années dans la tradition européenne des pays comme la France, l'Angleterre, l'Irlande ou l'Albanie. Tout cela m'a sans doute permis un type de recherche de terrain, aussi bien que diachronique et comparative, qu'on peut difficilement rencontrer dans d'autres situations ou d'autres disciplines. Les vingt années depuis mon départ de l'Albanie peuvent être vues comme une période d'incubation, une période latente pendant laquelle les questions disparates de mon expérience sur le terrain ont effectué leur travail inconscient, retrouvant silencieusement leurs marques, fournissant l'architecture mentale nécessaire pour une compréhension appropriée de cette expérience. À un autre niveau, mon expérience transculturelle semble souligner un point plus abstrait de transition, une conversion dans mon esprit des complications et incertitudes du travail de terrain vers la stabilité relative de la connaissance anthropologique.

Car la progression linéaire des données du travail de terrain ne signifie rien en soi, puisque ce n'est pas tellement la nature ou l'essence des données qui comptent mais l'intelligibilité d'une configuration globale, acquise après qu'un regard rétrospectif puisse mettre des expériences hétérogènes en relations. Seulement une telle architecture mentale qui met de l'ordre dans les expériences et refigure le passé peut reconstituer l'intimité perdue de l'expérience passée, indiquant une voie pour s'écarter de l'impasse impossible à atteindre « la vérité » d'une société ou «l'essence » d'une culture. Il s'agit de trouver un ordre intelligible 
par l'organisation différentielle des catégories empiriques. Il s'agit de cette intelligibilité ajustée au niveau de l'observation et de l'imagination, qui repose sur l'organisation et l'exploitation spéculatives du monde. Il s'agit ainsi de jouer le jeu de cette science que Lévi-Strauss nous a enseignée, qui met de l'ordre au monde et appréhende la réalité au niveau où les attributs des choses apparaissent comme propriétés logiques.

Pour illustrer, il suffit de mentionner un exemple que j'ai eu l'occasion d'explorer lors de mes enquêtes auprès des personnels des professions médicales en Italie. Les femmes immigrées albanaises en couches sont réputées être plus « hystériques » dans l'expression de leur douleur par rapport aux autres femmes appartenant à d'autres groupes immigrés, alors que leurs compagnons sont particulièrement agressifs envers le personnel médical en exigeant le soulagement des douleurs de leurs compagnes moyennant des sommes d'argent. Certes, il n'y a pas ici à démêler des manipulations occultées par des stéréotypes éventuels. Mais toutes les « missions de recherche sur le terrain » qu'on voudra, au moins telles qu'elles sont communément conçues, n'iront jamais au-delà de cette simple constatation de fait. Pour comprendre cela il sera à nouveau nécessaire d'être muni de cette expérience subjective des réalités socioculturelles et historiques qui seule pourra permettre de dépasser un certain empirisme encore présent dans les études sociologiques et politiques.

Clairement, dans l'ensemble de mes travaux j'adhère à cet argument essentiel qu'il s'agit d'une erreur si on s'intéresse à un phénomène ethnographique exclusivement dans le sens d'une investigation empirique, alors que ce qui est vraiment nécessaire pour son explication est sa construction imaginée comme objet d'investigation analytique. En effet, il y a déjà beaucoup d'anthropologues contemporains qui croient que le recours malinowskien à l'évidence empirique comme critère ultime de la connaissance anthropologique est mal orienté (e.g. Willerslev 2011). Car pour certains phénomènes dont s'occupent les anthropologues la compréhension se situe au-delà de l'évidence empirique seule. Plusieurs faits ethnographiques sont essentiellement des phénomènes métaphysiques et non pas empiriques. Pour les comprendre il ne suffit pas uniquement de bien pratiquer le travail de terrain réel et matériel, mais il faudra avant tout une puissance d'imagination spéculative du chercheur.

Plus que toute autre chose cette approche trouve son écho chez LéviStrauss dont le style d'investigation anthropologique s'est fait marquer par une interrogation délibérément spéculative de l'ethnographie dans un processus où la pensée abstraite donne force et signification aux observations ethnographiques. Vraisemblablement, cette construction 
épistémologique aura pour conséquence de faire ressortir des idées novatrices résultant de l'expérience vécue. Ainsi, la description des faits ethnographiques sera améliorée dans leur rapport aux mondes réels et historiquement fondés de la vie sociale, de sorte que l'approche puisse déboucher vers un compte-rendu plus détaillée des spécificités de la pratique et de l'idéologie culturelles dans la vie quotidienne. Idéalement, la méthode analytique qui émerge de l'ethnographie et de l'expérience subjective du travail de terrain, comme du contenu spécifique des faits, produit un savoir qui est à la fois riche et informé par la diversité des manières dont les individus pensent, sentent, fonctionnent et jouent leur part dans la vie. En même temps il s'agit d'une disposition complémentaire d'explorer le rôle des modèles culturels sur les similitudes et les différences comportementales de groupe. Cette nouvelle façon d'aborder l'évidence empirique disponible est potentiellement propice à expliquer comment les similitudes et les différences de pensée et de comportement social et culturel sont formées et maintenues dans différentes populations et comment elles sont souvent soutenues par les différences dans la distribution, l'organisation et le poids ou la saillance de la variation idiosyncratique des modèles et des valeurs culturelles.

Dans ce sillage et au meilleur de ma connaissance expérientielle, à quoi sauf indication contraire référence est faite dans l'ensemble de mes travaux, toute autre évidence disponible est placée, autant que possible, dans son contexte géographique, historique, ethnographique, économique, social, politique, idéologique et religieux. Certes, je me rends clairement compte de la difficulté d'utiliser simultanément des approches distinctes. Je crois pourtant que la tentative de les articuler l'une par rapport à l'autre peut mener à un problème intellectuel fascinant. Les aspects conceptuels de cette situation montrent non seulement comment traiter n'importe quel problème de structure sociale existante mais peuvent également avoir des implications théoriques et méthodologiques importantes au-delà des problèmes spécifiques adressés. Ils suggèrent qu'il est important de ne pas compter sur les observations superficielles des données de l'ethnographie seule. Plutôt, l'analyse critique de l'évidence empirique et les intersections de l'ethnographie avec aussi bien la compréhension expérientielle que la collecte systématique de données peuvent faire déduire de nouvelles significations dans l'espace des compréhensions idiographiques et nomothétiques de la culture, de l'esprit et du comportement.

\section{Profondeur historique et approche comparative}

L'étude de la continuité structurelle et du changement processuel dans la dialectique du long et du court terme nécessite aussi la prise en considération d'explications historiques et sociologiques. La reconnais- 
sance de la dimension diachronique est si importante que toute étude des relations sociales et toute recherche des significations culturelles nécessitent d'être complétées par la description du changement historique (Comaroff \& Comaroff 1992). Cela invalide en même temps la perspective d'une «culture primordiale» isolée, puisque le passé se présente finalement comme un pays étranger. L'étude anthropologique de terrain se voit ainsi compléter par le répertoire des méthodes développées dans la recherche historique. La nécessité d'une perspective diachronique a été reconnue à peu près universellement en réaction contre l'école de Malinowski et son accent sur le "présent ethnographique ». L'histoire orale et les méthodes historiques et linguistiques sont utilisées avec succès pour redécouvrir le passé. Aussi beaucoup de progrès sont faits dans les années récentes dans l'étude et la reconstruction des cultures populaires et des sociétés anciennes de l'Europe moderne, grâce à l'utilisation des sources d'archives aussi bien que des divers textes produits au cours des siècles par les voyageurs et les missionnaires. Au moyen d'une juxtaposition textuelle appropriée il est devenu possible de générer des considérations et des hypothèses qui sont ensuite testées en utilisant les méthodes de terrain.

L'examen critique de l'histoire intellectuelle et des revendications récentes de renouvellement des perspectives anthropologiques en histoire nécessitent une intention particulière, d'une part, sur l'examen des multiples utilisations et des compréhensions de l'histoire et de l'ethnographie en tant que sources documentaires et cadres conceptuels dans la littérature anthropologique et, d'autre part, sur l'évaluation de la logique et des méthodes utilisées pour incorporer documents historiques et données ethnographiques. Une anthropologie de l'histoire suggère que l'anthropologie historique est un mode d'enquête qui vise à construire des ponts et à établir le dialogue entre différents points de vue, moyens analytiques et échelles spatio-temporelles. Le point de vue que je défends suppose que l'histoire est «obtenue» par la médiation de systèmes symboliques qui ont leur propre logique ou structure interne, c'est-à-dire par un ordre culturel profond qui est à la fois structurant et structuré par l'histoire. Ainsi, l'approche historique exige un engagement envers la recherche et l'interprétation à la fois holistique et profondément contextuelle, ce qui exige une concentration sur des variations à travers l'espace-temps dans des séquences socio-historiques spécifiques. La méthode historique telle que je l'ai appliquée dans mes travaux se concentre sur la façon dont des principes symboliques et structuraux abstraits sont exprimés en stratégies sociales concrètes, dans des cas socio-historiques spécifiques et dans la façon dont ceux-ci changent à travers le temps, par exemple par rapport à l'intersection des identités locales et de leurs contenus culturels. 
Effectivement, mon intérêt pour les analyses inspirées de l'anthropologie historique s'est exprimé assez tôt, depuis mes premiers travaux publiés en Albanie sur l'influence des réalités albanaises envers les manifestations culturelles médiévales en Europe (Doja 1984), aussi bien que sur le rôle des légendes de tradition historique et mythologique ou des fables de tradition orale dans la socialisation historique (Doja 1989). La référence aux origines est importante parce que la façon dont une institution vient à l'existence peut exercer une forte influence sur son fonctionnement ultérieur. Ainsi, dans un grand nombre de travaux, les analyses d'histoire sémantique du vocabulaire des institutions m'ont permis d'appréhender la signification de la dynamique et de la morphologie structurelle des relations et des interactions sociales.

Dans une série de travaux portant sur la morphologie du système de nomination dans ses rapports avec la structure sociale (Doja 1997c, 1998c, 2005b, 2006g), j'ai montré comment dans la tradition albanaise, le nom renvoie à la fois à la lignée généalogique, familiale et parentale, ainsi qu'à une appartenance territoriale. Si le prénom individuel se transmet surtout dans la lignée paternelle, la transmission s'effectue en général de façon alternée, faisant appel aux ancêtres maternels aussi. Le système de nomination albanais fait appel à trois éléments : le prénom individuel, le nom individuel du père et un troisième nom (le nom de famille) à référence généalogique ou territoriale. L'anthroponymie albanaise se révèle ainsi dans l'origine toponymique des noms. Les noms de personne renseignent sur l'origine géographique de la population, sa stabilité ou sa mobilité. Le nom établit la connexion entre l'espace vécu du groupe et les autres «nous », membres dispersés de la parentèle. Il sous-tend à la fois un champ parental et un champ territorial, aussi bien qu'il définit les inscriptions du mariage et les modalités de l'affinité.

Utilisant les mêmes méthodes d'analyse historique et sémantique du vocabulaire des institutions, j'ai montré comment dans la société albanaise les valeurs idéologiques et les pratiques symboliques de l'amitié, de l'alliance et de la parenté s'organisent dans un système de relations ambivalentes et d'interactions opposées, complémentaires et interchangeables (Doja 1999b). Notamment, si l'amitié entretient une relation parallèle avec l'alliance et le mariage, cette relation privilégiée est exprimée aussi bien dans les termes du vocabulaire que dans les relations institutionnelles. Du même coup j'ai découvert que les valeurs sociales de cette construction idéologique sont placées sous le signe de l'ambivalence. Alliance et vengeance, amitié et hostilité ne sont que différentes expressions, linguistiques et sociales, de la même relation structurelle. 
Dans un projet similaire, j'ai exploré plus spécialement l'intérêt de procéder à des analyses d'histoire sémantique des termes du vocabulaire des institutions qui servent à exprimer les notions de religion et de croyance (Doja 2000b), plus spécialement liées aux pratiques d'honneur et d'alliance dans la structure sociale (Doja 2011). À travers cette analyse j'ai notamment entrepris une approche linguistique et anthropologique croisée qui peut s'avérer cruciale pour comprendre les valeurs sociales de la morale et de la religion.

J'ai eu aussi l'occasion d'aborder les questions de méthode en anthropologie par une critique du cadre comparatif de la description des stratégies religieuses des Bektachis au Kosovo (Duijzings 2000) ou des interactions discursives du processus d'apprentissage spirituel chez les Bektachis albanais (Trix 1993), pour voir dans quelle mesure l'analyse de discours et l'ethnographie sont capables de saisir et d'exprimer le contenu culturel pour écrire et dire l'histoire ou la culture (Doja 2004b). Cependant, au-delà d'une simple question de méthodologie, il semble important par la même occasion, comme j'ai examiné ailleurs (Doja 2003, 2006d, 2006e, 2006f), de cerner de façon plus profonde les tribulations dans l'histoire du Bektachisme, pour mieux appréhender sa nature comme un ordre mystique et hétérodoxe à l'intérieur de l'islam, ainsi que sa structure religieuse comme un système idéologique et culturel.

Si on s'accorde sur l'importance des sources historiques et démographiques, les anthropologues sociaux ont plutôt tendance à se détourner de l'utilisation des enquêtes et des statistiques. Les soucis que les données quantitatives sont trop minces, trop décontextualisées aussi, ou trop politiquement suspectes, ont tous contribué au déclin des données d'enquête en anthropologie, d'ailleurs parfois avec bonne raison. Les tests statistiques sont d'une utilité plus restreinte, surtout par rapport aux difficultés de comparaisons interculturelles, ne serait-ce que pour un nombre limité de cas d'une complexité interne très élevé, au point que certains anthropologues sont devenus tellement sensibles à pareilles complications qu'ils ont développé une aversion excessive envers les statistiques et l'idée d'utiliser des méthodes équivalentes dans le travail de terrain. Les généralisations et la formation des théories progressent plutôt en recherchant soigneusement des modèles d'interprétation, que par l'application des tests statistiques.

Cependant, certaines questions sont mieux adressées par une quantification. Mon intention n'est ni de me détourner de la recherche culturelle rapprochée des gens ordinaires situées dans un lieu et un temps spécifiques, ni d'être indifférent aux ambitions et aux limitations de la démographie. Au contraire, ces données contiennent non seulement une information riche et géo-référencée sur les dépenses de revenu et de 
consommation, sur le fond et les caractéristiques d'éducation, d'emploi, d'histoire résidentielle, de migration et d'exposition aux médias, mais également des informations complètes sur les histoires rétrospectives de reproduction, les préférences de fertilité, la connaissance et l'utilisation des méthodes de planification familiale, le mariage et l'activité sexuelle, le nourrissage au sein et les autres pratiques d'alimentation infantile pour toutes les femmes dans le ménage, aussi bien que des informations sur la mortalité des enfants. Comme j'ai démontré récemment (Doja $2010 \mathrm{~b}$ ), tout cela permet d'obtenir une image plus complète pour l'analyse du comportement de fertilité en Albanie, qui permettra à son tour d'évaluer de façon critique l'activisme culturel et l'idéologie culturelle sous-jacente au mythe de beaucoup d'enfants et des familles nombreuses chez les Albanais, tel qu'il est donné par les observations superficielles de l'ethnographie des travaux de terrain ou l'utilisation sélective des données historiques et démographiques dans les approches documentaires.

Au-delà des exigences du travail de terrain et de l'expérience ethnographique ou de la considération des sources historiques et démographiques, la recherche anthropologique systématique requiert aussi une approche largement comparative. Car voir simplement comment plusieurs concepts des valeurs culturelles peuvent diverger n'est pas satisfaisant. La description locale nécessite d'être abordée par une analyse comparative, qui seule permet de produire des généralisations théoriques fondées sur des données ethnographiques et historiques issues du terrain de recherche.

Les démarches comparatives ont d'abord impliqué la perspective historique en anthropologie sociale. James Frazer, un des pères fondateurs de la discipline au XIX ${ }^{\mathrm{e}}$ siècle en Angleterre, travaillait sans doute de façon comparative, même si son évolutionnisme de salon et son scénario historique spéculatif furent plus tard décisivement rejetés. Néanmoins, avec le transfert vers le fonctionnalisme synchronique basé sur la recherche de terrain, les comparaisons supra-ethniques sont devenues de plus en plus problématiques. Malgré les déclarations de RadcliffeBrown en marge de Malinowski pour utiliser les méthodes comparatives et les constructions de modèles à la manière des sciences naturelles, comme l'a affirmé Edmund Leach (1976/2000), le travail comparatif de l'école structural-fonctionnaliste britannique n'a produit que de très modestes résultats, malgré la grande qualité de plusieurs monographies. Plusieurs anthropologues ont mené des études de cas toujours plus détaillées, sans s'efforcer sérieusement de mieux affiner les méthodes de comparaison.

Le diffusionnisme allemand et autrichien ainsi que ses prolongements américains étaient aussi basés sur la comparaison culturelle. Mais 
ils sont aujourd'hui aussi dépassés que l'évolutionnisme unilinéaire du $\mathrm{XIX}^{\mathrm{e}}$ siècle. Les facteurs politiques et les changements dans les modes intellectuelles ont joué ici un rôle important. La plupart des questions intéressantes ouvertes dans ces lignes de recherche, en l'occurrence celles concernant les conditions d'acceptation ou de rejet des éléments culturels externes, sont délaissées sans réponses conclusives. Le relativisme culturel, devenu particulièrement prégnant aux États-Unis, décrivait plutôt les valeurs de chaque culture identifiable comme ayant une nature essentielle qui demeure inchangée et incommensurable. Pareils propos se rapprochent facilement des sentiments affichés par les apologistes des différents mouvements ethniques et nationalistes qui évoquent des entités dont les éléments culturels immuables sont fortement différenciés.

Du point de vue actuel, certains des efforts d'anciens chercheurs pour fonder une «science naturelle de la société » semblent être dévalués par des faiblesses manifestes. Bien que les analyses statistiques des matériaux ethnographiques collectés selon des critères disparates aient eu quelque succès - comme l'Atlas ethnographique de Murdock (1981), - elles ont aussi rencontré des critiques bien légitimes. Sélectionner le matériau et décider de son allocation requiert déjà des catégorisations, qui semblent arbitrairement s'imposer dans chaque cas individuel, caricaturées parfois comme "compartiments» ou "départements». L'économie, la religion ou la parenté ne sont pas distinguées de la même manière dans tous les lieux. Afin d'atteindre des dimensions comparatives couvrant toute la richesse des spécificités culturelles, des abstractions sont exigées là où les résultats semblent souvent se réduire à des lieux communs.

La construction théorique basée sur la comparaison contrôlée et sur la connaissance cumulative est pourtant possible en anthropologie. $\mathrm{La}$ comparaison peut se poursuivre à différents niveaux, au macro-niveau extrême, par exemple entre les sociétés hiérarchiques de la charrue en Eurasie et les sociétés égalitaires basées sur les technologies de bêchage ou de déblayage en Afrique sub-saharienne (Goody 1976, 1990), ou bien dans un cadre régional soigneusement spécifié, comme par exemple l'aire méditerranéenne (Davis 1977) ou les régions bantoues d'Afrique australe (Kuper). Mais on peut aussi envisager des questions plus spécifiques en relation avec les facteurs historiques et les processus de changements dans les systèmes de parenté, à l'instar des études d'anthropologie amérindienne (Spoehr 1947), et les reconstructions identitaires chez différents groupes après leurs déplacements loin de leurs territoires d'origine.

Ainsi, la comparaison est possible au niveau global, mais il est plus utile de se centrer sur des cas où une ou plusieurs variables spécifiées 
diffèrent à l'intérieur d'une région qui offre un degré élevé de correspondances à la fois institutionnelles et culturelles. Notamment, par ce souci de comparatisme, j'ai porté sur les spécificités albanaises ce type de regard anthropologique qui permet l'intégration et la comparaison de matériaux de ce genre recueillis ailleurs dans d'autres cultures. J'ai été ainsi amené à me servir des résultats de l'analyse ethnologique de la culture des sociétés européennes, plus particulièrement française, ainsi que d'un grand nombre de données fournies par la littérature de l'anthropologie africaniste en particulier, mais aussi américaniste et océaniste.

Toutefois, en recourant systématiquement au comparatisme à l'assise des interprétations, je me suis bien gardé d'un autre risque connu, quand la comparaison devient accumulation, revue des faits attestés ou prothèse interprétative déconnectée de la réalité. Dans la plupart des cas retenus, l'analyse est effectuée en partant de rites réels et non de rites types, avec une attention particulière à la diversité des contextes. Le projet anthropologique va au-delà des sphères de l'imagination et de la fiction en se basant sur l'observation dans le long terme au moyen de la participation physique et la compétence linguistique, en tenant compte de la dimension diachronique et des matériaux historiques. À cause des difficultés d'arriver à des dimensions communes de comparaison dans l'investigation de la diversité culturelle globale, il m'a paru opportun dans un premier temps de travailler sur un nombre de cas relativement restreint. Si l'application des tests statistiques dans la validation d'hypothèses explicatives a été ainsi plus difficile, cela m'a protégé contre les généralisations abusives et permis de garder un haut degré de cohérence, retrouvée dans la prise en compte de la réplication des cas que dans la recherche sociale l'on considère comme le meilleur instrument de validation.

Cela ne veut pas dire abandonner la recherche de modèles et de généralisations. Car la preuve positive et les tests ne détruisent jamais une théorie, quelle que soit son degré de généralité. Elles se contentent de la modifier jusqu'au point où elle se voit remplacée par une meilleure théorie. C'est le sens même de la Structure des révolutions scientifiques (Kuhn 1962/2012) qui s'appliquerait plus aisément à une théorie fondée sur les données de terrain que sur une théorie hypothético-déductive. La comparaison se veut une méthode rigoureuse, combinant les analyses inductives et déductives et portant moins sur les faits et les objets que sur leur capacité à donner naissance à des généralisations théoriques. La production théorique ne s'appuie pas nécessairement sur le fait en soi, mais sur la catégorie conceptuelle qu'on extrait de ce fait (Glaser \& Strauss 1967). La propriété conceptuelle d'une catégorie peut être produite à partir d'un fait qui devient alors simplement un élément dans 
un univers de nombreux indicateurs possibles pour le concept et de données pouvant lui être associées. En ce sens, on compare moins des faits ou des résultats que des démarches et des hypothèses d'indicateurs conceptuels de catégorie.

Ainsi, si j'ai exploré un certain nombre de questions liées à la société albanaise, j'ai recouru systématiquement à l'analyse comparative, avec les limitations de validité résultant de théories de « rang moyen » soigneusement spécifiées, dans la mesure où elles concernent les motivations de ceux qui se sentent impliqués et leurs conséquences sociales dans la communauté sociale où ils vivent. Ce faisant, je n'ai pas étudié la spécificité de la culture albanaise comme une culture particulière d'une société particulière. Car l'objectif principal de mes travaux ne saurait être nécessairement de montrer le caractère «albanais » authentique et culturellement spécifique des données que j'ai analysées, ni simplement de montrer une similarité avec les données recueillies ailleurs dans d'autres cultures. Sans doute, j'ai cherché à rendre les données culturelles albanaises intelligibles à la communauté académique internationale, comme c'est le cas avec mon travail sur les structures de l'organisation sociale (Doja 1999a) ou sur les pratiques culturelles de construction de l'identité individuelle, collective et sociale, y compris les pratiques de la transmission des connaissances (Doja 2000a). Or, si dans ce type de travail, la tendance est forte de présenter une compilation de matériaux historiques, ethnographiques et folkloriques puisés chez les érudits locaux ou dans la littérature disponible, je cherche avant tout à exposer les données culturelles albanaises à une analyse critique approfondie, par une approche comparative, afin de produire des généralisations théoriques qui se situent conceptuellement au-delà des intérêts descriptifs et particuliers des spécialistes de la région.

Partant d'un souci d'analyse comparative, quand j'ai exploré par exemple les interactions interculturelles entre les groupes ethniques voisins et leur impact sur la construction identitaire (Doja 1999c) ou la politique de la religion dans l'histoire albanaise (Doja 2000c), j'ai voulu jeter sur les caractéristiques spécifiques de culture albanaise un regard sociologique et anthropologique encore inexploré dans les études albanaises. La production de théorie à partir de l'analyse comparative exige une multitude de cas soigneusement choisis, mais comme Glaser et Strauss ont insisté, il ne s'agit pas de "connaitre tout le terrain » ou de sélectionner tous les faits «à partir d'un soigneux échantillonnage au hasard » (Glaser \& Strauss 1967 : 30). La tâche du sociologue ou de l'anthropologue ne consiste pas à fournir une description complète d'un sujet, mais à développer une théorie qui permette de rendre compte d'une partie importante des comportements considérés. Le sociologue ou l'anthropologue dont l'objectif majeur est de produire de la théorie 
fondée sur les données ethnographiques et historiques de son terrain de recherche n'a pas besoin de connaitre la situation concrète mieux que les acteurs sociaux. Son travail et sa formation le conduisent à faire ce que les gens ordinaires ne peuvent pas faire, c'est-à-dire, produire des catégories générales, assorties de leurs propriétés, capable de rendre compte de situations et de problèmes spécifiques.

Plus concrètement, l'objectif théorique de mes travaux n'est pas de montrer et décrire n'importe quelles spécificités culturelles. À travers l'analyse des données culturelles provenant d'une société particulière, dans mon cas la société albanaise, par opposition à la diversité culturelle et les différences culturelles avec d'autres sociétés n'importe où elles ont pu se situer et n'importe quand elles ont pu exister, je cherche à montrer que la culture albanaise n'est ni occidentale ou orientale, ni européenne ou non européenne, ni africaine, amérindienne ou mélanésienne, mais elle est tout aussi importante que d'autres cultures, sans exception, pour fournir des explications sociologiques et anthropologiques sur l'histoire et la société humaine.

D'une part, les données de la culture albanaise m'ont aidé pour tirer des conclusions originales, par exemple, sur la signification profondément sociale et politique de la nature de la religion (Doja 2000b), sur la relation entre l'idéologie de l'honneur, les valeurs morales-religieuses et l'organisation sociale (Doja 2011), ou sur la discrimination idéologique qui se cache derrière les processus de catégorisation suivant les affiliations religieuses et les assignations sexuées (Doja 2008c). D'autre part, une approche largement comparative entre les hérésies médiévales chrétiennes, les cultes millénaristes indigènes et les «nouveaux » mouvements religieux occidentaux m'a aidé à mieux comprendre le rôle politiquement conservateur de la transmission de la connaissance spirituelle dans l'histoire d'un mouvement religieux tel que le Bektachisme (Doja 2006d, 2006e, 2006f).

Curieusement, mon livre sur les pratiques culturelles de construction de la personne chez les Albanais (Doja 2000a) est toujours rejetée en Albanie simplement parce qu'il soulève des questions largement comparatives. Comme il m'a été rapporté, pour mes anciens collègues albanais, il est inacceptable de laisser entendre que « la culture magnifique de notre peuple albanais semblerait comme africaine » (sic!). C'est peut-être un simple ouï-dire, mais en dépit de mon expérience de l'ennui que la comparaison avec les sociétés africaines a suscité chez mes collègues albanais, c'est précisément le caractère politique de la segmentation lignagère, attestée par Meyer Fortes et Edward EvansPritchard dans les sociétés africaines (Fortes \& Evans-Pritchard 1940/1970 ; Evans-Pritchard 1940/1987, 1951/1990 ; Fortes 1945/1967, 1949/1967), qui m'a suggéré de mieux comprendre qu'il y a aussi une 
dimension politique, en particulier dans l'analyse de la politique lignagère segmentaire dans la société albanaise (Doja 1999a) ou dans l'analyse de la soi-disant moralité albanaise de l'honneur et de l'hospitalité (Doja 1999b).

Si les analyses sociologiques et anthropologiques sont comparatives et cosmopolites par nature, dans la mesure où elles prennent en compte un ensemble aussi varié que possible d'autres cultures différentes, l'objet de l'anthropologie n'est qu'en apparence l'étude des différentes coutumes dans d'autres cultures. Son objectif principal est d'expliquer la multiplicité et la diversité culturelle au moyen des dispositions communes, unifiés et partagés à l'échelle de l'humanité pour produire la culture, les idées, les normes, les institutions et les comportements sociaux. Ce n'est que sur cette base que l'anthropologie pourra devenir valide et significative à expliquer également les singularités culturelles dans une société donnée, y compris la propre société de l'anthropologue, dans mon cas la société albanaise. Dans ce cas, une nouvelle signification peut prendre également mon analyse des dimensions politiques et idéologiques de la production des connaissances et leur utilisation par les chercheurs nationaux et étrangers, comme c'est le cas avec les analyses critiques des études dites «albanologiques" sur la culture et l'histoire albanaise ou la mystification du prétendu caractère patriarcal de la famille albanaise (Doja 2010b) et d'autres questions similaires. ${ }^{1}$

Pour une liste complète des publications et citations, voir :

http://www.researcherid.com/rid/C-1637-2008

http://scholar.google.fr/citations?user=2rvPcj0AAAAJ 


\section{CHAPITRE 3 \\ Champs thématiques}

Les recherches les plus spécifiques exposées ci-après s'inscrivent dans un enchaînement de champs thématiques, qui ont tenté de construire dans le domaine des études albanaises et sud-est européennes une approche socio-anthropologique de la construction culturelle des identités sociales. Si dans ce texte qui reprend la première partie du Mémoire d'Habilitation l'analyse s'est limitée à la culture albanaise, dans la deuxième partie du Mémoire d'Habilitation qui sera reprise à une autre occasion la démarche s'est prolongée en privilégiant l'impact des relations interethniques et de la dynamique culturelle des valeurs sociales.

Dans la perspective de l'anthropologie symbolique du langage, de la culture et de la communication, privilégiant la sémiotique de la culture et l'anthropologie générative, j'ai commencé par étudier les transformations narratives et mythologiques de la tradition orale et littéraire. Dans ce domaine j'ai exploré la logique par laquelle les symboles sont créés, utilisés et manipulés dans la société. J'ai dédié une attention particulière aux systèmes de classification et aux approches structurales de l'esprit, à l'organisation du temps et de l'espace, au symbolisme du corps, de la gestuelle et du langage non verbal, à l'impact des rites, des manières et des pratiques cérémonielles dans le groupe social, aussi bien qu'aux analyses narratives et textuelles de la littérature orale, aux analyses d'histoire sémantique du vocabulaire des institutions, à l'histoire comparée des locutions idiomatiques, etc.

Cet intérêt s'est manifesté depuis mes études universitaires quand, dans le cadre du mémoire de Diplôme d'études supérieures de lettres modernes et de français langue étrangère, obtenu à l'Université de Tirana, j'ai effectué une recherche en sciences du langage et de la communication portant sur l'étude comparée de l'expression des représentations sociales en français et en albanais. Ensuite, dans une étude portant sur l'histoire médiévale de certains monuments de la littérature et de la langue française, concernant notamment les derniers épisodes de la Chanson de Roland et certaines variantes historiques de la locution «bâtir des châteaux en Espagne », j'ai montré l'influence des réalités historiques albanaises sur les manifestations culturelles françaises aux $\mathrm{XI}^{\mathrm{e}}$ et $\mathrm{XII}{ }^{\mathrm{e}}$ siècles (Doja 1984). Avant mon départ de l'Albanie, j'ai aussi publié une série d'articles, en albanais et en français, qui se sont 
inspirés de recherches sur les traditions narratives et d'analyses textuelles des fables et légendes de tradition orale (Doja 1985, 1986a, 1986b, 1989) aussi bien que sur les traditions orales et rituelles des stratégies matrimoniales (Doja 1987, 1988a) et des représentations collectives de la naissance et de la socialisation (Doja 1990a).

Mettant à profit ma première expérience d'enseignement et de recherche en anthropologie de l'art, littérature orale et ethnomusicologie, j'ai poursuivi en France cet intérêt de recherche dans un grand nombre de travaux portant sur les rituels, les cérémonies et les autres pratiques du comportement symbolique (Doja 1993, 1995b, 1997b, 1999d, 2005a, 2005d). J'ai exploré les rituels et cérémonies de mariage, de naissance et autres moments du cycle de vie aussi bien que les récits populaires et autres traditions narratives et discursives dans l'interaction de la culture orale et visuelle avec une fonction essentiellement dramaturgique, à travers laquelle les stratégies sociales sont mises en scène comme une sorte de spectacle expressif.

Ces travaux ont porté entre autres sur les représentations collectives et les modalités d'expression rituelle et ethnolinguistique concernant le comportement symbolique entourant l'allaitement de l'enfant (Doja 1993), le rapport entre les représentations de la fécondité et les rites agraires (Doja 2005a), les attributs essentiels des figures mythologiques du destin dans la tradition albanaise et des autres populations balkaniques et européennes (Doja 2005c). Cet intérêt s'est manifesté dans d'autres travaux portant sur des réflexions théoriques concernant les caractéristiques essentielles et le rôle socialisateur des berceuses de tradition orale (Doja 1997a). L'exploration et l'utilisation de catégories analytiques m'ont permis de rendre compte du développement corporel dans ses rapports avec la transition sociale de l'individu, notamment à travers les cérémonies et les pratiques symboliques relatives à la coupe rituelle des cheveux et à la circoncision (Doja 1999d), aussi bien que d'un certain nombre de théories diffuses sur l'imaginaire du double et de l'incarnation à travers les cérémonies et les pratiques symboliques relatives à l'imposition du nom qui ont révélé non seulement les rapports entre la généalogie de la structure sociale et la structuration du nom de famille (Doja 1997c, 1998c, 2005b, 2006g), mais aussi les représentations du rapport social entre les sexes (Doja 1995b), les valeurs idéologiques et structurelles du système des relations ambivalentes d'amitié et d'alliance (Doja 1999b), le rapport privilégié entre valeurs sociales de la morale et de la religion (Doja 2011), ou encore l'instrumentalisation des frontières entre les catégories religieuses et les métaphores de genre (Doja 2008c). 


\section{Naître et grandir chez les Albanais}

Ma thèse de Doctorat soutenu à l'EHESS en 1993 fut reprise dans une version revue, corrigée et sensiblement modifiée et développée, dans mon ouvrage Naître et grandir chez les Albanais (Doja 2000a), qui a aussi intégré une bonne partie de mes travaux antérieurs portant sur l'analyse anthropologique sociale et culturelle des représentations collectives et des pratiques symboliques relatives à l'enfance dans la société albanaise. L'étude du système des formes d'expression orale et de représentation symbolique est conduite d'un point de vue socioanthropologique et ethnolinguistique éclairant les processus de construction identitaire et de socialisation. L'analyse a débouché sur l'hypothèse que l'ampleur et la diversité des relations et des valeurs sociales, culturelles et identitaires reposent largement sur les processus éducatifs symboliques et non-institutionnalisés.

Le besoin et l'exigence de représenter par une démarche symbolique et d'organiser de façon rituelle le processus naturel de la naissance comme le processus culturel de la socialisation sont inhérents à toutes les sociétés humaines. Elles ont toujours cherché à transmettre l'expérience collective à travers l'ensemble de leurs traditions. Autour de ces événements dont dépend la continuité de la communauté, autour de ces moments importants où l'organisation sociale rencontre l'existence individuelle, toutes les sociétés ont élaboré des représentations collectives et des formes symboliques multiples et variées.

Par une démarche anthropologique coordonnant la documentation empirique à l'interprétation théorique ainsi que l'examen logique à la perspective historique, j'ai voulu contribuer à une appréhension de la valeur culturelle des représentations collectives et des formes d'expression symbolique liées aux traditions de la naissance et de la socialisation dans l'interdépendance de leurs aspects sémantiques, fonctionnels et morphologiques, avec les relations sociales, spirituelles et culturelles auxquelles elles se sont référées. Ce rapport interactif est recherché dans le processus de revalorisation historique et idéologique des valeurs culturelles de l'univers symbolique, moral et artistique de ces traditions et de leurs références dans la vie sociale et les intentions humaines, ainsi que dans l'interaction avec la structure de l'organisation sociale.

La relation systématique des traditions de la naissance et de la socialisation aux autres formes d'activité pratique, dans toutes les facettes de la vie sociale et culturelle, a défini les rôles occupés dans ces traditions par les démarches rituelles et cérémonielles comme par les ouvertures artistiques et esthétiques. Les traditions de la naissance et de la socialisation comme celles des autres moments du cycle de la vie ou de 
l'année, peut-être plus évidemment que dans d'autres cas, font ouvrir un éventail de recherche plus large, marqué par un rapprochement des fonctions éducatives avec les fonctions esthétiques, comme avec les fonctions sociales, morales, psychologiques et idéologiques.

Il n'y a qu'une approche interdisciplinaire qui puisse appréhender ces traditions spéciales, qui concernent pareils moments critiques en développement continuel, comme la naissance et la socialisation. L'anthropologie actuelle nous apprend à considérer les sociétés et les cultures dans leur totalité, comme des systèmes où tout se tient, où toute composante et toute représentation de la conscience sociale ne sont appréhendées et expliquées qu'à partir de l'ensemble dans lequel elles sont incluses. Les représentations collectives et les formes culturelles d'expression symbolique, qui se rapportent à pareils phénomènes comme la naissance et la socialisation, présentent divers aspects, qui peuvent sans doute être traités séparément ou l'un après l'autre, mais qui constituent cependant une réalité unique à plusieurs dimensions. J'ai tenté d'appréhender de façon synthétique dans son ensemble la variété considérable des conceptions et des pratiques, à l'aide desquelles les Albanais ont donné leur code culturel à la filiation biologique, à travers les différents aspects et les étapes successives de tout le processus de la naissance et de la socialisation.

Dans l'étude des traditions culturelles, parallèlement à l'analyse des fonctions et des valeurs morphologiques, j'ai également tenu compte des rapports avec la structure de la société et des relations récurrentes établies entre les individus en communauté. En plus, ces relations sont définies non seulement en considérant les traditions culturelles comme le produit des petits groupes ou des structures élémentaires de l'organisation sociale, mais aussi du point de vue du contenu que la vie sociale a apporté dans les relations de ces groupes et de ces structures en les englobant dans un système plus large, dans le système des relations sociales de la société globale. En reconsidérant ces traditions comme un phénomène social, culturel et institutionnel, il apparaît qu'elles ont un contenu plus complexe provenant de la vie culturelle et des relations sociales de toute la société. Elles représentent différentes relations, définies en grande partie par les rapports économiques et matériels, politiques et juridiques, éthiques et moraux, esthétiques, psychiques, idéologiques, religieux, nationaux, etc.

Ces traditions se distinguent aussi par le fait d'avoir représenté les développements non uniformes des régions et zones culturelles locales, aussi bien que l'évolution des différents aspects des relations sociales constituant la structure globale de l'organisation sociale, culturelle et spirituelle. Dans ce sens, la variété des représentations sociales actualisées dans les traditions de la naissance et de la socialisation se rapporte 
aux différences locales existant entre les régions différentes de l'aire de peuplement albanais, comme aux changements historiques que la société albanaise a dû subir dans ses relations familiales, économiques, sociales et spirituelles (Doja 1998a).

L'accent est mis à la recherche de la construction théorique d'un objet anthropologique englobant les problèmes de socialisation et de personnalisation de l'individu par une démarche élaborée, d'une part, autour d'analyses d'institutions intermédiaires productrices d'identité, comme le groupe familial et parental, et d'autre part, autour d'analyses de différentes formes culturelles et de représentations collectives d'expression symbolique.

Les croyances et les représentations collectives de la personne constituent une communication symbolique, qui régit un comportement symbolique, actualisé dans un ensemble de formes symboliques. Ces formes sont surtout d'expression orale, mais aussi gestuelle et matérielle, sous forme d'objets ou d'objectivations. Elles constituent un système à plusieurs niveaux typologiques, sémantiques et fonctionnels, embrassant différentes dispositions mentales : magique et religieuse, cérémonielle, esthétique, ludique, classificatoire, etc. Il s'agit de tout un appareil symbolique où l'on peut énumérer différents rituels et pratiques magiques ou cérémonielles : fêtes, chants et danses, berceuses, comptines et formulettes, vœux et félicitations, incantations, charmes et exorcismes, devinettes et proverbes, noms et prénoms, ainsi que d'autres formes et pratiques similaires. Elles transposent par la voie de la transmission orale les représentations collectives du processus de la naissance, du développement et de l'éducation.

Je pourrai illustrer cette perspective par mes recherches et mes réflexions théoriques sur les caractéristiques essentielles et le rôle socialisateur des berceuses de tradition orale (Doja 1997a). Les recherches sur le terrain m'ont démontré que la berceuse n'est pas un acte immanquable ni nécessaire. Elle jouit d'une indépendance relative surtout grâce à sa fonction et son caractère circonstanciel. Elle comprend tous les produits musicaux et verbaux qui par leur pratique constante dans un groupe donné remplissent la fonction de l'endormissement de l'enfant. L'enfant l'admet comme un rythme berceur, ses codes étant de nature verbale, musicale et cinétique. L'acte moteur du bercement est reproduit de façon palpable dans l'organisation binaire de la structure tonique et métrique du texte musical et du texte verbal de la berceuse. Elle s'avère donc être en quelque sorte un bercement phonique. Cependant les berceuses constituent aussi des messages entiers visant un contact plus intensif avec l'enfant au moyen du langage. Ce niveau de communication, à travers les formes du monologue actif qui souvent prend les traits d'un dialogue fonctionnel, crée souvent des situations possibles pour 
l'invention et l'élaboration de structures poétiques spéciales. L'enfant commence ainsi à se familiariser avec le monde naturel et culturel, social et symbolique, qui l'entoure. Les figures humaines de son petit théâtre imaginaire deviennent de véritables êtres actifs, au milieu desquels sa place est d'ores et déjà définie. C'est dire que la socialisation et l'éducation de l'enfant ont déjà commencé dès le berceau, d'abord de façon plutôt instinctive, et ensuite de plus en plus consciemment.

Dans l'intention de mieux comprendre ce qu'on pourrait appeler les « intuitions » du savoir populaire, à propos par exemple de la modulation précoce du rapport mère-enfant par l'intermédiaire des comptines et des berceuses, il a fallu aussi que je porte un regard extérieur à certains résultats des recherches interdisciplinaire au carrefour de la psychologie analytique et transculturelle du développement de l'enfant et de l'anthropologie médicale ou la sociologie clinique de la famille. Dans cette perspective, j'ai montré comment chez les Albanais, dont les traditions patriarcales sont souvent faussement assumées (cf. Doja 2010b), l'attitude psychologique de l'entourage à l'égard de la femme enceinte devient caractéristique d'un comportement social différent, particulièrement de la part des femmes plus âgées, qui l'entourent de leur sollicitude (Doja 1993). L'enfant reste encore longtemps après la naissance totalement dépendant de sa mère, alors que l'allaitement prend une importance énorme et s'accompagne de rites qui visent non seulement à protéger l'enfant au sein, mais aussi à rendre compte d'un système éducatif symbolique.

Par une analyse fonctionnelle des traditions de la naissance et de la socialisation j'ai essayé d'appréhender la représentation des formes et des expressions orales et rituelles, verbales et musicales, visuelles et graphiques, gestuelles et dramaturgiques, comme des moyens d'influence organique et symbolique, établissant des liens internes, profonds et interactifs entre l'enfant, la mère et la communauté familiale, parentale et sociale en fonction de la personnalisation et de la socialisation des nouveaux individus. En transposant les croyances, les représentations, les conceptions et les mentalités collectives dans le contexte social et dans l'ambiance psychologique qui attendent et entourent la naissance et le développement des enfants, les formes et les pratiques ont toujours joué l'un des rôles les plus importants dans l'assomption des fonctions culturelles et intégrantes d'ordre psychologique et affectif aussi bien que social et éducatif.

Par ces travaux j'ai montré comment le groupe social organise des rites pour préserver son mode de vie aussi bien que pour s'organiser devant les dangers et les menaces réelles ou fantasmatiques. Pour ceux qui prennent part à la célébration du rite, son importance est à la fois sociale, psychologique et symbolique. Le rite a une fonction expressive 
à travers la mise en scène d'un scénario symbolique qui décode un certain nombre de valeurs clés et d'orientations culturelles. Dans le rite il y a également une fonction créatrice, en ce sens qu'il permet presque la formulation ou la reformulation des modèles de conduite dans la société.

L'étude comparative des formes différentes de représentations sociales a été l'occasion d'explorer les approches fonctionnelles et expressives de traditions culturelles symboliques, rituelles, verbales, musicales, visuelles, graphiques et dramaturgiques. L'intérêt de ces travaux, centrés à l'étude culturelle de l'enfance et la notion de personne, la parenté et l'organisation sociale, est notamment de considérer les rituels de cycle de vie comme un site de construction et de négociation des identités et des relations sociales, aussi bien que de démonstration d'une réelle politique culturelle dans les domaines de production rituelle et de socialisation quotidienne.

Effectivement, ce système de formes d'expression symbolique et de pratiques de transmission orale a incarnée la dimension sémantique et fonctionnelle des traditions de la naissance et de la socialisation et a concrétisé les conceptions et les représentations collectives de la reproduction et de la personnalisation de l'individu, le long de tout le processus du cycle de vie, en commençant dès avant la naissance, en passant par l'âge adulte, jusqu'après la mort. C'est ce système de formes symboliques et de représentations collectives qui exerce une action efficace en vue de l'établissement des premiers schémas interactifs et du développement des premières expériences structurantes de l'individu par rapport à ses rôles et à ses statuts ultérieurs.

\section{Techniques du corps et pratiques d'éducation}

Dans ces travaux j'ai montré que les formes et les pratiques d'expression symbolique sont incorporées dans de nombreuses expériences sociales primaires des enfants, à l'intérieur de ce que Vygotsky appelait «zone du développement proximal» d'un enfant (Rogoff \& Wertsch 1984), même si elle est culturellement variable. Par exemple, dans les sociétés avec des rites de passage très élaborés pour les enfants, cette zone du développement proximal peut être décisivement décalée à différentes étapes de la vie. Dans les sociétés européennes l'équivalent de cette zone se limite d'abord à un espace domestique défini par les parents et d'autres personnes qui s'occupent primairement des enfants. Dans ce cas, contrairement au mode d'interaction «proximale », ce qui caractérise le type de communication instaurée autour des enfants est plutôt un mode de communication que j'ai considérée plutôt comme étant plus «distale». Dans tous les cas, quand les psychologues prennent en compte les différences interculturelles dans la transmission des 
savoirs et de la connaissance (Shweder \& Bourne 1984), ils considèrent que beaucoup de ce qui se passe pour une recherche clinique sur la personnalité ne concerne réellement que les constructions culturelles de la notion de personne. Mon analyse des traditions albanaises montre aussi que le développement social des enfants se passe effectivement sous les contraintes serrées des pratiques de succession d'âges, de socialisation et d'éducation non-institutionnalisée (Doja 2000a).

Cependant, les représentations collectives sont intériorisées, non pas par un processus de transmission des savoirs et de la connaissance qui impliquerait un transfert direct d'un modèle narratif aux enfants mais par la traduction des récits dans des ordres d'expériences cinesthésiques et des performances corporelles. Les pratiques symboliques ne racontent pas tellement un modèle de création des savoirs et de la connaissance mais rendent possible un processus culturellement motivé de transformation des savoirs et de la connaissance. De cette façon, la traduction des institutions culturelles dans des expériences personnelles implique l'incorporation et la transformation des significations primaires de l'expérience de la part des enfants qui subissent une transformation progressive de l'expérience d'eux-mêmes à travers des pratiques d'éducation organisée et ritualisée.

Cette approche, comme celle du travail de Christina Toren dans l'ethnographie fidjienne (1999) qui parallèle à plusieurs égards mon travail dans l'ethnographie albanaise, nous permet de comprendre comment ce processus se produit sans recours aux concepts de société ou de culture comme entités transhistoriques. Ainsi, tandis que les enfants entrent dans un monde qui leur est donné, ils doivent nécessairement se faire une idée de ce monde pour eux-mêmes pour ensuite s'en faire une idée par rapport aux idées que d'autres en font. Effectivement, un enfant qui grandit dans un village albanais viendra nécessairement à se faire une idée du monde d'une façon qui sera en quelque sorte reconnaissable comme albanaise, en raison d'interactions denses avec d'autres villageois albanais.

Néanmoins, deux remarques s'imposent. D'abord, du fait que les enfants se font nécessairement une idée du monde par leurs propres expériences uniques, rien ne garantit qu'ils se font tous la même idée exactement de la même manière. Ensuite, le fait que tous les enfants dans le village albanais se font une idée du monde selon des manières qui sont manifestement des versions de l'une l'autre ne signifie pas pour autant que nous devons poser a priori une société ou une culture commune dans lesquelles ils ont été tous « enculturés » ou " socialisés ». Au lieu de cela, nous pouvons considérer ces commensalités comme le fondement des vies sociales spécifiques auxquelles les enfants s'engagent, 
c'est-à-dire comme l'effet de la façon dont ces enfants, à mesure qu'ils grandissent, sont venus avec le temps à se constituer eux-mêmes.

Ce sont notamment ces façons de se faire une idée du monde dans lequel on vit qui constituent cette éducation que j'ai appelée symbolique et non-institutionnalisée. Cependant, ces formes et pratiques éducatives implicites restent nécessairement complémentaires aux formes et pratiques modernes de l'éducation institutionnalisée, ainsi qu'aux résultats éducationnels de toute la culture moderne qui, de même que l'éducation familiale contemporaine, agissent plutôt comme des moyens d'influences réfléchies et directes, pratiques et concrètes. En effet, si les sciences de l'éducation sont bien plurielles, étudiant à la fois les phénomènes macro-éducatifs et les phénomènes micro-éducatifs, ainsi que les méthodes de l'éducation et les mécanismes de transmission des savoirs, alors elles doivent nécessairement inclure également les formes symboliques et les pratiques éducatives non-institutionnalisées, comme un autre facteur de richesse et de dynamisme à la fois pratique et théorique.

À ce propos, il est utile de rappeler les simplifications conventionnelles des relations de genre, telles qu'elles sont exemplifiées dans la mise en pratique des dichotomies traditionnelles des domaines public et privé. Une conséquence de ces dichotomies a été la négligence de ces activités liées à la sphère privée, qui inclut l'apprentissage culturel et la transmission des savoirs et de la connaissance, de même que la formation identitaire des individus et du groupe ou la construction culturelle de la personne et la reproduction sociale. En imposant les contraintes des pratiques de socialisation et d'apprentissage culturel des enfants, ainsi que des règles de mariage et de transmission de propriété, la société contrôle la reproduction des prétentions d'appartenance. Cependant, les premiers agents de cette éducation non-institutionnalisée sont les femmes, puisqu'elles sont les socialisateurs primaires des enfants. Elles sont en grande partie responsables d'inculquer les croyances, les comportements et les fidélités culturellement appropriées pour assurer la continuité entre les générations. Leur rôle inclut l'apprentissage de la langue «maternelle », les symboles, les rites, les divisions du travail et les conceptions du monde du groupe, qui contribuent à l'entretien des rapports sociaux et à la satisfaction des besoins de base dont finalement dépend la continuité des mondes culturels.

Quand nous négligeons ces processus d'éducation et de reproduction socioculturelle, nous tombons facilement dans la réification de nos constructions au lieu de les comprendre dans leur contexte historique. Mais si on explore les moyens par lesquels les enfants sont culturellement élevés dans une notion d'appartenir à un groupe parental ou territorial, ou mieux à ces collectivités plus larges telles que les groupes ethniques et les États-nations balkaniques (Karakasidou 1997), les 
femmes semblent avoir un rôle actif et vocal dans de tels processus, un rôle qui est généralement plus subtile que celui des hommes et peut-être plus significatif aussi. La contribution sensible et continue des femmes dans leur rôle de prendre soin des enfants, où l'on s'attend à ce qu'elles participent à ces processus éducatifs qui socialisent les enfants selon les lignes garantissant les futurs intérêts du groupe social, a fait d'elles les principaux médiateurs et interprètes culturels des pratiques éducatives et des idéologies de groupe. Dans un sens, les femmes sont arrivées à agir en tant que médiateurs entre le groupe et la famille, négociant l'interaction et l'échange entre les domaines prétendus public et privé (Ortner 1974). Par leur influence de médiation, même les processus potentiellement disruptifs de l'apprentissage culturel sont tempérés par des processus plus modérés de changement culturel et de transformation identitaire.

Dans cette perspective, prolongeant mes travaux sur l'enfance et les pratiques éducatives non-institutionnalisée, la contribution originale d'une socio-anthropologie de l'enfance et de l'éducation est ici favorable à un changement de regard et un renouvellement des approches, au-delà de l'étude historique de la constitution des différentes pratiques de l'enfant et de l'histoire des idées et des représentations concernant l'enfance et son éducation. Si on veut saisir les politiques d'institution et les pratiques d'acteurs dans leurs cadres sociaux et dans leurs ancrages culturels, tout en interrogeant l'éducation comme instance majeure de structuration symbolique de l'humain et du social, alors les méthodes d'analyse privilégiées passeront par une approche socio-anthropologique qui permet notamment de penser les enfants dans leur altérité et de considérer que les cultures enfantines et le rôle social des enfants, aussi bien que les pratiques d'acteurs et les politiques d'institution éducative sont enracinés à la notion d'agence. Il est évident alors qu'il faudra reconnaître l'enfant comme un sujet actif et créatif, qui s'approprie l'héritage culturel et les savoirs collectifs reçus dans l'environnement socioculturel et qui s'initie aussi par la promotion de ses droits et l'évolution de son statut. Ce faisant, cette nouvelle approche socioanthropologique devra rompre avec les perceptions classiques de la construction sociale et symbolique de l'enfance qui associaient les rites de passage aux discours des adultes sur les enfants, comme des adultes en devenir et bénéficiaires passifs de l'éducation.

L'action sociale éducative et l'agence humaine motivée se produisent dans le contexte du rapport des enfants comme individus à de plus larges collectivités sociales et politiques, comme l'école et la famille. Afin de comprendre la teneur et la signification de ces deux domaines croisés, il faudra non seulement questionner les rapports entre la construction sociale et symbolique de l'enfance et la construction de l'enfant 
comme acteur, mais aussi considérer la manière dont les enfants sont incorporés à ces collectivités, à la fois matériellement et symboliquement. Notamment, ma réflexion se poursuit sur la construction sociale et symbolique de l'enfance ne se référant pas simplement à la reproduction des modèles sociaux mais également envisagée comme une construction propre aux enfants, c'est-à-dire explorer comment l'enfant se donne à voir et comment il se construit lui-même, quelle est sa place dans la société et comment sa voix est prise en considération. Cette approche met nécessairement en valeur l'implication concrète de l'enfant et sa contribution à la transformation du procès de socialisation, amenant ainsi à repenser la manière dont nous concevons le processus éducatif. L'intention affichée est, bien entendu, d'approfondir la connaissance des mondes de l'enfance et de la vie quotidienne ordinaire et extraordinaire des enfants, pour relier ensuite cette connaissance aux autres dimensions de la vie sociale et culturelle, afin de promouvoir finalement une meilleure compréhension de la société, de la communauté ou du groupe social et culturel à qui appartiennent les enfants.

Pour ce faire, il me semble opportun de mettre à profit l'approche socio-anthropologique de la dynamique des valeurs interculturelles, afin d'explorer spécifiquement une série de problématiques dans différents contextes, tels que ruptures familiales et communautaires, migration et familles transnationales, conflits et relations interethniques, actions et interventions humanitaires, politiques publiques d'éducation et de planification familiale, mondes virtuels de technologies nouvelles de reproduction et de communication, ainsi que les formes nouvelles de parenté et de soins (individuelle, familiale, institutionnelle), de relations intergénérationnelles et de transmission culturelle (entre semblables, à l'intérieur des familles, par les institutions séculaires ou religieuses). Pour explorer ces configurations et pouvoir inférer la dimension cognitive du monde de l'enfant, c'est-à-dire comment l'enfant conceptualise son monde ordinaire, les points d'ancrage privilégiés sont le corps, le genre, la santé, le langage et les jeux des enfants migrants et réfugiés ou dans d'autres situations de désaffiliation familiale, de globalisation des valeurs et d'ethnicisation des rapports sociaux.

En fin de compte, les caractéristiques conceptuelles d'une socioanthropologie de l'enfance et de l'éducation font apparaitre l'utilité heuristique des notions utilisées et, finalement, les influences réciproques et les synergies entre anthropologie sociale et sciences de l'éducation. Ainsi, la théorisation des pratiques éducatives et la connaissance de l'enfant sont liées à la fois aux représentations sociales de l'enfance et aux apprentissages humains et la transmission des savoirs en société, saisis dans leurs variations culturelles dans le temps et dans 
l'espace aussi bien que dans leurs relations avec la culture prise au sens anthropologique général.

L'étude à l'intérieur d'une société particulière de la mise en relation de la théorie identitaire et de la théorie sociale, telle qu'elle est affirmée au moins dans les représentations et les pratiques éducatives, de même que l'analyse des effets de cette mise en relation sur la hiérarchisation de la vie sociale et l'intégration de la vie individuelle, demeurent toujours insuffisantes. Il faudrait nécessairement prendre en compte le plus grand nombre de sociétés possibles pour rendre manifestes les structures anthropologiques d'intégration et de reproduction du jeu idéologique dans son ensemble. L'étude du fonctionnement général de l'ensemble des processus éducatifs et de transmission des savoirs et de la connaissance exigerait, dans cette perspective, une connaissance plus approfondie de tous les aspects fondamentaux de caractère sémantique, fonctionnel et morphologique des différentes formes et pratiques d'éducation et de représentation. Pour connaître plus profondément le processus de fonctionnement de l'éducation non-institutionnalisée, en plus des représentations collectives actualisées dans les différentes formes symboliques, dont le nombre ne sera jamais fini, il est nécessaire que le champ de la recherche soit élargi sur d'autres terrains d'investigation, notamment en ce qui concerne les rapports de ces traditions avec la structure de la société comme avec le système des formes modernes de l'éducation institutionnalisée. C'est aussi, en fin de compte, d'une révision des perspectives anthropologiques qu'il s'agit, révision qui passerait par le refus d'envisager indépendamment infrastructure et superstructure, héritage et hérédité, tradition et innovation, société et individu, ou encore éducation institutionnalisée et non institutionnalisée, phénomènes macro-éducatifs et micro-éducatifs, méthodes d'éducation et mécanismes de transmission des savoirs et de la connaissance.

\section{Les notions de personne et d'identité}

La personne, la famille, les systèmes de parenté, d'hérédité et d'héritage, ont toujours été des thèmes cruciaux de l'anthropologie sociale. Centrée sur la problématique de la construction sociale et la gestion individuelle des identités, l'analyse de ces notions concerne nécessairement les principales représentations et conceptualisations historiques qui analysent à un moment donné le statut et la formation de l'appartenance territoriale et des modes d'enracinement collectif, social et culturel. Les formes et les procédures culturellement instituées pour situer l'individu dans une catégorie d'appartenance et le singulariser, la notion de personne avec l'ensemble de ses composantes essentielles de caractère corporel, affectif, symbolique, culturel et social, ainsi que d'autres processus et déterminants culturels et sociaux, sont autant de 
mécanismes qui produisent et mettent en tension l'individu et la configuration sociale de son groupe avec d'autres. Tout cela permet de préciser comment l'individu se pose face aux autres et à lui-même, face à son propre groupe culturel et social ou à d'autres groupes, quelle image il entend ou est censé présenter et préserver aux regards d'autrui et à ses propres yeux.

Mon effort d'analyse s'est inscrit en rupture avec les études ethnographiques qui jusqu'à présent n'ont envisagé les processus de construction de la personne et de socialisation que dans des optiques particulières ou culturellement spécifiques aboutissant à la construction d'objets partiels qui mutilent l'ensemble des représentations collectives. Parlant des théories locales de la transmission et de l'hérédité, Marc Augé et Françoise Héritier (1982) ont déjà regretté que les études sur la notion de personne notamment, fréquemment rapportée aux grands mythes cosmogoniques, ont visé davantage une vision de l'univers qu'une idée de l'homme. De même, les études sur les croyances religieuses sont opérées dans une optique qui n'envisage que partiellement la relation à autrui, parfois même en représentant cette relation comme inverse des relations réelles. Enfin, les études menées sur le fonctionnement des sociétés laissent fréquemment à part le secteur des représentations, comme si la théorie et la pratique de la vie en groupe étaient une chose et les représentations collectives de la personne une autre, radicalement différente de la première. D'un côté on étudie la notion d'hérédité, de l'autre celles d'héritage et de succession, comme on étudie d'un côté la notion de personne et de l'autre celle de parenté et de groupe social. On aboutit ainsi à des visions parcellisées et mutilantes du jeu social dans son ensemble et de l'intégration de l'individu dans le jeu social.

J'ai essayé de montrer qu'il existe dans le domaine albanais et sudest européen, comme dans l'ensemble de la littérature anthropologique, une masse considérable de matériaux bien recueillis touchant aux représentations collectives de l'influence psychique, de l'hérédité biologique, de l'identité, de l'intégration, du développement, de l'éducation, etc. Il m'a paru possible désormais une prise en compte systématique des notions de personnalisation et de socialisation comme objet anthropologique, qui peut très bien aboutir à l'étude systématique du rapport établi par la pensée collective entre représentations symboliques et représentations sociales, entre théorie identitaire et théorie sociale.

En dépit de leur éloignement dans l'espace et de leurs contenus culturels profondément hétérogènes, aucune des sociétés constituant un échantillon fortuit ne semble tenir pour acquise une identité substantielle. Elles la morcellent en une multitude d'éléments dont, pour chaque culture bien qu'en termes différents, la synthèse pose un problème. 
Attribuer à un individu la qualité de personne présuppose l'existence d'un ordre de symboles, d'une logique des représentations taxonomiques et d'un dispositif rituel qui lui assignent une place aussi bien qu'un rôle dans la société et lui assurent une reconnaissance morale et religieuse, sociale et juridique. Toute recherche anthropologique sur la notion de personne conduit à s'interroger non seulement sur les différentes conceptions que les cultures ont élaborées, c'est-à-dire sur les systèmes de pensée qui, selon certaines règles logiques et normatives, confèrent à l'être humain une identité sociale, mais aussi sur le statut de personne, c'est-à-dire sur les systèmes institutionnels qui accordent des droits à l'individu et lui prescrivent des devoirs.

La construction de la personne ne cesse jamais qu'à la suite de déterminations intermédiaires et échelonnées agissant à travers un système cohérent de représentations collectives et de formes symboliques. Généralement, elles représentent l'enjeu sémantique et fonctionnel qui concourt à mettre l'individu dans la voie de sa socialisation. Les fonctions sociales et éducatives visent à minimiser les désordres psychologiques, en vue de rendre le processus de socialisation socialement plus efficace.

Les représentations collectives et les croyances se rapportant aux différentes modalités du processus de personnalisation et de socialisation ne peuvent pas être conçues indépendamment de l'élaboration d'un système de croyances et de conceptions conventionnelles sur les modalités de reproduction de l'individu. Par les différents cheminements subtils de la logique symbolique, ces manifestations agencent, d'une manière ou d'une autre, les représentations collectives de la personne, de la constitution corporelle, de la transmission héréditaire et de l'identité sociale. Elles essayent de déterminer en quelque sorte l'hérédité réelle et symbolique, sociale et culturelle, de l'individu au sein de son groupe d'appartenance.

Toutes les sociétés humaines, historiques ou actuelles, ont des manières spécifiques de penser la transmission héréditaire des traits physiques, psychiques ou de comportement des ascendants aux enfants. Elles présentent à ce sujet des ensembles idéologiques structurés. Un grand nombre de sociétés ont élaboré des théories génétiques originales qui ne se contentent pas, généralement, de penser le lien biologique de consanguinité, le phénomène de ressemblance/similitude ou la maladie et la mort, mais renvoient à un modèle d'explication qui rend compte d'une façon globale de l'existence du monde, humain et extrahumain, en justifiant idéologiquement son existence, son organisation et sa reproduction. Elles font de l'individu un être solidaire de la société et du monde où il vit. 
Ainsi, les croyances et les représentations liées aux modalités de reproduction et de développement de l'individu constituent une configuration symbolique où se trouvent réunis, dans une sorte de symbiose, la mère, le monde surnaturel et non-humain et l'enfant à naître. Le thème de l'apparentement du nouveau-né avec le monde extrahumain occupe une place importante dans les représentations collectives de l'enfant qui, dans la société albanaise, comme d'ailleurs dans d'autres sociétés, est souvent considéré comme n'étant pas un être humain à part tout à fait entière, tant que les rituels suivant sa naissance ne l'ont pas intégré définitivement au groupe social. Et cela malgré le fait que certains spécialistes d'ethnologie sud-est européenne ont ignoré ou nié, dans les sociétés balkaniques, l'existence des croyances concernant une éventuelle vie qui précède la naissance ou des croyances concernant la réincarnation (Stahl 1977). Pareilles affirmations, que les spécialistes de la région ont généralement presque toujours avancées, peut-être même un peu trop souvent, sont sûrement fondées plutôt sur un modèle d'interprétation restreint que sur un corpus de documents insuffisant. À travers les croyances, qu'au moins les documents albanais m'ont permis de reconstituer, se dégagent effectivement des liens substantiels que l'enfant est censé entretenir avec le monde d'où il sort, lequel coïncide non seulement avec la longue chaîne des ascendants, mais aussi avec le monde des morts et le monde surnaturel et non-humain en général, actualisées entre autres par la mythologie générative du symbolisme élémentaire des rites de fécondité (Doja 2005a) ou celle des divinités de la terre et du destin (Doja 2005c).

Les documents qui se rapportent aux représentations actualisées dans les cérémonies de l'imposition du nom permettent également de dégager dans la tradition albanaise des éléments évidents d'une conception diffuse de théories comme celle du double ou de la réincarnation (Doja 1999b, 2005b, 2006g). Le nom se transmet généralement de génération en génération, surtout dans la lignée paternelle, du grand-père au petitfils ou à l'arrière-petit-fils. Mais plus que le nom, on cherche à transmettre les différentes connotations symboliques liées aux traits de caractère et à la force vitale des ascendants de la maison, aussi bien qu'aux relations cultivées avec l'ancêtre fondateur de la lignée que, par la réattribution du nom, on croyait faire revivre et réincarner dans le nouveau-né. Les Albanais possèdent ainsi un corps de croyances et de pratiques qui a trait aux rapports d'identité et de substitution entre l'enfant et un ascendant mort ou vivant. On constate cependant que la théorie conventionnelle albanaise de la transmission ne s'intéresse pas de la même manière à tous les individus, privilégiant tantôt l'héritage agnatique, tantôt le rapport entre l'oncle maternel et le neveu utérin. Le principe de la réincarnation d'un ancêtre, ou de son retour, ne se traduit pas non plus dans des spéculations abstraites, mais plutôt dans des 
applications à des événements particuliers ayant lieu à des moments particuliers. Il s'agit moins d'une doctrine que d'une possibilité, voire d'une hypothèse qui prend corps en présence de certains indices relevés chez l'enfant ou bien de certains tours aléatoires que peuvent prendre les rituels.

Tout individu est inscrit à une chaîne donnée de filiation où il occupe une place déterminée. Les critères d'une telle détermination sont en général les conceptions sur les ressemblances et les différences corporelles, les liens de parenté, en lignée paternelle comme en lignée maternelle, les cérémonies célébrant la naissance, tout aussi bien que les marques et les pratiques d'augure, de prévoyance, de divination et de prédestination. À travers ces conceptions se trouvent conjoints les éléments individuels, qui assignent la singularité à l'individu, les éléments hérités, qui marquent son insertion à la chaîne familiale et parentale, les éléments symboliques, qui l'intègrent au monde cosmique, ainsi que les attributs dont la personne s'enrichit et qui assurent son identification sociale en l'exprimant, comme c'est le cas du nom, en particulier. C'est notamment l'ensemble de ces éléments et attributs multiples qui confondent l'individu dans l'espace qui l'entoure et dans le temps où il s'inscrit.

La notion de personne inclut, en plus de l'individu, son environnement social et culturel direct qui donne sens à son existence. Elle est donc définie par les situations, les événements et les puissances sociales actives ayant une fonction intégrante. Elle n'a jamais été une forme rigide et inerte. La personnalisation a toujours inclus les multiples originalités individuelles, ainsi qu'une sorte d'historicité spécifique. Les instances traditionnelles comme les anciens ou les sages ont eu notamment le devoir d'interpréter toute originalité qui pourrait se constituer en événement.

L'identité a été et continue d'être, un des concepts les plus bourdonnants dans les sciences sociales. Qu'on parle de sexe ou de toxicomanie, de conflit ethnique ou de football, de jeux vidéo ou de musées, le terme d'identité doit nécessairement surgir à quelque endroit ou un autre de l'analyse. Notamment, dans certains de mes travaux et mes enseignements sur la construction sociale de l'identité, j'ai tenté de cerner ce que signifie exactement l'identité et si elle constitue vraiment un concept analytique et utile pour les sciences sociales, en abordant les questions d'identité dans deux directions corrélées. D'une part, j'ai exploré les voies dans lesquelles le concept d'identité est généralement utilisé et théorisé en anthropologie et dans les sciences sociales en essayant d'exposer comment les questions d'identité surgissent et sont différemment adressées par rapport à l'appartenance ethnique et l'idée de nation, le genre et la sexualité, les différentes crises et conflits liés à la moderni- 
té. D'autre part j'ai essayé de mettre en doute épistémologique et de critiquer les suppositions implicites dans l'idée d'identité et d'explorer le discours sur l'identité comme quelque chose, qui est en soi un produit de relations sociales et culturelles particulières, y compris dans le monde universitaire.

\section{La morphologie sociale}

À travers les travaux sur la construction de l'identité de la personne chez les Albanais, j'ai eu l'occasion d'étudier en profondeur les structures d'organisation, les représentations collectives et les stratégies individuelles et sociales en analysant les pratiques symboliques et l'identité culturelle des groupes d'appartenance. J'ai mis en œuvre une approche structurelle accompagnée de contextualisations sociales et culturelles, historiques et idéologiques, religieuses ou nationales, dans la corrélation entre valeurs sociales et culturelles. Les descriptions morphologiques et ethnographiques des structures d'organisation sociale, des représentations collectives et des pratiques symboliques, sont poursuivies dans mes travaux par l'élaboration d'hypothèses considérant le jeu de forces opposées et complémentaires dans lequel se réalisent la construction identitaire de même que la production idéologique et immatérielle.

Dans cette optique les forces uniformisatrices du pouvoir dominant sont considérées en relation avec les stratégies d'expression diversifiée des dominés (Doja 1996, 2003), de la même façon que dans les stratégies sociales entre les groupes l'opposition entre relations pacifiques et amicales et relations conflictuelles et hostiles est surmontée à travers l'hypothèse de l'ambivalence des relations d'échange et de réciprocité (Doja 1999b).

Ces travaux m'ont permis d'aborder, d'une part, des questions touchant à la fonction symbolique dans les relations sociales et, d'autre part, de voir comment les représentations collectives de même que la structure sociale se construisent autour d'une duplicité de valeurs antagonistes, manifestant toujours une tendance de polarisation, exprimée aussi bien dans les éléments naturels et dans les cycles vitaux, que dans les événements temporels et dans les inscriptions spatiales, ou encore dans les relations affectives et dans les valeurs sociales, dans les systèmes idéologiques et dans les pratiques de domination.

Pour comprendre la construction des identités sociales et l'interaction des valeurs culturelles, il m'a paru intéressant d'explorer aussi les différents systèmes d'organisation sociale, notamment la coexistence de structures lignagères et parentales, familiales et domestiques. Dans la littérature anthropologique on a souvent mentionné 
l'organisation sociale de type tribal ou lignager, conservé jusqu'au XIX siècle dans une zone vaste du Sud-est européen qui comprend le Monténégro, le Nord de l'Albanie et une grande partie de la Macédoine, où cohabitent des groupes slaves, albanais ou mixtes. Ce type d'organisation pourrait bien avoir déterminé, entre autres, une forme archaïque d'État qui a dû se différencier, durant les $\mathrm{XVIII}^{\mathrm{e}}$ et $\mathrm{XIX}^{\mathrm{e}}$ siècles, au sein des lignages slaves ou slavo-albanais du Monténégro.

En ce qui concerne la structure de l'ordre tribal, il semble y avoir peu de chances qu'elle fût de type communautaire, comme Marx et Engels l'avaient souligné et l'idéologie communiste officielle l'a relayé par la suite. Durkheim (1893/1986) a déjà mis en évidence le trait segmentaire pour les sociétés d'ordre tribal et les études sur le caractère segmentaire des sociétés méditerranéennes nord-africaines ont eu par la suite une certaine influence sur le développement de l'école sociologique durkheimienne. Ces études vont se renouveler après la guerre par les travaux de Jacques Berque (1955/1978) et surtout par le rapprochement qui est fait alors entre ces sociétés et les sociétés lignagères et segmentaires de l'Afrique noire. À l'instar de Evans-Pritchard (1949) qui applique aux Bédouins de la Cyrénaïque les conclusions de ses analyses de la société nuer (Evans-Pritchard 1940/1987), cette approche qui privilégie les phénomènes d'équilibre et d'égalitarisme est codifiée dans les travaux d'Ernest Gellner (1969) et a inspiré nombre d'études sur l'ordre tribal, l'organisation économique, politique ou religieuse. L'utilisation de nouvelles données en provenance des sociétés sud-est européennes d'en face, généralement inaperçues par les études méditerranéennes peut alors renouveler des approches comparables.

Dans cette perspective, à l'instar des travaux de Pierre Bourdieu (1972/2000) ou Raymond Jamous (1981), j'ai eu l'occasion d'accorder une place plus large aux modèles locaux. J'ai montré notamment que dans la société albanaise on peut repérer deux formes de références : une forme typifiante, segmentaire et holiste, représentée par la notion de fisi, lignage, et une forme classifiante, linéaire et individualisatrice, représentée par la notion de lisi i gjakut, " arbre de sang » (Doja 1999a). Catégories linéaires et catégories segmentaires ne s'opposent pas, puisqu'il s'agit toujours de filiation patrilinéaire. Mais contrairement au système segmentaire, les catégories linéaires ne permettent pas de remonter les générations. Si un grand nombre de parents situés collatéralement se reconnaissent appartenir au même arbre de sang, il leur faudra nécessairement un marqueur symbolique héréditaire, qui palliera le défaut de mémoire et/ou de segmentation à partir de l'axe vertical. La fixation du nom patronymique, le nom de famille transmissible, devient alors nécessaire. L'opposition entre système segmentaire et système linéaire 
procède aussi comme une catégorie sociale qui permet l'ouverture transactionnelle dans des relations stratégiques orientées vers l'autre.

Me rapportant à cette problématique, dans mes travaux sur le système des valeurs idéologiques et des relations ambivalentes d'amitié, d'alliance et de parenté, j'ai montré comment l'ouverture et la nécessité de s'ouvrir aux «autres » sont sévèrement contrôlées et hautement codifiées (Doja 1999b). C'est notamment à travers une construction idéologique du système d'amitié qu'on s'ouvre aux autres en même temps que les autres gravitent vers «nous ». Dans la perspective de la conception conventionnelle il faut comprendre l'amitié non pas comme un sentiment affectif de la personnalité individuelle mais comme une relation fonctionnelle de la structure sociale. Cet interstice relationnel entre « nous » et les « autres » se réalise culturellement tout au long des événements sociaux et rencontres codifiées marquant la vie collective et les relations interpersonnelles des cycles de vie.

Le caractère archaïque des villages, presque toujours sous la direction d'une assemblée constituée d'anciens, est probablement déterminé par l'existence de divisions segmentaires propres aux systèmes lignagers, particulièrement accusées dans le Nord de l'Albanie. Mais ce caractère est également redevable au rôle des pasteurs, dont les plus connus sont les Aroumains, les Saracatsanis (de langue grecque) ou les Yuruks (de langue turque), et qui parcourent l'ensemble du Sud-est européen en pratiquant l'élevage nomade et en transhumant. Les corrélations sont souvent compliquées par le fait qu'il semble y avoir deux voies diamétralement opposées qui répondent à la même série de conditions. Par exemple, la limitation des ressources de pacage chez les pasteurs sud-est européens semble se rapporter à deux stratégies tout à fait différentes pour y faire face : d'une part le contrôle démographique, l'émission des migrants et les limitations dans l'utilisation des ressources, d'autre part le développement au-delà des limites biologiques au moyen d'adoptions libérales d'étrangers, l'agressivité militaire et l'expansion des dépenses cérémonielles. Les facteurs qui déterminent les préférences dans ces cas restent encore à explorer.

Explorant les diversités locales des traditions culturelles (Doja 1998a), j'ai montré que dans les groupements sans organisation de type lignager explicite, il est tout aussi important d'évaluer l'impact de l'unité sociale et territoriale conventionnelle la plus large, le «pays» : appelée «terre » (tara) en Roumanie (Stahl 1986), ou "montagne » (mali) en Albanie, et qui se présente comme une confédération de villages. En pays albanais plus particulièrement, la notion de «montagne » (mali) représente effectivement une organisation économique et sociale d'origine médiévale, formée de pasteurs ayant une propriété commune sur les pâturages sans avoir nécessairement des liens de 
parenté. Ce n'est qu'à partir du $\mathrm{XV}^{\mathrm{e}}$ siècle que cette forme d'organisation sera supplantée par d'autres unités segmentaires qui ont pris des appellations différentes, fisi ou fara. Sur les fondements de fisi, à partir du XVIII ${ }^{\mathrm{e}}$ siècle, s'établit bajraku, une unité territoriale, administrative et militaire, qui renforce davantage les différences régionales. Toutefois, c'est le terme de montagne qui est resté dans l'appellation ultérieure de la plupart des régions culturelles qui ont reposé sur les anciennes divisions.

Souvent, on a opposé les structures lignagères aux structures familiales, comme des «structures orientales» aux «structures occidentales », ce qui est encore plus vrai dans les études d'anthropologie de la Méditerranée (Albera, Blok \& Bromberger 2001 : 215-230). Or, ce que les anthropologues ont appris est que dans une perspective globale et interculturelle, la «famille » est en premier lieu extrêmement difficile, certains diraient même impossible, à définir. Lévi-Strauss (1956/1983) a essayé de la définir mais il a rapidement renoncé à la tâche, concluant qu'aucune définition ne pourrait couvrir toutes les institutions diverses que les anthropologues considèrent régulièrement comme "famille». Ses formes sont si variées qu'elles ont été étudiées tantôt du côté des structures de la parenté, tantôt des groupes domestiques et de leur reproduction. Pour des raisons partiellement liées aux modes de financement de la recherche, ces problématiques, très vivaces dans les pays de l'Europe du Sud jusqu'à la fin des années 1980, ont cédé la place, dans les années 1990 à des thèmes répondant à la « demande sociale».

Des questions touchant à ce qui fait problème dans la famille ont été privilégiées. Certaines tendances affectent l'étude de la famille en anthropologie juridique et en anthropologie des sentiments, ou encore dans ces enquêtes dirigées vers des figures quelque peu marginales, comme les adoptés, les enfants illégitimes, les célibataires et d'autres, bien que trop peu d'attention ait été donnée aux familles «reconstituées » par des anthropologues à la différence des sociologues. En revanche, les anthropologues ont donné un plus grand poids aux sexualités alternatives aussi bien qu'aux maladies sexuellement transmises telles que le Sida. De telles études sont liées aux intérêts dans l'identité et le corps, et évoquent les nouveaux modèles de procréation.

Ce qui, bien sûr, oblige à penser la famille ou le groupe domestique dans son entier. La question du corps a conduit à s'interroger à nouveau sur les composantes de la personne et les représentations de la procréation, souvent dans une optique liée aux représentations de l'ethnicité. Aujourd'hui, il y a un appel pour " un retour à la famille » comme un thème légitime en anthropologie pour l'étude de beaucoup d'autres facettes de la vie sociale, mais il s'agit d'un retour qui est animé par l'addition de nouveaux intérêts et abordé avec de nouveaux moyens. 
Les formations sociales sud-est européennes se laissent plutôt éclairer par référence à la notion de maison, qui est moins familière aux ethnologues qu'aux historiens des périodes médiévales de l'Europe et du Proche Orient. Cette notion, repérable ailleurs dans le monde, reprise et élaborée par Lévi-Strauss dans ses derniers enseignements (1984 : 187241), ne coïncide pas nécessairement avec la lignée agnatique, mais consiste en un héritage spirituel et matériel, comprenant la dignité, les origines, la parenté, les noms et les symboles, la position, la puissance, la richesse et les privilèges. La maison est une "personne morale ", détentrice d'un domaine composé à la fois de biens matériels et immatériels, et « qui se perpétue par la transmission de son nom, de sa fortune et de ses titres en ligne réelle ou fictive, tenue pour légitime à la seule condition que cette continuité puisse se traduire dans le langage de la paternité et de l'alliance, et le plus souvent des deux ensemble » (LéviStrauss $1984: 190$ ).

Dans cette perspective, je me suis intéressé avec profit à la considération des différences existant entre le type de famille rurale basée sur l'existence d'un seul couple marié avec les enfants non mariés, prévalant sur l'ensemble du Sud-est européen, de la Grèce à la Roumanie, et le groupe domestique composé de plusieurs couples mariés, maintenu chez une partie des Albanais et des Slaves du Sud jusqu'au milieu du $\mathrm{XX}^{\mathrm{e}}$ siècle. À Kosova ou en Macédoine occidentale, par exemple, on trouvait encore récemment certains groupes domestiques qui dépassaient la centaine de personnes. Surtout dans les régions où les droits coutumiers étaient particulièrement respectés, dans les grandes habitations vivaient des familles d'un type qu'on peut appeler, à la suite de LéviStrauss (1983 : 77), plutôt domestique que conjugal. Elles reposaient sur des mécanismes complexes et rigides d'organisation et elles étaient caractérisées comme un groupe social à fonctions multiples : économique, politique, juridique et coutumier (Doja 1999a).

Cette organisation familiale était basée sur la cohabitation du père et des fils mariés, les fils ne se séparant qu'après la mort du père. En comparaison, dans la société des Slaves du Sud, le modèle dominant est celui d'une communauté familiale basée sur la cohabitation des frères, même en dehors de la présence vivante du père. Ce type d'organisation, connu sous le nom de zadruga, a donné lieu à une abondante littérature ethnologique, où il a été souvent présenté comme un modèle de démocratie familiale égalitaire, au moins entre les hommes (Sicard 1943; Byrnes 1976). La maison, le groupe domestique, la communauté de vie et l'exploitation agricole, apparaissent toujours dans les deux cas comme l'élément central de l'organisation sociale, à travers les comportements et les manifestations symboliques. Or, si le groupe slave est organisé selon un principe horizontal : importance des relations collaté- 
rales, primauté du tangible et du contemporain, dans le groupe albanais domine le principe vertical qui soumet le bas, le jeune, le présent, le fils, au haut, à l'ancien, au passé, au père.

Chez les Albanais, les rapports intrafamiliaux sont marqués par une double relation de domination : domination des hommes sur les femmes et domination des aînés sur les plus jeunes. Les formes du respect sont complexes et très strictement observées. L'autorité du chef de famille est totale, bien que son pouvoir ne soit pas véritablement absolu, en ce sens que la propriété est collectivement celle du groupe et qu'il ne peut en aucune manière en disposer ou l'aliéner à sa guise. En tout cas, l'idéologie de filiation patrilinéaire était soulignée par des normes d'héritage également partagé, selon lesquelles chaque frère avait droit à une part égale de la propriété de la famille. La dialectique de la dynamique familiale était assez simple. La «moralité » dominante stipulait que les familles communes devraient rester ensemble dans des unités productives cohésives. Mais si les désaccords à propos de la gestion de la famille commune devenaient irréconciliables, chaque frère avait le droit de se retirer de la famille étendue, d'assumer le contrôle de sa part légitime du domaine familial, d'établir ainsi sa propre famille nucléaire, avec prises de décision indépendantes, et potentiellement, avec le mariage de ses propres fils, de fonder aussi une autre famille étendue. Or il n'est pas surprenant que cette division de famille, bien que généralement pratiquée, soit considérée comme «moralement mauvaise ». La moralité circonscrite par de tels sentiments était une moralité familiste. C'était une moralité de croissance organique et de développement, de filiation commune et de destinée collective, une moralité de pouvoir qui reconnaissait que la puissance ne peut résider que dans les nombres.

Les structures sociales chez les Albanais et les autres populations sud-est européennes sont fortement prégnantes. Elles mettent l'accent sur la primauté de la filiation et des liens du sang et elles se caractérisent d'une survalorisation de la consanguinité au détriment de l'alliance. L'organisation repose sur la cohérence de groupes agnatiques, fondés sur la parenté par les hommes, dont les femmes ne sont que des éléments secondaires et pour qui le système de transmission des biens, essentiellement patrilinéaire, exclut en la matière toute stratégie matrimoniale (Doja 1999a).

Se rapportant à cette même problématique, certains de mes travaux et mes enseignements ont porté sur les représentations sociales du rapport entre les sexes et sur les discours et les pratiques mettant en ouvre l'opposition masculin/féminin (Doja 1995b). Sans contester l'idée du système patriarcal de la famille albanaise, j'ai montré aussi (Doja 2010b) à quel point les mythes et les idéologies culturelles associées à la patrilinéarité sont confondus avec les pratiques réelles du patriarcat à tel 
point qu'on suppose trop facilement que le langage patriarcal et les discours qui soutiennent symboliquement la patrilinéarité débouchent uniformément sur des résultats et des pratiques qui sont tout simplement patriarcales. Dans le discours traditionaliste des Albanais, le trait principal du statut social de la femme et sa seule fonction socialement appréciée ne se fonde que sur des aptitudes à la procréation et à la maternité. L'enfant albanais est avant tout un fils : il va succéder à son père, hériter de lui, garantir la pérennité de la lignée et honorer les ancêtres. La fille est une future épouse, une mère en puissance, tandis que des images polyvalentes font de l'enfant de sexe masculin le symbole de la transformation radicale, du renouveau et de la régénération.

Or si la femme n'a de valeur que par les rôles qu'elle assume dans la reproduction lignagère et dans le travail domestique et productif, la fille et la sœur sont par contre objet d'amour pour les siens au sein de son groupe d'origine. Elle continue d'appartenir à celui-ci au-delà du mariage, si non effectivement au moins affectivement. Par ailleurs, dans ces systèmes où le souci du lignage, des liens du sang, et surtout le sens de l'honneur et de la chasteté sexuelle produisent une stricte séparation des sexes, la sœur constitue pour son frère la seule image féminine accessible, et réciproquement. Cette hypertrophie du sentiment fraternel porte évidemment en elle la menace de l'attirance incestueuse allant à l'encontre de l'état de société qui repose sur la prohibition de l'inceste. Un nouveau terrain d'investigation supplémentaire permettrait alors de comprendre que les sociétés sud-est européennes constituent à cet égard un état limite.

L'utilisation de la méthode structurale et l'analyse comparée des structures sociales et des constructions narratives, chez les Albanais plus particulièrement, se prêtent à l'interprétation de la proximité affective extrême et fusionnelle du frère et de la sœur comme une transformation structurale, correspondant dans une «spéculation mythique» à l'éloignement maximal dans le cycle mythologique du frère mort, à l'union dans la mort dans le mythe de Gjergj Elez Alia, à la catastrophe sociale ou naturelle dans le cycle mythologique du mariage de germains, ou bien au retour à l'état de société dans le cycle narratif du mari revenant au mariage de sa femme et aux exploits légendaires en matière de capture de femmes dans le cycle des gestes de Muyi. La loi sociale, l'honneur, la vengeance, le prestige, etc. atteignent ainsi dans le mythe au plus haut degré de la rigueur. Dans cette perspective, les mythologies, les traditions narratives et les littératures sud-est européennes trouvent finalement un éclairage différent dans une interprétation tant soit peu originale. 


\section{Les valeurs de l'honneur}

L'honneur est une composante essentielle de la notion de personne qui m'est apparue cruciale pour comprendre la portée de l'ensemble du système des valeurs sociales ainsi que le fonctionnement du groupe social, familial et parental, ainsi que celui même de la société tout entière. Chez les Albanais, l'expression de cette notion fondamentale a reposé non seulement sur un « code de l'honneur » très strict, mais aussi sur des structures lignagères fortement prégnantes, sur la séparation des sexes et sur la primauté de la filiation et des liens du sang, censés mettre en œuvre une responsabilité collective dans les mécanismes complexes des systèmes d'alliance et de vengeance.

Dans une perspective historique, l'identification de ce concept local comme une notion sociologique et anthropologique devient possible, d'une part, à travers d'autres notions qui recouvrent et d'une certaine façon constituent généralement la notion de personne : chasteté, courage, hospitalité, protection, largesse, clémence, mesure, noblesse et prestige. L'honneur demeure ainsi une composante essentielle de la notion de personne et ses principes chez les Albanais font partie intégrante des discours et des pratiques culturelles du processus de construction de l'identité de la personne. Dans la majorité des discours symboliques et des pratiques culturelles sont évoquées notamment les valeurs morales qui dans la société traditionnelle albanaise reposaient effectivement sur cette notion (Doja 2000a). D'autre part, les valeurs de l'honneur restent intimement liée aux valeurs essentielles de la société albanaise, tantôt religieuses tantôt ancestrales, probablement d'une façon comparable à l'exemple qui nous est donné par l'honneur dans le Sud de la Méditerranée (Jamous 1981), liée aux valeurs religieuses et la baraka, «bénédiction divine » du groupe familial.

Effectivement, le caractère spécifique de la religion chez les Albanais semble certainement peu commun et difficile à saisir si on utilise schématiquement les catégories traditionnelles pour comprendre la religion. Or, à travers une analyse linguistique et anthropologique des termes du vocabulaire des institutions qui servent à exprimer les notions d'honneur et de croyance, j'ai notamment abordé une nouvelle appréhension du rapport entre les valeurs sociales de la morale et de la religion (Doja 2011). Pour désigner la religion aussi bien que la croyance les Albanais utilisent des termes qui tirent leur origine dans le même fond commun indo-européen avec les termes latins ou grecs anciens équivalents. Mais à la même souche d'autres mots restent attachés en albanais, qui désignent les valeurs morales de l'honneur comme le serment et la parole donnée aussi bien que les stratégies d'alliance matrimoniale. Il m'est devenu possible alors de mieux comprendre que les discours sur l'honneur ne représentent pas seulement une valeur 
morale et quasi religieuse constituante de la personne, une parole donnée, parole d'honneur à accomplir nécessairement un engagement ou une obligation, mais cette notion semble représenter également une institution juridique et historique du droit coutumier. En effet, j'ai tenté d'analyser le rôle de la foi et des valeurs morales et contractuelles qui y sont attachées non seulement dans l'histoire des idées et des pratiques religieuses, mais aussi dans les systèmes de parenté et d'alliance ou dans les systèmes narratifs de tradition orale qui se développent comme substituts à d'autres formes d'institutions et de représentations sociales.

On pourrait certainement utiliser la notion de l'honneur comme un outil précieux pour comparer les différentes sociétés sud-est européennes et méditerranéennes. Non seulement l'honneur est en rapport avec les structures sociales sur lesquelles reposent les sociétés de cette région, mais cette notion fut au cœur des études méditerranéennes dès leur première vogue (Peristiany 1966 ; Pitt-Rivers 1977). L'honneur est envisagé à travers les représentations sociales de la plupart des populations méditerranéennes non seulement comme un principe, comme un idéal égalitaire (Bourdieu 1972/2000 ; Pitt-Rivers 1977), sans rapport avec le pouvoir économique ou politique (Lison-Tolosana 1966/1983), relevant d'une éthique de l'intégrité, de la noblesse du corps et de l'âme (Campbell 1964), mais aussi comme une idéologie de défense du patrimoine commun (Schneider 1971; Davis 1977) dans les conditions de la société sans État. Curieusement ces études ont ignoré les données sudest européennes et albanaises en particulier (Giordano 2012).

Les Albanais ont maintenu des discours formels de l'honneur qui ont constamment médiatisé certains domaines de l'action collective. Dans ce sens, besë était une promesse solennelle pour appuyer quelque chose d'important ou s'associer avec quelqu'un en vue d'une action commune ou dans une entente collective avec la garantie de la parole donnée que les engagements pris seraient absolument respectés et honorés. C'était comme si ces discours de l'honneur étaient censés assurer la solidarité et la cohésion du groupe social, sanctionnant le respect des règles dans les relations interpersonnelles et familiales, régionales et interrégionales, de la vie sociale dans la communauté locale, en accord avec les traditions et les coutumes de la région et du pays. L'analyse des différentes conventions historiques en vue d'actions communes, telles qu'elles sont exprimées aussi par le terme composé de besëlidhje, littéralement «alliance sur la base de l'honneur », montre à quel point les pratiques culturelles étaient informées par des discours historiques spécifiques centrés sur la notion de l'honneur. On connait dans l'histoire albanaise plusieurs cas de besëlidhje régionales et interrégionales qui ont produit et reproduit ces discours de l'honneur en vue d'assurer la cohésion des mouvements concertés entre individus et communautés. Dénommée «besë alba- 
naise ", ce discours de l'honneur semble avoir pris une valeur culturelle pertinente dont le terme a pénétré avec le même sens dans les autres langues sud-est européennes.

Chez les Albanais on reconnaît des fonctions plus spéciales à cette institution notamment dans le contrôle des pouvoirs aveugles de la vengeance. Cette notion de l'honneur chez les Albanais et dans le Sudest européen offre un exemple privilégié à travers lequel on comprend comment le système de vengeance, propre à cette région, constitue un élément décisif dans l'établissement et la reproduction des rapports sociaux internes à la société (Blok 1974 ; Black-Michaud 1975 ; Boehm 1984 ; Verdier 1981). La vengeance apparait dans cette région, de même que dans le Rif marocain (Jamous 1981), comme constitutive de l'armature sociale, elle est un effet de la violence instituée dans l'état même de société et non pas seulement une phase temporelle durant laquelle la violence doit être socialement prise en charge. Or le système de vengeance, dès lors qu'elle existe comme une institution sociale, exige des membres de la société qu'ils effectuent des choix cruciaux, vis-à-vis des morts comme des vivants. Dans ces conditions on peut remarquer qu'ils s'engagent par rapport aux valeurs éthiques de l'honneur, qui apparaît de ce fait comme une valeur socialement fondatrice, comme l'un des faits sociaux privilégiés à travers lesquels se redéfinit constamment un ordre symbolique.

Dans ce contexte, l'institution de l'honneur était avant tout la parole donnée par la maison de la victime au meurtrier et à sa famille avec l'engagement de ne pas se venger jusqu'à un délai déterminé afin de leur rendre possible la gestion des affaires sociales et économiques les plus urgentes. C'est exactement un tel moment qui s'est illustré dans le fameux Avril brisé d'Ismail Kadaré. Chez les Albanais, l'honneur était aussi un pacte en vue de suspendre les hostilités et les vengeances échangées entre lignages ou villages aux temps difficiles, garanti par la parole donnée à toutes les parties. On pourrait invoquer d'autres textes tels que l'Iliade, le Mahabharata ou l'Ancien Testament, ou encore l'ensemble de la tradition orale sud-est européenne, pour montrer comment l'expression des valeurs de l'honneur peut être constamment réitérée dans des situations narratives dominées par un contexte de vengeance.

Cette idée se retrouvait chez les Albanais dans les rapports d'hospitalité. Les discours de l'honneur insistent plus particulièrement sur le fait que l'hôte est avant tout protégé par cette institution aussi longtemps qu'il était reçu ou lors de son voyage jusqu'au prochain lieu sûr. C'était un serment de protection dont on jouissait lors du séjour, mais pour entendre pleinement cette relation fondamentale, il faut se représenter la situation de l'hôte en visite dans un pays où, comme 
étranger, il est privé de tout droit, de toute protection, de tout moyen d'existence. Il ne trouve accueil, gîte et garantie que chez celui avec qui il est en rapport d'hospitalité (Doja 1999b : 222-227).

Or dans l'univers albanais de l'honneur, un autre terme technique s'est développé, ndore, littéralement "entre les mains de...», qui correspond plus exactement à la notion de protection. Si à propos de besë il s'agit d'une parole donnée, contrainte d'honneur à accomplir nécessairement un engagement ou une obligation, la notion de ndore diffère de besë du fait que c'est un pacte unilatéral, il s'agit d'une parole demandée, qui n'en est pas moins pour autant une contrainte d'honneur (Doja 1999b : 225-226). La notion de ndore se présente ainsi comme une autre institution juridique du droit coutumier albanais. Le fondement institutionnel de ces conceptions est tel que les implications sociales dont ces rapports personnels sont chargés sont susceptibles de se réaliser dans des circonstances exceptionnelles, comme une convention solennelle de type bien défini, qui lie et qui comporte des engagements réciproques, avec serments (besë), sacrifices (ndore) et dévouements (bindem). La notion de l'honneur se rapporte alors à une hiérarchie de prestige remise sans cesse en question dans un processus permanent de compétition à la poursuite de fins qui ne sont atteintes que relativement.

Les valeurs de l'honneur renvoient en dernière instance aux représentations concernant la distinction des sexes dont on a souligné, depuis Bourdieu (1972/2000, 1998), la portée structurelle et les fonctions symbolique et cognitive. On a soutenu en particulier que chez les Albanais les relations de genre ont été informées par la tension qui sépare les valeurs d'autonomie et d'empêtrement, et que ces valeurs ont pris leurs significations particulières dans une structure de prestige se rapportant à l'honneur et à la vengeance (Shryock 1988).

De manière générale, les groupes entretenant entre eux des relations de vengeance sont aussi ceux entre lesquels on se marie. Le modèle albanais dans lequel l'exogamie est privilégiée semble être une inversion structurale du modèle commun partout dans la Méditerranée islamique où l'endogamie est privilégiée. Parmi les musulmans du Proche Orient, en général les tensions entre les groupes partenaires du mariage peuvent s'éviter au moyen du mariage dans la sphère domestique. Les Albanais, qu'ils soient musulmans ou chrétiens, ont suivi la direction opposée. La tension est évitée en se mariant dans des familles socialement et spatialement éloignées de la sienne propre. Ainsi, les fiançailles s'arrangeaient volontiers en croisant les lignes de vengeance, typiquement avec d'anciens ou éventuels ennemis. Chaque alignement matrimonial était tenu comme un point d'attachement dans un système qui représentait tous ces attachements comme autant de relations vulnérables de conflit potentiel. 
Plus exactement, quand j'ai exploré les idéologies implicites dans les pratiques et les stratégies d'alliance et de vengeance (Doja 1999b), j'ai remarqué que chez les Albanais, si une relation d'alliance s'établit entre deux arbres de sang par un rapprochement parallèle au moyen d'un même arbre de lait partagé, une relation de vengeance s'établit de la même manière entre deux arbres de sang différents à travers une distance conflictuelle, souvent forcée par la difficulté de partager un arbre de lait. Ceci peut être le résultat d'une dégradation, pour une raison ou une autre, des valeurs incarnées dans le sang.

Dans la société albanaise, comme dans l'ensemble du Sud-est européen, l'honneur d'un groupe familial dépend d'un état d'équilibre entre, d'un côté, la pureté généalogique du sang et, de l'autre, la considération du nom. À l'intérieur du groupe il semble que tout est mis en œuvre pour assurer cet équilibre. Chacun des sexes prend soin que l'autre agisse dans le plus grand respect des traditions. Les hommes veillent au respect de la modestie sexuelle des femmes afin que la pureté de leur généalogie ne soit pas altérée et les femmes incitent les hommes à ne pas laisser détériorer leur renommée. La perte de l'honneur engendre la « honte » (Peristiany 1966 ; Pitt-Rivers 1977). Le groupe peut alors être contraint de rétablir, à plus ou moins brève échéance, l'équilibre perdu. Ainsi, les motivations et les stratégies sociales liées à l'honneur finissent par se transformer en règles juridiques.

En revanche, les femmes sont amenées à jouer le rôle central, puisqu'elles sont liées aux deux parties, par la naissance avec l'une, par l'alliance avec l'autre. Dans ce cas il est toujours intéressant d'interroger toute une mythologie sud-est européenne pour voir combien elle est sous-tendue par les valeurs de ce code de l'honneur exprimé à travers la loi de la parole donnée chez les Albanais et les Grecs anciens ou le poids de la malédiction ou de l'excommunication chez les Slaves et les Grecs modernes.

Les anthropologues ont été souvent tentés par les inversions ordonnées entre structures exogamiques et structures endogamiques pour rechercher "une structure profonde» dans la Méditerranée ou pour décrire un ensemble de transformations qui pourraient produire les différentes formes sociales associées à une valeur méditerranéenne récurrente de la conservation de l'autonomie et de l'équivalence. De même le complexe d'honneur et de honte est désormais battu en brèche par beaucoup d'anthropologues qui considèrent les insuffisances perçues de ce modèle comme un défi nécessaire et important (Herzfeld 1980 ; Wikan 1984 ; Gilmore 1987 ; Goddard 1994 ; Giordano 2012). Une de ses faiblesses consiste dans sa corrélation excessivement rigide avec les distinctions de genre, n'arrivant pas à conceptualiser le genre en tant que tel, mais réifiant l'honneur en s'appropriant le besoin d'explication et 
d'analyse. Aussi, se concentrant principalement sur les communautés «traditionnelles », il ne peut pas confronter les processus globaux qui empiètent sur des phénomènes locaux.

Beaucoup d'études récentes modifient la clef à comprendre les modèles sociaux de la région avec d'autres notions comme la pudeur, les modèles historiques de l'étiquette, une politique de l'émotion, les utilisations de l'espace physique, etc. Ils n'abandonnent pourtant pas d'emblée le modèle ancien, mais le trouvent toujours utile pour caractériser le monde des intérêts concurrentiels officiellement sanctionnés de la communauté de village, confirmant de ce fait aussi l'enclenchement mutuel intime de ces valeurs avec la présence de l'État dans la sphère sociale. Comme le remarque Herzfeld (in Albera, Blok \& Bromberger 2001 : 203-211), toutes ces études, dans différentes manières, placent le modèle plus ancien en pleine vue, là où la maladresse provoquée par ses propensions à modifier des formes peut être utilisée pour obtenir plutôt que supprimer le rôle de l'agence dans la vie sociale.

Ainsi, malgré les mises en garde répétées contre les risques d'une généralisation abusive, la problématique de l'honneur est constamment liée aux autres problématiques de construction des identités sociales, existantes dans les sociétés sud-est européennes et méditerranéennes. Elle se présente typiquement comme un «fait social total », au sens que Marcel Mauss (1924/2007) a donné à cette notion. Les valeurs de l'honneur sont considérées comme des liens communautaires propres aux sociétés sud-est européennes, comme outils de construction sociale intermédiaire, qui donnent aux comportements individuels des bases spécifiques puisées dans des groupes sociaux singuliers, producteurs d'identités fortes et différenciées. Les questions concernent ainsi l'analyse des représentations collectives de l'environnement socioculturel et naturel, à travers terminologies et taxonomies, parallèlement avec une réflexion sur les problèmes d'organisation sociale (parenté, famille, relations entre les sexes, règles de mariage, etc.), aussi bien que de mythologie et de tradition narrative, mettant en œuvre des procédés de transformation générative d'une société sud-est européenne à l'autre.

\section{La construction des genres}

Les recherches courantes n'en appellent que trop correctement l'attention sur l'importance désormais donnée aux études de genre. Cela a été longtemps une facette d'intérêt dans le bassin méditerranéen, avec ses déesses mères, ses concepts d'honneur et de honte, le rôle des femmes dans la production aussi bien que dans la reproduction, et de temps en temps dans les affaires politiques. En effet, c'est avec l'insistance croissante des féministes que nous sommes amenés à considérer que la dynamique des rapports de genre soutient les relations 
sociales et permet les conflits violents de tous les types. Mais l'intérêt s'est énormément développé avec l'avènement de la seconde vague du féminisme, à tel point qu'il semble parfois avoir inondé l'étude des autres aspects de la vie domestique.

Les applications féministes des notions de genre sont dans une certaine mesure contraintes par les engagements normatifs du féminisme et par le point de vue distinctif dont ces engagements résultent. L'effort de travailler dans un cadre d'épistémologie féministe peut n'arriver jamais à s'affranchir complètement de la tâche principale de travailler à partir des expériences des femmes, et la plupart des féministes regardent cette orientation comme réellement primaire. Il n'est pas surprenant alors que leur travail, comme par exemple dans l'étude des systèmes traditionnels albanais et balkaniques des relations de genre, se soit concentré typiquement et presque exclusivement sur la subordination des femmes en tant que groupe désavantagé. Beaucoup de commentateurs suivent dans ce sillage, reproduisant fréquemment les stéréotypes qui dépeignent les femmes albanaises et sud-est européennes comme soumises et silencieuses, remettant aux décideurs masculins les sujets qui concernent la sphère publique du contrôle des ressources matérielles, de l'avenir des enfants et de l'image publique de la famille.

La riposte féministe courante est que la plupart des champs d'étude de la société patriarcale ont été dominés par les figures masculines et les thèmes masculinistes. Il est discutable, cependant, que l'accent sur cet aspect, au moins dans l'étude des systèmes traditionnels albanais des relations de genre, soit simplement le legs de l'ethnographie albanaise. Si dans la plupart des cas la littérature se compose de récits de voyages et de mémoires classiques des coutumes locales, les meilleures ethnographes de la société albanaise étaient des femmes (e.g. Durham 1909/1994, 1928/1979 ; Hasluck, M. 1954 ; Backer 1979/2003), mais qui ont pourtant enregistré un monde social distinctivement mâle. En fait, même si apparemment à propos des hommes, le traitement par les études traditionnelles de l'homme générique comme la norme humaine a systématiquement exclu de la considération ce qui est spécifique à la notion de genre, que ce soit par rapport aux femmes ou par rapport aux hommes. La généralisation excessive du mâle au nom d'une expérience humaine générique a non seulement faussé notre compréhension de ce qui est spécifique aux féminités, mais elle a également exclu l'étude de toutes les expériences spécifiques au genre, pour autant qu'elles sont des formations sociales, historiques et culturelles spécifiques et variables, plutôt qu'un paradigme universel de l'expérience humaine.

En fait, au-delà du propre sexe des chercheurs et des thèmes qu'ils ou elles choisissent d'explorer, la raison doit être plutôt dans l'erreur la plus significative, celle qui entrave les analyses précises et augmente les 
malentendus dans tous les domaines. C'est la confusion des catégories. La même erreur se produit quand la virilité ou le fait d'être un homme sont assimilés au vieux code de l'honneur et que les femmes « occupent » la nouvelle position normative des droits de l'homme d'une façon exclusive, ne permettant pas aux hommes d'en faire partie. Partout où ceci se produit, cela signifie que les hommes sont enfermés dans leur rôle de dominateurs dans des systèmes patriarcaux d'oppression, puisque les femmes ont réclamé le monopole d'en être les victimes. Ainsi en est-il que, alors qu'une grande partie du corpus de travaux dans la politique du genre sont puissamment éclairants, les approches féministes peuvent aussi paraître brusquement rétrécies.

Une critique essentielle des approches existantes peut être avancée, tout en insistant sur le fait que la variable du genre, inclusivement abordée, n'est que rarement reconnue de façon explicite et presque jamais articulée à un niveau théorique. Peut-être les efforts pionniers dans les études des rapports de genre, avec leur engagement normatif à la réduction de toute injustice sociale, pourraient utilement se compléter par des recherches plus élargies et plus nuancées. Plus de considération pourrait être consacrée aux significations culturelles et aux expériences de vie distinctes par rapport aux genres, et pouvoir ainsi éviter cette espèce d'essentialisme de genre se rattachant autant au mythe de l'homme qu'à un mythe de la femme. En fait, la reconnaissance des subjectivités multiples des femmes a récemment contribué à la dissipation du mythe de la femme essentielle.

Un compte-rendu des idées sur le genre n'est pas, cependant, là où l'analyse devrait finir. La reconnaissance d'une position saillante des idées de genre dans les structures générales de l'action peut contribuer pour comprendre à la fois la subjectivité des acteurs et l'objectivité des formes sociales. Conformément aux versions en cours des théories de la pratique (Bourdieu 1980), cette position pourrait donner aux notions de genre chez les Albanais et dans les sociétés sud-est européennes une cohérence structurale qu'elles ont précédemment manquée dans les approches féministes. Cette position voudrait que les idées de genre soient traitées dans la rhétorique locale et significative du prestige, sans considérer pourtant cette rhétorique comme structurellement insulaire ou auto-génératrice. Les structures de prestige où l'honneur et le genre sont conceptuellement intégrés fournissent la connexion analytique dans laquelle les fondements des différences dans les processus sociaux des transactions matérielles, des relations de pouvoir, des notions d'histoire et de moralité peuvent être discernées et articulées d'une façon qui est à la fois systématique pour l'analyste et significative pour l'acteur. À ce point de conjoncture, pour autant qu'elle comporte des définitions de la sexualité et de la valeur sociale, est alors accordé par nécessité «une 
interdépendance dynamique » significative (Ortner \& Whitehead 1981) entre les relations de genre et les projets sociaux et politiques plus larges. En élucidant le contexte des relations de genre de cette façon, la conceptualisation du genre peut être analytiquement décentrée et culturellement spécifié.

L'intérêt analytique n'est donc plus dans la détermination structurale mais dans la médiation conceptuelle. On peut montrer comment des mythologies sont projetées et déterminées par la construction de la rhétorique selon les notions de genre, en même temps qu'elles demeurent soulignées par le contexte local, économique et politique, des structures de prestige. L'avantage de cette approche est dans la capacité d'adapter les deux côtés d'analyse structurale et d'approche féministe en anthropologie et rendre au genre ce qu'il a toujours été : la manifestation d'une logique plus générale, un dispositif structural des représentations globales du monde. Essentiellement, la réalité du monde doit être située dans la morphologie de production signifiante des relations, des structures et des valeurs sous-jacentes à l'arrangement et à la construction d'un contexte socioculturel selon les notions de genre. Sans cette formulation, le prestige et le genre dans la société albanaise et ailleurs seraient réduit à un ensemble d'images mentales concernant, comme l'a noté Shryock (1988: 117), «non pas les soucis pratiques des hommes et des femmes comme ils vivent, mais les conceptions idéales de l'homme et de la femme comme on les pense ».

Les mémoires ethnographiques de la morphologie sociale et des relations de genre chez les populations pastorales sud-est européennes ont indiqué le marginalisation des femmes dans ces groupes patrilinéaires et dans la vie culturelle de la communauté, particulièrement dans ces régions distinctivement rurales et montagneuses de Bosnie, Monténégro, Serbie, Kosova, Macédoine, Albanie et Grèce. Cependant, les valeurs qui justifient la stratification des genres dans ces sociétés ne peuvent pas se comprendre comme émanant tout simplement du consensus ou de la soumission mais plutôt du conflit d'intérêts opposées qui sont redéfinis selon les lignes de genre. Ce sont les conditions externes qui ont défini des lignes de conduite optimales pour la survie, tout en reliant les conditions résultantes de l'existence sociale aux mécanismes logiques idéaux qui expriment les conflits inhérents aux systèmes établis des rôles et des statuts de genre.

Il est important de rappeler que chez les Albanais comme ailleurs les femmes apparaissaient comme des points d'articulation entre des groupes antagoniques d'hommes (Doja 1999a, 1999b). Selon LéviStrauss, «dans la société humaine, ce sont les hommes qui échangent des femmes, et pas l'inverse » (1958: [45]). Si Lévi-Strauss doit être pris à la lettre, la même orientation dans son œuvre servirait alors de 
dispositif méthodologique et pas comme une opinion. Car si pour la plupart de l'histoire humaine les hommes ont été des échangeurs sexuels et les femmes des pièces sexuelles d'échange, alors beaucoup de coutumes, clichés et traits de personnalité apparaîtraient assez raisonnables (Rubin 1975 : 176). Que la théorie de l'échange des femmes soit universelle ou non, cela restera ouvert à la discussion, mais elle fournit un modèle correct des structures de la parenté. En effet, au moins dans les sociétés sud-est européennes, la formulation de Lévi-Strauss peut convenablement se paraphraser pour dire que l'échange des femmes débouche sur la formation des groupes de parenté hiérarchisés suivant les lignes de genre.

Les évaluations négatives attribuées aux femmes reflètent, en grande partie, l'agitation avec laquelle les hommes entre en relations d'alliance. En fait, c'était au niveau du mariage que, selon les hommes albanais, les femmes étaient les plus menaçantes à l'ordre social. Le dilemme de base du groupe agnatique était de traiter la présence anormale des femmes qui sont dans le groupe mais pas $d u$ groupe. Les structures formelles dans toutes ces sociétés sont basées exclusivement sur des relations entre parents mâles. Les seules unités sociales durables sont formées par la ligne de filiation masculine, alors que les femmes sont échangées entre ces unités pour procréer de futures générations de mâles, ne laissant aucune marque durable de leur propre existence dans les termes de la structure formelle. En fait, comme Denich (1974 : 246, 259) l'a si convenablement exprimé, les jeux de mâles agnatiquement apparentés «auraient fonctionné d'une manière beaucoup mieux ordonnée si les femmes n'existaient pas du tout ».

Mais puisque les femmes existent et sont évidemment nécessaires pour la survie du groupe, j'ai montré comment la règle d'exogamie laissaient les hommes ouverts aux rapports avec ceux dont ils ne partageaient ni les intérêts ni le prestige ou l'honneur (Doja 1999b). Ces contradictions inhérentes entre la structure et la réalité de patrilinéarité dans les sociétés sud-est européennes constituent un «paradoxe patrilinéaire ", dans le sens que la structure nie l'existence formelle des femmes alors que la survie du groupe en dépend (Denich 1974), plus ou moins de la même façon que dans les sociétés matrilinéaire où un «puzzle matrilinéaire » de la structure nie l'importance de la paternité alors que la réalité se présente tout à fait autrement (Richards 1950).

Les études courantes insistent sur le fait que le genre est un dispositif structural de la réalité sociale et comme tel il doit être mis sur le tapis, systématiquement étudiée, pour incorporer ses effets symboliques et matériels dans notre production des analyses historiques et contextuelles qui permettent une transformation sociale efficace. Cependant, aussi longtemps que les contradictions à l'intérieur de la structure patrilinéaire 
ne sont pas identifiées, les mécanismes de domination masculine ne seront pas entièrement compréhensibles.

L'arrangement clair et fonctionnellement admis de la structure indique le problème du groupe patrilinéaire exogame qui doit consolider les intérêts de ses épouses à travailler dans l'avantage du groupe au lieu de miner sa cohésion. Maintenir le comportement des femmes en conformité avec leurs fonctions nécessaires et les empêcher d'affaiblir la solidarité agnatique et la position d'unité du groupe dans ses luttes externes ont exigé la soumission des femmes aux intérêts du groupe. C'est l'élaboration de mécanismes institutionnels coercitifs pour contrôler les femmes plus que toute autre chose qui indique que les femmes ne sont pas soumises par nature, mais que la coercition était nécessaire pour réconcilier l'opposition entre leurs intérêts individuels et les conditions de survie du groupe (Denich 1974). En effet, la perspective selon laquelle les constructions sexuées sont utilisées pour traduire des différences de pouvoir entre les hommes s'est révélée largement fructueuse (Ortner \& Whitehead 1981), d'autant plus qu'un tel processus ne se limite pas aux sociétés méditerranéennes, ni en l'occurrence les sociétés sud-est européennes ou balkaniques.

Le manque initial d'unité d'intérêt entre une épouse et le groupe de son mari rend l'opposition et la hiérarchisation des relations de genre une clef de voûte du groupe domestique patrilinéaire. La bifurcation idéologique des qualités masculines et féminines est exagérée proportionnellement à la fragilité de la solidarité agnatique et, concomitamment, dans la mesure où les femmes sont perçues comme facteurs de tension et comme sources de dissension. Les mémoires ethnographiques ont constamment montré que beaucoup prétendaient que les familles étendues se divisaient si les «femmes se chamaillaient et les hommes étaient paresseux » (Campbell 1964). En fait, les conflits surgissaient entre les mâles à propos de l'attribution des tâches et quand les décisions concernaient le réinvestissement des revenus et la redistribution des ressources. L'attribution commune des pressions de division aux «belles-sœurs qui se chamaillent» a plutôt reflété qu'elle a décrit ces tensions.

Là où la solidarité masculine est de grande importance, il est utile de trouver un masque idéologique pour les rivalités entre les hommes. Une telle mystification est utile pour détourner les réalités du conflit entre les hommes eux-mêmes sur leurs femmes, là où elles pouvaient se traiter avec moins de subversion à l'égard de la base fondamentale du groupe. Les nombreuses sources d'opposition interne sont idéologiquement combinées. Elles sont articulées dans l'élaboration de la dichotomie hommes-femmes qui exprime la vraie opposition entre les hommes et les femmes, en même temps qu'elles servent d'écran pour cacher les 
oppositions fondamentales entre les hommes eux-mêmes. Ce modèle conscient est une simplification de la réalité, "voulu non pas pour expliquer les phénomènes mais pour les perpétuer », comme l'aurait dit Lévi-Strauss (1958 : [273]).

Si on a discuté que chez les Albanais les idées de genre ont été informées par la tension qui oppose les valeurs d'autonomie et d'incertitude et que ces valeurs ont pris leurs significations particulières dans une structure de prestige de l'honneur et de la vengeance (Shryock 1988), c'est que la perception traditionnelle des femmes s'est ancrée dans ce qu'elles sont censées diminuer l'idéal masculin de l'honneur indépendant et autosuffisant. Plus les hommes étaient pensés être omnipotents, plus cette omnipotence était menacée par les femmes apparemment insignifiantes, ce qui impliquait un problème de contrôle sur les femmes. En conséquence, les valeurs exagérées de la suprématie masculine se sont reliées aux mécanismes d'oppression féminine.

La dimension la plus significative de la sévérité des mesures dérivait naturellement de l'importance symbolique du sexe dans la situation d'environnement social concurrentiel où les groupes agnatiques ont existé. La capacité des hommes d'une maison à contrôler leurs femmes n'était qu'un des indicateurs de leur puissance. En conséquence, les Albanais et autres Sud-est Européens se sont rendu compte que ce sont les femmes qui affectent le prestige d'un homme, un fait qu'ils affirmaient explicitement. Les mémoires ethnographiques ont constamment montré que l'évidence du manque de contrôle sur les femmes pourrait indiquer une faiblesse et révéler probablement la vulnérabilité des hommes à d'autres défis externes (Denich 1974 : 254-255). Puisque la posture d'invulnérabilité du groupe, représentée par son « honneur », est cruciale à sa situation concurrentielle envers d'autres groupes, il est évident que la posture d'adultère des femmes, faisant de l'intégrité morale et de l'honneur de la famille un "objet de risée » (Campbell 1964 : 152), seraient très préjudiciables aux hommes essayant de jouer leurs rôles dans l'arène publique.

Comme les théories locales de la sexualité et de la réputation sociale s'expriment généralement dans les mêmes termes, chez les Albanais et autres Sud-est Européens, la rhétorique de l'honneur était autant leur idéologie de genre qu'une évaluation de leur pensée économique et politique. Dans ce sens, alors que la structure de prestige de l'honneur donne valeur aux dimensions matérielles de l'ordre politique et économique, les idées de genre prennent leur valeur par rapport à de telles structures de prestige plus larges. Aucun doute que les structures de prestige exerçaient « la plus claire et la plus intelligible » influence sur la manière que ces gens avaient l'habitude de penser au sujet du genre. 
Dans les structures de prestige d'une société d'honneur, l'homme est défini en tant que l'acteur principal, peu importe l'ampleur réelle et fonctionnelle des activités féminines. Il est le sujet, elle est objet. Il est le défenseur de l'honneur contre l'humiliation, défini comme étant responsable, réfléchi et rationnel. On s'attend à ce qu'il protège ses femmes, au moins aussi longtemps qu'il les évalue comme «ressource ", c'est-à-dire comme prix et symbole de son honneur ou comme mères de ses enfants. Une femme est « digne » par rapport aux intérêts de son protecteur masculin, son mari. Sa tâche est de donner naissance à ses enfants et servir de symbole et de prix pour l'honneur de son homme. C'est l'idéal traditionnel d'une «propre » femme. En d'autres termes, dans une société d'honneur les femmes sont devenues des démonstrations « matérielles » $\mathrm{du}$ « jeu de puissance » masculin.

Une femme, lors de son mariage, quitte sa famille pour vivre dans celle de son mari. Ses enfants appartiendront à la lignée de celui-ci, alors qu'elle-même restera toujours étrangère, mall $i$ huaj, «bien d'autrui ». Dans le discours traditionaliste les femmes albanaises sont décrites comme «propriété des hommes, destinées à être achetées, vendues et fiancées avant la naissance », juste comme "des sacs à remplir» (Gjeçov 1933/1993). Ce n'est que lors de la naissance d'un enfant qu'elle sera reconnue comme épouse à part entière. Jusque-là, elle pouvait toujours être répudiée. Dans les sociétés pastorales sud-est européennes seulement comme mère de fils une épouse obtient une place dans le groupe, assurée par un lien de sang. Le mariage ne devient définitif, comme Lévi-Strauss (1956/1983 : 75) l'a souligné à propos de plusieurs sociétés comparables, que lorsque la femme a donné naissance à un enfant de sexe masculin. Une variante de ce thème, plus particulièrement dans les régions rurales, est l'espoir d'avoir des fils parce que seulement un héritier mâle peut perpétuer le patrilignage et célébrer les rites qui honorent les ancêtres. À cette condition seulement le mariage a rempli sa fonction la plus essentielle, qui est de perpétuer la lignée de l'époux.

Dans une société d'honneur une femme est considérée comme « indigne » et de peu d'importance si elle ne peut donner des enfants à son mari ou sinon accroître l'honneur de la famille de son mari. Le destin des femmes stériles est d'ailleurs indicatif, car elles restent isolées dans le groupe, incapable de forger des liens de sang. Une femme stérile est souvent méprisée car elle est considérée comme un être inachevé, incomplet, totalement déficient. Elle était parfois remplacée par une autre épouse, surtout dans les régions du Nord. Le sort de la femme albanaise est toujours incarné dans son statut de mère, autrement dit dans son barku, le «ventre », terme utilisé couramment pour désigner l'ensemble des enfants qu'une femme met au monde. Si elle fait naître 
des enfants sains et nombreux, on lui reconnaîtra au moins le fait qu'elle a assuré la continuation de la lignée et du lignage. Comme il apparaît dans la plupart des documents albanais, autant du Nord que du Sud (Doja 1990b : 133-135), le prestige de la femme se mesure alors dans le nombre d'enfants et, plus que tout, des enfants de sexe masculin, qu'elle donne à la famille, à la lignée et à la parentèle. Le fait d'être mère a donné à la femme albanaise le statut et la considération sociale, l'identité et l'appui affectif et économique.

Cependant, c'est une fausse interprétation de la réalité de prendre à valeur faciale les énoncés moraux tels qu'ils sont patriarcalement préjugés et de les considérer plus qu'une expression de l'idéologie et de la propagande patriarcale. Le besoin pressant pour beaucoup d'enfants et des familles nombreuses ne saurait être le trait distinctif d'un patriarcat réifié albanais ou balkanique, comme quelques spécialistes de la région (e.g. Kaser 1992) voudraient nous faire croire. Il faudra plutôt insister, dans ce contexte, comme j'ai démontré récemment (Doja 2010b), sur une sorte de littéralisme spéculatif et de typologisme imaginaire dans les recherches actuelles qui semble être responsable de la construction d'une idée reçue qui associe le mythe de beaucoup d'enfants et les structures familiales complexes chez les Albanais plus étroitement avec l'existence de traits culturels patriarcaux. Ainsi, le mythe de nombreux enfants au sein de la famille albanaise, supposée élargie et patriarcale, qui est construit et véhiculé tant par les écrits de la littérature spécialisée que par la presse et les opinions stéréotypées, n'a fait que communément et simplement occulter une dimension purement idéologique d'activisme culturel.

Nous pouvons raisonnablement considérer que l'activité rituelle et les représentations collectives de la reproduction qui mettent systématiquement l'accent sur la fonction exclusive des femmes à porter des enfants doivent faire partie d'une idéologie purement instrumentale alimentée par un activisme culturel tenace où les femmes sont délibérément assujetties à la reproduction du groupe social. Car en réalité la famille albanaise est depuis fort longtemps confrontée à des taux de fécondité particulièrement bas et à un âge moyen de mariage des femmes relativement élevé, ce qui nécessite l'examen des données historiques, ethnographiques et démographiques dans une perspective théorique beaucoup plus nuancée, capable de saisir la complexité des structures de parenté patrilinéaire et des idéologies et pratiques patriarcales. Une analyse critique de l'idée reçue sur la maternité, basée sur les données ethnographiques, historiques et démographiques traditionnelles, vise à illustrer l'insuffisance du paradigme historico-ethnographiquedémographique face à une évidence empirique plus nuancée. En revanche, comprendre comment les éléments idéologiques sont soulignés 
par l'activisme culturel devra déboucher, contrairement aux études courantes, à comprendre que l'affichage du besoin urgent pour enfants mâles ne pouvait que mieux dissimuler d'autres raisons beaucoup plus troublantes.

Ce qui est important et qui n'a été que rarement explicitement articulé est que la maternité n'est pas l'équivalent sémantique de la paternité. Traditionnellement, comme Carol Delaney (1991) a remarqué dans le contexte similaire de la société rurale turque, même la contribution physiologique à l'enfant est codée différemment pour les hommes et pour les femmes, et donc leur relation à l'enfant est imaginée comme différente. Les femmes sont fécondes et la maternité a signifié donner naissance et nourrir, tandis que la paternité a signifié engendrer. C'est ce qui est considéré comme le rôle primordial, essentiel et créateur faisant de l'homme celui qui apporte la raison, l'ordre et la réglementation dans la vie créée.

Voilà pourquoi, comme dans la société albanaise, les enfants appartiennent à leur père ; ils font partie de son sang et n'appartiennent pas à la femme de la même manière. Pour cette raison, les capacités procréatives des hommes sont les raisons données pour leur puissance et leur autorité. Les hommes sont considérés comme les auteurs/créateurs des enfants comme Dieu est censé être l'Auteur/Créateur du monde. En Islam le mâle humain est dans la procréation métaphoriquement analogue à Dieu, alors que dans le christianisme Dieu le père s'est substitué au mâle humain dans un acte extraordinaire de procréation. La distinction peut insister sur des différences d'importance doctrinale, mais elle est négligeable pour la compréhension du concept de paternité. Dans les cultures influencées par le monothéisme le monde entier est symboliquement construit et systématiquement intégré entre les notions de la conception et la conception de la divinité. Ces systèmes, qui embrassent le monogénisme et le monothéisme, ne sont pas simplement des systèmes de domination masculine, mais de la domination, de l'objectivisation et de l'institutionnalisation de l'idée que le mâle en tant que père est considéré comme le créateur de la vie humaine, tout comme Dieu est censé être le créateur de la vie universelle. Et toute la signification du patriarcat réside dans la glorification du « père ».

Or la femme se trouve dans cette bien étrange situation d'incarner à elle seule un lignage masculin. Elle ne fait qu'un avec le «ventre», qui la désigne en même temps que ce qui n'est pas elle. D'autant plus que le pouvoir procréateur de la femme est ce qu'on ne maitrise pas mais aussi ce qui inquiète : en mettant au monde un mâle, la mère fonde une lignée et ce nouveau-né de sexe masculin concentre sur lui tous les dangers, toutes les menaces et tous les espoirs (Doja 1990b : 133). Dans cette perspective, il n'est pas correct d'affirmer que les femmes ne sont pas 
des composantes significatives des cultures rurales dites balkaniques, dont l'élément décisif serait exclusivement d'étoffe masculine. La naissance de l'enfant, consciemment ou inconsciemment, serait la sacralisation des œuvres de la femme, qui pour une fois au moins prévaudraient sur la masculinité.

La reproduction est une des activités les plus politiquement efficaces, car les plus chargées de pouvoir. Même si elle est ignorée par convention comme une dimension de la sphère privée apparemment apolitique, les relations de pouvoir dans la reproduction conditionnent fondamentalement qui «nous» sommes et comment les groupes eux-mêmes s'alignent de manières coopérative, concurrentielle et complémentaire. Dans ce sens, les relations de genre sont une dimension cruciale de la dynamique des identités de groupe et des conflits entre les groupes. Les femmes servent également de marqueurs symboliques de l'identité culturelle du groupe. Images, symboles, rituels, mythes et langages partagés jouent des rôles essentiels dans la reproduction des groupes sociaux qui sont basés sur les liens abstraits entre les hommes qui sont distancés des activités de reproduction.

Le domaine symbolique s'élève ainsi à une importance stratégique. Les relations sociales patriarcales peuvent se laisser interpréter comme une façon de construire les formes durables d'organisation sociale et d'identité du groupe. Mais aussi longtemps que les hommes cherchent la continuité et l'affiliation au groupe, ils essayent d'institutionnaliser les relations sociales qui engendrent des fidélités à un groupe défini en ligne masculine et se prolongeant au-delà du lien entre mère et enfant. La domination masculine ne serait alors fondamentalement que le contrôle de la fécondité, l'appropriation de la fécondité de la femme, au moment où celle-ci est une ressource de reproduction du groupe. Le reste, toutes les composantes psychologiques et les attitudes et pratiques particulières qui composent les portraits de la masculinité et de la féminité selon les différentes sociétés et qui sont censées justifier la domination des hommes sur les femmes, ne sont qu'un produit de l'éducation et de l'idéologie. En accord avec les versions récentes d'analyse structurale (Héritier 1996, 2002) et d'approche féministe (Yuval-Davis 1997), l'appropriation de la fécondité passera par le contrôle de la reproduction sexuelle : échange et répartition des femmes entre les hommes et appropriation des produits de leur fécondité.

Dans les sociétés patriarcales le milieu est propice à cette signification de la fécondité et de la capacité à l'enfantement qui leur est particulière. Pour être incluses au sein de la communauté, les femmes doivent accepter leur rôle reproducteur, qu'il soit réel ou potentiel. En tant que reproductrices biologiques et sociales, ce sont les capacités et les activités des femmes qui sont privatisées, tandis que leur liberté et leur auto- 
nomie sont limitées, dans la mesure où elles sont exclues de la définition des intérêts du groupe et qu'elles sont contraintes de se conformer aux prétendus besoins prescrits par le groupe. Ainsi exclues, les femmes se voient en même temps refuser le statut de personne réservé au groupe des décideurs, un refus institutionnalisé par la dichotomie entre le public et le privé. En résumé, la cohérence et la continuité de la hiérarchie du groupe et celle des genres, qui en découle, sont uniquement maintenues et sécurisées par la limitation de l'autonomie, de la liberté de choix et de la maturité sociale des reproductrices biologiques et sociales du groupe.

Ce sont les conséquences du discours idéologique et de la distribution actuelle des relations de pouvoir au sein des structures patriarcales, lesquelles sont préservées, et bien souvent attisées, par des situations politiques et économiques exceptionnelles ou menaçantes qui peuvent réduire les femmes à une non-existence virtuelle, et les soumettre à l'humiliation et à la violence physique et mentale. En tant qu'inégalité la plus naturalisée, une inégalité qui sert par là même à justifier une multitude de hiérarchies, la hiérarchie des genres est au centre de la construction et de la reproduction des relations sociales asymétriques. En ce sens, concevoir la hiérarchie des genres et la domination du masculin sur le féminin comme des données naturelles cache leur contexte historique, politique et idéologique, et désactive notre connaissance des relations hiérarchiques ainsi que notre volonté de les transformer. L'analyse de la question des genres ne prétend donc pas que cette problématique est toujours la dimension première, ou la plus remarquable, dans un contexte particulier, mais qu'elle agit de manière constante, non seulement par un processus de subordination des femmes, mais aussi par la construction de projets politiques de plus grande envergure, produisant ainsi une différence qu'il devient urgent de reconnaître et de dépasser.

\section{Transformations sociales et politiques}

L'essentiel pour l'anthropologue social est que toute identité émerge au cours des relations humaines et sociales. Poursuivant mon activité de recherche sur les formes fondamentales de l'identité sociale, incluant l'âge, le sexe et le statut social, politique et professionnel, je suis nécessairement amené à explorer leurs liens avec l'appartenance ethnique et le nationalisme (Doja 2004a), qui seront repris plus en détail à une autre occasion. Un objectif supplémentaire a été constamment de rattacher davantage mes travaux antérieurs sur la construction identitaire, la socialisation et les structures sociales chez les Albanais et les autres populations sud-est européennes, à l'étude de la transition actuelle des structures sociales et politiques en Europe orientale. 
Certains aspects complémentaires des relations sociales sont pourtant d'une plus grande importance quand on explore leur existence et leurs caractéristiques plus particulièrement dans le monde contemporain. Si le passage à l'économie de marché et la montée des États de droit sont normalement au centre des intérêts à un niveau officiel, je suis plus sensible au fait que certaines approches des conformités et des moralités dirigent notre attention vers des systèmes plus subtils de normes et de valeurs qui intègrent les individus socialement.

Par exemple, l'étude de la construction et de la déification du pouvoir communiste, d'une part, et des formes actuelles de dénégation collective, d'autre part, me parait tout aussi riche d'enseignements. Beaucoup de milieux et d'individus ont participé, peu ou prou, aux mécanismes d'agrandissement imaginaire du pouvoir communiste et de ses représentants. Les formes de symbolisation du pouvoir officiel se sont réalisées à travers un processus où le rôle des rites, des fêtes et des commémorations fut prépondérant. Les imaginaires sociaux ont ainsi constitué un ensemble symbolique qui a concouru à un dédoublement de l'identité sociale de la personne. Les images du parti, du militant, du héros, bâties dans le statuaire, la littérature, le cinéma, etc. ont pu ainsi s'ériger en autant de représentations officielles de la personne. Alors que le chez-soi, le repli sur la famille et le réseau familial a montré l'importance de l'institution de la maison, autour de laquelle se sont organisés les groupes sociaux de référence. Elle a toujours marqué la morphologie sociale dans son ensemble comme la construction sociale des identités individuelles. Le pouvoir communiste a pourtant réussi à s'en servir pour asseoir le totalitarisme et le centralisme d'un système outrancier sans précédent dans l'histoire politique de ces sociétés, d'une part, par la promotion des groupes familiaux se rapprochant en bloc du pouvoir officiel, ou bien au contraire, d'autre part, par la poursuite des persécutions et la «purification » des réseaux familiaux jusque dans les membres les plus éloignés. Par ailleurs, la construction d'un espace privé plus ou moins protégé a réussi à cloisonner des représentations subtiles d'une autre identité sous-jacente de la même personne, ce qui témoigne en même temps de l'importance d'une approche anthropologique des constructions identitaires en Europe.

À ce propos, lors de mes recherches d'histoire et d'anthropologie du système culturel albanais dans les conditions du régime autocratique et totalitaire (Doja 1998b), j'ai eu l'occasion de montrer comment les formes traditionnelles d'expression culturelle, outre la réduction générale dans leurs tendances principales, ont aussi subi des distorsions de reconstitutions et d'actualisations folkloristes. Sous prétexte d'efficacité, ou plus simplement par absence de véritable projet culturel et social, une telle entreprise pseudo-culturaliste a généralement réduit la légitimité 
des revendications d'identité à des valeurs figées. Le recours à une conception idéaliste de la culture, par exemple, est conçu en dehors de l'histoire et des contradictions sociales, malgré la terminologie avancée par l'ethnologie albanaise officielle. La vision officielle de la culture, appauvrie et réductrice, a nié en son propre sein les tendances universalistes, les traits communs qu'elle partage avec les autres cultures et sociétés, notamment avec les voisins, les Slaves au Nord et à l'Est ou les Grecs au Sud, allant de ce fait à l'encontre de la dynamique de l'échange interculturel dont résultent toutes les sociétés sans exception. Un tel enfermement des identités est devenu dangereux à plusieurs égards, d'autant plus qu'il a autorisé proprement la manipulation politique.

Parallèlement, si on se réfère aux formes actuelles de dénégation collective après la chute du communisme, on pourrait proposer un cadre plus large, comparable à ce qui est suggéré par Lindner (2002) se référant au rôle joué par l'humiliation dans la structure sociale et le changement historique. Un tel cadre se situerait dans une longue transformation historique en cours qui concerne la norme sociale pour évaluer les comportements humains passant de l'ancien code de l'honneur à l'idéologie moderne des droits de l'homme. Pendant les deux cents dernières années, et particulièrement pendant le dernier demi-siècle, la diffusion de l'idéologie des droits de l'homme a popularisé le principe selon lequel tous les êtres humains devraient s'attendre à recevoir un traitement respectueux seulement en raison de leur humanité, sans référence au genre, à l'appartenance ethnique ou à d'autres critères «secondaires ». Les droits de l'homme sont ainsi orientés suivant le principe de l'égalité entre hommes et femmes, à la différence du code d'honneur qui assume une inégalité fondamentale entre eux. Les principes des droits de l'homme et leur fort accent sur l'égalité sont devenus si omniprésents, particulièrement en Occident, qu'il est facile d'oublier qu'ils se sont développés en réaction à un code d'honneur traditionnel (Nisbett \& Cohen 1996). L'honneur est ce qui agit dans les branches traditionnelles de la Mafia ou, plus généralement, dans les vendettas (Blok 1974 ; Black-Michaud 1975 ; Boehm 1984).

Dans une culture de vendetta, il est honorable, parfaitement légitime, et hautement «obligatoire » de se venger de l'humiliation en tuant une personne ciblée. Le contraire est vrai dans une société où les droits de l'homme universels sont reconnus ; "réparer» l'humiliation signifie reconstituer la dignité de la victime par un dialogue compréhensif, par des excuses sincères, et finalement par la réconciliation. Les droits de l'homme représentent un tournant fondamental dans la logique des changements sociaux. Ils transforment des pratiques traditionnelles «normales » en abus illégitimes. Ils placent des adeptes du vieux code en confrontation directe avec les adhérents au nouveau code. 
Dans la société des droits de l'homme, hommes et femmes sont des acteurs égaux dans le monde social, et tous deux fervents défenseurs de leur dignité personnelle contre l'humiliation. Ils sont tous deux définis comme responsables, réfléchis et capables de faire une part égale à la rationalité comme aux émotions. Ils se voient tous deux dotés d'un noyau dur de dignité, en raison de leur appartenance à l'humanité, sans référence au genre.

Cependant, les hommes et les femmes peuvent être également «indignes » dans une société de droits de l'homme, et par conséquent se mettre en danger à cause de l'hostilité des autres ou d'eux-mêmes, s'ils ne peuvent pas satisfaire ou n'arrivent pas à reconnaître les normes de l'idéologie des droits de l'homme. Les jeunes hommes sans éducation ont des problèmes particuliers avec la transition vers les nouveaux modes de vie et se trouvent sans rôle respectable. Ils sont humiliés aussi bien au sens du code d'honneur que de celui du code des droits de l'homme. Ils se sentent humiliés dans l'ancien contexte parce qu'ils ne peuvent pas gagner leur vie, prendre soin d'une famille, et être un digne patriarche. Ils se sentent humiliés dans le nouveau contexte parce que leur prouesse masculine, leurs virtuosités physiques et leur capacité à émerveiller les gens, ont peu de valeur dans la société globale de l'information. Ils peuvent dédaigner les « débiles » qui réussissent, mais ils ne peuvent pas les imiter. À moins qu'un tel jeune homme parvienne à devenir une étoile du football, peu de carrières lui sont ouvertes. Dans des cas extrêmes, il peut devenir voyou, membre d'un gang violent, alcoolique, drogué.

Dans le cas des femmes, les jeunes femmes sans éducation ont aussi des problèmes spécifiques liés à la transition vers les nouveaux modes de vie et, comme leurs frères ou leurs compagnons, elles se trouvent sans rôle respectable. Elles aussi sont humiliées aussi bien dans les anciens que dans les nouveaux contextes. Une jeune femme sans éducation peut choisir de devenir une mère, même à un âge très jeune, mais elle se verra consigner en marge de la société, avec peu d'argent ou de reconnaissance, puisque l'ancien rôle modèle de femme "protégée » a perdu de sa crédibilité dans une société des droits de l'homme. Comme le code d'honneur affaiblit son emprise, peu de gens sont enclins à donner reconnaissance et glorifier une jeune femme rien que pour sa maternité dévouée. Ainsi, manquant d'éducation et de confiance en ellemême, elle n'est pas plus disposée à réussir avec succès dans le nouveau contexte des droits de l'homme. Comme dans le cas de son frère ou de son compagnon, elle constate que les vieilles manières de gagner le respect ont disparu, alors que les portes du nouveau monde restent fermées. 
En fait, la situation est bien plus compliquée, puisqu'une personne ou un groupe de personnes peuvent être définies par ses parents, ses voisins ou ses amis, différemment de ce qu'elles se définissent ellesmêmes, comme par exemple dans des contextes d'immigration. Un dilemme semblable est apparu aux personnes qui préconisent les droits de l'homme tandis que leur propre famille s'attend à ce qu'ils défendent leur honneur. La renaissance de vieilles affaires de vendetta en Albanie post-communiste en transition fournit en exemple de tels cas où beaucoup de gens se sont trouvés confrontés à ce dilemme on ne peut plus sérieux, coincé entre deux mondes, le monde de l'honneur et le monde des droits de l'homme.

Plus sérieusement, si l'honneur constitue la structure de prestige par excellence dans une société régie par son code traditionnaliste, les études féministes ont montré comment le même processus de différenciation et subordination dans les relations de genre s'est effectivement exacerbé par l'idéologie sexuée exhortée par les États nations au XIX ${ }^{\mathrm{e}}$ siècle ou plus récemment par les régimes militaires et autoritaires (Enloe 1993 ; Yuval-Davis 1997). À ce propos, j'ai montré comment la politique tristement efficace des viols et autres violences et atrocités sexuelles interethniques pendant les récentes guerres en ex-Yougoslavie sont devenues possibles (Doja 2001a). Contrairement à certains savants français qui ont préféré dans leur analyse l'aspect impulsif et la représentation «esthétique » (sic !) des viols (Nahoum-Grappe 1996), j'ai montré que la politique des viols devait être considérée en prenant en considération l'arrière-plan culturel propre aux groupes concernés. C'est plus particulièrement l'impact d'un symbolisme partagé des structures de parenté, qui fait que les revendications des factions opposées soient souvent exprimées dans les mêmes termes, ce qui révèle en même temps les règles sans merci du jeu politique et idéologique. ${ }^{1}$

Sûrement le viol est un sujet qui mérite une attention anthropologique plus proche, particulièrement en ce qui concerne ces aspects importants des relations de genre et de la sexualité qui sont liés à

\footnotetext{
Ce sujet est développé plus en détail dans une série de conférences invitées et communications : «Des atrocités sexuelles et autres violences dans les conflits ethniques : paradoxes venus d'ailleurs ou sensations dans le cénacle savant », Séminaire Jean Stcetzel d'Anthropologie et de Psychologie Sociale, Université Paris Descartes en Sorbonne, 13 Janvier 2000 ; «Cultural similarity, segmentary social structure and cognitive processes of categorization in the arena of ethnic conflicts ", Department of Anthropology Special Meeting, National University of Ireland, Maynooth, ${ }^{\text {st }}$ March 2000 ; "The politics of mass rapes in ethnic conflicts », Medical Anthropology Seminars, University College London, $5^{\text {th }}$ February 2004 ; «Raw madness and cooked crime: the politics of rapes as an instrument of ethnic cleansing », Societies in Transition, Annual Conference of Anthropological Association of Ireland, University of Limerick, 1-2 June 2004.
} 
l'ethnicité. En effet, alors que peu de renvois existent entre les sciences sociales et humaines, il y a plus de similitudes que des différences dans les approches contemporaines de l'ethnicité et de la sexualité, à tel point que le croisement de la problématique de l'ethnicité et du genre est devenu le centre de beaucoup d'intérêt dans les recherches de ces dernières années (voir Nagel 2000). Cependant, j'ai d'abord conceptualisé le complexe des viols en conflit ethnique principalement comme un argument théorique pour faire mieux apparaître le principe structurant des inévitables options manichéennes dont l'objectif destructif est d'aggraver et d'exacerber le conflit interethnique. Le viol réunit des catégories disjonctives (cf. Hage 1997) de la même façon que le cumul de l'identique en anthropologie de l'inceste (Héritier 1994), l'idéologie du sang lors des activités de chasse (Testart 1986) ou le sens implicite de la pollution rituelle (Douglas 1966). Je crois alors que la triste efficacité de la politique des viols dans ce conflit ethnique est devenue possible notamment grâce à une politique délibérément instrumentale exploitant la similarité culturelle et les traits culturels identiques, par la transgression du principe structurel des identités indiscernables, qui va nécessairement produire le danger et la pollution sociale.

En effet, pendant les guerres en ex-Yougoslavie comme ailleurs, pour que la triste efficacité des viols de masse soit possible comme un instrument de la purification ethnique, il était nécessaire que les valeurs de l'honneur aient pu se mettre en avant par une sorte d'agencéité (agency) politique et instrumentale. Cette agence additionnelle a été fournie par le rôle croissant du discours traditionaliste et nationaliste faisant nécessairement éclater le système entier de l'ordre moral et de la morphologie sociale en premier lieu, précisément en mettant à l'avant les valeurs destructives de l'idéologie de l'honneur. C'est ce qui a rendu possible par la suite à ce que l'ethnicité soit convertie en conscience nationaliste, que cette conscience s'organise et que le nationalisme organisé devienne militariste, masculiniste, misogyniste, raciste et violent.

Les manières dont le contexte politique et le fond culturel peuvent influencer la signification politique incorporant les viols dans une stratégie de guerre semblent utiles pour examiner et comprendre comment les conceptions de la responsabilité et des rôles attendus entre les sexes à un moment et un endroit particuliers peuvent mener les acteurs sociaux à commettre des atrocités qui transgressent les codes moraux de leur propre société tout en condamnant leurs victimes au silence. En fait, du moment que les projets nationalistes ont mobilisé un discours traditionaliste sur la construction sociale des genres et de la guerre, en effet ils ont engendré la guerre, comme un phénomène fortement hiérarchisée 
sur l'opposition masculin/féminin, comptant sur un ordre moral réifié et une idéologie de groupe assumée de la part des gens entrainés en conflit.

Dans ce sens, ce ne sont pas les rapports de pouvoir qui sont impliqués dans la re-traditionalisation des valeurs. C'est le changement des structures macrosociologiques qui alimente cette re-traditionalisation et c'est l'usage instrumental des valeurs identitaires et des valeurs morales et sociales qui fait que le viol soit aussi efficace comme une arme de purification ethnique. Si on s'accorde ainsi pour suggérer que le viol a une fonction politique immédiate, il devient suffisamment clair dans ce cas que la logique des rapports familiaux, basé sur un discours traditionaliste qui insiste fortement et délibérément sur l'idéologie patriarcale où l'honneur est central et générateur de violence, lie fortement la production des sujets masculins à la politique ethnique. Il s'agirait alors d'une contribution importante à une discussion de la guerre (Kaldor 1999/2006) qui est souvent limitée à des concepts généraux comme le nationalisme ou les régimes corrompues qui utilisent leurs propres populations pour atteindre des buts privés.

La connaissance acquise par l'appréhension expérientielle du travail de terrain et dans la théorie anthropologique peut montrer comment des mythologies projetées sont déterminées par la construction du monde en fonction du modèle des rapports de genre, alors même qu'elles restent appuyées sur un fond culturel local. Un des résultats les plus importants à la fois de l'analyse structurale et de l'approche féministe a dû indiquer que le genre est un dispositif structural des représentations globales du monde. Essentiellement, la réalité du monde se situe dans la signification produite par la morphologie des relations, des structures et des valeurs qui sous-tendent l'arrangement des rapports de genre et la construction des genres dans un contexte socioculturel.

Après le débat sur les manières d' « écrire la culture » (Clifford \& Marcus 1986) et la déclaration de guerre contre toutes sortes de réification et d'essentialisme, nous sommes devenus encore moins aptes à gérer cette dimension de la vie humaine que les anthropologues avaient l'habitude de s'en réclamer l'expertise, à savoir ce côté normatif, nonrationnel, et pourtant intrinsèquement significatif de la vie sociale que nous appelons toujours «culture ». Dans notre ardeur à déconstruire les quelques entités qui étaient autrefois considérées comme « réelles » et à préférer les notions de processus et d'agence aux notions de structure et de culture, nous avons contribué à rendre intellectuellement et politiquement litigieux le fait de parler intelligemment au sujet des différences qui affectent très concrètement la vie des gens. Accepter la validité du témoignage des viols par rapport au manque de liberté éprouvé par beaucoup de femmes n'est pas proposer la condamnation générale d'une culture donnée. En reconnaissant les dimensions cultu- 
relles des actes humains et de leurs motifs, il n'est pas nécessaire d'impliquer une compréhension réductionniste de la culture, qui ramènerait tous les membres d'une communauté à des êtres sociaux qui «ont une culture » et "sont culturellement déterminés » dans leurs expériences individuelles, leur subjectivité de la souffrance et leurs aspirations personnelles, ni qu'ils sont préprogrammés pour réagir de la même manière toujours et partout.

L'analyse des notions de personne et de construction des genres, de famille et de systèmes de parenté, d'hérédité et d'héritage, que j'ai eu l'occasion de centrer sur la problématique de la construction des identités sociales, contribue certainement à l'approche des relations interethniques et de la dynamique culturelle des valeurs sociales, plus particulièrement dans les études sur le symbolisme des conflits de groupes ethniques (Doja 1999c). La reformulation de la problématique des multiplicités taxonomiques d'identification, incluant les conceptions de la personne, les relations familiales et les structures parentales, aussi bien que les valeurs d'appartenance ethnique et nationale, linguistique et religieuse, se trouve véhiculée, en période d'adversité sociale, à la fois par le passage de l'alliance à la filiation et par les préférences structurelles tangibles, sous-tendues par des valeurs et des discours idéologiques différents.

Ces réajustements discursifs permettent aussi de mieux appréhender, dans un contexte de crise, le repli sur les liens de filiation d'abord et les stratégies d'alliance ensuite. Ce sont ces liens qui organisent la défense du groupe de façon stable et structurée, alors que le recours aux valeurs idéologiques et culturelles s'ajoute à la structure du modèle social comme un mécanisme complémentaire et réactionnel. On observe ainsi l'engendrement d'unités sociales d'un nouveau type.

Les réseaux sociaux appuyés sur les relations classiques de patronage et de clientélisme, tenues pour caractéristiques des sociétés méditerranéennes (Gellner \& Waterbury 1977 ; Giordano 2012), s'appuient davantage sur la maison qui apparaît à nouveau comme une création institutionnelle judicieuse, telle qu'elle fut conceptualisée par LéviStrauss dans ses derniers enseignements (1984 : 187-241). Notamment, la maison permet de composer des forces contradictoires traduisant un état où les intérêts politiques, qui tendent à envahir le champ social, empruntent encore le langage de la parenté mais doivent en même temps le subvertir. Actuellement, dans les sociétés sud-est européennes, l'alliance matrimoniale, qui sert à établir et à renforcer la puissance familiale, acquiert de plus en plus une valeur sociale aussi grande que le clientélisme à un certain patronage politique. Les maisons assurent donc de nouvelles charges sociales apparues dans le processus de transition, où la façon dont les lignées s'entrecroisent et se nouent compte autant 
sinon plus que leur continuité. Mais ce qui est beaucoup plus important est que la maison tient une fonction de solidarité sociale que les pouvoirs publics ont perdue ou ne peuvent plus tenir.

Or, la priorité donnée à ce clivage, pourrait être lue à nouveau avec son potentiel de risques politiques répercuté dans l'explosion des nationalismes. Le social réapparaît désormais, sous une forme spécifique du processus de transition, dans les revendications nationales. On voit bien tout l'intérêt, dans ce contexte spécifique, d'étudier les liens qui relient les différents réseaux de formations familiales et de structures parentales aux revendications nationales. Une étude comparée entre structures familiales, nationalités et religions dans plusieurs terrains différenciés pourrait devenir capable d'explorer cette question globale et d'affiner la connaissance.

L'approche comparative entre Kosova et Albanie, concernant l'aire de peuplement albanais dans le Sud-est européen, paraît à nouveau très instructif dans le champ des sciences sociales. On peut remarquer d'emblée que cette approche aura à cœur de présenter les formations familiales dans leurs composantes ethniques et religieuses. Comme je l'ai déjà signalé, une réalité taxonomique, identifiée par des critères multiples, tels ceux de personne, de famille, de parenté, de nationalité et de religion, pourrait alors proprement s'élaborer (Doja 1995a). En termes d'un complexe conceptuel intégrant parentés, nationalités et religions, quel exemple plus déconcertant pouvait-on imaginer que celui des Albanais de part et d'autre de la frontière ? Ce qui amène, de surcroît, à découvrir la confrontation entre deux politiques familiales opposées dans les anciens régimes communistes de la Yougoslavie titiste et de l'Albanie de Hoxha.

Dans cette perspective, même si la maison n'est pas toujours clairement identifiable en tant que forme institutionnelle, cette notion sera utilement appliquée. C'est parce qu'elle peut révéler un schéma organisateur, ou fournir pour le moins une grille de lecture qui permet de résoudre des contradictions apparentes, de mieux comprendre comment des catégories jugées incompatibles peuvent peu à peu se confondre, et leur opposition recevoir une valeur positive, dans ces sociétés où s'esquisse une volonté consciente d'ouverture à un devenir historique nouveau.

La maison est ainsi considérée comme un espace social et socialisé et non pas comme un refuge déréalisé et anhistorique. Les politiques publiques, implicites ou explicites, menées en direction des familles sont par ailleurs révélatrices d'enjeux sociaux et économiques, mais également des valeurs et des objectifs de solidarité sociale, que s'assignent les responsables. Par leur place au cœur des remaniements du public et du privé, elles deviennent un excellent miroir de l'évolution sociale et 
politique. Les formes d'organisation familiale apparaissent comme une réponse, une adaptation, un compromis à l'hostilité extérieure ou à ce qui la favorise. Il ne suffit pas de dire qui fait quoi dans la maison, mais aussi comment et pourquoi, ce qui amène à envisager les valeurs et les différences culturelles.

On ne saurait négliger le tissu familial comme fait et objet politique et social de développement en ce qu'il interfère grandement avec les évolutions en cours et à venir. Dans cette perspective, je me suis interrogé sur la façon dont les maisons, en tant qu'unités sociales de base, se sont adaptées pour biaiser, aussi bien avec le régime politique que la pression des conventions culturelles, pour survivre et améliorer leurs conditions de vie. La relation est étroite entre comment ruser avec les coutumes familiales et les activités traditionnelles et comment ruser avec l'État ou le système politique et juridique. D'autant plus que le pouvoir officiel pénétrait dans le même jeu de ruse pour parfaire ses mécanismes d'assujettissement.

Sur un autre registre, durant la période d'apogée du socialisme, des actions drastiques étaient entreprises pour imposer un modèle d'égalité des sexes, alors que dans les dernières années il y a un retour à la maison familiale, comme unité de base de production et de consommation, et les pressions externes ont diminué. Certains chercheurs parlent maintenant d'un retour à la patriarcalité tribale balkanique (Kaser 2000), mais comme j'ai eu l'occasion de montrer à propos des taux de fécondité et du mythe des familles élargies avec beaucoup d'enfants (Doja 2010b), la sensibilité expérientielle du travail de terrain de même qu'une attention particulière aux données locales des sources orales de la période présocialiste révèlent que ces verdicts sont beaucoup trop simplistes, d'autant plus que l'État socialiste lui-même a continuellement renforcé les dispositions patriarcales.

Le besoin d'études similaires se fait sentir dans d'autres sociétés sudest européennes, où les expériences contrastives du socialisme ont contribué à l'émergence de différences significatives dans une région qui ne cesse de manifester de larges continuités culturelles. Une relation comparable pourrait être décelée en Europe occidentale aussi, face à la morosité actuelle des situations de crise et d'exclusion, notamment en Europe du Sud où la prégnance de la maison est probablement visible plus que partout ailleurs. D'où l'intérêt d'une démarche comparative dans les études sud-est européennes plaçant l'institution familiale et ses valeurs culturelles au centre des processus de développement économique, social, politique et institutionnel, en Europe balkanique comme en Europe méditerranéenne, en Europe de l'Est comme en Europe l'Ouest. Il y a plusieurs formes de collaboration avec les experts des politiques sociales. Les crises des familles et des États dans d'autres 
parties du monde sont tout à fait différentes sur certains points de vue de base, mais là encore il y a plusieurs opportunités pour des recherches comparatives.

Les anthropologues (Segalen 1981 ; Goody 1983, 2000) en collaboration avec les historiens (Gullestad \& Segalen 1995 ; Kertzer \& Barbagli 2001) ont étudié la transmission de la propriété familiale à travers les générations et ses conséquences sur la structure sociale et le développement économique. Les familles peuvent aujourd'hui être effectivement considérées comme un espace élémentaire du développement économique et social dans les sociétés sud-est européennes, tandis que l'ancien système s'écroule et que le nouveau n'arrive pas encore à se consolider. Elles supportent tout le poids social des processus de transition, au moment où les infrastructures et les superstructures défaillent et se transforment.

La famille est de la même façon, en Ouest comme à l'Est, un champ privilégié d'observation, non seulement des mentalités et pratiques quotidiennes, mais aussi des mouvements d'avenir. Elle est un indicateur de la manière dont les populations vivent, accélèrent, freinent ou simplement s'adaptent aux réalités changeantes. D'un côté, la recherche anthropologique en Europe de l'Ouest s'approfondit sur les décisions des individus et des familles dans les environnements complexes où les régulations de l'État (systèmes de taxation et de sécurité sociale) changent continuellement. Si dans ce domaine les États cherchent à contrôler les dépenses de santé et de sécurité sociale, les familles ont à affronter la nécessité de vendre leurs habitations afin de financer les soins dus aux membres âgés de la famille. De l'autre côté, l'intérêt de la démarche en Europe de l'Est est finalement porté au remaniement entre espace public et espace privé que traduit l'institution familiale dans la transition politique. Alors que les allocations de chômage, par exemple, s'organisent laborieusement, ce sont bel et bien les maisons qui nourrissent leurs sans-emploi. Ce sont elles également qui organisent la débrouillardise et le bricolage social, l'économie souterraine des entreprises pyramidales (entre autres) et des revenus non déclarés, à un moment où la redistribution des pouvoirs d'un centralisme paralysé vers des autorités locales inexpérimentées n'a pas encore fait la preuve de son efficacité. Dans ce processus de transition des structures sociales, il faudra mettre l'accent sur l'observation des changements et des ressorts fondamentaux, sur leur condition juridique, leur rôle économique et leur fonction sociale. 


\section{CHAPITRE 4 \\ Prolongements}

Les champs thématiques que j'explore dans mes travaux et mes enseignements m'ont permis de poursuivre l'élaboration des réflexions théoriques, dans le cadre des approches anthropologiques de la construction des identités sociales, en passant de la socio-anthropologie de l'enfance et de l'éducation à la sociologie des religions et des relations interethniques, en privilégiant plus particulièrement l'approche épistémologique et politique des phénomènes d'idéologie et de pouvoir, de différence et de similarité, de frontière et d'agence.

L'objectif est naturellement d'intégrer dans le même cadre analytique et conceptuel les rapports entre les conceptualisations et les idéologies tellement différentes de personne et d'éducation, de parenté et de genre, de culture, de langue et de religion, de territoire et de mémoire, d'ethnicité et de nationalisme, de citoyenneté et de droit socioculturel, y compris le savoir académique et universitaire ou les notions de démocratie et de modernité, de démocratisation et de modernisation. Il est important en effet d'examiner les processus éducatifs et socioculturels sousjacents non seulement aux idéologies et politiques de conversions et de constructions identitaires, de réformes spirituelles et de mouvements d'affirmation nationale, mais aussi aux discours idéologiques de propagande communiste et nationaliste, tout comme aux moralités de la démocratie et aux espérances de la modernisation censées rendre compte des processus de ces transformations socioculturelles qui se rapportent à la transition postsocialiste et à l'intégration européenne, ou encore aux efforts académiques de poststructuralisme et de postmodernisme dont le seul but ne serait, semble-t-il, que de négocier une certaine autorité de leadership universitaire.

Dans cet effort, la question du pouvoir et des rapports politiques restera centrale à l'ensemble des propositions théoriques, à ce point qu'on devra considérer plutôt comme réducteur de la traiter séparément. Il faudra avant tout faire une distinction entre pouvoir et politique et s'intéresser à l'usage instrumental des valeurs morales et culturelles des identités sociales. Pour cela il me semble nécessaire de démontrer l'importance de l'approche anthropologique dans la compréhension des conflits contemporains dans la région balkanique, en se gardant bien de tomber sur des réactions de mode qui mondialiseraient abusivement 
l'expérience récente des Balkans. Aussi faudra-t-il se garder du risque que le choix de propositions théoriques ne débouche pas sur des propositions essentialistes ou instrumentalistes, tout en s'efforçant de trouver avant tout les moyens théoriques pour ériger un pont analytique entre les expériences sociales des gens ordinaires et les structures politiques des entités nationales construites en leur nom et censées en accord avec leur vie sociale et culturelle.

Mes travaux montrent, entre autres, l'importance de prendre en considération les structures anthropologiques des cultures et des sociétés, plus spécifiquement les processus symboliques qui s'ancrent au plus profond des traditions socioculturelles et qui sont d'autant plus importants pour analyser les évènements contemporains. Ainsi, les mobilisations ethniques, les affiliations religieuses ou les rapports de genre ne sauraient être des critères objectifs pour définir les groupes, mais plutôt des catégories à penser les groupes. Plus précisément, ils semblent être essentiellement des ressources politiques instrumentales à déterminer les relations hiérarchiques entre les individus au sein d'un groupe ou d'un réseau socioculturel. En revanche, les processus par lequel se réalisent le pouvoir de la communauté et l'instrumentalisation politique de l'identité doivent se repérer dans les discours disciplinaires ainsi que dans les pratiques culturelles courantes qui toutes ensemble tentent de faire valoir le contrôle autoritaire sur la production sociale et la reproduction biologique et culturelle, avec comme résultat de faire taire l'agencéité humaine, plus particulièrement celle des femmes, sous l'apparence de cohérence structurelle.

L'idéologie culturelle est souvent ethnicisée dans les conflits ethniques, de même que l'identité est idéologisée dans les discours sociaux et les débats académiques. Une confusion fréquente est faite entre la socialisation culturelle, l'identification ethnique et la construction identitaire. Si ces processus sont étroitement liés et s'interpénètrent les uns les autres, ils ne sont pas de même nature et ils n'ont pas nécessairement un lien généalogique entre eux. Pour saisir le caractère dialectique de leur connexion, de même que le caractère politiquement instrumental des relations entre les structures sociales, les discours de réformes culturelles et les idéologies des mouvements de construction identitaire, il est important de comprendre, au-delà d'une simple juxtaposition linéaire bien connue, qu'il s'agit principalement d'explorer une causalité structurelle entre les transformations sociales, les mouvements culturels et les doctrines idéologiques. À cet égard, fondé sur une comparaison anthropologique et historique dans le domaine religieux entre les hérésies médiévales chrétiennes, les cultes millénaristes indigènes et les « nouveaux » mouvements religieux occidentaux, mon hypothèse est que les revendications hétérodoxes d'une conception hiérarchisée de la 
divinité dans les doctrines religieuses ainsi que la consolidation sociale d'approches diversifiées et réflexives dans les discours académiques et les pratiques culturelles correspondent à une idéologie égalitaire dans la société humaine. À l'inverse, le but ultime de toute revendication n'est autre que d'établir un ordre social hiérarchique, qu'il soit religieux, patriarcal, national, politique ou académique, aspirant à contrôler des discours, des pratiques, des idéologies et des politiques monothéistes, unifiées et exclusives.

Si l'on veut étudier le rôle ou la fonction que la religion joue dans la société, tout en considérant l'homme en tant que constructeur de mondes symboliques, il faut s'attacher à chercher, sinon des lois, du moins des processus généraux, comme le rééquilibrage politique du religieux par rapport au reste de la vie sociale, chaque fois que l'écart est trop grand, et qui montre plus particulièrement comment le transfert religieux d'un domaine à un autre entièrement différent pointe nécessairement vers une dimension idéologique dissimulée derrière les discours doctrinaux autoritaires. Quoique le détour puisse paraître un peu long, pour essayer de donner, non une réponse générale, mais la réponse qui convient à un cas particulier envisagé, il faudrait en effet considérer plus profondément certaines caractéristiques de la religion qui de ce point de vue paraissent plus essentielles que d'autres.

En l'occurrence, dans certains de mes travaux portant sur la religion et la croyance (Doja 2000b, 2011), j'ai montré que l'approche analytique permet de conceptualiser la religion comme un phénomène double, procédant de deux démarches séparées, à la fois complémentaires et opposées, qui s'expriment aussi bien dans les processus d'intériorisation et d'extériorisation que d'orthodoxie et de subversion, concurremment comme scrupule subjectif ou lien objectif, contrainte et déplacement. Plus particulièrement, si le caractère ambivalent de la religion correspond à l'opposition entre les conceptions du divin unifié ou hiérarchisé, les discours et pratiques religieuses sont entachées d'une forte instrumentalité idéologique, étayant respectivement des ordonnances socioculturelles ou des épistémologies questionnant l'ordre établi.

Considérant les projections religieuses et les idéologies d'affirmation identitaire, en comparaison avec le polythéisme des religions populaires et le panthéisme des mouvements religieux mystiques, j'ai soutenu l'hypothèse que le développement des pratiques religieuses et des mouvements successifs de conversion et reconversion chez les Albanais et les autres populations sud-est européennes ont dû tenir lieu, entre autres, de mécanismes psychiques de déplacement et de projection, se laissant interpréter comme des expressions de conflit et de protestation (Doja 2000c). En restructurant la mémoire collective et en imaginant le passé, les mouvements ethno-religieux construisent le nationalisme et 
donnent sens aux transformations socioculturelles. Pour apprécier leur réelle signification historique et les soumettre à une analyse anthropologique plus effective, il faudra les faire inscrire dans une dynamique sociale des idéologies d'objectivation et de résistance face aux pressions exercées par les autorités du pouvoir politique et religieux.

Cette façon de voir les choses permet de comprendre non seulement la structure de la religion comme un système idéologique et culturel, mais aussi comment et dans quelles conditions la religion est aujourd'hui instrumentalisée dans les pays du sud-est de l'Europe. Ainsi mes recherches historiques et ethnographiques de terrain en Bosnie, en Albanie, au Kosovo, en Macédoine et en Turquie illustrent bien le caractère du Bektashisme comme un ordre mystique et hétérodoxe à l'intérieur de l'islam. Plus particulièrement, en explorant les vicissitudes subies par le Bektashisme au cours de son histoire, en passant de l'Anatolie ottomane à la Turquie contemporaine (Doja 2006d) ou à l'Albanie indépendante et postcommuniste (Doja 2006e), j'ai montré à quel point la tendance spirituelle d'un mouvement mystique hétérodoxe récupère les perspectives socioculturelles et nationalistes pour les transformer en réformes orthodoxes et autoritaires afin d'asseoir son pouvoir (Doja 2006f).

Il y a lieu de réfléchir aussi sur la possibilité théorique d'utiliser des exemples sud-est européens de matériels ethnographiques de terrain comme un outil conceptuel et réflexif, afin de comprendre le profil des conflits ethniques en comparaison avec celui des débats théoriques dans l'arène universitaire. ${ }^{1}$ Ainsi, si on privilégie l'approche structurelle et cognitive de la relativité des valeurs de groupe, une considération plus attentive sur les données du dernier conflit ethnique entre Serbes et Albanais permettra d'approfondir la connaissance du profil théorique des conflits ethniques et d'affiner le cadre conceptuel du phénomène ethnique. Notamment, si on compare le profil des conflits ethniques avec celui des débats théoriques en sciences sociales, la considération

\footnotetext{
Ces réflexions sont initiées à l'occasion d'une série de communications : « Models of ethnicity reproduction: from ethnic object to academic subject ", Rethinking Primordialisms: Kinship, Religion and Ethnicity in the Formation of Modern Nationalism, $6^{\text {th }}$ Conference of European Association of Social Anthropologists, Krakow (Poland), $26^{\text {th }}-29^{\text {th }}$ July 2000 ; "Cultural similarity, segmentary social structure and cognitive processes of categorization in the arena of ethnic conflicts », Department of Anthropology Special Meeting, National University of Ireland, Maynooth, $1^{\text {st }}$ March 2000 ; "Ethnicity models of continuity and change », Race, racism, and interculturalism: the role of anthropology in the modern world, Annual Conference of the Anthropological Association of Ireland, National University of Ireland at Maynooth, Kildare, $8^{\text {th }}-9^{\text {th }}$ June 2002 ; « Structural cognitive models of ethnicity: an anthropological view on the relativity of groups values ", Senior Fellowship introductory Lecture, $13^{\text {th }}$ November 2002, College of Humanities, University of Limerick, Ireland.
} 
des approches opposées de l'ethnicité comme des données empiriques se révèle assez utile pour comprendre la nature même des débats dans l'arène universitaire. L'intention de mes recherches est effectivement de tenter d'utiliser la compréhension des processus cognitifs et structuraux de la catégorisation de l'ethnicité, autrement dit comment la similarité et la différence se produit à un niveau empirique, pour voir comment cette compréhension pourrait aider à repenser la théorisation du rapport entre les approches essentialistes et instrumentalistes du nationalisme.

À ce sujet, les débats récents explorant certaines problématiques centrales sur la nature de l'identité sociale et de la notion de personne, dans une approche parallèle à celles de Michel Foucault sur les relations de pouvoir et de savoir dans l'exploration des «technologies » de construction de la personne (Foucault 1976/1994, 1980, 1988), posent le problème de l'efficacité explicative des approches sociologiques et anthropologiques de l'identité et de la subjectivité, afin d'évaluer les arguments théoriques qui interprètent les formes changeantes de la subjectivité comme une réponse aux larges transformations socioculturelles résumées par la notion de «modernité ».

Lors de mes réflexions sur le concept de frontière dans la théorie anthropologique et la science sociale, ${ }^{2} \mathrm{j}$ 'ai souligné le concept de mobilité parmi un certain nombre de dispositifs et de caractéristiques formelles des identités. Simplement en supposant des mouvements de personnes, objets, capitaux, images, idées et informations à travers le monde et entre différents lieux d'appartenance, la mobilité implique en soi, d'une manière ou d'une autre, le croisement d'une frontière dans un endroit et un temps donné. Pris dans l'ensemble, ces aspects de mobilité, de spatialité et de temporalité, sont importants parce qu'ils rendent possible d'opérationnaliser un écart épistémologique vers les changements, transitions et transformations sociales, en concentrant l'attention de façon novatrice sur le fait même d'une condition de dépassement d'une frontière.

Telles problématiques sont très importantes pour la science sociale contemporaine, remontant jusqu'au modèle développé par Van Gennep (1909/1981) et repris par Victor Turner (1969). Peut-être contrairement aux idées reçues, elles peuvent aussi revendiquer un rapport majeur avec les procédures d'analyse transformationnelle inaugurées et développées par Lévi-Strauss dans l'analyse structurale des mythes (Lévi-Strauss 1955/1958). Au cours du criticisme anti-structural, l'objectif central de

L'occasion m'a été donnée par une invitation pour présenter une conférence lors de la création d'un nouveau Centre d'études sur les frontières à l'Université du Glamorgan au Pays de Galles : "The boundary condition in social and anthropological theory », paper presented to the new Centre for Border Studies, University of Glamorgan, Wales, U.K., $7^{\text {th }}$ June 2003. 
l'approche épistémologique de Lévi-Strauss semble avoir été perdu au détriment collectif de l'anthropologie et des sciences sociales. Or, par son caractère monumental, l'œuvre de Lévi-Strauss évoque celle des fondateurs de l'anthropologie, de Morgan à Frazer, alors que par la façon dont elle met en rapport le culturel et le mental, elle avait l'ambition de fournir une méthode rigoureuse d'investigation anthropologique proche du savoir scientifique, qui anticipe déjà sur une anthropologie théorique à venir (Doja 2008a). Le point fondamental reste l'émancipation de l'approche structurale hors du modèle linguistique, vers un nouveau contexte scientifique et technologique illustré en mathématiques, sciences de l'information, cybernétique et théorie des jeux, qui permet à l'anthropologie structurale de rendre compte de façon innovatrice des systèmes sociaux ou praxis des pratiques compétitives et stratégiques.

C'est surtout le développement de quelques tendances nouvelles et revigorées du paradigme structural, subsumées dans le concept d'expression canonique, qui montrent déjà l'espoir d'une ethnographie renouvelée qui pourrait faire une meilleure utilisation du raisonnement hypothétique et déductif, aussi bien que de la réflexivité et de la traductibilité des codes mutuellement convertibles concernant autant d'ancrages dans la réalité empirique des faits interculturels. Le projet théorique inspiré par l'analyse transformationnelle peut montrer que l'anthropologie structurale s'intéresse aussi et d'ailleurs assez intimement aux processus de conflit, de changement social, de praxis et d'agencéité au sein des réseaux socioculturels, ce qui paraît un aspect négligé mais essentiel de la théorie de Lévi-Strauss. Plus particulièrement, comme j'ai soutenu ailleurs (Doja 2008a, 2010a), je crois que l'exigence d'une condition de frontière, requise dans la formalisation canonique comme un catalyseur de sens, pourrait déjà anticiper l'instrumentalisation politique d'une agencéité idéologique et d'une pratique discursive, dont l'absence supposée a valu à l'analyse structurale, non seulement les critiques les plus virulentes, mais surtout d'être injustement négligé, mais qui pourrait être d'un grand intérêt pour l'analyse comparative de la construction identitaire et de la dynamique interculturelle.

Ainsi, après une critique détaillée de la rhétorique postmoderniste du poststructuralisme (Doja 2006b, 2006c, 2007), j'ai pris position pour initier un développement innovateur, qui suggère notamment l'éventualité d'élaboration d'une nouvelle vision des futurs développements de l'anthropologie et de la théorie sociale, me basant sur la tradition française d'anthropologie, en faveur d'un mouvement qu'on pour- 
rait qualifier de néo-structuralisme morphodynamique et constructiviste (Doja 2005e, 2006a, 2008a, 2008b, 2010a). ${ }^{3}$

Si la description morphologique des structures d'organisation sociale est effectuée dans mes travaux par une démarche rigoureuse dans un esprit d'évaluation critique et parfois polémiste, j'ai toujours été soucieux d'apporter des contributions sinon originales du moins fécondes en nouvelles pistes de réflexion à explorer. C'est là je pense que réside, en ce qui me concerne, la meilleure caution, porteuse d'avenir, pour une orientation dans les études interculturelles vers les méthodes et les approches essentielles forgées par l'approche structurale en sociologie et anthropologie en tant que sciences empiriques, théoriques et appliquées.

J'espère ainsi que ma contribution à l'effort de recherche qui intègre des perspectives complémentaires, du point de vue épistémologique et empirique, puisse devenir une autre instance à faire progresser notre compréhension théorique du monde, suivant le renouveau fondamental de ce genre de discussion théorique vigoureuse vers les modèles d'explications causales qui ont tendu à disparaître dans les années 1980. En particulier, une compréhension critique des rapports interactifs entre structure et agence, sous l'effet de l'idéologie et de la culture en tant qu'instruments politiques de l'hégémonie et du pouvoir, semble particulièrement propice à saisir les nouvelles constructions des identités et la dynamique des valeurs interculturelles. Car la théorisation des réseaux sociaux et culturels est liée aux représentations sociales des identités, qui ont certes une histoire, mais qui ne nous apprendraient pas grandchose sur les interactions dynamiques des valeurs sociales et culturelles si on ne les saisissait pas dans leurs variations idéologiques.

$\mathrm{Si}$, anthropologiquement parlant, la culture se réfère d'abord à quelque chose d'universellement partagée, elle se situe et se transmet à l'intérieur des groupes sociaux et elle devient de ce fait un marqueur de différence entre les groupes. Or c'est précisément à partir de là que les dangers de la réification deviennent possible de même que l'usage abusif de la notion de culture. En effet, face aux ambivalences du concept d'identité culturelle et les rapports complexes entre la construction du sujet et la position qu'il se donne dans une société aux références culturelles multiples et évolutives, je crois qu'il y a nécessité de mettre

J'ai eu également l'occasion de présenter ces propositions théoriques, spécifiquement fondées sur l'évidence empirique de mes recherches ethnographiques sur le terrain, lors d'une communication à la $108^{\mathrm{e}}$ Conférence annuelle de l'Association Anthropologique Américaine : "Morphodynamics and Agency : From Post-Structuralism to Neo-Structuralism ", paper presented to the Invited Presidential Session "Lévi-Strauss, Europe and the Ends of Anthropology», American Anthropological Association 108th Annual Meeting, Philadelphia, PA, December 2-6, 2009 (http //eprints.ucl.ac.uk/19165/). 
en perspective contrastée, d'un côté, le discours néolibéral sur le multiculturalisme et la légitimité culturelle qui est revendiqué à chaque fois qu'on parle de démocratisation culturelle, et de l'autre côté, le concept anthropologique de culture qui nous permet d'articuler et d'expliquer de manière intégrée les similarités et les différences culturelles. Je crois qu'une telle perspective contrastée entre le discours néolibéral et la notion anthropologique de culture pourrait seule nous permettre de mieux cerner les environnements culturels et les situations sociales pour mieux évaluer et programmer les politiques publiques.

Une telle perspective aura d'autant plus d'avantage qu'elle permettra aussi d'inscrire de façon novatrice l'approche anthropologique de la dynamique interculturelle et de la politique identitaire dans le mouvement récent de renouvellement des sciences sociales, dont les nouveaux objectifs et domaines de recherches donnent la priorité aux questions posées par une société globale, l'hybridation culturelle, le transnationalisme, les contacts culturels, les conflits ethniques et la responsabilité des politiques publiques en vue de la coexistence pacifique, de l'intégration et du développement du capital social dans les sociétés multiculturelles postmodernes. Ces tendances ont provoqué de nouvelles manières de pensée et ont favorisé la reconstruction de nouvelles hypothèses et paradigmes fondamentaux, qui mettent à profit la perspective anthropologique transactionnelle fondée à la fois sur l'interactionnisme social et sur l'échange social.

Si dans le meilleur des cas ce mouvement de renouvellement des sciences sociales s'inspirait plus profondément de l'approche anthropologique de la dynamique interculturelle et de la politique identitaire, il trouverait sa meilleure application dans la promotion de politiques publiques qui devraient encourager le passage de la société multiculturelle (centrée sur la reconnaissance d'autres cultures) à la dynamique interculturelle (centrée sur les interactions aux frontières culturelles). C'est ce qui est parfois qualifié même de révolution Copernicienne, au moins dans le domaine des sciences de l'éducation (Coulby 2006; Portera 2008). De toute façon, c'est ce qui pourra nous rediriger, je crois, vers ces développements négligés dans les sciences sociales, mais qui sont potentiellement féconds pour construire l'approche novatrice des phénomènes sociaux et l'épistémologie des sciences sociales que nous appelons.

En effet, la société multiculturelle met l'accent sur la diversité culturelle des sociétés humaines et des groupes sociaux et vise à développer la conscience des différences culturelles, en promouvant des attitudes antidiscriminatoires, qui peuvent bien fonctionner dans des situations sociales sans tension ni conflit, mais qui pourront vraisemblablement devenir une source d'ethnicisation et de radicalisation raciste dans les 
situations sociales caractérisées par une pression conflictuelle. En revanche, l'approche interculturelle transpose l'attention des images statiques et stéréotypées des cultures et des différences culturelles à la perspective dynamique des cultures en contact, en promouvant des attitudes interculturelles, des compétences interculturelles et des relations interculturelles, qui permettent de faire tomber les stéréotypes et les discriminations sous-tendues par la présomption fallacieuse de supériorité culturelle.

Finalement, dans ce contexte, la considération de la région sud-est européenne comme une aire culturelle se définissant comme un champ à la fois composite et instructif, pourrait présenter des chances importantes dans la reconsidération des approches théoriques et le développement des nouvelles approches. Déjà dans l'anthropologie britannique, comme l'a souligné Gellner (1995), la révolution malinowskienne est née de la transplantation des pratiques est-européennes à l'Ouest, en les dotant d'un raisonnement occidental. Malinowski a pris le style populiste-nationaliste de la recherche ethnique en Europe de l'Est, il l'a transplanté des Carpates aux îles Trobriands, il l'a séparé de son utilisation comme propagande nationaliste et il l'a appelé fonctionnalisme. Désormais, de nouveaux aperçus en provenance des études sud-est européennes pourraient à nouveau permettre de prendre une vue originale dans le domaine de la construction des identités et des transformations sociales, à un moment où les approches sociales sont sensibles à l'ouverture de nouvelles perspectives non-conventionnelles. 



\section{Annexes}

\section{Deux lettres de Claude Lévi-Strauss}

\section{2 avril 2006}

Cher Monsieur,

Les deux articles ${ }^{1}$ que vous avez bien voulu m'envoyer m'ont vivement touché. Vous avez une connaissance approfondie de mon œuvre, et, tout en lui attribuant plus d'importance qu'elle n'en a à mes propres yeux, vous en faites une présentation pénétrante. Vous m'apprenez aussi beaucoup sur mes critiques, qui me laissent généralement dans l'ignorance de ce qu'ils écrivent à mon sujet et dont je n'ai pas la curiosité de m'informer.

Avec mes remerciements, je vous prie, cher Monsieur, de me croire, en toute sympathie, votre

Claude Lévi-Strauss

(Doja 2005e, 2006a). 
LABORATOIRE D'ANTHROPOLOGIE SOCIALE

$$
\text { in rualet } 2006
$$

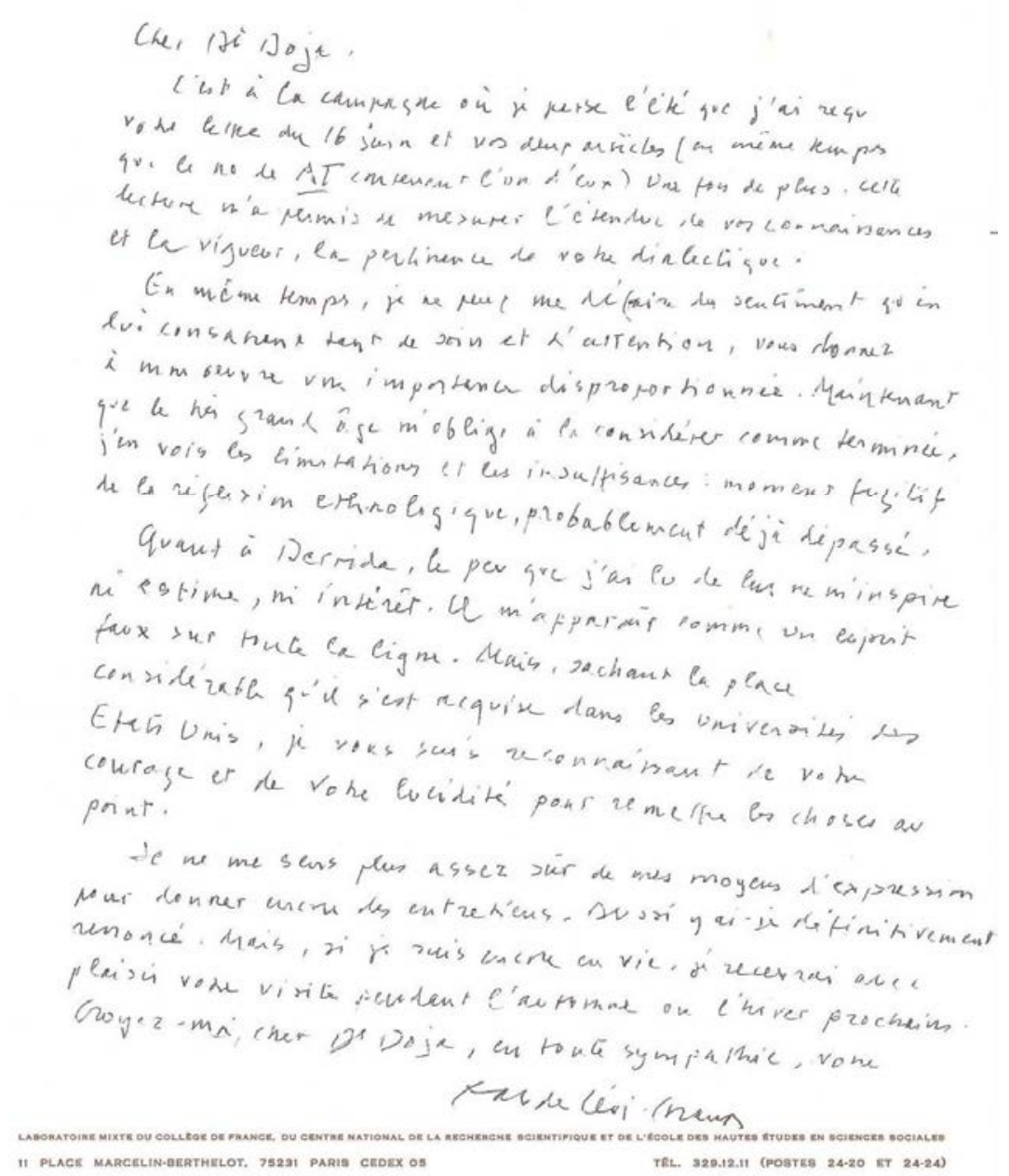

Figure 1. Lettre de Claude Lévi-Strauss reproduite dans : Anthropology Today, vol. 26 (5), p. 20, doi:10.1111/j.1467-8322.2010.00758.x (http://hal.ccsd.cnrs.fr/halshs-00523837). 
1 juillet 2006

Cher Dr. Doja,

C'est à la campagne où je passe l'été que j'ai reçu votre lettre du 16 juin et vos deux $\operatorname{articles}^{2}$ (en même temps que le no. de $A T$ contenant l'un d'eux). Une fois de plus cette lecture m'a permis de mesurer l'étendue de vos connaissances et la rigueur, la pertinence de votre dialectique.

En même temps, je ne peux me défaire du sentiment qu'en lui consacrant tant de soin et d'attention, vous donnez à mon œuvre une importance disproportionnée. Maintenant que le très grand âge m'oblige à la considérer comme terminée, j'en vois les limitations et les insuffisances : moment fugitif de la réflexion ethnologique, probablement déjà dépassé.

Quant à Derrida, le peu que j'ai lu de lui ne m'inspire ni estime, ni intérêt. Il m'apparaît comme un esprit faux sur toute la ligne. Mais sachant la place considérable qu'il s'est acquise dans les universités des États-Unis, je vous suis reconnaissant de votre courage et de votre lucidité pour remettre les choses au point.

Je ne me sens plus assez sûr de mes moyens d'expression pour donner encore des entretiens. Aussi y ai-je définitivement renoncé. Mais, si je suis encore en vie, je recevrai avec plaisir votre visite pendant l'automne ou l'hiver prochain.

Croyez-moi, cher Dr Doja, en toute sympathie, votre

Claude Lévi-Strauss

(Doja 2006b, 2006c). 


\section{Résumé du rapport de soutenance HDR}

\section{Ayant eu lieu le 18 juin 2004 à la Faculté des Sciences Humaines et Sociales de l'Université Paris Descartes, en Sorbonne}

Le rapport de soutenance rend tout d'abord hommage à la qualité du dossier présenté à l'appui de la demande de l'habilitation à diriger des recherches : un mémoire substantiel, deux livres (en français et en anglais), une quarantaine d'articles publiés dans des revues reconnues, des contributions originales à des ouvrages collectifs, ainsi que de nombreuses communications à des réunions scientifiques internationales. Les ouvrages d'Albert Doja sont très variés même s'ils sont essentiellement consacrés à l'Albanie et à la région balkanique. Il y a beaucoup de thèmes importants abordés et une quantité significative de propositions. C'est un corpus très riche, plein d'idées intéressantes qui poussent à repenser les concepts de base.

Les rapporteurs notent qu'il y a deux thématiques organisent le dossier, celui de la construction culturelle de la personne (morphologie sociale, parenté et relations de genre) et celui des relations interethniques élargies aux champs de la religion, de la nation et de la folklorisation des traditions culturelles et notamment des conflits qu'enclenchent tous ces éléments. Sa thèse de Doctorat qui était en grande partie basée sur les données folkloriques et ethnographiques cherchait à comprendre la constitution de la personne en Albanie en utilisant des bases d'interprétation anthropologique où les influences les plus explicites sont les œuvres de Lévi-Strauss. De la construction de la personne le regard s'est très naturellement porté vers les valeurs et les traits structurels qui façonnent la société albanaise (un système lignager, l'idéologie du sang, l'hypertrophie du sentiment fraternel, le sens de l'honneur, la codification de l'amitié, etc.).

Ces approfondissements et ces élargissements de la problématique de départ ont abouti, par touches successives, à un riche tableau où l'étude de la socialisation, de la formation de personne, la nature de la culture régionale, la structure sociale, la construction de l'honneur, les pratiques religieuses par rapport à la distribution linguistiques contribuent à un effort orienté vers une compréhension de la spécificité des sociétés et des cultures albanaises et sud-est européennes. De là il se met à analyser les formes et la dynamique de l'identité ethnique, nationale et le conflit. Son anthropologie représente une excellente combinaison qui devrait être utile dans la recherche régionale. Il s'agit d'une anthropologie sociale et historique des «traditions » mais dans la mesure où elle se situe dans un balancement entre ethnie et nation on peut considérer qu'il s'agit d'une anthropologie du juste milieu qui d'ailleurs ne sacrifie nullement l'actualité comme en témoignent les analyses consacrées au phénomène des viols ou encore à l'exercice démocratique. Enfin il discute les questions plus contemporaines qui relèvent des transformations politiques et sociales dans la région, l'introduction de la démocratie, la migration et l'intégration. Le mémoire 
distingue d'ailleurs très bien les champs de recherche et les champs d'implication. Dans ce parcours Albert Doja démontre sa maîtrise de la région du point de vue historique, linguistique et culturelle en même temps qu'il intègre en grande partie ces connaissances dans les discussions théoriques contemporaines dans la discipline.

Catherine Quiminal (Professeur, Paris VII) note que ce dossier met en évidence de manière convaincante l'intérêt, pour l'anthropologie, d'aborder des terrains concernant des sociétés du sud-est européen, puisque l'auteur revendique également une démarche comparative peu développée par l'anthropologie de l'Europe. De tels terrains permettent de "passer de l'Autre primitif ou archaïque, conventionnel ou populaire, en situation néocoloniale ou dans une communauté locale, vers l'étude des processus dynamiques et transactionnels de transformation sociale, de modernisation et de globalisation ». Albert Doja y fait état des connaissances historiques, géographiques, ethnologiques concernant la région. Il en restitue de manière critique les conditions de production et de reproduction et les limites. L'histoire des cultures du Sud-Est européen nécessite, selon l'auteur, une nouvelle formulation, un regard orienté sur la construction des identités, les transformations familiales et sociales. Le mode d'analyse proposé pour aborder des sociétés que l'auteur préfère qualifier de « conventionnelles » plutôt que de traditionnelles, s'éloigne volontairement de la monographie d'un groupe artificiellement isolé à la recherche de survivances, pour se focaliser sur les institutions centrales et les valeurs dominantes. Anthropologue né en Albanie, formé en France, ayant un engagement maintenu pendant plusieurs années dans des relations personnelles étroites en Europe du sud-est aussi bien qu'en Europe de l'Ouest, vivant et travaillant depuis de longues années en France, en Grande Bretagne et en Irlande, il se trouve dans une position propice à un type de recherche de terrain diachronique et comparative.

Jonathan Friedman (Directeur d'études, EHESS) note également que dans sa tentative de caractériser la région balkanique comme située entre deux complexes de civilisation en réponse aux discussions classiques basées sur la notion de région croisée entre l'orient et l'occident et le réductionnisme que cela peut entraîner, Albert Doja propose de redéfinir la région en termes de frontières plus fluides et de coexistence entre peuples différents. Ici il prend en compte à la fois la culture ou la société dans le sens objectiviste de l'observateur et l'identité culturelle ou ethnique qui est pratiquée dans les interactions entre membres de différentes populations. Sa discussion de la méthode est fort intéressante et reflète le parcours de sa formation. Il insiste sur la nécessité de combiner des méthodes différentes, historiques et comparatives, ethnographie, analyses de textes et recherches sur les documents archivés.

Jean Copans (Professeur, Paris V) note que Albert Doja passe d'une folkloristique classique de recueil des traditions à une anthropologie politique ou politologie géostratégique plurinationale. La question est d'importance car on 
doit se demander quelles sont les méthodologies de terrain les plus adéquates à l'étude des relations interethniques et des valeurs culturelles. Peut-on enquêter directement sur le processus de construction de l'ethnicité, peut-on observer en direct sa genèse interactive ou faut-il attendre un degré de fusion, de formalisation et de verbalisation pour la saisir et puis la déconstruire? Si les africanistes sont obsédés par cette question, pour Albert Doja il s'agit d'une nouvelle théorie, assez subtile et complexe. L'ethnicité est une question de point de vue, de position que redouble ici le problème de l'observation de la violence. L'anthropologie du génocide, de la souffrance et de l'affliction est à la mode mais c'est la mémoire qui joue le rôle central, de même que c'est le processus d'observation qui fournit des réponses empiriques aux nouvelles questions décisives qui mettent en cause les méthodes de la discipline.

Michael Herzfeld (Professeur, Harvard University), note également qu'on ne peut qu'être profondément frappé par la grande envergure des observations d'Albert Doja sur l'ethnographie albanaise et par l'érudition qui les soutient. On constate, bien sûr, que les données dont Albert Doja traite sont riches d'informations et d'aperçus. Il est allé bien loin au-delà de la prospective limitée des chercheurs antérieurs à lui. Il a mené de sérieuses enquêtes empiriques et fait preuve qu'il possède suffisamment la capacité de fournir des descriptions nuancées des faits sociaux. Souvent il révèle une sensibilité ethnographique presque éclatante, là où on est peut-être le moins préparé à le rencontrer, comme c'est le cas notamment dans son article sur les problèmes de stabilité au Kosovo, là où une petite scène de tension et de méprise dans un café Internet révèle l'univers du «transnational» dans toute sa complexité. Mais ce qui sauve les analyses des études folkloriques traditionnelles (isolation intellectuelle et stigmatisation par l'association avec des nationalismes exceptionnellement durs et revanchistes) consiste avant tout en deux points forts : sa connaissance, évidemment bien profonde et circonstanciée, de l'histoire des théories les plus importantes en anthropologie sociale d'un côté, et sa méfiance soit du nationalisme soit des critiques souvent trop simplistes avancées par des savants qui n'avaient peut-être pas considéré que le modèle d'une identité construite peut devenir abusive dans le cas où elle sert à soutenir des idéologies identitaires opposées selon la rhétorique de l'opposition entre le faux et le réel.

En ce qui concerne le champ des ethnicités comparées de l'Europe, Jean Copans note que des nationalités de l'empire austro-hongrois on glisse à l'ethnicisme avec des intellectuels organiques (et parfois des ethnologues) tout aussi responsables (et coupables!). Michael Herzfeld aussi mentionne les observations d'Albert Doja sur les points de parallélisme entre la politique ethnique et le comportement des savants, pour noter que celle-ci est une comparaison qui a pu achever un très haut niveau d'importance analytique. Le rapporteur est bien d'accord avec les observations d'Albert Doja, car ce qui est d'une importance capitale est le fait qu'il réussit à nous rappeler que les savants font déjà partie de ce qu'ils étudient, qu'ils le veuillent ou non. Il faut souligner que 
bien que d'autres ethnologues aient déjà établi des rapports, soit historiques, soit formels, entre le nationalisme et l'anthropologie, Albert Doja achève sur ce point une formulation suffisamment généralisable et heuristiquement suggestive pour qu'on puisse en dériver des projets « de terrain » à l'avenir.

À ce propos Christian Bromberger (Professeur, Université de Provence) et Jonathan Friedman (Directeur d'études, EHESS) notent tous les deux que les interprétations des violences et des atrocités sexuelles dans les conditions de conflit interethnique pendant les guerres de Bosnie et du Kosovo sont fort intéressantes. Jean Copans (Professeur, Paris-V) estime aussi que l'hypothèse d'Albert Doja sur l'équivalence culturelle des modèles de lecture du viol par la victime et par celui qui l'a perpétré est pertinente. Albert Doja montre comment la pollution du sang dans des sociétés qui en ont érigé la pureté en valeur dominante vise et "amène nécessairement le désordre et l'éclatement du système social et du groupe tout entier ». La substitution d'une ligne paternelle externe à la ligne établie par le mariage par l'agression désorganise profondément l'ordre parental de la société locale.

Jean-Pierre Warnier (Professeur, Paris-V) note à ce propos que les cadres d'analyse proposés par Albert Doja relèvent du structuralisme (Hage, Héritier, Testart, Douglas) en termes de catégories disjonctives et de rituels par rapport aux représentations des humeurs corporelles et à la réalité physique de l'agression-intrusion. Le cadre théorique structuraliste est traditionnellement considéré rebelle à l'analyse politique, mais le mérite d'Albert Doja est de montrer que la «culture» des protagonistes permet de comprendre l'impact ravageur du viol sur la subjectivité des acteurs, situant le viol dans un rapport de force et de pouvoir - pouvoir qui, comme le répétait Michel Foucault, s'adresse toujours au corps dans sa matérialité.

Dans ses analyses des causes des viols, Albert Doja est convaincu que l'explication doit être cherchée dans le fait que les valeurs d'honneur sont mises en avant par une sorte d'agencéité (agency) politique et instrumentale. Par ailleurs, les rapports de pouvoir ne sont pas impliqués dans la retraditionalisation des valeurs. C'est le changement des structures macrosociologiques qui alimente cette re-traditionalisation et c'est l'usage instrumental des valeurs identitaires et des valeurs morales et sociales de l'honneur ou de la religion qui fait que le viol soit aussi efficace comme une arme de purification ethnique. Ainsi on peut suggérer que le viol a une fonction politique immédiate.

Jonathan Friedman note qu'un point bien fort dans les recherches d'Albert Doja consiste à démontrer l'importance de l'anthropologie dans la compréhension des conflits contemporains dans la région balkanique. Il démontre que la logique des rapports familiaux, basé sur un modèle fortement patriarcal où l'honneur est central et génératif des feuds (vendetta) qui bloque la résolution des conflits sans la violence. Cette logique lie la production des sujets masculins à la politique ethnique. C'est une contribution importante à une discussion de la guerre qui est souvent limitée à des concepts généraux comme le nationalisme 
ou les régimes corrompues qui utilisent leurs propres populations pour atteindre des buts privés. Dans sa discussion des rapports complexes entre l'État, les discours nationalistes et la façon dont ils sont assimilés en bas de l'ordre politique, Albert Doja suggère le rôle important de la mondialisation dans le déclenchement de la fragmentation à l'intérieur de l'État-nation. Il discute la façon dont se développent les débats entre Albanais et Serbes à propos du statut historique de Kosovo, où les intellectuels ont joué un rôle important.

Certes Albert Doja construit son champ de manière historique, anthropologique et comparative. Même si cette comparaison s'arrête essentiellement aux frontières des Balkans, Jean Copans ajoute toutefois que par ailleurs il nous propose une théorie générale de 1'ethnicité. Il faut donc discriminer entre généralisation et comparaison. Or les sociétés des Balkans sont des sociétés de l'histoire écrite ce qui modifie les perceptions anthropologiques habituelles. Nous ne sommes pas dans le contexte postcolonial habituel mais le choix de propositions cognitivistes ne débouche heureusement pas sur des propositions essentialistes ou instrumentalistes, ni sur des réactions de mode qui mondialiseraient abusivement l'expérience récente des Balkans.

Christian Bromberger note à ce propos que l'auteur, traitant du thème des identités, renvoie dos à dos les « primordialistes » et les « instrumentalistes » en notant justement que même si « les attributs culturels tenus pour être la marque distinctive d'un groupe peuvent faire l'objet de transformations, de substitutions, de réinterprétations, cela ne conduit pas à poser que l'identification ethnique peut s'exercer à partir de n'importe quoi ». Jonathan Friedman ajoute aussi que la discussion d'Albert Doja sur les rapports entre l'ethnicité instrumentale et primordialiste est importante, même si elle reprend partiellement des discussions connues ailleurs aussi. Le fait que la manipulation de l'identité reste toujours dans des limites encadrées par une espace identitaire qui a ses propres limites implique que l'instrumentalisme est toujours limité et que « on ne peut s'identifier à partir de n'importe quoi ». Mais Albert Doja marque un point important quand il soutient que ces deux concepts sont mieux compris si on les considère comme des aspects d'un même phénomène.

Jean-Pierre Warnier remarque que la question du pouvoir et des rapports politiques apparaît souvent dans les travaux d'Albert Doja, mais là où il se rapproche le plus d'une analyse politique, c'est dans l'article « The politics of religion ». D'un point de vue théorique, il ne semble pas suffisant de renvoyer dos à dos primordialistes et constructivistes, comme le fait pourtant le candidat. C'est l'analyse du pouvoir qui permet de trancher entre les deux, ainsi que l'a suggéré Jean-François Bayart dans son livre L'Illusion identitaire. À cette question concernant le pouvoir, Albert Doja répond que c'est précisément parce la question du pouvoir et des rapports politiques est centrale à l'ensemble de ses travaux qu'on devrait considérer plutôt réducteur de la traiter séparément. Le candidat dit faire une distinction entre pouvoir et politique et qu'il s'intéresse à l'usage instrumental des valeurs morales et sociales de l'identité. 
Catherine Quiminal note à ce propos que les processus que Albert Doja qualifie de construction identitaire se développent en fonction d'enjeux sociaux et politiques circonstanciés parce que définis par des rapports de force internes aux sociétés considérées et par les relations plaçant ces dernières sous la dépendance d'autres sociétés, rapports et relations qui sont générateurs de domination, de discriminations et de résistances. Ces relations ont sûrement des incidences sur la compréhension de ce qu'Albert Doja appelle indifféremment dynamique des valeurs culturelles ou dynamique culturelle des valeurs sociales.

Christian Bromberger note également l'importance des processus de construction et d'affirmation des identités collectives, ainsi abordées par Albert Doja, dans une région marquée par une forte fragmentation des appartenances confessionnelles. L'auteur souligne le rôle des affiliations religieuses (le Bektachisme par exemple) dans la construction des nationalismes et dans les phénomènes de résistance qui ont ponctué l'histoire complexe de l'Albanie et du sudest de l'Europe. Il analyse, de façon éclairante et à diverses échelles chronologiques, les phénomènes de conversion et de reconversion religieuses dont l'Albanie a été le théâtre.

Également fructueuse est pour Michael Herzfeld l'explication que Albert Doja suggère de l'islamisation compréhensive d'une grande partie de la population albanaise. Il étend son modèle aux cas des bosniaques, et on ne peut que regretter qu'il n'est pas encore arrivé à comparer d'autres cas, tel celui de la Crète (où la cruauté des autorités vénitiennes assurèrent leur défaite par les Turcs et donc fournit un cas extrêmement clair de ce que Albert Doja indique pour l'Albanie). Quelle ironie historique que ce soit l'Église catholique qui, par l'oppression des populations orthodoxes, ait déclenché la réaction par lequel l'Islam gagna son importance actuelle en Albanie, même si c'est dans ses aperçus historiques plutôt qu'ethnographiques où Albert Doja semble achever son plus haut niveau de perspicacité !

Catherine Quiminal souligne aussi l'hypothèse suivante proposée par l'auteur : «Le développement des pratiques religieuses et des mouvements successifs de conversion et reconversion parmi les Albanais... se laisse interpréter comme des expressions de conflit et de protestation, conduisant aux mouvements nationaux et au nationalisme ». L'étude de la dynamique de ces mouvements a permis à l'auteur de «comprendre la relativité des conflits politicoreligieux et ethnico-nationaux... et de mettre la signification des changements d'appartenance religieuse dans la perspective de négociation et de redéfinition des identités sociales ». La religion s'ethnicise à des fins de rassemblement. Nation, nationalisme et citoyenneté sont des notions également appréhendées par l'auteur comme constructions identitaires et idéologiques. L'ethnicité est considérée finalement comme « une forme et une métaphore de l'activité et de l'organisation sociale ».

Jonathan Friedman note aussi que la discussion par Albert Doja de la démocratisation possible de l'Albanie est assez prometteuse, même si elle est encore 
à ses débuts. Il est d'accord avec l'auteur qui se demande dans quels sens peut se produire une démocratisation dans une société où un affaiblissement de l'État débouche sur un renforcement des rapports parentaux et claniques, où les hiérarchies clientélistes sont à l'ordre du jour ainsi que l'identité du type clanique dominante. Mais on peut aussi suggérer que c'est au contraire les soidisant institutions démocratiques qui sont adaptées à des stratégies «conventionnelles ", semblable à la démocratie africaine (ou du moins congolaise).

En fin de compte, les ouvrages d'Albert Doja représentent un corpus marqué d'une vaste érudition qui suscite de nouveaux points de départ pour une ethnologie comparative de la région balkanique. Avant tout, il a trouvé les moyens théoriques pour ériger un pont analytique entre les expériences sociales des gens ordinaires et les structures politiques des entités nationales construites en leur nom et, selon les discours officiels, en accord avec leur vie sociale et culturelle. Pour conclure, le rapport de soutenance revient sur l'originalité du dossier « en rendant hommage au travail accompli par Albert Doja », et souligne "l'intérêt d'une discussion entre anthropologues européanistes et anthropologues des aires culturelles plus traditionnelles de la discipline», aussi bien que «l'impression positive qui se dégage de cette œuvre riche et d'un parcours où chaque étape inaugure un renouvellement des perspectives et des thématiques ».

Après délibérations, le jury décide à l'unanimité de décerner à Albert Doja le titre d'Habilitation à diriger les recherches. ${ }^{3}$

3 Signé par les membres du Jury: Jean Copans (Professeur Paris V), Rapporteur Principal; Catherine Quiminal (Professeure Paris VII), Rapporteure; Christian Bromberger (Professeur Aix-Marseille I), Rapporteur; Michael Herzfeld (Professeur Harvard University), Rapporteur; Jonathan Friedman (Directeur d'études EHESS), Président du Jury ; Jean-Pierre Warnier (Professeur Paris V), membre invité. 


\section{Références}

Albera, Dionigi, Anton Blok \& Christian Bromberger, eds. 2001. L'anthropologie de la Méditerranée - Anthropology of the Mediterranean. Paris : Maisonneuve \& Larose.

Amselle, Jean-Loup. 1990. Logiques métisses : anthropologie de l'identité en Afrique et ailleurs. Paris : Payot. [Engl. transl. Stanford, Calif. : Stanford University Press, 1998].

Amselle, Jean-Loup. 2000. Branchements : anthropologie de l'universalité des cultures. Paris : Flammarion.

Anderson, Benedict. 1983/2006. Imagined communities: reflections on the origin and spread of nationalism. Revised edition. London/New York: Verso.

Anderson, Robert T., (ed.). 1971. Traditional Europe : a study in anthropology and history. Belmont, Calif.: Wadsworth Publishing.

Arensberg, Conrad M. 1963. « The Old World poeples: the place of European cultures in world ethnography », Anthropological Quarterly, 36 (3): 75-99.

Augé, Marc \& Françoise Héritier. 1982. «La génétique sauvage », Le Genre Humain, 3-4 : 127-136.

Backer, Berit. 1979/2003. Behind stone walls: changing household organization among the Albanians of Kosova, (eds) Antonia Young \& Robert Elsie. Peja: Dukagjini Books, 2003 (http://www.elsie.de/en/books/b31.html). [Masters thesis : Institute of Social Anthropology, University of Oslo, Norway, 1979].

Bakic-Hayden, Milica \& Robert Hayden. 1992. «Orientalist variations on the theme "Balkans": Symbolic geography in recent Yugoslav cultural politics ", Slavic Review, 51 (1) : 1-15, doi:10.2307/2500258.

Balandier, Georges. 1955. Sociologie actuelle de l'Afrique Noire : dynamique sociale en Afrique centrale. Paris : Presses Universitaires de France.

Bausinger, Herman. 1993. Volkskunde ou l'ethnologie allemande : de la recherche sur l'antiquité à l'analyse culturelle. Paris : Éditions de la Maison des sciences de l'homme. [Orig. Volkskunde : von der Altertumsforschung zur Kulturanalyse. Darmstadt, 1971, Tübingen, 1979].

Beitl, Klaus, Christian Bromberger \& Isac Chiva, eds. 1997. Mots et choses de l'ethnographie de la France : regards allemands et autrichiens sur la France rurale dans les années 30. Paris : Éditions de la Maison des sciences de l'homme. [Édition parallèle en allemand : Wörter und Sachen, 1992].

Bellier, Irene \& Thomas M. Wilson, eds. 2000. An anthropology of the European Union: building, imagining, and experiencing the new Europe. Oxford: Berg Publishers. 
Berque, Jacques. 1955/1978. Structures sociales du Haut-Atlas. $2^{\mathrm{e}}$ edition. Paris : Presses Universitaires de France.

Berque, Jacques. 1989. Mémoires des deux rives. Paris : Seuil.

Black-Michaud, Jacob. 1975. Cohesive force: feud in the Mediterranean and the Middle East. Oxford: Blackwell.

Blok, Anton. 1974. The Mafia of a sicilian village, 1860-1960: A study of violent peasant entrepreneurs. Oxford: Blackwell.

Boehm, Christopher. 1984. Blood revenge: the enactment and management of conflict in Montenegro and other tribal societies. Lawrence: University Press of Kansas (Publications in Ethnohistory).

Boissevain, Jeremy. 1979. « Toward an Anthropology of the Mediterranean », Current Anthropology, 20 (1): 81-93.

Boissevain, Jeremy. 1994. «Towards an anthropology of European communities? », In: Victoria Goddard, Josep Llobera \& Cris Shore (eds), The Anthropology of Europe: identity and boundaries in conflict, Oxford: Berg.

Bourdieu, Pierre. 1972/2000. Esquisse d'une théorie de la pratique. Paris : Seuil, 2000.

Bourdieu, Pierre. 1980. Le sens pratique. Paris : Minuit.

Bourdieu, Pierre. 1998. La domination masculine. Paris : Seuil.

Bourguet, M.-N. \& Bernard Lepetit, eds. 1997. L'invention scientifique de la Méditerrannée. Paris : EHESS (Recherches d'histoire et de sciences sociales, 77).

Braudel, Fernand. 1949/1979. La Méditerrané et le monde méditerranéen à l'époque de Philippe II. $4^{\mathrm{e}}$ edition. Paris : Armand Colin.

Byrnes, Robert, (ed.). 1976. Communal families in the Balkans: the zadruga. Notre Dame, Ind.: University of Notre Dame Press.

Campbell, John. 1964. Honour, family, and patronage: A study of institutions and moral values in a Greek mountain community. Oxford: Clarendon.

Chiva, Isac \& Utz Jeggle, eds. 1987. Ethnologies en miroir : la France et les pays de langue allemande. Paris : Éditions de la Maison des sciences de l'homme (Ethnologie de la France, 7). [Édition parallèle en allemand : Deutsche Volkskunde, französische Ethnologie].

Clifford, James \& George E. Marcus, (eds). 1986. Writing culture: the poetics and politics of ethnography. Berkeley: University of California Press.

Cohen, Abner. 1969. Custom and politics in urban Africa: a study of Hausa migrants in Yoruba towns. London: Routledge \& Kegan Paul.

Comaroff, Jean \& John Comaroff. 1992. Ethnography and the historical imagination. Boulder: Westview Press.

Coulby, David. 2006. "Intercultural education: theory and practice», Intercultural Education, 17 (3) : 245-257, doi:10.1080/14675980600840274.

Cuisenier, Jean, (ed.). 1979. Europe as a cultural area. Hague/Paris: Mouton (World Anthropology). 
Davis, John. 1977. People of the Mediterranean: an essay in comparative social anthropology. London: Routledge \& Kegan Paul.

Delaney, Carol. 1991. The seed and the soil: gender and cosmology in Turkish village society. Berkeley: University of California Press (Comparative Studies on Muslim Societies, 11).

Denich, Bette. 1974. « Sex and power in the Balkans », In: Michelle Rosaldo \& Louise Lamphere (eds), Woman, culture, and society, Stanford, Calif.: Stanford University Press, pp. 243-262.

Doja, Albert. 1984. «Le sol albanais à l'origine d'une locution française : bâtir des châteaux en Albanie », Les Lettres Albanaises, 7 (4) : 98-102.

Doja, Albert. 1985. «Rreth një legjende popullore për Skënderbeun [A folk legend on Scanderbeg] », Nëntori, 32 (2) : 185-193.

Doja, Albert. 1986a. «Esope et la tradition de la fable albanaise », Les Lettres Albanaises, 8 (1) : 127-135.

Doja, Albert. 1986b. «Portée signifiante et particularités de motifs dans les légendes populaires albanaises », Les Lettres Albanaises, 8 (4) : 117-122.

Doja, Albert. 1987. «La transposition poétique du décor de noces », Culture Populaire Albanaise, 7 : 103-123.

Doja, Albert. 1988a. «La poétisation du cérémonial des noces », Les Lettres Albanaises, 10 (2) : 186-204.

Doja, Albert, (ed.). avec Jorgo Panajoti \& Agron Xhagolli. 1988b. Proza Popullore, vol. 6. Tirana: Akademia e Shkencave (Trashëgimia Kulturore Shqiptare, Folklor I).

Doja, Albert. 1989. «Considérations sur le genre de la fable orale », Çështje të Folklorit Shqiptar, 4 : 137-165. [Publication en français : Les Lettres Albanaises 12 (1), 1990, 155-176].

Doja, Albert. 1990a. «Aspekte të pasqyrimit të marrëdhënieve shoqërore në folklorin e lindjes [Aspects of the representation of social relations in birth and age-grading folk practices] », Kultura Popullore, 11 (2): 53-68.

Doja, Albert, (ed.). avec Kozma Vasili. 1990b. Këngë të lindjes dhe ninulla [Birth and cradle songs]. Tirana: Akademia e Shkencave (Trashëgimia Kulturore Shqiptare, Folklor IV, Lirika Popullore 4).

Doja, Albert. 1993. "Lait de mère, fils de famille", La Psychanalyse de l'Enfant : Revue de l'Association Freudienne Internationale, 14 : 39-62.

Doja, Albert. 1995a. "À propos de la famille dans les Balkans en transition », Bulletin de Liaison du Centre d'Études Balkaniques de l'INALCO, 13 : 89-95.

Doja, Albert. 1995b. «Le sexe de la naissance : masculin-féminin dans la société traditionnelle albanaise », Ethnologie Française, 25 (4) : 650-667, doi: $10.2307 / 40989578$.

Doja, Albert. 1996. «L'idée de nation : du postulat de Marcel Mauss à la question actuelle des identités nationales et culturelles ", Revue de l'Institut de Sociologie (Université Libre de Bruxelles) (1-4) : 201-212.

Doja, Albert. 1997a. «L'enchantement socialisateur : la berceuse dans la tradition orale », In : Nicole Belmont \& Jean-François Gossiaux (eds), De la 
voix au texte : l'ethnologie contemporaine entre l'oral et l'écrit (Actes du $119^{\mathrm{e}}$ Congrès national des sociétés historiques et scientifiques), Paris : CTHS, pp. 85-108.

Doja, Albert. 1997b. «Le comportement symbolique autour de la prime enfance ", L'Ethnographie : Revue de la Société d'Ethnographie de Paris, 93 (1-2) : 43-87.

Doja, Albert. 1997c. «Noms d'ancêtre et noms de famille », In : Tiphaine Barthelemy \& Marie-Claude Pingaud (eds), Généalogie entre science et passion (Actes du $120^{\mathrm{e}}$ Congrès National des Sociétés Historiques et Scientifiques), Paris : Éditions du CTHS, pp. 347-360.

Doja, Albert. 1998a. « À propos de la diversité locale des traditions culturelles albanaises », Ricerca Folklorica : Contributi allo Studio della Cultura delle Classi Popolari, 38 (1-2) : 63-74, doi:10.2307/1479953.

Doja, Albert. 1998b. «Évolution et folklorisation des traditions culturelles », East European Quarterly, 32 (1): 95-126.

Doja, Albert. 1998c. «Inscription patronymique et mythologie de fondation : Éléments d'analyse pour une généalogie des noms de personne chez les Albanais ", Anthropos: International Review of Anthropology and Linguistics, 93 (1-3) : 155-172, doi:10.2307/40465786.

Doja, Albert. 1999a. "Morphologie traditionnelle de la société albanaise", Social Anthropology: Journal of the European Association of Social Anthropologists, 7 (1): 37-55, doi:10.1017/S0964028299000038.

Doja, Albert. 1999b. « Amitié, alliance, parenté : idéologie et pratique dans la société traditionnelle », In : Georges Ravis-Giordani (ed.), Amitiés : Histoire et Anthropologie, Aix-en-Provence : Presses de l'Université de Provence, pp. 217-255.

Doja, Albert. 1999c. «Ethnicité, construction nationale et nationalisme dans l'aire albanaise : Approche anthropologique du conflit et des relations interethniques », Ethnologia Balkanica: Journal for Southeast European Anthropology, 3: 155-179.

Doja, Albert. 1999d. «Développement corporel et transition sociale chez les Albanais », Journal of Mediterranean Studies, 9 (2): 232-274.

Doja, Albert. 2000a. Naître et grandir chez les Albanais : la construction culturelle de la personne. Paris/Montreal : L'Harmattan.

Doja, Albert. 2000b. «Histoire et dialectique des idéologies et significations religieuses », European Legacy-Towards New Paradigms: Journal of the International Society for the Study of European Ideas, 5 (5): 663-686, doi:10.1080/713665519.

Doja, Albert. 2000c. « The politics of religion in the reconstruction of identities: the Albanian situation ", Critique of Anthropology, 20 (4): 421-438, doi: $10.1177 / 0308275$ X0002000404.

Doja, Albert. 2000d. «Entre invention et construction des traditions : l'héritage historique et culturel des Albanais ", Nationalities Papers: The Journal of Nationalism and Ethnicity, 28 (3): 417-448, doi:10.1080/713687477. 
Doja, Albert. 2001a. "Atrocités des conflits ethniques : paradoxes venus d'ailleurs ou sensations dans le cénacle savant», Social Anthropology: Journal of the European Association of Social Anthropologists, 9 (2): 223226, doi:10.1017/S0964028201000167.

Doja, Albert. 2001b. «Démocratie et stabilité dans le Sud-Est Européen : facteurs humains, culturels et sociaux », Les Temps Modernes, 56 (615-616) : 147-166.

Doja, Albert. 2003. «Confraternal religion : from liberation theology to political reversal », History and Anthropology, 14 (4): 349-381, doi:10.1080/0275720032000156488.

Doja, Albert. 2004a. Construction des identités sociales: relations interethniques et dynamique des valeurs culturelles. Post-Doctoral Habilitation à Diriger des Recherches: Faculté des Sciences Humaines et Sociales, Université Paris Descartes, Sorbonne, Paris.

Doja, Albert. 2004b. «Cultural politics and spiritual making of anthropologists », Reviews in Anthropology, 33 (1): 73-94, doi:10.1080/713649341.

Doja, Albert. 2005a. « Dreaming of fecundity in rural society », Rural History: Economy, Society, Culture, 16 (2) : 209-233, doi:10.1017/S09567933050014 82.

Doja, Albert. 2005b. "The imaginary of the name ", Irish Journal of Anthropology, 8 (1): 31-50.

Doja, Albert. 2005c. «Mythology and Destiny», Anthropos: International Review of Anthropology and Linguistics, 100 (2): 449-462, doi:10.2307/40466549.

Doja, Albert. 2005d. «Rethinking the Couvade », Anthropological Quarterly, 78 (4): 919-951, doi:10.1353/anq.2005.0053.

Doja, Albert. 2005e. «The advent of heroic anthropology in the history of ideas ", Journal of the History of Ideas, 66 (4): 633-650, doi:10.1353/jhi.2005.0054.

Doja, Albert. 2006a. « The shoulders of our giants: Claude Lévi-Strauss and his legacy in current anthropology », Social Science Information, 45 (1): 79-107, doi: $10.1177 / 0539018406061104$.

Doja, Albert. 2006b. «The kind of writing: anthropology and the rhetorical reproduction of post-modernism », Critique of Anthropology, 26 (2): 157-180, doi:10.1177/0308275X06064993.

Doja, Albert. 2006c. « The predicament of heroic anthropology », Anthropology Today, 22 (3): 18-22, doi:10.1111/j.1467-8322.2006.00439.x.

Doja, Albert. 2006d. « A political history of Bektashism from Ottoman Anatolia to Contemporary Turkey », Journal of Church and State, 48 (2): 421-450, doi: $10.1093 /$ jcs/48.2.423.

Doja, Albert. 2006e. «A political history of Bektashism in Albania », Totalitarian Movements and Political Religions, 7 (1): 83-107, doi:10.1080/14690760500477919. 
Doja, Albert. 2006f. « Spiritual surrender: from companionship to hierarchy in the history of Bektashism ", Numen: International Review for the History of Religions, 53 (2): 448-510, doi:10.1163/156852706778941996.

Doja, Albert. 2006g. "Rituals of naming and exposure », Onoma: Journal of the International Council of Onomastic Sciences, 41: 237-270.

Doja, Albert. 2007. «Creative misreading and bricolage writing: A structural appraisal of a poststructuralist debate », Portuguese Review of the History of the Book, 11 (22): 89-104.

Doja, Albert. 2008a. «Claude Lévi-Strauss at his Centennial: toward a future anthropology », Theory, Culture \& Society, 25 (7-8): 321-340, doi:10.1177/0263276408097810.

Doja, Albert. 2008b. «From Neolithic Naturalness to Tristes Tropiques: the emergence of Lévi-Strauss's new humanism ", Theory, Culture \& Society, 25 (1): 77-100, doi:10.1177/0263276407085154.

Doja, Albert. 2008c. «Instrumental borders of gender and religious conversions in the Balkans », Religion, State \& Society, 36 (1): 55-63, doi:10.1080/09637490701809738.

Doja, Albert. 2010a. «Claude Lévi-Strauss (1908-2009): The apotheosis of heroic anthropology », Anthropology Today, 26(5): 18-23, doi:10.1111/j.1467-8322.2010.00758.x.

Doja, Albert. 2010b. «Fertility Trends, Marriage Patterns and Savant Typologies in Albanian Context », Journal of Family History, 35 (4): 346367, doi:10.1177/0363199010381045.

Doja, Albert. 2011. «Honneur, Foi et Croyance : approche linguistique anthropologique des valeurs morales et religieuses ", Anthropos: International Review of Anthropology and Linguistics, 106 (1): 161-172.

Douglas, Mary. 1966. Purity and danger: an analysis of concepts of pollution and taboo. London : Routledge \& Kegan Paul.

DuBoulay, Juliet. 1974. Portrait of a Greek mountain village. Oxford: Clarendon (Oxford Monographs on Social Anthropology).

Duijzings, Ger. 2000. Religion and the politics of identity in Kosovo. London: Hurst.

Durham, Edith. 1909/1994. High Albania. London: Virago, 1994.

Durham, Edith. 1928/1979. Some tribal origins, laws and customs of the Balkans. London: Allen \& Unwin, 1979.

Durkheim, Emile. 1893/1986. De la division du travail social. Paris : Presses Universitaires de France, 1986.

Durkheim, Emile. 1895/1988. Les règles de la méthode sociologique. Paris : Flammarion, 1988.

Eggan, Fred. 1954. «Social anthropology and the method of controlled comparison », American Anthropologist, 56 (5): 743-763.

Enloe, Cynthia. 1993. The morning after: sexual politics at the end of the Cold War. Berkeley: University of California Press. 
Evans-Pritchard, Edward E. 1940/1987. The Nuer: a description of the modes of livelihood and political institutions of a Nilotic people. Oxford: Clarendon, 1987.

Evans-Pritchard, Edward E. 1949. The Sanusi of Cyrenaica. Oxford: Clarendon.

Evans-Pritchard, Edward E. 1951/1990. Kinship and marriage among the Nuer. Oxford: Clarendon, 1990.

Fortes, Meyer. 1945/1967. The dynamics of clanship among the Tallensi: being the first part of an analysis of the social structure of a Trans-Volta tribe. London: Oxford University Press (International African Institute), 1967.

Fortes, Meyer. 1949/1967. The web of kinship among the Tallensi: the second part of an analysis of the social structure of a Trans-Volta tribe. London: Oxford University Press (International African Institute), 1967.

Fortes, Meyer \& Edward E. Evans-Pritchard. 1940/1970. African political systems. London: Oxford university press (International African Institute), 1970.

Foucault, Michel. 1976/1994. La volonté de savoir (Histoire de la sexualité, 1). Paris: Gallimard, 1994.

Foucault, Michel. 1980. Power/knowledge: selected interviews and other writings, 1972-1977, (ed.) Colin Gordon. New York: Pantheon Books.

Foucault, Michel. 1988. Technologies of the self: a seminar with Michel Foucault, (eds) Luther H. Martin, Huck Gutman \& Patrick H. Hutton. Amherst: University of Massachusetts Press.

Freeman, Suzan T. 1973. "Studies in rural european social organisation: introduction », American Anthropologist, 75 (3): 743-750.

Friedl, Ernestine. 1963. Vasilika: a village in modern Greece. New York: Holt, Rinehart \& Winston.

Gellner, Ernest. 1969. Saints of the Atlas. London : Weidenfeld \& Nicolson.

Gellner, Ernest, (ed.). 1985. Islamic dilemmas: reformers, nationalists, industrialization: the southern shore of the Mediterranean. Berlin/New York: Mouton.

Gellner, Ernest. 1995. Anthropology and politics: revolution in the sacred grove. Oxford: Blackwell.

Gellner, Ernest \& John Waterbury, eds. 1977. Patrons and clients in Mediterranean societies. London: Duckworth.

Gerndt, Helge, (ed.). 1987. Volkskunde und Nationalsozialismus. München: Münchner Vereinigung für Volkskunde (Münchner Beiträge zur Volkskunde, 7). [Cf. Helge Gerndt, « Deutsche Volkskunde und Nationalsozialismus : was haben wir aus der Geschichte gelernt», In: Schweizerisch Archiv für Volkskunde 91 (1995): 53-75].

Gilmore, David. 1980. The people of the plain: class and community in lower Andalusia. New York: Columbia University Press.

Gilmore, David. 1982. "Anthropology and the Meditarranean area », Annual Review of Anthropology, 11. 
Gilmore, David, (ed.). 1987. Honor and shame and the unity of the Mediterranean. Washington, D.C.: American Anthropological Association (AAA Special Publications, 22).

Giordano, Christian. 2012. «The Anthropology of Mediterranean Societies », In: Ullrich Kockel, Mairead N. Craith \& Jonas Frykman (eds), A Companion to the Anthropology of Europe, Oxford: Blackwell, pp. 13-31.

Giordano, Christian \& Johanna Rolshoven, eds. 1999. Europäische Ethnologie Ethnologie Europas / Ethnologie européenne - ethnologie de l'Europe. Freiburg, Schweiz: Universitätsverlag (Studia ethnographica Friburgensia, 22).

Gjeçov, Shtjefen. 1933/1993. Kanuni i Lekë Dukagjinit [Law of Leka Dukagjini]. Shkodra: Shtypshkronja Franceskane, 1993. [Transl. Italian, Roma: Reale Academia 1941; German, in: Zeitschrift für vergleichende Rechtswissenschaft 54-56, 1954-1958; Bilingual Albanian-English, New York: Gjonlekaj Publishing 1989 ; French, Peja: Dukagjini Books 2001].

Gjergji, Andromaqi. 1964. «Vestigia del matriarcato in alcune antiche usanze della vita familiare », Rassegna di Studi Albanesi, vol. 1, pp. 27-31.

Glaser, Barney G. \& Anselm L. Strauss. 1967. The discovery of grounded theory: strategies for qualitative research. Chicago: Aldine.

Gluckman, Max. 1956. Custom and conflict in Africa. Oxford: Blackwell.

Goddard, Victoria. 1994. « From the Mediterranean to Europe: honour, kinship, and gender », In: Victoria Goddard, Josep Llobera \& Chris Shore (eds), The Anthropology of Europe: identity and boundaries in conflict, Oxford: Berg Publishers, pp. 57-92.

Goddard, Victoria, Josep Llobera \& Cris Shore, eds. 1994. The Anthropology of Europe: identity and boundaries in conflict. Oxford: Berg (Explorations in Anthropology).

Goody, Jack. 1976. Production and reproduction: a comparative study of the domestic domain. Cambridge: Cambridge University Press.

Goody, Jack. 1983. The development of the family and marriage in Europe. Cambridge: Cambridge University Press.

Goody, Jack. 1990. The oriental, the ancient, and the primitive: systems of marriage and the family in the pre-industrial societies of Eurasia. Cambridge: Cambridge University Press (Studies in literacy, family, culture, and the state).

Goody, Jack. 2000. The European family: an historico-anthropological essay. Oxford: Blackwell (Making of Europe).

Gossiaux, Jean-François. 1995. «Le sens et le verbe : sur deux modes opposés d'instrumentalisation politique du folklore », L'Homme : Revue Française d'Anthropologie, 35 (135) : 127-134.

Gullestad, Marianne \& Martine Segalen, eds. 1995. La famille en Europe : parenté et perpétuation familiale. Paris : Découverte (Collection Recherches, Série changement social en Europe occidentale).

Hage, Per. 1997. «Unthinkable categories and the fundamental laws of kinship », American Ethnologist, 24 (3): 652-667. 
Hasluck, Frederick. 1929/2000. Christianity and Islam under the Sultans. Oxford: Clarendon. [Reprint Istanbul : Isis, 2000].

Hasluck, Margaret. 1954. The unwritten law in Albania. Cambridge: Cambridge University Press.

Héritier, Françoise. 1994. Les deux sœurs et leur mère : anthropologie de l'inceste. Paris : Odile Jacob.

Héritier, Françoise. 1996. Masculin/féminin : la pensée de la différence. Paris : Odile Jacob.

Héritier, Françoise. 2002. Masculin/féminin II : Dissoudre la hiérarchie. Paris : Odile Jacob.

Herzfeld, Michael. 1980. «Honour and shame: problems in the comparative analysis of moral systems », Man (N.S.), $15 \quad$ (2): 339-351, doi: $10.2307 / 2801675$.

Herzfeld, Michael. 1984. "The horns of the Mediterranean dilemma », American Ethnologist, 11 (3): 439-454.

Herzfeld, Michael. 1987. Anthropology through the looking-glass: critical ethnography in the margins of Europe. Cambridge: Cambridge University Press.

Herzfeld, Michael. 2001. «Ethnographic and epistemological refraction of Mediterranean identity », In : Dionigi Albera, Anton Blok \& Christian Bromberger (eds), L'anthropologie de la Méditerranée - Anthropology of the Mediterranean, Paris : Maisonneuve \& Larose, pp. 663-683.

Holy, Ladislav \& Milan Stuchlik. 1983. Actions, norms, and representations: foundations of anthropological inquiry. Cambridge: Cambridge University Press (Cambridge studies in social anthropology, 45).

Inalcik, Halil. 1973. The Ottoman Empire: the Classical Age, 1300-1600. London: Weidenfeld \& Nicolson (History of Civilisation).

Jakobson, Roman \& Claude Lévi-Strauss. 1962. «Les Chats de Charles Baudelaire ", L'Homme : Revue Française d'Anthropologie, 2 (1) : 5-21. [English translation : Krystyna Pomorska and Stephen Rudy (Eds), Language in Literature, Cambridge, MA : Belknap, 1987, pp. 180-197].

Jamous, Raymond. 1981. Honneur et baraka : les structures sociales traditionnelles dans le Rif. Cambridge/Paris : Cambridge University Press/Editions de la Maison des sciences de l'homme (Atelier d'anthropologie sociale).

Kaldor, Mary. 1999/2006. New and old wars: organized violence in a global era. Stanford, Calif.: Stanford University Press, 2006.

Karakasidou, Anastasia. 1997. Fields of wheat, hills of blood: passages to nationhood in Greek Macedonia 1870-1990. Chicago: University of Chicago Press.

Kaser, Karl. 1992. Hirten, Kämpfer, Stammeshelden: Ursprünge und Gegenwart des Balkanischen Patriarchats. Wien: Böhlau. [English partial translations: "The origins of Balkan Patriarchy », Modern Greek Studies Yearbook, 8 (1992) 1: 1-39; «The Balkan Family: Redefining a problem », 
Social Science History, 18 (1994) 2: 243-269 ; « The Balkan joint family: Seeking its origins », Continuity and Change, 9 (1994) 1: 45-68].

Kaser, Karl. 2000. «The history of the Albanian family in the $20^{\text {th }}$ century: a first profile ", Ethnologia Balkanica: Journal for Southeast European Anthropology, 4 : 45-57.

Kaser, Karl \& Joel M. Halpern. 1998. "Historical myth and the invention of political folklore in contemporary Serbia”, The Anthropology of Eastern Europe Review, 16 (1). Retrieved from: www.depaul.edu/ rrotenbe/aeer/ aeer16_1.html.

Kertzer, David \& Marzio Barbagli, eds. 2001. The history of the European family. New Haven, Conn.: Yale University Press.

Kockel, Ullrich, Mairead N. Craith \& Jonas Frykman, eds. 2012. A Companion to the Anthropology of Europe. Oxford: Blackwell.

Kuhn, Thomas S. 1962/2012. The Structure of Scientific Revolutions. 4th edition. Chicago: University of Chicago Press, 2012.

Kuper, Adam. 1988. The invention of primitive society: transformations of an illusion. London/New York: Routledge.

Leach, Edmund. 1976/2000. "Social anthropology: a natural science of society? [British Academy Radcliffe-Brown Lecture]", In: Stephen Hugh-Jones \& James Laidlaw (eds), Anthropology and society, London: Yale University Press, 2000 (The Essential Edmund Leach, 1), pp. 80-97.

Leach, Edmund. 1989. "Tribal ethnography: past, present, and future", In: Elisabeth Tonkin, Maryon McDonald \& Malcolm Chapman (eds), History and ethnicity (A.S.A. monographs, 27), London: Routledge, pp. 34-47.

Lévi-Strauss, Claude. 1955/1958. "La structure des mythes", Anthropologie structurale, Paris: Plon, 1958, pp. 227-255.

Lévi-Strauss, Claude. 1955. Tristes Tropiques. Paris : Plon. [Nouvelle edition, 1973.

Lévi-Strauss, Claude. 1956/1983. «La famille», Le regard éloigné, Paris : Plon, 1983, pp. 65-92.

Lévi-Strauss, Claude. 1958. Anthropologie structurale. Paris : Plon.

Lévi-Strauss, Claude. 1960/1973. «Le champ de l'anthropologie », Anthropologie structurale deux, Paris : Plon, 1973, pp. 11-44.

Lévi-Strauss, Claude. 1949/1967. Les structures élémentaires de la parenté. $2^{\mathrm{e}}$ edition. Paris/Hague : Mouton.

Lévi-Strauss, Claude. 1983. Le regard éloigné. Paris : Plon.

Lévi-Strauss, Claude. 1984. Paroles données. Paris : Plon.

Lindner, Evelin G. 2002. "Gendercide and humiliation in honor and human rights societies », Journal of Genocide Research, 4 (1): 137-155.

Lison-Tolosana, Carmelo. 1966/1983. Belmonte de los Caballeros: anthropology and history in an Aragonese community. Princeton, N.J.: Princeton University Press, 1983. 
Marcus, George E. 1995. «Ethnography in/of the world system: the emergence of multi-sited ethnography », Annual Review of Anthropology, 24: 95-117.

Mauss, Marcel. 1924/2007. Essai sur le don : forme et raison de l'échange dans les sociétés archaïques. Paris : Presses Universitaires de France, 2007, doi:10.1522/cla.mam.ess3.

Merleau-Ponty, Maurice. 1960. «De Mauss à Claude Lévi-Strauss », Signes, Paris : Gallimard, pp. 143-157.

Mitchell, J. Clyde. 1956. The Kalela dance: aspects of social relationships among urban Africans in Northern Rhodesia. Manchester: Manchester University Press (Rhodes-Livingstone papers, 27).

Murdock, George P. 1981. Atlas of world cultures. Pittsburgh: University of Pittsburgh Press.

Nagel, Joane. 2000. «Ethnicity and sexuality », Annual Review of Sociology, 26: 107-133.

Nahoum-Grappe, Veronique. 1996. «L'usage politique de la cruauté : l'épuration ethnique, ex-Yougoslavie, 1991-1995 », In : Françoise Héritier (ed.), De la violence, Paris : Odile Jacob, pp. 275-323.

Niedermüller, Peter \& Bjarne Stoklund, eds. 2001. Europe: cultural construction and reality. Copenhagen: Tusculanum.

Nisbett, Richard E. \& Dov Cohen. 1996. Culture of honor: the psychology of violence in the South. Boulder, Colo.: Westview Press.

Nixdorff, Heide \& Thomas Hauschild, eds. 1982. Europäische Ethnologie: Theorie- und Methodendiskussion aus ethnologischer und volkskundlicher Sicht. Berlin: Dietrich Reimer Verlag (Ethnologische Paperbacks).

Ortner, Sherry. 1974. « Is female to male as nature is to culture? », In: Michelle Rosaldo \& Louise Lamphere (eds), Woman, culture, and society, Stanford, Calif.: Stanford University Press, pp. 67-87.

Ortner, Sherry \& Harriet Whitehead, eds. 1981. Sexual meanings: the cultural construction of gender and sexuality. Cambridge: Cambridge University Press.

Peristiany, John, (ed.). 1966. Honour and shame: the values of Mediterranean society. London: Weidenfeld \& Nicholson.

Peristiany, John, (ed.). 1968. Contributions to Mediterranean sociology: Mediterranean rural communities and social change. Hague/Paris: Mouton.

Peristiany, John, (ed.). 1976a. Kinship and modernization in Mediterranean society. Rome: Center for Mediterranean Studies, American Universities Field Staff.

Peristiany, John, (ed.). 1976b. Mediterranean family structures. Cambridge: Cambridge University Press (Cambridge studies in social anthropology, 13).

Peristiany, John \& Marie-Elisabeth Handman, eds. 1989. Le Prix de l'alliance en Méditerranée. Paris : Presses du CNRS.

Peristiany, John \& Julian Pitt-Rivers, (eds). 1992. Honor and grace in anthropology. Cambridge: Cambridge University Press (Cambridge studies in social and cultural anthropology, 76). 
Peters, Emrys L. 1990. The Bedouin of Cyrenaica: studies in personal and corporate power, (ed.) Jack Goody. Cambridge: Cambridge University Press (Cambridge studies in social and cultural anthropology, 72).

Pina-Cabral, Joao. 1989. "The Mediterranean as a category of regional comparison: a critical view », Current Anthropology, 30 (3): 399-407.

Pitt-Rivers, Julian. 1954/1971. The people of the Sierra. London: Weidenfeld \& Nicholson, 1971.

Pitt-Rivers, Julian, (ed.). 1963. Mediterranean countrymen: essays in the social anthropology of the Mediterranean. Paris: Mouton (Recherches Mediterranéennes, Études, 1).

Pitt-Rivers, Julian. 1977. The fate of Shechem or the politics of sex: essays in the anthropology of the Mediterranean. Cambridge: Cambridge University Press.

Portera, Agostino. 2008. «Intercultural education in Europe: epistemological and semantic aspects », Intercultural Education, 19 (6): 481-491, doi:10.1080/14675980802568277.

Radcliffe-Brown, Alfred. 1952. Structure and function in primitive society. London: Cohen \& West.

Richards, Audrey. 1950. «Some types of family structures among the Central Bantu », In: Alfred Radcliffe-Brown \& Daryll Forde (eds), African systems of kinship and marriage, Oxford: Oxford University Press, pp. 207-251.

Rogoff, Barbara \& James V. Wertsch, eds. 1984. Childrens learning in the Zone of Proximal Development. San Francisco: Jossey Bass.

Roksandic, Drago, (ed.). 1998. Microhistory of the Triplex Confinium. Budapest: Central European University Press.

Roux, Michel. 1992. Les Albanais en Yougoslavie : Minorité nationale, territoire et développement. Paris : Éditions de la Maison des Sciences de l'Homme.

Rubin, Gayle. 1975. «The traffic in women: notes on the political economy of sex », In: Rayna Reiter (ed.), Toward an Anthropology of Women, New York: Monthly Review Press, pp. 157- 210.

Sant-Cassia, Paul. 1991. « Authors in search of a character: personhood, agency and identity in the Mediterranean », Journal of Mediterranean Studies, 1: 117.

Schmitt, Oliver J. 2009. Skanderbeg: der neue Alexander auf dem Balkan. Regensburg: Pustet. [Albanian transl. Tirana : K\&B, 2008].

Schneider, Jane. 1971. «Of vigilance and virgins: honor, shame and access to resources in Mediterranean societies », Ethnology: An International Journal of Cultural and Social Anthropology, 10: 1-24.

Schneider, Jane \& Peter Schneider. 1976. Culture and political economy in western Sicily. New York: Academic Press.

Schneider, Jane \& Peter Schneider. 1996. Festival of the poor: fertility decline and the ideology of class in Sicily, 1860-1980. Tucson: University of Arizona Press (Hegemony and experience). 
Segalen, Martine. 1981. Sociologie de la famille. Paris : Armand Colin.

Shore, Cris. 2000. Building Europe: the cultural politics of European integration. London/New York: Routledge.

Shryock, Andrew J. 1988. «Autonomy, entanglement, and the feud : prestige structures and gender value in Highland Albania", Anthropological Quarterly, 61 (3): 113-118.

Shweder, Richard \& Edmund Bourne. 1984. « Does the concept of the person vary cross-culturally? », In: Richard Shweder \& Robert LeVine (eds), Culture theory: Essays on mind, self and emotion, Cambridge: Cambridge University Press, pp. 158-199.

Sicard, Emile. 1943. La Zadruga sud-slave dans l'évolution du groupe domestique. Paris : Ophrys.

Spoehr, Alexander. 1947. Changing kinship systems: a study in the acculturation of the Creeks, Cherokee, and Choctaw. Chicago.

Stahl, Paul-Henri. 1977. "Soi-même et les autres : quelques exemples balkaniques », In : Claude Lévi-Strauss (ed.), L'identité, Paris : Grasset \& Fasquelle, pp. 287-303.

Stahl, Paul-Henri. 1986. Household, village, and village confederation in southeastern Europe. Boulder/New York: Columbia University Press (East European monographs, 200).

Stirling, Paul. 1965. Turkish village. London: Weidenfeld \& Nicolson.

Stocking, George W., (ed.). 1996. Volksgeist as method and ethic: essays on Boasian ethnography and the German anthropological tradition. Madison: University of Wisconsin Press (History of anthropology, 8).

Testart, Alain. 1986. Essai sur les fondements de la division sexuelle du travail chez les chasseurs-cueilleurs. Paris : Éditions de l'École des Hautes Études en Sciences Sociales.

Theodoratus, Robert J. 1969. Europe: a selected ethnographic bibliography. New Haven, Conn.: Human Relations Area Files (Behavior science bibliographies).

Todorova, Maria. 1997. Imagining the Balkans. New York: Oxford University Press.

Toren, Christina. 1999. Mind, materiality, and history: explorations in Fijian ethnography. London/New York: Routledge.

Trix, Frances. 1993. Spiritual discourse: learning with an Islamic master. Philadelphia, PA: University of Pennsylvania Press (Conduct and Communication Series).

Turner, Victor. 1969. The ritual process: structure and anti-structure. Chicago: Aldine (The Lewis Henry Morgan Lectures, 1966).

Van Gennep, Arnold. 1909/1981. Les rites de passage. Paris : Picard, 1981.

Verdier, Raymond, (ed.). 1981. La vengeance : études d'ethnologie, d'histoire et de philosophie. Paris : Editions Cujas. 
Wallerstein, Immanuel M. 2004. World-systems analysis: an introduction. Durham: Duke University Press.

Wikan, Unni. 1984. "Shame and honour: a contestable pair », Man (N.S.), 19 (4): 635-652, doi:10.2307/2802330.

Willerslev, Rane. 2011. «Frazer strikes back from the armchair: a new search for the animist soul », Journal of the Royal Anthropological Institute, 17 (3): 504-526, doi:10.1111/j.1467-9655.2011.01704.x.

Wolf, Eric R., (ed.). 1984. Religion, power, and protest in local communities: the northern shore of the Mediterranean. Berlin/New York: Mouton.

Yuval-Davis, Nira. 1997. Gender and Nation. London: Sage. 


\section{Dans la collection « Europe des cultures »}

Vol. 1. Mark Dubrulle et Gabriel Fragnière (dir.), Identités culturelles et citoyenneté européenne. Diversité et unité dans la construction démocratique de l'Europe, 2009.

Vol. 2. Gily Coene et Chia Longman (dir.), Féminisme et multiculturalisme. Les paradoxes du débat, 2010.

Vol. 3. Muriel Rouyer, Catherine de Wrangel, Emmanuelle Bousquet et Stefania Cubeddu (dir.), Regards sur le cosmopolitisme européen. Frontières et identités, 2011.

Vol. 4. Lénia Marques, Maria Sofia Pimentel Biscaia and Glória Bastos (eds.), Intercultural Crossings. Conflict, Memory and Identity, 2012.

Vol. 5. Léonce Bekemans (ed.), A Value-Driven European Future, 2012.

Vol. 6. Albert Doja, Invitation au terrain. Mémoire personnel de la construction du projet socio-anthropologique, 2013.

Vol. 7. Alain Michel, Dompter le dragon nucléaire? Réalités, fantasmes et émotions dans la culture populaire, 2013. 
Visitez le groupe éditorial Peter Lang sur son site Internet commun www.peterlang.com 